UNIVERSIDADE DE SÃO PAULO

INSTITUTO DE GEOCIÊNCIAS

\title{
ANÁLISE TAFONÔMICA DAS OCORRÊNCIAS FOSSILÍFERAS DE MACROINVERTEBRADOS DO MEMBRO ROMUALDO (ALBIANO) DA FORMAÇÃO SANTANA, BACIA DO ARARIPE, NE DO BRASIL: SIGNIFICADO ESTRATIGRÁFICO E PALEOAMBIENTAL
}

\section{ALEXANDRE MAGNO FEITOSA SALES}

Orientador: Prof. Dr. Marcello Guimarães Simões

TESE DE DOUTORAMENTO

COMISSÃO JULGADORA

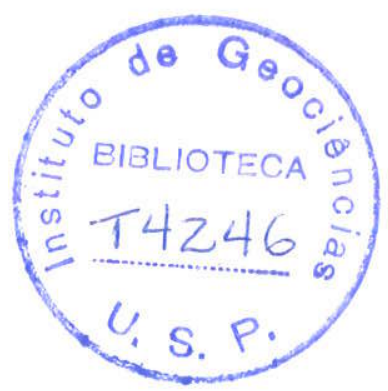

Nome

Presidente: $\quad$ Prof. Dr. Marcello Guimarães Simões

Examinadores: Prof. Dr. Francisco Pinheiro Lima Filho

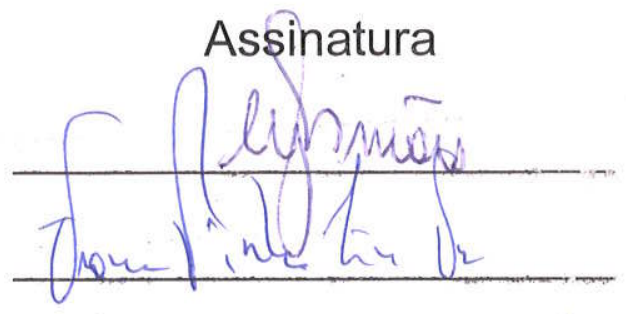

Prof. Dr. Ismar de Souza Carvalho

Prof. Dr. Luiz Eduardo Anelli

Prof. Dr. Setembrino Petri

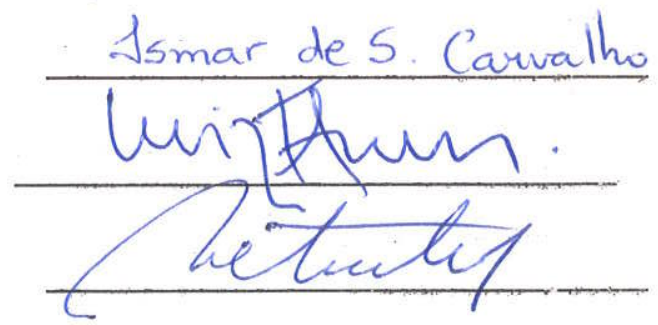

SÃO PAULO

2005 
UNIVERSIDADE DE SÃO PAULO

INSTITUTO DE GEOCIÊNCIAS

\title{
ANÁLISE TAFONÔMICA DAS OCORRÊNCIAS FOSSILÍFERAS DE
} MACROINVERTEBRADOS DO MEMBRO ROMUALDO (ALBIANO) DA FORMAÇÃO SANTANA, BACIA DO ARARIPE, NE DO BRASIL: SIGNIFICADO ESTRATIGRÁFICO E PALEOAMBIENTAL

\author{
Alexandre Magno Feitosa Sales
}

Orientador: Prof. Dr. Marcello Guimarães Simões

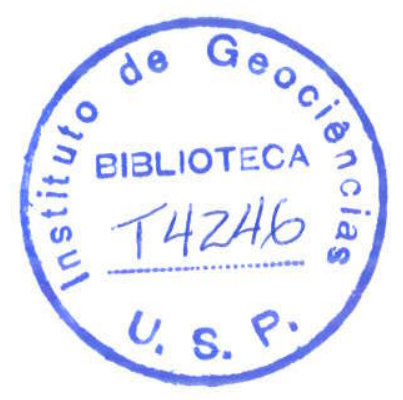

垫

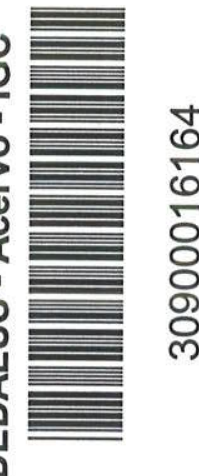

TESE DE DOUTORAMENTO

Área de Concentração: Geologia Sedimentar

SÃO PAULO 


\section{Sales, Alexandre Magno Feitosa}

Análise Tafonômica das ocorrências fossiliferas de macroinvertebrados do Membro Romualdo (Albiano) da Formação Santana, Bacia do Araripe, NE do Brasil / Significado Estratigráfico, e Paleoambiental / Alexandre Magno Feitosa Sales. - São Paulo, 2005.

p.: 131 il.

Tese de Doutorado: IG / USP - data da defesa Orient:: Simões, Marcello Guimaräes

1. Paleontologia: Tafonomia. 2. Macroinvertebrados Fósseis. 3. Bacia do Araripe: Formação Santana, Membro Romualdo. ITítulo 


\section{Dedicatória}

Ao Sr. Vicente Alexandre, professor, antropólogo, naturalista, ex-padre, poeta e disseminador da ciência paleontológica na Região do Araripe. 


\section{Agradecimentos}

Ao professor Dr. Marcello G. Simões pela orientação, incentivo, críticas construtivas e estímulo profissional ao longo de toda à etapa.

A Fundação de Amparo a Pesquisa do Estado de São Paulo (FAPESP), proc. 00/06441-9.

Aos professores Doutores Setembrino Petri e Jorge Hachiro pelas valiosas contribuições no exame de qualificação.

Aos professores do IG USP, pelas discussões e auxílio, em especial ao Prof. Dr. Paulo Gianini, com relação a petrografia sedimentar.

Ao Laboratório de Paleozoologia Evolutiva (LPE), Departamento de Zoologia, Instituto de Biociências, (IB-UNESP), Campos de Rubião Júnior, Botucatu, SP, que proporcionou através de sua estrutura e equipamentos, a maior parte das pesquisas.

Aos professores do Departamento de Zoologia, IBB-UNESP, que permitiram o uso de equipamentos e laboratórios, especialmente a Wilson Uieda e Lúcia Fraçoso.

Ao Instituto de Geociências (USP), em específico aos laboratórios de Petrografia Sedimentar (GSA) e Microscopia Ótica (GMG).

Ao Geólogo Mitsuru Arai (CENPES/PETROBRAS), pelas análises palinológicas de amostras e sugestões sobre o tema.

A Henrique Lima e Eduardo Koutsoukos (CENPES/PETEROBRAS) e Wania Dulepa (IG/USP), pelas observações $\mathrm{e}$ indicações com relação ao conteúdo micropaleontológico das seções petrográficas.

As Prof.(a) Somália Viana e Sônia Agostinho (DEGEO, CT, UFPE) pela consulta às coleções paleontológicas Karl Beurlen (CPKB) e Geraldo Munis (CPGM) e material bibliográfico.

Ao Prof. MSc. Sebastião Waldemir Mourão (Departamento de Lingua Portuguesa UECE) por ter realizado a primeira correção ortográfica.

Ao CPCA-Crato / DNPM $10^{\circ}$ - CE, pelo material bibliográfico cedido.

Ao Projeto Bacia Escola do Araripe (URCA) e ao CPCA-Crato / DNPM $10^{\circ}$ - CE, na obtenção das cartas topográficas, escalas 1:100.000, SUDENE/ SGE, 1982. 
Ao arquivo técnico da biblioteca da CPRM-PE, Recife, em especial ao geólogo Luis Carlos (CPRM/Recife/PE), pelo auxílio na aquisição de bibliografias.

A Universidade Regional do Cariri (URCA), ao Centro Paleontológico da Chapada do Araripe (CPCA-Crato/DNPM $10^{\circ}$. CE) e a Fundação Casa Lima Botelho/ Museu de Ciências Naturais e História Barra do Jardim, Jardim, CE, na logística nas atividades de campo.

Aos funcionários do Departamento de Zoologia do IBB, UNESP, Maria, Juliana Ramos, Hamilton, Flávio da Silva, Pizanni e Tatiana Jorge, pela atenção.

Aos funcionários do IG USP, Ana Paula e Magali, Tadeu, Ericsson, Isaac Jamil, Elaine, Brenda, èrica, Cida, Estela, Angélica, Cláudio Hopper, Claudionor, Henrique, José, Edmir, Paulinho e José Carlos, pela atenção.

A estagiária Bruna Flabersson do Lab. de Sedimentologia e Microscopia òtica (IGUSP) pelo auxílio com programas para uso de captura de imagens.

Ao colega Rodrigo Salveati (GSA/PPG/IGc/USP) pelo auxílio na confecção de mapas e figuras.

Ao Sr. Vicente Alexandre, professor, antropólogo, naturalista, exmpadre, poeta e disseminador da ciência paleontológica, pela indicação das ocorrências fósseis na região de Araripina, PE e amizade.

Aos amigos Dr. Francisco Pinheiro Lima Filho (UFRN/DEGEO) e Dr. Cláudio P. Florêncio (PETROBRÁS/-Natal), pelo estímulo e proveitosas discussões.

Aos Professores MSc.Eva Batista Caldas (UFC-DEGEO) e Dra. Loreci G. de O. Legeur (UFC-DEGEO), Dr. Francisco Pinheiro Lima Filho (UFRN-DEGEO) e Dr. Benjamim Bley de Brito Neves (IG-USP), pelo incentivo e descoberta inicial do "Araripe".

Pelo valoroso auxílio em etapas de Campo, agradeço ao Geólogos Artur Andrade (CPCA-DNPM-CE), Idalécio Freitas (URCA), ao Biólogo Marcos Bissaro Júnior (IBUSP) e ao Geógrafo Lúcio Silva Júnior.

Ao professor Marcello Simões e Karla Kotzian e aos colegas do Laboratório de Paleozoologia de Invertebrados (IBB-UNESP) Sabrina Coelho, Juliana Leme, Fernanda Torrelo, Luis Melo, e aos estagiários e Sabrina Pereira, Ricardo Watanabe, Larissa e Jackline pelo incentivo, amizade e apoio em Botucatu. 
Aos colegas e amigos de Pós-Graduação do IG-USP: Francisco Willian (Chico Bill), Patrícia Cristalli, Afonso Nogueira, André Ferrari, André (Frutinha), Alexandre Tomio, Cristiano Massur, Weber Werner, Renato Ghilardi, Rodrigo Salveati, pelo incentivo.

A todos os colegas, amigos e funcionários do CRUSP, por todo o companheirismo.

A todos pela acolhida em São Paulo, em especial a Agro, Irena, Glorinha, Dalata, Miguel, Carlos, Carol, Empata, Bis, Chapa, Marcelão, Graminha, Neivaldo, Goiâno, Mauro, Werner, Delsio, Elcio, Cláudio, Ana Paula (Nem), Troglo, Poblema, Valente, Torrinha, C. Bill e Patrícia, Anísia, Anna, Cláudio Florêncio, Pinheiro, Wells, Laila, Fernando Laureano, André Ferrari, Alexei, Gelson Fambrinni, Professores Ivo Karman, B. Bley B. Neves e Cláudio Riccomini.

Ao corpo de funcionários do Museu de Paleontologia da Universidade Regional do Cariri (URCA), especialmente a Joaquim Ribeiro de Sá Barreto, por todos os pequenos e grandes favores prestados na impressão desse documento.

A Paulo Albuquerque, Flavia Cristalli, Anna Helena e Júlia Helena, por todos e incalculáveis momentos de alegria e amiade.

A minha familia, especialmente a Lana Luiza, que mesmo à distância, acompanharam e me estimularam. 


\section{SUMÁRIO}

Dedicatória

Agradecimentos

Índice

Lista de figuras

Lista de tabelas

Lista de siglas

Lista de abreviações

Abstract

Resumo

1. Introdução

2. Problemática envolvida

3. Objetivos

3.1. Objetivos específicos

4. Revisão da literatura

4.1.O Cretáceo do Nordeste brasileiro

4.2 A Bacia Sedimentar do Araripe

4.3. Formação Santana

4.3.2. Membro Ipubi

4.3.3. Membro Romualdo

4.4. Paleontologia da Formação Santana

4.5. Os macroinvertebrados fósseis do Membro Romualdo

4.6. Tafonomia

4.7. Estratigrafia de seqüências

4.8. Aplicação em conjunto da tafonomia e estratigrafla de sequências 26

5. Metodologia

5.1. Escalas de abordagem e análises usadas 28

5.2. Atividades de campo 33

$\begin{array}{ll}\text { 5.2.1. Coleta } & 33 \\ 5.2 .2 . \text { Levantamento de seços } & 37\end{array}$

5.2.2. Levantamento de seções 37

5.3. Trabalhos de laboratório 38

5.3.1. Descrição tafonômica 38

5.3.2. Terminologias empregadas na descrição das feições macroscópicas 40

5.3.3. Classificações das concentrações fossiliferas 47

5.3.4. Conceitos empregados 48

5.3.4.1. Retroalimentação tafonômica 48

5.3.4.2. Fácies tafonômicas $\quad 50$

5.3.4.3. Assinatura tafonômica $\quad 51$

5.3.4.4. Mistura temporal $\quad 51$

5.4. Estudos petrográficos 53

5.4.1. Carbonatos 53

5.4.1.1. Calcários $\quad 54$

5.5.Trabalhos de gabinete 58

5.5.1. Correlação de perfis 58

6. Resultados $\quad 59$ 
6.1. Concentrações fossilíferas

6.1.1. Concentrações em Romualdo

6.1.2. Concentrações em Jamacaru

6.1.3. Concentrações em Serra da Mãozinha 64

6.1.4. Concentrações em Sítio Saco 64

6.1.5. Concentraçäo em Jatobá 65

6.1.6. Concentrações em Sítio dos Negros 70

6.1.7. Concentrações em Engenho 70

6.1.8. Concentração em Sobradinho

6.1.9. Concentrações em Canastra 73

6.1.10. Concentração em Torre $\quad 74$

6.1.11. Concentração em Caboclos $\quad 74$

6.1.12. Concentração em Marcolândia $\quad 75$

6.1.13. Concentração em Santana do Cariri 75

6.1.14. Concentrações em São Gonçalo 76

6.2. Dados petrográficos 78

6.3. Dados palinológicos 81

7. Discussão 12

7.1. Tafonomia 82

7.2. Petrografia e palinologia $\quad 85$

7.3. Ciclos sedimentares $\quad 87$

7.4. Determinação dos tipos de concentrações 92

7.4.1. Concentrações geradas por tempestitos proximais 94

7.4.1.1. Concentração com carapaças de equinóides (tempestitos 96 proximais)

7.4.2. Concentrações geradas por tempestitos distais 99

7.4.3. Concentração com assembléia autóctone (primariamente biogênica) 100

7.4.4. Concentração com resíduos transgressivos 102

7.5. Aspectos paleogeográficos, paleoambientais e paleoecológicos 103

$\begin{array}{ll}\text { 7.5.1. Paleogeográfia } & 103\end{array}$

7.5.2. Paleoambiente 105

7.5.3. Paleoecologia 110

$\begin{array}{ll}\text { 8. Conclusões } & 116\end{array}$

$\begin{array}{ll}\text { Referências bibliográficas } & 115\end{array}$

Pranchas

Anexos 


\section{LISTA DE FIGURAS}

Figura 1. Mapa de localização da Bacia Sedimentar do Araripe e Bacias Interiores do Nordeste, com principais falhamentos no contexto tectônico regional, baseado em Ponte \& Ponte-Filho (1996).

Figura 2. Figura 2 - Mapa geológico simplificado da Bacia do Araripe (modificado de ALBUQUERQUE ET AL., 2000; SALES \& SIMÕES, 2000) e esquema litoestratigráfico simplificado com seqüências (modificado de PONTE \& PONTE-FIL.HO, 1996).

Figura 3. Mapa gravimétrico bourguer da Bacia do Araripe, com intervalo de contorno de 5 miligals, baseado em Oliveira (1983)

Figura 4. Carta estratigráfica, biocronoestratigráfica, litoestratigráfica e estratigrafia genética da Bacia do Araripe (PONTE, 1992b).

Figura 5. Mapa morfo-estrutural na capa da Chapada do Araripe, baseado em Lopes (1992).

Figura 6. Seções estratigráficas esquemáticas, ilustrando o controle tectônico sobre a sedimentação mesozóica nas bacias do Nordeste do Brasil (PONTE \& PONTE FILHO, 1996).

Figura 7. Quadro comparativo com as colunas estratigráficas propostas para a seqüência sedimentar do Araripe. Compilado de Assine (1990), Dantas \& Lopes (1996); Neumann (1999).

Figura 8. Quadro A - Fauna e flora fósseis do Membro Crato, Quadro 2 fauna e flora fósseis do Membro Romualdo, baseados em Maisey (1993), Martill (1993) e Viana (1999).

Figura 9. Quadro contendo a fauna de macroinvertebrados bentônicos (moluscos e equinóides) do Membro Romualdo da Formação Santana, Bacia do Araripe.

Figura 10. Quadro mostrando a relação entre a tafonomia, suas subdivisões e os eventos responsáveis pela origem das concentrações fossiliferas (SIMÕES \& HOLZ, 2000).

Figura 11. Diagrama ilustrativo dos niveis de descrição e interpretação de camadas à análise de uma bacia sedimentar (AIGNER, 1984). Em vermelho, o nivel hierárquico referente à análise estratinômica das camadas, contendo as concentrações.

Figura 12. Perfis de correlação entre os poços 4-BO-1-PE e 2-AP-1-CE (LIMA \& VIEIRA-FILHO, 1997).

Figura 13. Esquema ilustrativo do ciclo transgressivo-regressivo, da seqüência pós-rifte ( $2^{\circ}$ ordem) da Bacia do Araripe (PONTE, 1994). 
Figura 14. Mapa geológico simplificado com os pontos de ocorrência das concentrações fossiliferas de macroinvertebrados bentônicos do Membro Romualdo.

Figura 15. A, terminologia empregada na descrição do grau de empacotamento dos bioclastos na matriz sedimentar (partes duras esqueléticas); B, diferentes graus de empacotamento dos bioclastos, segundo a forma e tamanho das partículas bioclásticas (KIDWELL \& HOLLAND, 1991).

Figura 16. Orientação dos bioclastos em planta, com identificação de direções dos paleofluxos (correntes e fluxos oscilatórios), Allen (1990) Fürsich (1980), Allen (1990).

Figura 17. Descrição da biotrama, na observação dos bioclastos em corte e planta, e emprego dos termos segundo Kidwell et al. (1986) e Kidwell \& Bosence (1991).

Figura 18. Geometria dos depósitos, estabelecida a partir de parâmetros bidimensionais, da natureza da superficie deposicional, da bioturbação de organismos, do modo de vida dos organismos e dos processos físicos, de acordo com Kidwell et al. (1986).

Figura 19. Processos relacionados à classificação das concentrações esqueletais em nove tipos e suas distribuiçöes ao longo de um gradiente de águas rasas - profundas (FÜRSICH \& OSCHMANN, 1993).

Figura 20. Classificação dos calcários baseada na composição (FOLK, 1959).

Figura 21. Classificação de rochas carbonáticas (DUNHAM, 1962).

Figura 22. Classificação da porosidade (na cor azul) em sedimentos carbonáticos (CHOQUETE \& PRAY, 1970).

Figura 23. Explicação das legendas para litotipos e minerais, estruturas e fósseis e feições estratigráficas, dos perfis litoestratigráficos esquemáticos.

Figura 24. Perfil estratigráfico esquemático da seção Romualdo, Crato, $C E$, localizada a $7,3 \mathrm{~km}$ a sudeste da cidade de Crato, próximo à Rodovia $C E$ 125 (Crato-Arajara). Coordenadas geográficas S $07^{\circ} 17^{\prime} 603^{\prime \prime}$ e W 39 $23^{\prime}$ $536^{\prime \prime}$, do topo do perfil, na ocorrência da concentração na cota $632 \mathrm{~m}$.

Figura 25. Perfil estratigráfico esquemático parcial do Membro Romualdo, em Jamacaru, Missão Velha, CE, localizado em drenagem primária, a 300 metros da Rodovia Estadual CE113, Km 18 (Missão Velha - Jamacaru), coordenadas geográficas $S 07^{\circ} 23^{\prime} 856^{\prime \prime}$ e W $39^{\circ} 08^{\prime} 592^{\prime \prime}$.

Figura 26. Perfil estratigráfico esquemático da seção 1, Membro Romualdo, 
Formação Santana, Serra da Mãozinha, Missão Velha, CE. Coordenadas UTM no topo do perfil (0489121/9186484), onde ocorrem as concentrações fossiliferas, próximo à estrada não pavimentada Sítio Encruzilhada-Abaiara.

Figura 27. Perfil estratigráfico esquemático da seção 2, Formação Santana, Serra da Mãozinha, Missão Velha, CE. Coordenadas UTM (0489443 / 9186270), no topo do perfil, onde ocorre concentração fossilífera, próximo à estrada não pavimentada Sitio Encruzilhada-Abaiara.

Figura 28. Representação litológica esquemática das concentrações do Sítio Saco (ponto 1 e 2), Porteiras, CE e ocorrências correlatas, $8 \mathrm{~km}$ ao norte da sede do município, próximo à estrada não pavimentada, com coordenadas geográficas: $S 07^{\circ} 29^{\prime} 904^{\prime \prime}$ e w $39^{\circ} 09^{\prime} 616^{\prime \prime}$ e cota de $759,5 \mathrm{~m}$.

Figura 29. Perfil estratigráfico esquemático, da Formação Santana em Porteiras, CE, $4 \mathrm{~km}$ a NW da cidade homônima, curso de drenagem (Riacho dos Bois). Coordenadas geográficas: $S 07^{\circ} 31^{\prime} 49,1^{\prime \prime}$ e W $39^{\circ} 09^{\prime} 48,8^{\prime \prime}$ da concentração fossilifera de macroinvertebrados, no topo da seção.

Figura 30. Perfil estratigráfico esquemático, Formação Santana, Sítio Sobradinho, Jardim, CE, distando $19 \mathrm{~km}$ no rumo $E$, da sede do município. No topo da seção, cota $770 \mathrm{~m}$ e coordenadas geográficas $S 07^{\circ} 34^{\prime} 16^{\prime \prime} \mathrm{e} \mathrm{W}$ $39^{\circ} 09^{\prime} 50,3^{\prime}$, concentração fossilífera de macroinvertebrados bentônicos.

Figura 31. Seção estratigráfica esquemática, Membro Romualdo, Formação Santana, Sítio Caboclos, Fronteiras, PI. A seção dista $8 \mathrm{~km}$ para NW, de Caldeirão Grande do Piauí, com início em S $07^{\circ} 17^{\prime} 58^{\prime \prime}$ W $040^{\circ} 36^{\prime} 27,1^{\prime \prime}$.

Figura 32. Quadro sinóptico da evolução tectono-sedimentar da Bacia mesozóica do Araripe $\left({ }^{\star}\right)$, escala geocronométrica segundo Cowie \& Basser (1989) in Ponte \& Ponte Filho, (1996).

Figura 33. Correlação estratigráfica dos perfis da seção sedimentar do Membro Romualdo, da Formação Santana, com distribuição vertical dos tipos de concentrações fossiliferas de macroinvertebrados bentônicos, em arcabouço de ciclos de $3^{a}$ ordem.

Figura 34. Seção litoestratigráfica, na lavra da Mina Pedra Branca, porção norte da Bacia do Araripe, extraído de Martill (1993).

Figura 35. Escala semiquantitativa de desarticulação de carapaças de equinóides, proposta por Kidwell \& Baumiller (1990) e estágios correlatos para o depósito com carapaças de equinóides da Bacia do Araripe.

Figura 36. Mapa de localização da Bacia do Araripe no contexto tectônico regional e possíveis sentidos de direções de proveniência da incursão marinha Albiana, na área da Bacia do Araripe (Baseado em Lima-Filho et al., 1996; Ponte \& Ponte-Filho, 1996; Mabessone et al., 1999). 


\section{LISTA DE TABELAS}

Tabela 1. Ocorrência de macroinvertebrados fósseis do Membro Romualdo (Formação Santana), nos estados do Ceará, Pernambuco e Piauí.

Tabela 2. Categoria de feições macroscópicas usadas na análise tafonômica, para a interpretação da gênese dos depósitos de bioclastos (adaptado de KIDWELL, 1991; SIMÔES \& HOLZ, 2000).

Tabela 3. Mineralogia dos esqueletos carbonáticos: mineralogia dominante e mineralogia menos comum (TUCKER, 2001).

Tabela 4. Constituintes e características das seções petrográficas das rochas carbonáticas que contém assembléias fósseis esqueléticas de macroinvertebrados bentônicos.

Tabela 5. Assembléia de palinomorfos de Sítio Saco.

Tabela 6. Assembléia de palinomorfos de Serra da Mãozinha.

\section{LISTA DE SIGLAS}

CPKB.

CPGM

CPCA.

CPRM

DNPM

FAPESP.

DGSA

GPS

IBACIP

IBB

LPE.

SGE

SUDENE

TAZ

UFC

UFPE.
Coleção Paleontológica Karl Beurlen

Coleção Paleontológica Geraldo Munis

Centro de Pesquisas da Chapada do Araripe

Companhia de Pesquisas e Recursos Minerais

Departamento Nacional da Produção Mineral

Fundação de Amparo à Pesquisa do Estado de São

Paulo

Departamento de Geologia Sedimentar e Ambiental Global Position Sytem

Indústria Barbalhense de Cimento Portland S.A.

Instituto de Biociências de Botucatu

Laboratório de Paleozoologia Evolutiva

Serviço Geográfico do Exército

Superintendência para o Desenvolvimento do Nordeste

Zona Tafonômica Ativa

Universidade Federal do Ceará

Universidade Federal de Pernambuco 
UNESP

Universidade Estadual do Estado de São Paulo

USP

Universidade de São Paulo

URCA

Universidade Regional do Cariri

LISTA DE ABREVIAÇÕES

\begin{tabular}{|l|l|}
\hline biocl. & Bioclastos \\
\hline biv. & bivalves \\
\hline com. & concordante \\
\hline equin. & equinóides \\
\hline esp. & espesura \\
\hline espin. & espinho \\
\hline estrat. & estratigráfia \\
\hline frag. & fragmentação \\
\hline frat. & fraturada \\
\hline gast. & gastrópode \\
\hline int. & inteiras \\
\hline obl. & obliquo \\
\hline per. & perpendicular \\
\hline unid. & unidade \\
\hline
\end{tabular}




\begin{abstract}
The taphonomical study of the shelly assemblages of the upper portion of the Santana Formation (Cretaceous), Romualdo Member, Araripe Basin, is the main goal of this research. The used approach for the Araripe Basin deposits differs of previous ones by the integration of taphonomical, stratigraphical and petrographical tools. Shells and shell fragments of mollusks (gastropods and bivalves), sometimes associated to echinoderm remains are the main macrobenthos in the studied deposits. Taphonomic analysis allowed recognizing four different types of fossil concentrations: (a) proximal tempestites, (b) distal tempestites, (c) autochthonous concentrations (primarily biogenic) and (d) lag concentrations. These concentrations and associated deposits were mostly generated by multiple storm events. Hence, the studied tempestites are mostly represented by "thousand year multiple-event concentrations". The above mentioned fossil concentrations were generated along a bathymetric gradient ranging from shallow to deep (below storm wave base) waters. This was indicated by the occurrence of invertebrate macrofossils preserved in life position (autochthonous concentrations). Texturally, the studied fossil concentrations are bioclastic wackestones-packstones, mainly with microsparitic calcite cement. Dissolution was the main diagenetic process. On the other hand, micritization allowed the preservation of original shell shape and size. In the studied sedimentary sequence, the skeletal concentrations occur in four different moments, in successive third order cycles. The fossils in the studied assemblages indicate a transitional (lagoonal) paleoenvironment, punctuated by Albian marine ingressions, as indicated by the presence of microfossils (dinoflagellates-Subtilisphaera) and macrofossils (echinoderms Pygurus and Faujasia). These ingressions may come from several possible seaways, such as (a) the intracratonic Parnaiba Basin, recording marine deposits in the Codó area, (b) the Potiguar Basin, in the northeastern portion, with marine deposits of the Malhada Vermelha, through the Pendência Graben (between the Potiguar Basin and Araripe Basin), and finally through (c) the Sergipe-Alagoas Basin, and the northern portion of the Tucano-Jatobá Basin. In this context, a precise
\end{abstract}


paleogeographic map pointing out the directions of the Cretaceous seaways of the Araripe Basin can not be accurately depicted, yet. 


\section{Resumo}

O estudo tafonômico de concentrações fossilíferas de macroinvertebrados da parte superior da Formação Santana (Cretáceo), litoestratigraficamente equivalente ao Membro Romualdo, da Bacia do Araripe é o tema central da presente pesquisa. A abordagem tafonômica empregada para os depósitos da Bacia do Araripe distinguese pela integração de ferramentas tafonômicas, estratigráficas e petrográficas. Os depósitos estudados contêm, predominantemente, fósseis de conchas de moluscos (gastrópodes e bivalves), às vezes, em associação com carapaças de equinóides e seus fragmentos. A análise tafonômica permitiu o reconhecimento de quatro tipos distintos de concentrações fossiliferas, ou seja: (a) tempestitos proximais, (b) tempestitos distais, (c) concentrações autóctones (primariamente biogênicas) e (d) resíduos transgressivos. Tais concentrações e depósitos associados foram gerados, em sua grande maioria, a partir de múltiplos eventos de tempestade. Assim sendo, muitos dos tempestitos estudados correspondem a concentrações do tipo "thousand year multiplemevent concentrations". A deposição das assembléias fossiliferas acima mencionadas ocorreu, possivelmente, a partir de um gradiente de águas rasas e profundas (abaixo do nível de base das ondas de tempestade), conforme evidenciado pela ocorrência de fósseis em posição de vida (concentrações autóctones). A análise petrográfica mostra que, texturalmente, os depósitos correspondem a wackestones packstones bioclásticos, com predomínio de cimento calcítico microesparítico. A atuação dos processos diagenéticos levou, principalmente, à dissolução das conchas. Já a micritização preservou a forma e os tamanhos originais dos bioclastos. Na seqüência sedimentar estudada, as concentrações fossilíferas ocorrem em quatro momentos distintos, compreendidos em ciclos sucessivos de $3^{\mathrm{a}}$ ordem. Os fósseis presentes nas concentrações fossilíferas estudadas sugerem paleoambiente transicional (lagunar), associado às incursões albianas, indubitavelmente marinhas, com microfósseis (dinoflagelados Substilisphaera) e macrofósseis (equinodermatas Pygurus e Faujasia) de caráter marinho. Proveniências vindas (a) da Bacia Intracratônica do Parnaíba, na porção noroeste do atual nordeste brasileiro, registrando a presença de depósitos marinhos na área de Codó; (b) da Bacia 
Potiguar, na porção nordeste, com os depósitos marinhos da Bacia de Malhada Vermelha, através do "Graben" Pendência, (entre as bacias Potiguar e Araripe) e, finalmente, (c) da Bacia de Sergipe-Alagoas e porção norte da Bacia Tucano-Jatobá, sugerem polêmica ainda com relação a um possivel mapa paleogeográfico preciso, apontando as direções das conexões marinhas da Bacia do Araripe, durante o Cretáceo. 


\section{Introdução}

A Bacia do Araripe, localizada no Nordeste do Brasil (Figura 1, p. 2), na região limitrofe dos estados do Ceará, Pernambuco, Piauí e Paraíba, inclui uma seqüência sedimentar, predominantemente mesozóica, embasada por rochas pré-cambrianas e uma fina capa de sedimentos paleozóicos. No intervalo mesocretáceo, ocorre a Formação Santana, pertencente ao Grupo Araripe, compreendida na seqüência pósrifte, de idade aptiana-albiana (Figura 2, p. 3), que se destaca por apresentar uma diversificada fauna e flora fósseis.

$\mathrm{Na}$ fauna fóssil da Formação Santana, os invertebrados são conhecidos, porém menos documentados, em relação à fauna de vertebrados. Dentre os invertebrados, os macroinvertebrados (gastrópodes, bivalves e equinóides), ocorrem na porção superior da Formação Santana, Membro Romualdo, sendo encontrados, principalmente, em bancos decimétricos recristalizados de calcarenitos. A origem e o significado paleoambiental e estratigráfico de tais depósitos são ainda muito discutidos e não totalmente esclarecidos.

Os estudos relacionados a macrofauna de invertebrados fósseis, sempre estiveram voltados, à taxonomia (BEURLEN, 1963, 1964, 1966, 1971; BRITO, 1981; CAVALCANTI \& VIANA, 1990) e poços abordaram caracteres paleogeográficos e tafonômicos (MABESSONE \& TINOCO, 1973; BERTHOU ET AL., 1990; MAISEY, 1991; MARTILL, 1993; WILBY, 1993; SIMÕES ET AL., 1995; VIANA, 1999, SALES \& SIMÕES, 2001; SALES ET AL., 2003a, b).

Tendo em vista estas considerações, busca-se neste trabalho, o estudo tafonômico, das concentrações fossilíferas de macroinvertebrados bentônicos, do Membro Romualdo da Formação Santana, Bacia do Araripe. Este estudo tafonômico subsidiará, o estabelecimento dos tipos de concentrações, o levantamento e delineamento de suas ocorrências na seção sedimentar e uma aplicação da tafonomia e no arcabouço estratigráfico prévio, da porção Albiana da bacia, para o conhecimento de suas origens. 


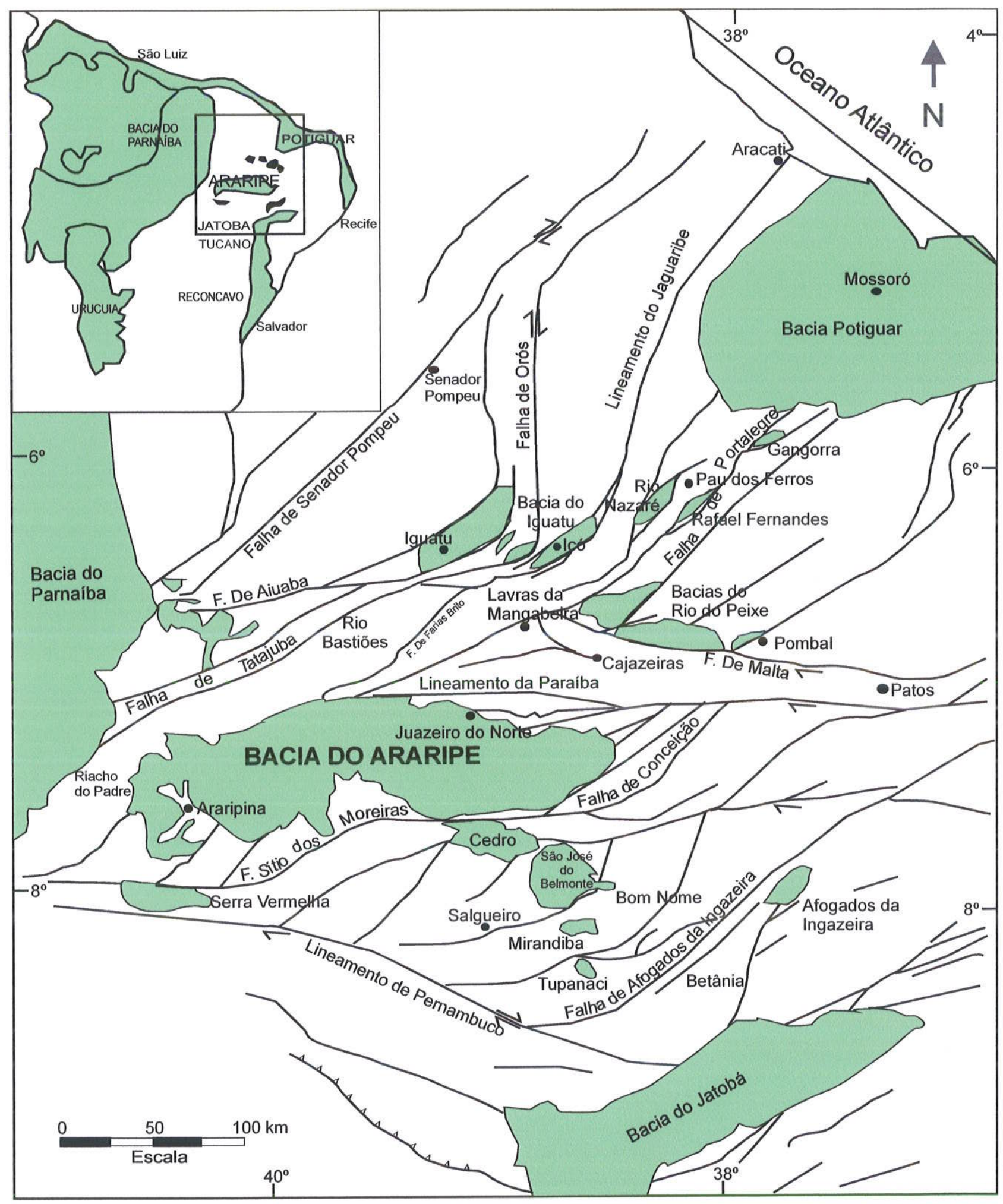

Figura 1. Mapa de localização da Bacia do Araripe e Bacias Interiores do Nordeste, com principais f a I h a m e ntos, no contexto t e c tôn icoregional, Ponte \& Ponte-Filho (1996). 


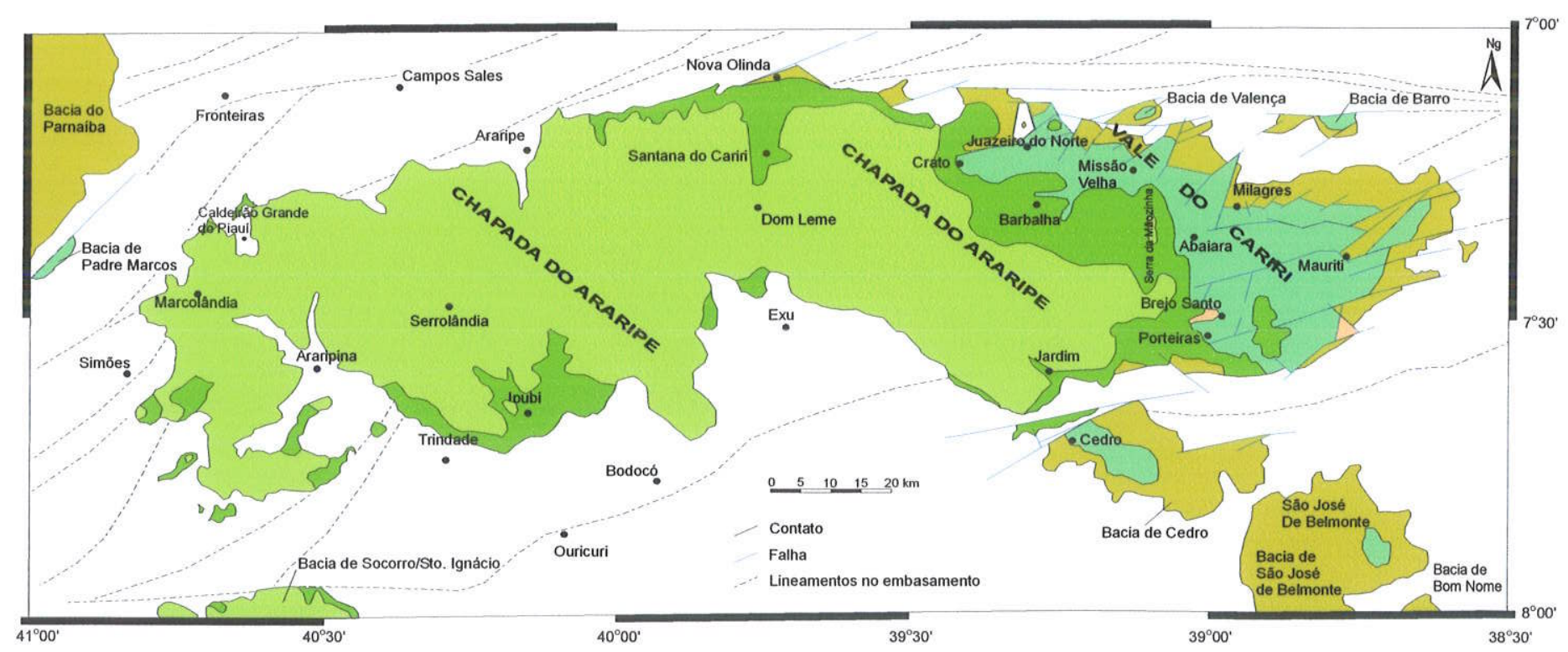

Embasamento cristalino

$\square$ Formação Mauriti

formações Brejo Santo, Missão Velha e Abaiara formações Rio da Batateira e Santana

formações Arajara e Exu

\begin{tabular}{|c|c|c|c|c|}
\hline \multirow{5}{*}{$\begin{array}{l}\text { O } \\
\text { O } \\
\text { N } \\
\text { O } \\
\text { ய } \\
\text { ¿ }\end{array}$} & \multirow[b]{2}{*}{ 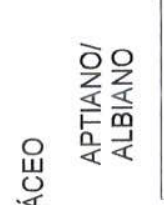 } & \multirow{2}{*}{$\begin{array}{l}\text { GRUPO } \\
\text { ARARIPE }\end{array}$} & \multirow{2}{*}{$\begin{array}{l}\text { SEQÜÊNCIA } \\
\text { PÓS-RIFTE }\end{array}$} & $\begin{array}{l}\text { Formação Exu } \\
\text { Formação Arajara }\end{array}$ \\
\hline & & & & $\begin{array}{l}\text { Formação Santana } \\
\text { Formação Rio da } \\
\text { Batateira }\end{array}$ \\
\hline & \multicolumn{4}{|c|}{ 点 DISCORDÂNCIA PRÉ-APTIANA } \\
\hline & $\begin{array}{l}\text { O을 } \\
\text { 岁玄 } \\
\text { 足 }\end{array}$ & \multirow{2}{*}{$\begin{array}{l}\text { GRUPO } \\
\text { VALE } \\
\text { DO } \\
\text { CARIRI }\end{array}$} & $\begin{array}{l}\text { SEQÜENCIA } \\
\text { SIN-RIFTE }\end{array}$ & Formação Abaiara \\
\hline & $\begin{array}{l}\text { JURÁS- } \\
\text { SICO }\end{array}$ & & $\begin{array}{l}\text { SEQÜÊNCIA } \\
\text { PRÉ-RIFTE }\end{array}$ & $\begin{array}{c}\text { Formação Missão } \\
\text { Velha } \\
\text { Formação Brejo } \\
\text { Santo }\end{array}$ \\
\hline \multicolumn{5}{|c|}{ DISCORDÂNCIA PRÉ-MESOZÓICA } \\
\hline \multicolumn{2}{|c|}{$\begin{array}{l}\text { PALEOZÓICO } \\
\text { SILURIANO? }\end{array}$} & \multicolumn{2}{|c|}{$\begin{array}{l}\text { SEQÜÊNCIA } \\
\text { BETA }\end{array}$} & Formação Mauriti \\
\hline \multicolumn{5}{|c|}{ DISCORDÂNCIA PRÉ-FANEROZÓICA } \\
\hline \multicolumn{2}{|c|}{$\begin{array}{l}\text { PRÉ- } \\
\text { CAMBRIANO }\end{array}$} & & \multicolumn{2}{|c|}{ EMBASAMENTO } \\
\hline
\end{tabular}

Figura 2 - Mapa geológico simplificado da Bacia do Araripe (modificado de ALBUQUERQUE ET AL., 2000; SALES \& SIMÕES, 2000) e esquema litoestratigráfico simplificado com seqüências (modificado de PONTE \& PONTEFILHO, 1996). 


\section{Problemática envolvida}

Uma primeira abordagem tafonômica de depósitos, contendo macroinvertebrados fósseis do Membro Romualdo, na Bacia do Araripe, tentativamente, coube a Santos (1982), na década de 80. A autora inicialmente interpretou os possíveis processos e produtos envolvidos na sua gênese, relacionando-os às influências de ambiente marinho raso, com predominância de ondas e tempestades.

Na década de 90, Berthou et al. (1990) e Martill (1993) defenderam a influência marinha, possivelmente relacionada a tempestitos, nos níveis carbonáticos (Membro Romualdo), contendo os fósseis de moluscos, ostracodes e equinóides. Berthou (1994) atentou para os atributos cronoestratigráficos da Bacia do Araripe, relacionados ao conteúdo paleontológico, destacando o uso de ostracodes e gastrópodes (i.e. Cassiopinae). Porém, em uma breve nota, Simões et al. (1995), reconheceram depósitos coquinóides e demonstraram sua gênese relacionada a eventos de alta energia (e.g., tempestades), representando tempestitos proximais (sensu, FÜRSICH \& OSCHMANN, 1986, 1993). Esses autores acrescentaram ainda que a heterogeneidade dos bioclastos podia ser entendida como um indicador de mistura temporal "Time Averaging" (sensu, WALKER \& BAMBACH, 1981; KOWALEWSKI, 1996, 1997).

A correlação estratigráfica de estratos mesozóicos, a partir de invertebrados marinhos, entre as bacias Potiguar (Formação Jandaira), Padre Marcos, Araripe (Formação Santana), Sergipe-Alagoas (Formação Riachuelo) e Camamu, registrada na literatura (SANTOS, 1960; SANTOS \& CASSAB, 1994; CASSAB, 1999; MACHADO \& CASSAB, 1997; BEURLEN, 1962, 1963, 1966; MABESSONE \& TINOCO, 1973; SANTOS, 1982; LIMA, 1979; MAISEY, 1991; MARTILL, 1993; SIMÕES ET AL., 1995, SALES ET AL., 1999; SALES \& SIMÕES, 2000; MANSO, 1999; CONCEICÃO ET AL., 1999; ANDRADE \& SOUSA LIMA, 1999), mostra a contemporaneidade desses registros nas bacias interiores do Nordeste e costeiras adjacentes cretácicas, correlacionados a superseqüência transicional e marinha de Ponte (1992a).

Nesse cenário, os depósitos contendo concentrações de macroinvertebrados fósseis do topo da Formação Santana (Membro Romualdo), passaram a ser 
observados como uma possivel e valiosa fonte para estudos tafonômicos, como sugerido por Sales et al. (1999) e colocado por Sales \& Simões (2000).

Os estudos tafonômicos de detalhe, nas décadas de 80 e 90 , no cenário mundial, destacam-se com o emprego dos conceitos de retroalimentação tafonômica (KIDWELL \& JABLONSKY, 1983); tafofácies (SPEYER \& BRETT, 1986; BRETT \& BAIRD, 1986); assinatura tafonômica (FÜRSICH \& OSCHMANN, 1993) e resolução temporal e especial (KOWALEWSKI, 1996,1997) e (abordagens conceituais), firmando-se também, como uma importante ferramenta em associação aos estudos sedimentológicos e estratigráficos.

Esses pressupostos teóricos são aqui abordados, como hipóteses de trabalho; visando a comprovação da gênese das concentrações dos macroinvertebrados fósseis das concentrações e identificação de seu processos e produtos. Primeiro, através do estudo tafonômico das concentrações de macroinvertebrados fósseis do Membro Romualdo, porção superior da Formação Santana e, segundo, por suas implicações paleoambientais e estratigráficas. Para isto, são empregadas metodologias multidisciplinares, integrando a paleontologia, sedimentologia e estratigrafia.

A fauna de macroinvertebrados (moluscos e equinóides), em específico as concentrações, localizadas no topo da Formação Santana apresentam duas características únicas, no que se refere à natureza das rochas e da tafonomia: A) os depósitos estão compreendidos na fase terminal da Formação Santana, com marcante influência marinha (BEURLEN, 1966; LIMA, 1978; ARAI \& COIMBRA, 1990; BERTHOU ET AL., 1990) e B) os fósseis estão, muitas vezes preservados em bancos coquinóides, de origem complexa (SIMÕES ET AL., 1995; SALES ET AL., 1999, SALES \& SIMÕES, 2000).

Como base no exposto anteriormente, decidiu-se investigar a gênese e o significado paleoambiental dos depósitos fossiliferos de macroinvertebrados bentônicos, do Membro Romualdo, visando a produção de dados tafonômicos e estratigráficos integrados. 


\section{Objetivos}

O presente estudo tem como objetivo a fundamentação da hipótese que fatores físicos e biológicos exercem importante controle na gênese das concentrações fossilíferas de macroinvertebrados, originadas a partir de eventos episódicos de alta energia (tempestades), associados a fluxos oscilatórios (e.g., AIGNER, 1985; FÜRSICH \& OSCHMANN, 1986, 1993; KIDWELL \& BOSENCE, 1991; SIMÕES ET AL., 1994, 1996; SIMÕES, 1996, 1998). O estudo tafonômico pode prover a identificação descrição dos processos envolvidos na gênese das acumulações esqueléticas, a mistura temporal e sua resolução temporal (sensu, KIDWELL, 1993). Desta forma, a análise tafonômica de alta resolução (veja, SIMÕES, 1998; SIMÕES \& KOWALEWSKI, 1998a), complementada por dados sedimentológicos e estratigráficos, permite inferências sobre os sistemas deposicionais e a identificação de superfícies cronocorrelatas. Como fonte de dados são aqui esudadas as concentrações do Membro Romualdo da Formação Santana, da Bacia do Araripe.

\subsection{Objetivos Específicos}

Os objetivos específicos são:

A) o estudo tafonômico das concentrações fossilíferas de macroinvertebrados do Membro Romualdo, Formaçăo Santana, com descrição da biotrama dos bioclastos (sensu, KIDWELL ET AL., 1986; KIDWELL, \& HOLLAND, 1991) e da natureza da matriz (sensu, FÜRSICH \& OSCHMANN, 1993), procurando entender a gênese (em termos de processo e produto) dos depósitos examinados;

B) comparação e correlação entre as concentrações fossiliferas;

C) levantamento de seções colunares litoestratigráficas, onde ocorrem os depósitos fossiliferos da sucessão albiana, visando correlações e,

D) análise da distribuição vertical dos padrões de preservação das diferentes concentrações e dos estilos bioestratinômicos (e.g. KIDWELL. ET AL., 1986; KIDWELL, 1991a; KIDWELL \& BRENCHLEY, 1996; SIMÕES, 1998; SIMÕES ET AL., 2000), dentro de um modelo de estratigrafia de seqüências. 


\section{Revisão da Literatura}

\subsection{O Cretáceo no Nordeste brasileiro}

Durante o Cretáceo Inferior, na região nordeste do Brasil, predominava um clima quente, provavelmente com uma ampla variação das condições de umidade (PETRI, 1998). Na passagem Aptiano-Albiano, de acordo com a análise comparativa da paleogeologia dos litorais, atlânticos brasileiro e africano, ainda com uma precária ligação ao mar aberto, o clima árido possibilitou a formação de evaporitos entre as cadeias Walvis-Rio Grande, ao sul, e Alagoas-Camerum, ao norte NORTHFLEET ET AL. ,1997). Esta fase evaporítica foi registrada na bacia do Araripe. Ainda de acordo com (NORTHFLEET ET AL. , 1997) ao longo das duas fendas, norte-sul e equatorial, a invasão marinha do Aptiano-Albiano, formou dois longos e estreitos golfos, aparentemente barrando a progressão das fendas norte-sul, onde atuava a geofratura de Pernambuco-Camerum. Entre o final do Turoniano e o Coniaciano, deixou de existir a barreira que unia o nordeste brasileiro à costa do Camerum-Nigéria. O vulcanismo do Cabo em Pernambuco (90 Ma - VANDOROS ET AL., 1966 e 105 + 1,8 Ma; LONG ET AL. 1986 IN LIMA FILHO, 1997), correlacionável aos granitos da África (Camerum e Nigéria), acompanharam a extinção da última barreira. O abaixamento do bloco, ao sul da geofratura da Paraíba, originou a Bacia do Araripe, isolada do sistema do rifte principal. A partir do albiano, completa-se, então, a fragmentação do paleocontinente Gondwana, com a deposição dos sedimentos marinhos transgressivos nas bacias marginais, das margens equatorial e oriental do Brasil (MATOS, 1987). Ainda no Albiano, a Bacia do Araripe experimentou um relaxamento tectônico e ajuste póstectônico propicio à sedimentação marinha e lagunar, clástico-carbonática, nos limites de uma ampla bacia interior (BRITO NEVES, 1990). Do Albiano ao Eocenomaniano prevaleceram, em todo nordeste brasileiro, condições marinhas mais francas, sujeitas a transgressões e regressões (NORTHFLEET ET AL. ,1997).

No mesocretácico, tem-se a representação das unidades com as maiores extensões e continuidades laterais, praticamente sincrônicas, depositadas sob regime 
de mar alto, incluindo o Grupo Araripe na Bacia do Araripe (ARAI, 1999), com a tectono seqüência pós-rifte (PONTE, 1992) (Figura 2, p. 3),

\subsection{Bacia Sedimentar do Araripe}

A bacia sedimentar do Araripe ocupa uma extensão de mais de $8.000 \mathrm{~km}^{2}$ na região limítrofe dos estados do Ceará, Pernambuco, Piauí e Paraíba. Possui uma forma alongada, estendendo-se por cerca de $250 \mathrm{~km}$ na direção leste-oeste e de até $75 \mathrm{~km}$, na direção norte-sul, ocorrendo numa área limitada pelas coordenadas geográficas: $38^{\circ}$ $30^{\prime}$ a $40^{\circ} 55^{\prime}$ de longitude oeste de Greenwich e $7^{\circ} 07^{\prime}$ a $7^{\circ} 49^{\prime}$ de latitude sul (Figuras 1 e 2 , p. 2 e 3). Regionalmente está inserida no conjunto geotectônico informalmente referido como "Bacias Interiores do Nordeste", encravada sobre a Zona Transversal de Dobramentos do Nordeste e Sistema Piancó-Alto Brígida (BRITO NEVES, 1990), no embasamento da Província Borborema, associada a grandes lineamentos précambrianos. A Bacia do Araripe tem seus limites controlados ao norte pelo Lineamento da Paraíba (Patos), a sudeste e leste pela falha da Conceição e a sudoeste pela falha de Sítio dos Moreiras (Figura 1, p. 2).

A origem da Bacia do Araripe está diretamente ligada ao evento da abertura do Oceano Atlântico Sul que envolveu toda a porção leste da Plataforma Sul-Americana responsável pela fragmentação do paleocontinente Gonduana e pela formação dos riftes mesozóicos do Nordeste brasileiro (PONTE \& PONTE FILHO, 1996). A intensa atividade da Plataforma Sul-Americana, resultado do tectonismo tafrogênico eocretácico (Neocomiano), chamado Reativação Vealdeniana (ALMEIDA, 1967), que possibilitou a formação de centros de deposição de seqüencias meso-cenozóicas, entre os quais, a seqüência sedimentar do Araripe.

O interesse pela bacia sedimentar do Araripe despontou a partir da década de 60 , com valiosas contribuições da Universidade Federal de Pernambuco (UFPE) (BEURLEN, 1962, 1963, 1966, 1971; MABESSONE \& TINOCO, 1973; MABESSONE, 1985), seguidos pelos trabalhos acadêmicos de Lima (1971, 1978), Silva (1983) e Assine (1990), os trabalhos do Departamento Nacional de Produção Mineral (DNPM), 
trabalhos da Companhia de Pesquisa e Recursos Minerais (CPRM) e trabalhos do Petróleo Brasileiro S. A. (PETROBRAS) e empresas empenhadas na pesquisa de petróleo nas Bacias Interiores do Nordeste. Um apanhado geral sobre a bacia sedimentar do Araripe e bacias interiores pode ser encontrado nas publicações de dois simpósios, realizados em 1990 e 1997, como também na coletânea bibliográfica, executada por Ponte \& Ponte (1996).

O arcabouço estrutural da bacia do Araripe foi melhor conhecido a partir da década de 80, onde-se destacam os trabalhos de Ghignone et al. (1986); Brito Neves (1990) e Ponte \& Ponte Filho (1996). A configuração estrutural da bacia, revelada com os trabalhos de levantamento gravimétricos e magnetométricos de Rand \& Manso (1984), e o mapa gravimétrico bourguer de Oliveira (1983) (Figura 3, p. 10), delineou o alto estrutural de Dom Leme, separando duas sub-bacias, sendo de Feira Nova a oeste (W) e a de Cariri a leste (E). Desta forma, a arquitetura da bacia compreende dois compartimentos com estilos estruturais distintos, superpostos: a zona de riftes, na parte inferior e a cobertura tabular meso-cretácea, sub-horizontal, encobrindo discordantemente.

O pacote sedimentar que preenche a Bacia do Araripe, como sintetizado em Ponte (1996), compreende quatro Seqüências: Beta, Pré-rifte, Rifte e Pós-rifte (Figura 2, p. 3). Sendo adicionada posteriormente, a seqüencia Zeta (PONTE ET AL., 1997), de idade cenozóica, que inclui as coberturas de depósitos eluvionares, coluvionares (tálus) e aluvionares. Quando se referem à evolução tectônica das Bacias interiores do Nordeste, Ponte et al. (1997) usam o termo Tectôno Seqüência Pós-Rifte para designar os estratos sedimentares, mesocretácicos de comportamento tabular e sub-horizontal, limitados na base por uma discordância regional pré-aptiana e, com topo exposto na capa de extensas chapadas que, no caso da seqüência Araripe, é nítido (Prancha 1 , Foto A). 


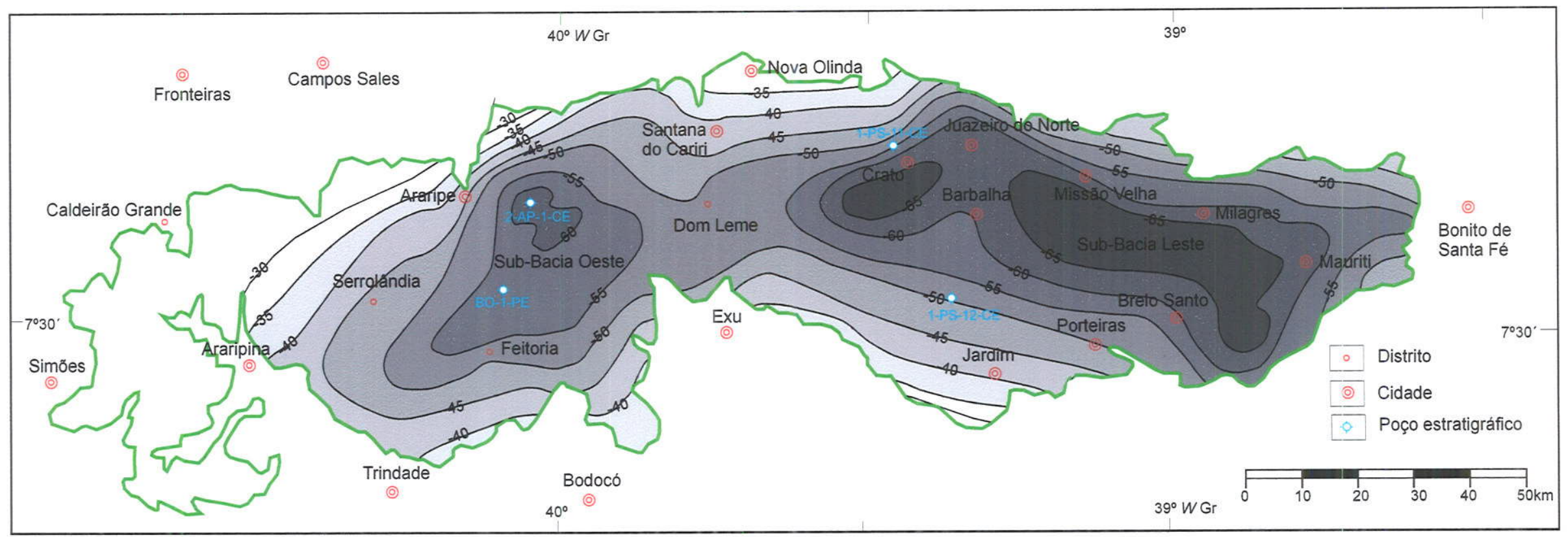

Figura 3. Mapa gravimétrico Bouguer da Bacia do Araripe, com intervalo de contorno $=5$ miligals. Baseado em Oliveira (1983). 
É neste contexto que, na bacia sedimentar do Araripe, encontra-se o Grupo Araripe, constituindo uma Seqüência Pós-Rifte (Figuras 2 e 4 , p. 2 e 12), predominantemente continental, contemporânea àquelas das superseqüências transicional e marinha das bacias pericratônicas brasileiras (PONTE, 1992). Na Bacia do Araripe, a Seqüência Pós-Rifte compreende o registro estratigráfico de ciclo deposicional transgressivo-regressivo completo, constituido por três sistemas deposicionais distintos (segundo PONTE, 1992a, b; PONTE \& PONTE-FILHO, 1996) (Figura 4, p.12):

A) fluvio-lacustre carbonático, de idade apitiana, englobando a Formação Rio da Batateira e o Membro Crato da formação Santana;

B) transicional-eveporítico e marinho litorâneo, eo-meso-albiano, incluindo os membros Ipubi e Romualdo da Formação Santana e a Formação Arajara e

C) sistema fluvial entrelaçado e meandrante albo-cenomaniono (?), constituindo a Formação Exu.

Ressalta-se que a feição geomorfológica da Chapada do Araripe foi desenvolvida no topo da Seqüência Pós-Rifte (Grupo Araripe), onde, no mapa morfo-estrutural de Lopes (1993), se observa que seus limites näo coincidem com os limites da bacia sedimentar (Figura 5, p. 13). 


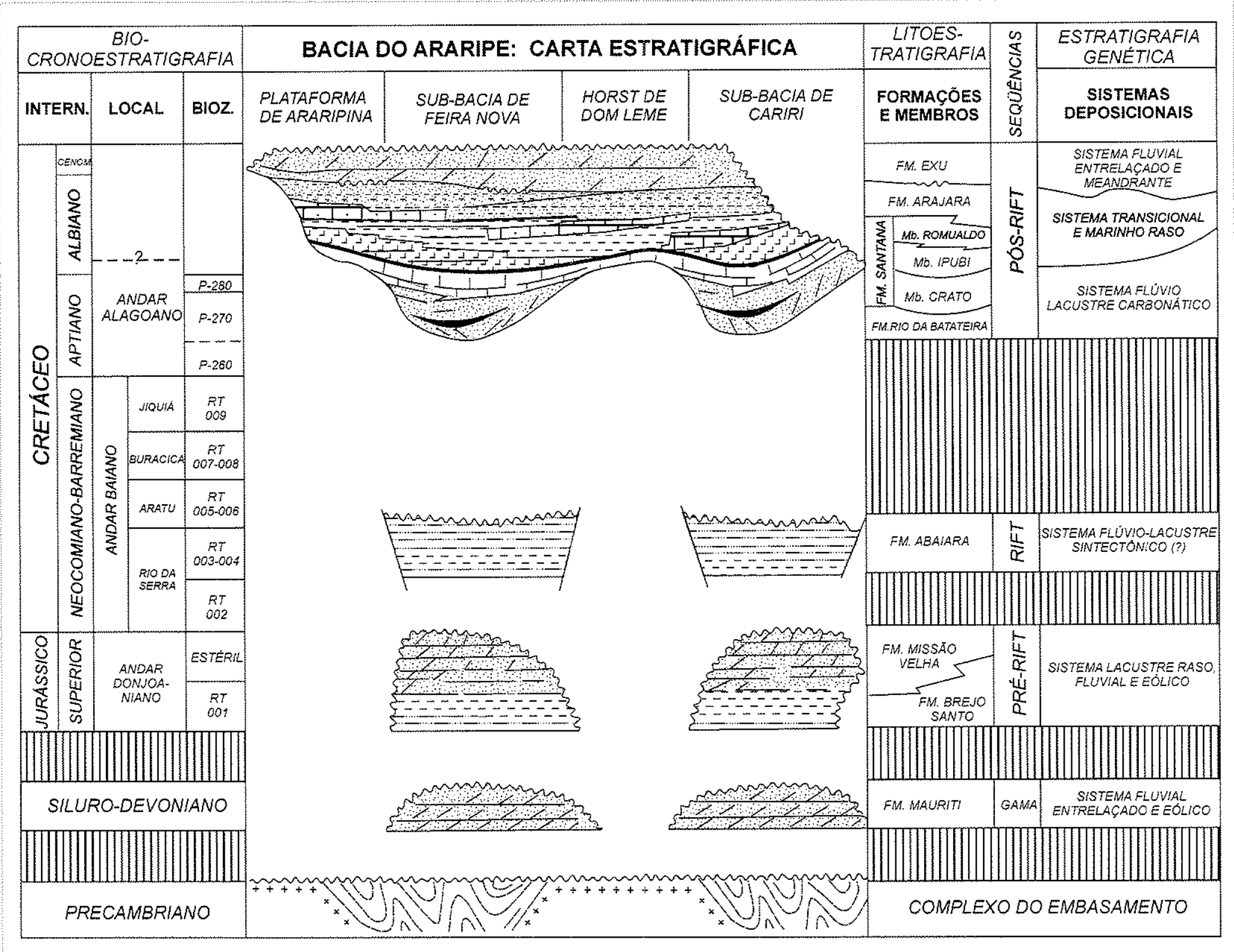

Figura 4. Carta estratigráfica, biocronoestratigráfica, litoestratigráfica e estratigrafia genética da Bacia do Araripe (PONTE, 1992b). 


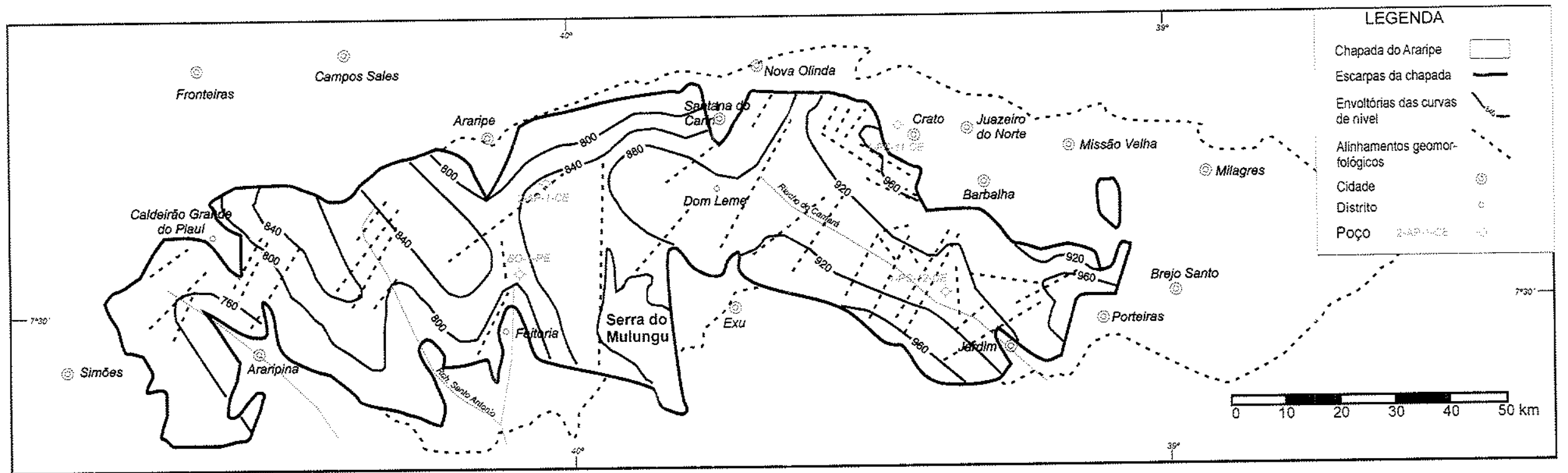

Figura 5. Mapa morfo-estrutural na capa da Chapada do Araripe. Baseado em Lopes (1993). 


\subsection{Formação Santana}

A Formação Santana, pertencente ao Grupo Araripe, compõe-se de três membros, da base para o topo, respectivamente denominados: Crato; Ipubi e Romualdo (BEURLEN, 1971) (Figuras 2, 4 e 5, páginas 3, 12 e 13). Nos membros Crato e Romualdo, encontram-se dois depósitos fossiliferos (e.g., Lagerstätten sensu SEILACHER, 1970 in MARTILL, 1990), mundialmente famosos.

Quanto à sua idade, os litótipos mesocretácicos da Formação Santana são considerados aptianos-albianos, principalmente, a partir de sugestões de comparações com registro de eventos tectono-sedimentares na estratigrafia das bacias marginais da América do Sul (PONS ET AL., 1990; ARAI ET AL., 1997). Na Figura 6 (p. 15), uma seção estratigráfica esquemática ilustra o controle tectônico sobre a sedimentação mesozóica nas bacias do Nordeste do Brasil.

Para a unidade litoestratigráfica, Formação Santana, muitos esquemas estratigráficos foram propostos, mas a nomenclatura proposta por Beurlen (1971) (Figura 7, p. 16), que diferenciou os membros Crato, Ipubi e Romualdo, è a mais empregada. Na evolução litoestratigráfica da bacia do Araripe, a proposta de Ponte \& Appi (1990) (Figura 7, p. 16) tem a melhor representação da seqüência sedimentar do Grupo Araripe, onde-se inclúi a Formação Santana.

A assembléia de microfósseis (pólens, esporos, dinoflagelados, ostracodes, foraminíferos e micromoluscos) da seção Santana, do poço 2-AP-1-CE (AZEVEDO \& TRAVASSOS PETRÓLEO S.A., 1986) mostra-se típico de ambiente mixohalino próximos à costa (lagunas e estuários), com possibilidades de ingressão marinha pulsativa, como demostrado em Arai \& Coimbra (1990) e Coimbra et al. (2002).

A sequência mais representativa da Formação Santana, contendo os três membros em superfície, ocorre na porção cearense da bacia, margeando continuamente a Chapada do Araripe, em sua porção norte e nordeste, estendendo-se pelos municipios de Santana do Cariri (de onde deriva o termo Formação Santana), Nova Olinda, Crato, Barbalha, Missão Velha e Abaiara, chegando às porções leste e sudeste nos municipios de Porteiras e Jardim (Figura 2, p. 3). 


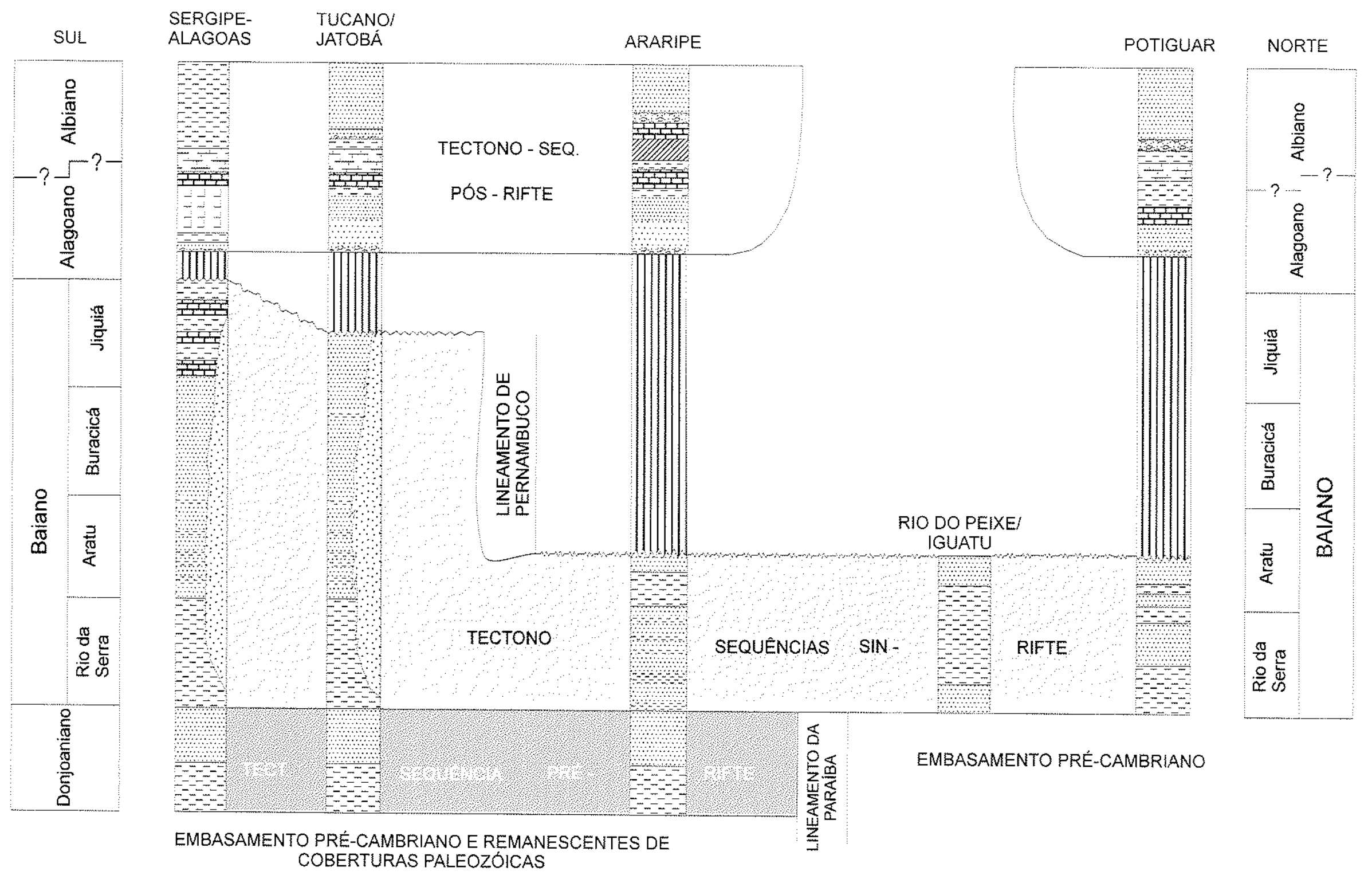

Figura 6. Seções estratigráficas esquemáticas ilustrando o controle tectônico sobre a sedimentação mesozóica, nas bacias do Nordeste do Brasil (PONTE \& PONTE FILHO, 1996). 


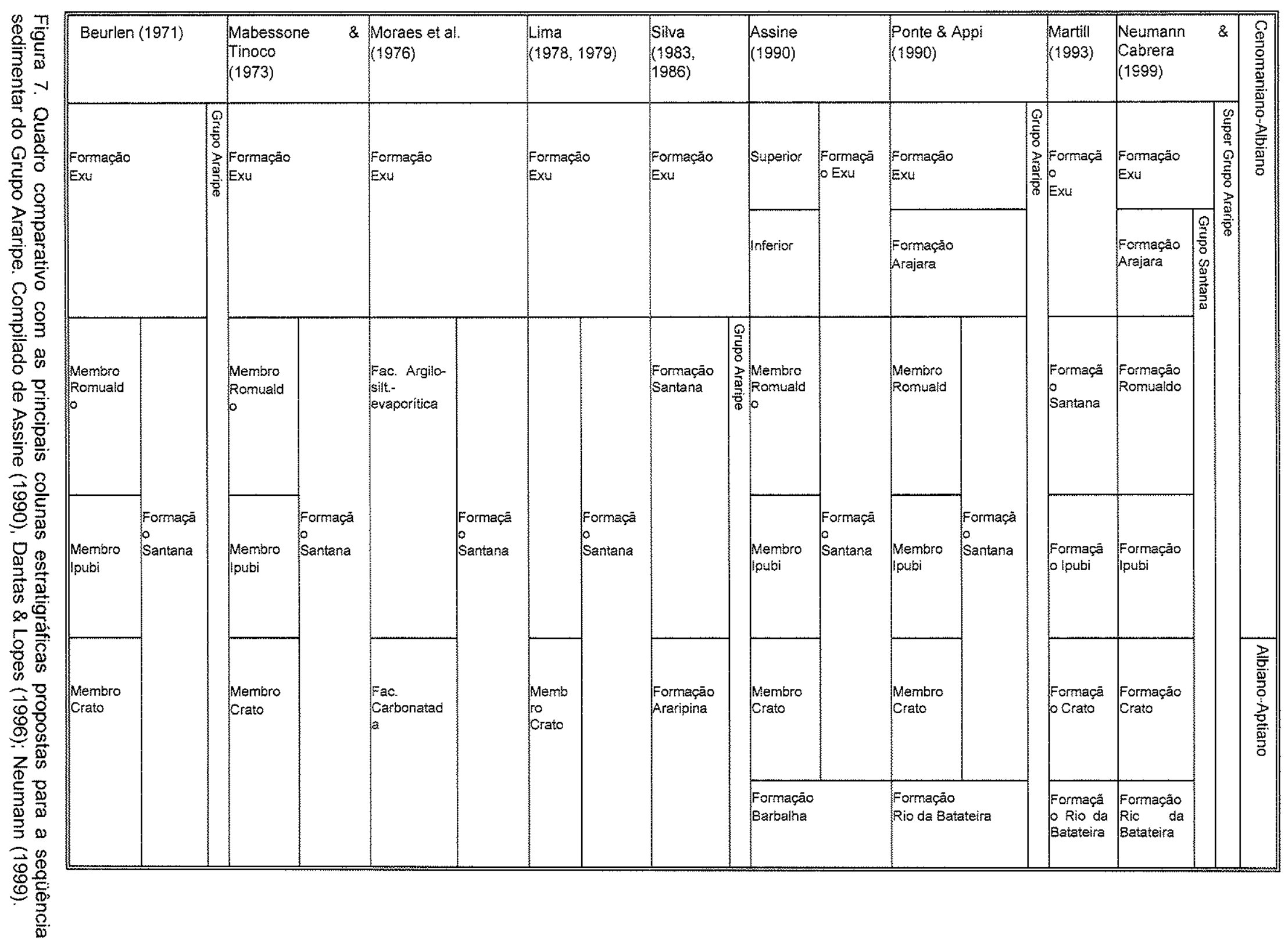




\subsubsection{Membro Crato}

Situado na porção inferior da Formação Santana, constitui-se da base para o topo, de folhelhos cinzas, castanhos, calciferos, laminados e calcários de natureza micrítica, cinza claros a creme, argilosos e laminação milimétrica a centimétrica localmente de cor acinzentada; com espessura média de 50 metros (PONTE \& APPI, 1990). São fossilíferos, incluindo grupos de vertebrados, invertebrados e plantas. Dentre os invertebrados, pequenos bivalves (de tamanhos milimétricos) podem ser encontrados dispersos nos calcários e siltitos arenosos. A seção-tipo do Membro Crato localiza-se na mina de calcário da Indústria Barbalhense de Cimento Portland (IBACIP), Município de Barbalha, (CE) (Prancha 1, Foto B), Sobre a evolução paleogeográfica do paleolago, ligado à deposição dos sedimentos do Membro Crato, Neumann (1999) identificou seis níveis lacustres, na evolução desses depósitos, com interdigitações de corpos carbonatados e terrígenos. O Membro Crato, na base, está em contato concordante com a Formação Rio da Batateira e discordante sobre a Formação Abaiara ou sobre o embasamento pré-cambriano. Seu contato superior com o Membro Ipubi é normal e gradacional (Figura 4, p. 12).

\subsubsection{Membro Ipubi}

Membro Ipubi corresponde aos depósitos de evaporitos, na porção mediana da Formação Santana, com camadas de gipsita de até 20 metros de espessura, de cores branca a cinza, maciças e fibrosas, e leitos descontínuos de pelitos verde escuros associados (PONTE \& APPI, 1990). A seção-tipo localiza-se na Mina de Gipsita, Casa de Pedra (antiga denominação), Municipio de lpubi (PE), na região do pólo gesseiro, onde se encontram as melhores exposições (Prancha 1, Foto $\mathrm{C}$ ). Acima das camadas de gipsita intercalam-se niveis de folhelhos betuminosos fossiliferos. O contato superior com o Membro Romualdo é brusco, sendo interpretado como uma discordância erosiva regional, segundo Silva $(1983,1988)$ e Ponte \& Appi (1990). 


\subsubsection{Membro Romualdo}

Sobrepondo-se ao Membro Ipubi, o Membro Romualdo apresenta um perfil, variando de folhelhos e arenitos friáveis esbranquiçados (Prancha 1, Fotos D, p. 132), intercalados por níveis de margas, lentes de gipsitas e calcários, em sua maioria, fossilíferos. O nome deriva da localidade de Romualdo, no Municipio de Crato (CE). O contato inferior com o Membro Ipubi é marcado por uma camada de microconglomerado (1-2m), esbranquiçado, imaturo, com estratificações cruzadas acanaladas (VIANA, 1990, PONTE \& APPI, 1990). Alguns autores (SILVA, 1983, 1988; BERTHOU ET AL., 1988) defenderam a ocorrência do micro-conglomerado, como marco de discordância erosiva regional e início de um novo ciclo deposicional lacustre (lagos rasos e efêmeros), porém essa discordância é localizada apenas em minas de gipsita, não ocorrendo ao longo de toda a bacia. O contato superior com a Formação Arajara é normal e gradacional, sendo composta por uma seqüência de siltitos, argilitos e arenitos, possivelmente relacionada ao mesmo sistema deposicional do Membro Romualdo (MABESSONE \& TINOCO, 1973; PONTE, 1992b; MARTILL, 1993) (Figura 4, p.12).

Para a origem do Membro Romualdo, na literatura, duas hipóteses são consideradas: uma origem marinha litorânea (CAVALCANTI \& VIANA, 1990; MEDEIROS, 1990; PONTE 1992b) e a origem a partir de um ambiente transicional (laguna), com periódicas ingressões marinhas, indicada pela presença de microfósseis (SANTOS \& VALENÇA, 1968; MABESSONE \& TINOCO, 1973; SANTOS, 1982; ARAI \& COIMBRA, 1990, COIMBRA ET AL., 2002), ainda não totalmente comprovadas. A segunda hipótese encontra subsídios nas evidências paleontológicas, pois a presença concomitante de fauna dulcícula e fauna marinha, como moluscos marinhos (BEURLEN, 1963), dinoflagelados e foraminíferos (LIMA, 1978; ARAI \& COIMBRA, 1990; COIMBRA ET A.L., 2002) e principalmente equinóides (BEURLEN, 1966, OLIVEIRA ET AL., 1979, BERTHOU ET AL., 1990; MARTILL, 1993), atestam inquestionavelmente a influência marinha na área. 


\subsection{Paleontologia da Formação Santana}

Historicamente, os fósseis da bacia sedimentar do Araripe são conhecidos desde o século XIX, com a publicação do livro "Viagem pelo Brasil" (Reise in Brasilien), entre 1823 e 1831, quando da realização de viagens e pesquisas pelo interior do "novo mundo", no periodo de 1817 a 1820, de dois naturalistas alemães: Johann Baptist von Spix e Carl Friedrich Philipp von Martius. Ainda no século XIX, os fósseis despertaram interesse de outros pesquisadores, como o botânico inglês Charles Gardner e o suiço Jean Luis Rodolphe Agassiz. Já no início do século $X X$, os fósseis foram seguidos por inúmeros pesquisadores estrangeiros como John $\mathrm{C}$. Branner e David $\mathrm{S}$. Jordan, seguidos por inúmeros pesquisadores estrangeiros e na, com destaque para $K$. Beurlen, Silva Santos, L. Duarte, M. Regali, I. Tinoco, R. Martins Neto, M. Lima, P. Wellnhofer, D. Grimaldi, J. Maisey, A. Kellner. D. Campos, Bernardes de Oliveira, D. Martill, S. Viana, dentre outros.

Alguns trabalhos apresentam listas sobre as ocorrências fossiliferas da Formação Santana (MABESSONE \& TINOCO, 1973; MAISEY, 1991; MARTILL, 1993; VIANA \& CAVALCANTI, 1990), demonstrando a diversidade da natureza da fauna de vertebrados e uma relativa, mas somente aparente, empobrecida fauna de invertebrados (MARTILL, 1990) (Figura 8, p. 20). Numa abordagem global, Martill (1990) correlacionou as características de preservação, diagenéticas e tafonômicas da Formação Santana, com outros importantes depósitos do tipo Lagerstätten (sensu, SEILACHER AT AL., 1985 In Martill, 1990), assinalando-a, como uma das melhores e mais importantes reservas paleontológicas cretácicas do mundo.

Os fósseis do sítio paleontológico da Bacia do Araripe destacam-se por possuirem os primeiros registros de tecidos moles de pterossauros e tiranossauros do mundo, as primeiras fanerógamas fósseis da América do Sul e abundância de peixes. 


\begin{tabular}{|c|c|c|c|}
\hline \multirow{9}{*}{$\begin{array}{l}\text { Quadro A } \\
\text { Fauna } \\
\text { e flora } \\
\text { fósseis } \\
\text { do } \\
\text { Membro } \\
\text { Crato }\end{array}$} & (Filo) & (Classe) & Ordem \\
\hline & Artropoda & Crustácea & $\begin{array}{l}\text { Decapoda } \\
\text { Ostracoda } \\
\text { Copepoda } \\
\text { Branchiopoda(Indet. conchostracan) } \\
\text { Malacostraca (Brachyura) }\end{array}$ \\
\hline & & Insecta & $\begin{array}{l}\text { Ephemeroptera } \\
\text { Odonata } \\
\text { Dermaptera } \\
\text { Phasmatodea } \\
\text { Isoptera } \\
\text { Homoptera } \\
\text { Heteroptera } \\
\text { Blattodea } \\
\text { Orthoptera } \\
\text { Neuroptera } \\
\text { Coleoptera } \\
\text { Díptera } \\
\text { Hymenoptera } \\
\text { Lepidoptera } \\
\text { Raphidioptera } \\
\text { Thichooptera } \\
\text { Mecoptera } \\
\text { Psocoptera } \\
\text { Plecoptera }\end{array}$ \\
\hline & (Subfilo) Chelicerata & Arachnida & $\begin{array}{l}\text { Araneae } \\
\text { Scorpionida }\end{array}$ \\
\hline & (Subfilo) Vertebrata & $\begin{array}{l}\text { Osteichthyes } \\
\text { Reptilia }\end{array}$ & $\begin{array}{l}\text { Actinopterygii } \\
\text { Pierosauria } \\
\text { Crocodylia } \\
\text { Testudines }\end{array}$ \\
\hline & & Lissamphibia & Anura \\
\hline & & Aves & \\
\hline & & Gimnospermas & \\
\hline & & Angiospermas & \\
\hline \multirow{9}{*}{$\begin{array}{l}\text { Quadro B } \\
\text { Fauna } \\
\text { e flora } \\
\text { fósseis } \\
\text { do } \\
\text { Membro } \\
\text { Romualdo }\end{array}$} & Filo & Classe & Ordem \\
\hline & \multirow[t]{2}{*}{ Mollusca } & Gastropoda & \\
\hline & & Bivalvia & \\
\hline & Echinodermata & Echinoidea & Cassiduloida \\
\hline & $\begin{array}{l}\text { Arthropoda } \\
\text { (Subfilo Crustácea) }\end{array}$ & $\begin{array}{l}\text { Decapoda } \\
\text { Ostracoda } \\
\text { Copepoda } \\
\text { Branchiopoda } \\
\text { Malacostraca }\end{array}$ & \\
\hline & \multirow[t]{2}{*}{$\begin{array}{l}\text { Chordata } \\
\text { (Subfilo Vertebrata) }\end{array}$} & \multirow[t]{2}{*}{$\begin{array}{l}\text { Chondrichthyes } \\
\text { Osteichthyes } \\
\text { Actinistia } \\
\text { Reptilia }\end{array}$} & \\
\hline & & & $\begin{array}{l}\text { Crocodilia } \\
\text { Pterosauria } \\
\text { (Sub Ordem) Dinosauria } \\
\text { Testudines } \\
\end{array}$ \\
\hline & & Gimnospermas & \\
\hline & & Angiospermas & \\
\hline
\end{tabular}

Figura 8. Quadro A - fauna e flora fósseis do Membro Crato, Quadro 2 - fauna e flora fósseis do Membro Romualdo, baseado em Maisey (1993), Martill (1993) e Viana (1999). 


\subsection{Os macroinvertebrados fósseis do Membro Romualdo}

Como estudos acerca dos peixes fósseis, não indicam um ambiente especificamente marinho, ou não marinho, para o Membro Romualdo (MAISEY, 1991), os fósseis de moluscos e equinóides (BEURLEN, 1962, 1964, 1966), juntamente com uma assembléia de microfósseis (ARAI \& COIMBRA, 1990, COIMBRA ET AL., 2002), são as evidências da influência marinha albiana, situada na porção superior do Membro Romualdo.

Os fósseis de invertebrados bentônicos da Formação Santana são em geral, relacionados às citações e relatos de ocorrências (BEURLEN, 1962, 1963, 1964, 1966, 1971; LEAL, 1962; MABESSONE \& TINOCO, 1973; OLIVEIRA ET AL., 1978; SANTOS, 1982; LIMA, 1979; CAVALCANTI \& VIANA, 1990; MAISEY, 1991; MARTILL, 1993). Na bacia do Araripe até o presente momento tem-se o registro de seis familias de gastrópodes, doze famílias de bivalves e duas famílias de equinóides (Fig. 9, p. 21).

\begin{tabular}{|c|c|c|c|c|}
\hline Filo & Classe & Ordem & Superfamília & Family \\
\hline \multirow{18}{*}{ Mollusca } & \multirow{6}{*}{ Gastropoda } & \multirow{4}{*}{ Caenogastropoda } & \multirow{2}{*}{ Cerithiacea } & Turritellidae \\
\hline & & & & Cerithiidae \\
\hline & & & Naticacea & Naticidae \\
\hline & & & Strombacea & Aporrhaidae \\
\hline & & Heterogastropoda & Architonicacea & Epitoniidae [=scala] \\
\hline & & $\begin{array}{l}\text { Archaeogastropod } \\
\text { a }\end{array}$ & Neritaceacea & Neritidae \\
\hline & \multirow{12}{*}{ Bivalvia } & Myoida & Myacea & Corbulidae [=Cyrenidae] \\
\hline & & \multirow{6}{*}{ Pterioida } & Anomiacea & Anomiidae \\
\hline & & & \multirow[t]{2}{*}{ Pteriacea } & Pteriidae \\
\hline & & & & Isognomonidae \\
\hline & & & \multirow[t]{2}{*}{ Ostreacea } & Plicatulidae \\
\hline & & & & Ostreidae \\
\hline & & & & Bakevelliidae \\
\hline & & Mytiloida & Mytilacea & Mytilidae \\
\hline & & \multirow[t]{2}{*}{ Veneroida } & Classatellacea & Crassatellidae \\
\hline & & & Veneracea & Veneridae \\
\hline & & Arcoida & Arcacea & Arcidae \\
\hline & & Unionoida & Unionacea & Unionidae \\
\hline \multirow{2}{*}{$\begin{array}{l}\text { Echinodermat } \\
\text { a }\end{array}$} & \multirow[t]{2}{*}{ Echinoidea } & \multirow[t]{2}{*}{ Cassiduloida } & & Clypeidae \\
\hline & & & & Faujassidae \\
\hline
\end{tabular}

Figura 9. Quadro contendo a fauna de macroinvertebrados bentônicos (moluscos e equinóides) da Formação Santana, Bacia do Araripe. 
Segundo Mabessone \& Tinoco (1973), na porção leste da bacia, duas espécies de gastrópodes da Subfamília Cassiopinae são conhecidas, sendo Craginia araripensis e Gymnentone romualdoi (BEURLEN, 1964); na parte central da bacia, o número de espécies de gastrópodes parece crescer e na porção oeste, os gastrópodes e bivalves são mais freqüentes, com a dominância das familias Anomiidae e Mytilidae, dentre os bivalves. Esta distribuição levou os autores a imaginar que, embora pouco diversificada, a associação de moluscos apresentaria uma típica variação na sua composição taxonômica com os gastrópodes na porção nordeste (Cassiopinae Beurlen, 1964) e, na porção sudoeste, um incremento na variação de tipos com a presença das famílias Cerithiidae, Scalidae, Natacidae, associados a bivalves como Pteriidae, Isognomonidae, Anomiidae, Mytilidae, Crassatellidae e Corbiculidea (Cyrenidae). Na região de Araripina, suldoeste da bacia, foram encontrados equinóides, representantes tipicamente marinhos (Faujasia araripenses e Pygurus tinocoi, BEURLEN, 1966), estratigraficamente, nos mesmos calcários com moluscos, associados aos bivalves Anomia e Brachidontes, e aos gastrópodes Turritella e Natica (Beurlen, 1962, 1963).

Esses depósitos fossiliferos, com restos esqueléticos de conchas, por vezes formam concentrações ou coquinas, preservados, na porçăo superior do Membro Romualdo (OLIVEIRA ET AL., 1979; SANTOS, 1982; BERTHOU ET AL;, 1990, MARTILL, 1993; SIMÕES ET AL., 1995; SALES ET AL. 1999).

Abordagens de cunho tafonômico desses depósitos carbonáticos, contendo fósseis de macroinvertebrados do Membro Romualdo, foram inicialmente feitas por Santos (1982), com interpretações superficiais sobre os possiveis processos e produtos envolvidos na sua gênese, relacionando-os à ambiente marinho raso sob a influência de ondas e tempestades.

A influência marinha, possivelmente relacionada a tempestitos, para esses depósitos de bancos carbonáticos, contendo moluscos e equinóides, pode ser ampliada, a partir dos relatos de Berthou et al. (1990), na porção centro-norte da bacia e de Oliveira et al. (1979, estampa 22, Figura 2) e Martill (1993, p.72), na porção leste da bacia. 
Numa abordagem, porém essencialmente voltada para a tafonomia de concentrações de macroinvertebrados fósseis, a partir de dados bioestratinômicos seguros, Simões et al. (1995), no Município de Crato, CE, reconheceram depósitos coquinóides (sensu, KIDWELL \& HOLLAND, 1991), internamente complexos, que mostraram gênese relacionada a tempestitos proximais (sensu, FÜRSICH \& OSCHMANN, 1986, 1993). Estes autores acrescentaram, ainda, que a heterogeneidade dos bioclastos podia ser entendida como um indicador de mistura temporal "Time Averaging" (sensu SIMÕES, 1998; SIMÕES \& KOWALEWSKI, 1998a).

Sales et al. (1999) reconheceram diferentes feições tafonômicas em concentrações fossilíferas, em depósitos na região da borda norte da bacia, possibilitando e confirmando para esses depósitos uma abordagem tafonômica, associada a estudos sedimentológicos e/ou estratigráficos e paleoambientais, buscando um detalhamento crono-estratigráfico para a fatia albiana da bacia sedimentar do Araripe.

\subsection{Tafonomia}

"Tafonomia" abrange a ciência que estuda os processos de fossilização e como esses afetam a qualidade do registro fóssil. Neste documento, a tafonomia é voltada para estudo de macroinvertebrados, no caso, os moluscos e equinóides, como fonte de informações geológicas, paleoambientais e paleobiológicas.

Com relação aos processos, envolvidos entre a morte e o soterramento dos organismos, como colocado por *Simões, (2003 divulgação restrita) "...processos de fossilização atuam como filtros e são coletivamente conhecidos como processos tafonômicos. Embora em sua grande maioria, os processos tafonômicos sejam destrutivos (transporte, fragmentação, dissolução), esses podem ser, ocasionalmente, construtivos (preservação de tecidos)". Em outras palavras, a tafonomia (sensu, BEHRENSMEYER \& KIDWELL, 1985) inclui o estudo dos processos de preservação e como estes são encontrados no registro fossilifero, compreendendo ainda duas subdivisões: a bioestratinomia e a diagênese dos fósseis. Ou seja, tafonomia é o estudo dos processos de fossilização (MULLER, 1976; 1979 in DONAVAN, 1991) que 
incluem o estudo da: necrólise, bioestratinomia, diagênese, a fase de soerguimento tectônico e até métodos de coleta e preparação, como citado por Holz \& Simões, (2002), apresentando-se como uma ferramenta multidisciplinar (Figura 10, p. 24).

Eventos

\begin{tabular}{|l|l|l|l|}
\hline \multirow{4}{*}{ Tafonomia } & \multicolumn{2}{|l|}{ Tectônica } & Soerguimento \\
\cline { 2 - 4 } & \multicolumn{2}{|c|}{ Petrografica sedimentar (Fóssil-diagênese) } & Diagênese \\
\cline { 2 - 4 } & Bioestratinomia & $\begin{array}{l}\text { Sedimentologia } \\
\text { (Processos) }\end{array}$ & Soterramento \\
\cline { 3 - 4 } & Necrologia & Transporte \\
& Tanatologia & Morte \\
\hline & Paleoecologia & Nascimento \\
\hline
\end{tabular}

Figura 10 - Quadro mostrando a relação entre a tafonomia, suas subdivisão e correlação com eventos responsáveis (SIMÔES \& HOLZ, 2000).

$\mathrm{Na}$ evolução da ciência tafonômica, na ultima década, foram incorporados importantes conceitos, destacando-se a retroalimentação tafonômica (KIDWELL \& JABLONSKY, 1983 KIDWELL ET AL., 1986), tafofácies (SPEYER \& BRETT, 1988; BRETT \& BAIRD, 1986), assinatura tafonômica (FÜRSICH \& OSCHMANN, 1993) e resolução temporal e espacial (KOWALEWSKI, 1996, 1997).

São relevantes os estudos de cunho eminentemente metodológico, especialmente os voltados ao reconhecimento e importância das assinaturas tafonômicas na identificação e determinação de tafofácies (BEST \& KIDWELL, 2000a, b, KIDWELL AT AL., 2001).

Somam-se, ainda, às análises tafonômicas, as abordagens de cunho estratigráfico (FÜRSICH \& ABERHAN, 1990; BRETT \& BAIRD, 1993; FLESSA ET AL.; 1993; FLESSA \& KOWALEWSKI, 1994; KIDWELL \& BEHRENSMEYER, 1993; KOWALEWSKI ET AL., 1998; KOWALEWSKI ET AL., 2000a, b; SIMÕES, 1998; SIMÕES \& KOWALESWSKI, 1998b; SIMÕES ET AL., 2000, 2001a, b, c, 2003, FÜRSICH \& PANDEY, 2003) e as análises voltadas ao uso de sucessões estratigráficas que apresentam um crescente enfoque (BRETT, 1995; HOLLAND, 1995a, b; SIMÕES, 1998, SIMÕES ET AL., 2000, 2001,2002a, b, c, 2003). 
Nesse cenário, têm tido crescente destaque, as concentrações fossilíferas de invertebrados marinhos, contemplando também estudos concernentes às reconstruções paleoambientais (BRETT \& BAIRD, 1997; SPEYER \& BRETT, 1991; KIDWELL, 1991A; KIDWELL \& HOLLAND, 1991; SIMÕES \& KOWALEWSKI, 1998a; MARTIN ET AL., 1999).

No Brasil estudos envolvendo análise tafonômica de alta resolução, em associação a estudos paleoecológicos, sedimentológicos e estratigráficos, têm sido desenvolvidos com destaque para A) o exame das assembléias fósseis de conchas e concentrações do Paleozóico da Bacia do Paraná (GHILARDI, 1999; GHILARDI ET AL., 2002, 2003; LIMA 1997; RODRIGUES, 2002; SIMÕES, 1998; SIMÕES \& KOWALESWSKI, 1998a, b; SIMÕES ET AL., 1994, 1995, 1998a, b, 2000, 2001; 2002a, b; TORELLO, 1999; TORELLO \& SIMÕES, 1994) e B) o estudo da paleofauna de vertebrados tríassicos, também da Bacia do Paraná (HOLZ \& SOUTO-RIBEIRO, 2000; HOLZ, 1998; HOLZ \& DIAS, 1998; HOLZ \& SCHULTZ, 1998; HOLZ \& SOARES, 1995; HOLZ \& BARBERENA, 1994, 1989; SCHULTZ ET AL., 1990).

Pode-se afirmar, então, que a tafonomia é uma ferramenta multidisciplinar, apresentando relação com vários eventos e ramos das ciências. Esta aplicação multidisciplinar relacionada aos estudos sedimentológicos e estratigráficos, é aplicada aos depósitos fossiliferos da Formação Santana (Albiano), Cretáceo da Bacia do Araripe, Nordeste do Brasil.

A Tafonomia, seu surgimento, avanços conceituais e as diversas aplicações, podem ser encontradas nos excelentes trabalhos de Allinson \& Briggs (1991); Donavan (1991), Kidwell \& Behrensmeyer, 1993; Brett \& Baird (1997) e Behrensmeyer, et al. (2000). No Brasil, um manual didático foi publicado por Holz \& Simões (2002), onde-se destacam a apresentação do tema "Tafonomia" e a natureza multidisciplinar desta ciência, incluindo exemplos. 


\subsection{Estratigrafia de Seqüências}

Estratigrafia de Seqüências é o estudo de relações de rochas sedimentares dentro de um arcabouço cronoestratigráfico de estratos relacionados geneticamente, limitados por superfícies de erosão ou não deposição, ou por suas concordâncias relativas (VAIL. ET AL., 1977). Pode ser resumida como sendo a subdivisão do preenchimento de uma bacia sedimentar em pacotes limitados por inconformidades e suas conformidades relativas (EMERY \& MYERS, 1998).

A análise estratigráfica com dados de campo é possivel através do uso de seções estratigráficas verticais ou seções colunares (MIALL, 1991). A partir da correlação de tais seções, a posição estratigráfica de afloramentos que ocorrem de maneira isolada pode ser determinada, permitindo uma análise estratigráfica em termos bacinais e/ou regionais.

Para reconstruções paleogeográficas e compreensão da distribuição espacial das fácies de uma bacia, isso se torna possivel pela divisão em tratos de sistemas, o que requer a identificação de limites de seqüências das superficies transgressivas e das superficies de máxima inundação marinha. As parasseqüencias carbonáticas são comumente agradacionais e raseiam para cima. Identificam-se parasseqüencias em ambientes de planície costeiras delta, de praia, de maré, de estuário e de plataforma.

Utilizando-se como datum (nível referencial horizontal), por exemplo, as superfícies limitantes de conjuntos de parasseqüências, ou as superfícies de inundação, de valor cronoestratigráfico, obtém-se uma correlação mais precisa.

Fazendo-se uso dos complexos de ciclos básicos de Karogodin (Karogodin, 1975 in Della Fávera, 2001) o registro sedimentar pode ser dividido em ciclos básicos que constituiriam complexos. Esses ciclos tem como base, somente a composição litológica das rochas. Seus triângulos representam a variação litológica de um determinado intervalo, retratando rochas mais grossas na base e rochas finas no vértice. $\mathrm{Na}$ realidade, tal variação composicional reflete essencialmente a migração dos sistemas deposicionais, em relação à linha de praia. Um triângulo com vértice para cima indica um intervalo que se torna mais distal para cima, isto é, de natureza transgressiva, ou simplesmente um corpo de origem fluvial (Della Fávera, 2001). Um corpo unido pelo 
vértice nada mais é do que a seqüências da Exxon, sendo o vértice da união a superfície de inundação máxima. Por outro lado, conjunto de triângulos unidos pela base seriam uma indicação da seqüência genéticas de Galloway (1989). Cada Triângulo individual ou conjunto de triângulo pode conter internamente outros triângulos com diferentes disposição. Esta faceta indica ordens diferentes de grandeza de seqüências. As unidades cronoestratigráficas e litológicas de extensão bacial, os PAC's são fundamentais em todo os aspectos da análise estratigráfica, incluindo correlação, interpretação paleoambiental e reconstrução paleogeolgráficas.

No Brasil, estudos envolvendo a disciplina Estratigrafia de Seqüências e suas aplicações podem ser encontrados em Holz (1998), Della Faverá (2001) e Severiano Ribeiro et al. (2001), dentre outros.

\subsection{Aplicação em conjunto da Tafonomia e Estratigrafia de Seqüências}

Nos últimos anos houve por parte de um grupo de estudiosos, voltados para os estudos tafonômicos, tais como C. Brett, G. Baird e S. Holland, nos Estados Unidos, F. T. Fürsich e W. Oschmann, na Alemanha, Fernando-Lopez, na Espanha e M. G. Simões e M. Holz, no Brasil, uma tentativa explicita de correlacionar a distribuição vertical e horizontal das diferentes concentrações fossiliferas marinhas, com dados estratigráficos, dentro de um caráter cronoestratigráfico. Pois, os processos controladores da gênese das seqüências sedimentares e parasseqüências são em grande parte, os mesmos que governam a formação e distribuição das ocorrências fossiliferas (FÜRSICH \& OSCHMANN, 1986, 1993; GASTALDO, 1988; STRAUSS \& SADLER, 1989; ATROPS \& FERRY, 1989; MARSHALL, 1990; KIDWELL, 1991a, c; SPEYER \& BRETT, 1991; BRETT \& SEILACHER, 1991; KIDWELL \& BOSENCE, 1991; ARMENTROUT, 1991; BEHRESMEYER \& HOOK, 1992; GREGORY \& HART, 1992; KIDWELL \& BEHRENSMEYER, 1993; BRETT, 1995, 1998; BRETT \& BAIRD, 1986, 1997; HOLLAND, 1995a, b, 1996, 2000; KIDWELL \& BRENCHLEY, 1996; FERNÁNDEZ-LOPEZ, \& MELÉNDES, 1996; FERNÁNDEZ-LOPEZ, 1997, 2000; HOLLAND \& PATZKOWSKY, 1997; DATTILO, 1996; MILLER ET AL., 1997; ABBOTT 
\& CARTER, 1997; HOLZ \& DIAS, 1998; HORTON ET AL., 1999; MARTIN ET AL. , 1999; SIMÕES ET AL., 1994, 2000, 2001, 2002a, b, 2003; HOLZ \& SIMÕES, 2002,).

Essa integração se apresenta entre os dinâmicos conceitos da análise estratigráfica (e.g., mapeamento das paraseqüências e seqüências) e da análise do registro fóssil (e.g., presença e ausência de fósseis na coluna geológica, mistura temporal de fósseis, etc.).

\section{Metodologia}

\subsection{Escalas de abordagem e análises usadas}

O registro fóssil é claramente condicionado pela história deposicional. Desta forma, superfícies chaves dentro de um arcabouço podem ser identificadas, auxiliadas pela ocorrência de concentrações esqueléticas específicas (e.g., BANERJEE \& KIDWELL, 1991; KIDWELL, 1991a; FÜRSICH \& OSCHMANN, 1993; GÓMEZ \& FERNANDEZ-LOPEZ, 1994; BRETT, 1995, 1998; FÜRSICH \& PANDEY, 2003), Existem entretanto, difículdades para o uso da Estratigrafia de Seqüências em estudos tafonômicos, devido ao incompleto registro dos Tratos de Sistemas em uma determinada seção (HOLLAND, 1995a). Outra dificuldade está na hierarquia de ordens empregadas, de $2^{a}$ e $3^{a}$ ordens, em escalas bacinais enquanto estudos tafonômicos de detalhe são em geral, realizados em escalas métricas e decimétricas, de $4^{a}$ ou $5^{a}$ ordem.

Vail et al. (1991), Estabeleceram as seguintes magnitudes para seqüências ou ciclos sedimentares: $1^{\circ}$ ordem $\rightarrow 50 \mathrm{Ma}, 2^{\circ}$ ordem $-3-50 \mathrm{Ma}, 3^{\circ}$ ordem $-0,5-3 \mathrm{Ma}, 4^{\circ}$ ordem - 0,08-0,5 Ma $5^{\circ}$ ordem - 0,03-0,08Ma, $6^{\circ}$ oedem - 0,01-0,03Ma.

Logo, para a aplicação e uso da estratigrafia de seqüências é de fundamental importância, o reconhecimento da hierarquia das unidades estratais, como as camadas, conjunto de camadas, parasseqüências, conjunto de parasseqüências e seqüências. 
No presente estudo a análise tafonômica das concentrações fossilíferas registradas na Bacia do Araripe emprega o recurso da análise em escala reduzida, camada-por-camada, correspondendo ao primeiro nível hierárquico de análise estratigráfica dinâmica (AIGNER, 1985; KIDWELL \& AIGNER, 1985, SIMÕES, 1998) (Figura 11, p. 30).

Estratégias para a utilização da Estratigrafia de Seqüências em estudos tafonômicos correspondem, A) ao uso de marcos estratigráficos seguros [e. g., superfícies de inundação máxima (SIM) ou limites de parasseqüências)] e B) a resoluções, envolvendo escalas de Tratos de Sistemas e parasseqüências (exemplos em, HOLZ \& SIMÕES, 2002; em especial, associadas àqueles.

Com relação ao estudo da estratigrafia da Bacia do Araripe, a Petrobrás tem realizado pesquisas, porém na maioria constituem-se de relatórios inéditos, podendose listar Appi et al. (1996), Hashimoto et al. (1987), Ponte \& Appi (1990), Silva Teles et al., (1991) e Matos $(1987,1992)$. Um interessante trabalho foi realizado por Ponte Filho (1992), na análise geo-histórica do poço 2-AP-1-CE, proporcionando uma reconstituição da evolução tectôno-sedimentar da sub-bacia de Feitoria que, se supõe como valida para toda a bacia (Ponte \& Ponte Filho, 1996).

Além dos trabalhos citados, importantes dados foram obtidos com os perfis compostos dos poços 2-AP-1-CE (ATP, 1986), 4-BO-1-PE (CPRM/DNPM, 1994) (Figura 12, P. 31) e OS-12-CE (CPRM/DNPM, 1978).

No arcabouço das seqüências sedimentares da Bacia do Araripe (SILVA, 1986; ASSINE, 1990; PONTE 1992a, b; PONTE \& APPI, 1990; PONTE FILHO, 1992; PONTE \& PONTE-FILHO, 1996; PONTE ET AL., 1997), a seqüência Pós-Rifte (2 ordem), onde está inserida a Formação Santana, faz parte de trato de sistemas transgressivoregressivo, onde Ponte (1994) esboçou um esquema ilustrativo (Figura 13, p. 32).

Marcos estratigráficos das sucessões da Bacia do Araripe são encontrados em estudos prévios (SANTOS, 1982; DELLA FÁVERA, 1984, 1987; BERTHOU ET AL., 1990; MARTILL, 1993), voltados para seu arcabouço estratigráfico (ASSINE, 1990; PONTE \& APPI, 1990; PONTE, 1992b; PONTE ET AL., 1997; MEDEIROS ET AL, 1997), todos com implicações para o entendimento dos processos envolvidos na gênese das seqüências deposicionais. 


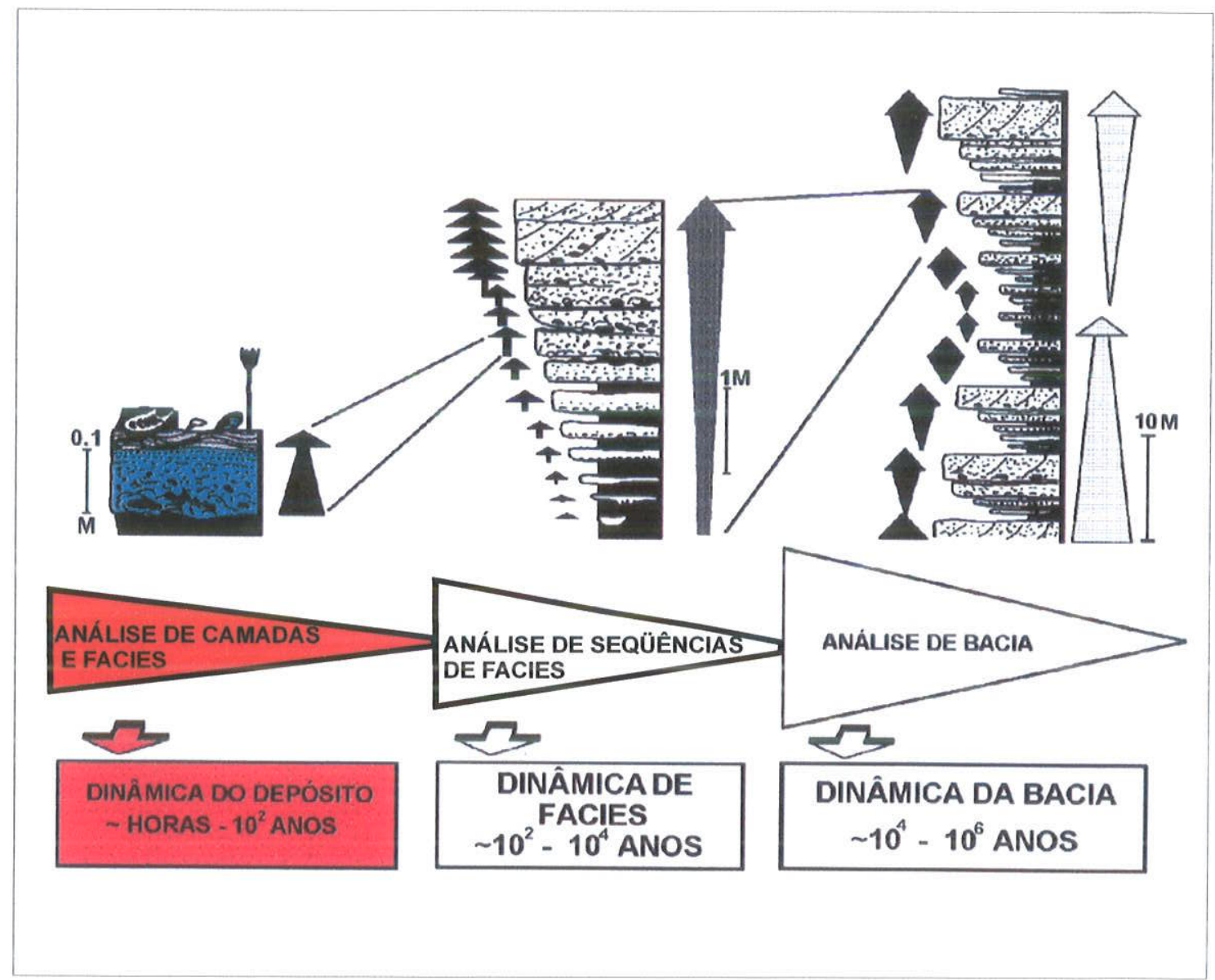

Figura 11. Diagrama ilustrativo dos níveis de descrição e interpretação de camadas à análise de uma bacia sedimentar (AIGNER, 1984). Em vermelho, o nível hierárquico referente á análise estratinômica das camadas contendo as concentrações. 


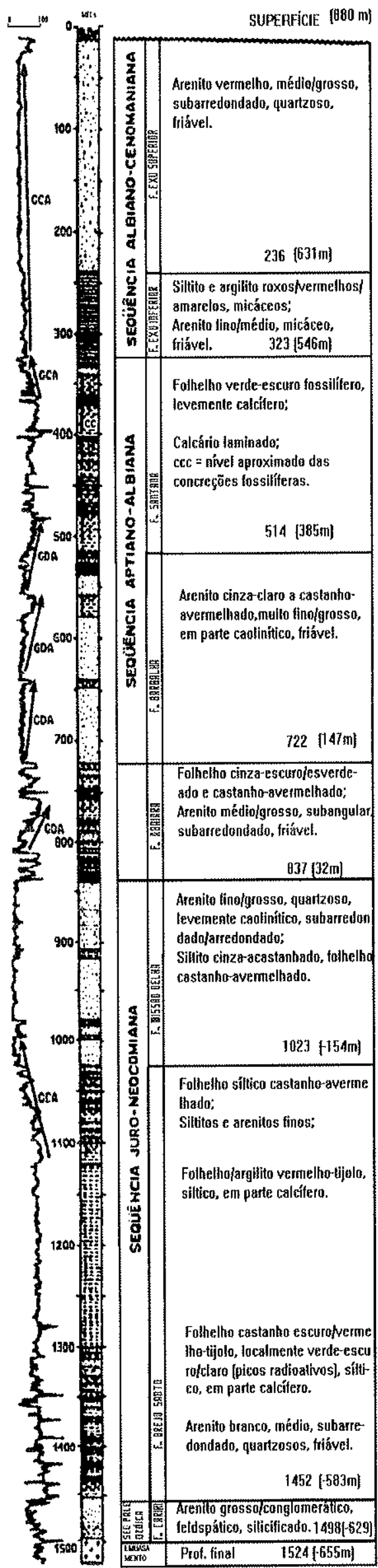

A

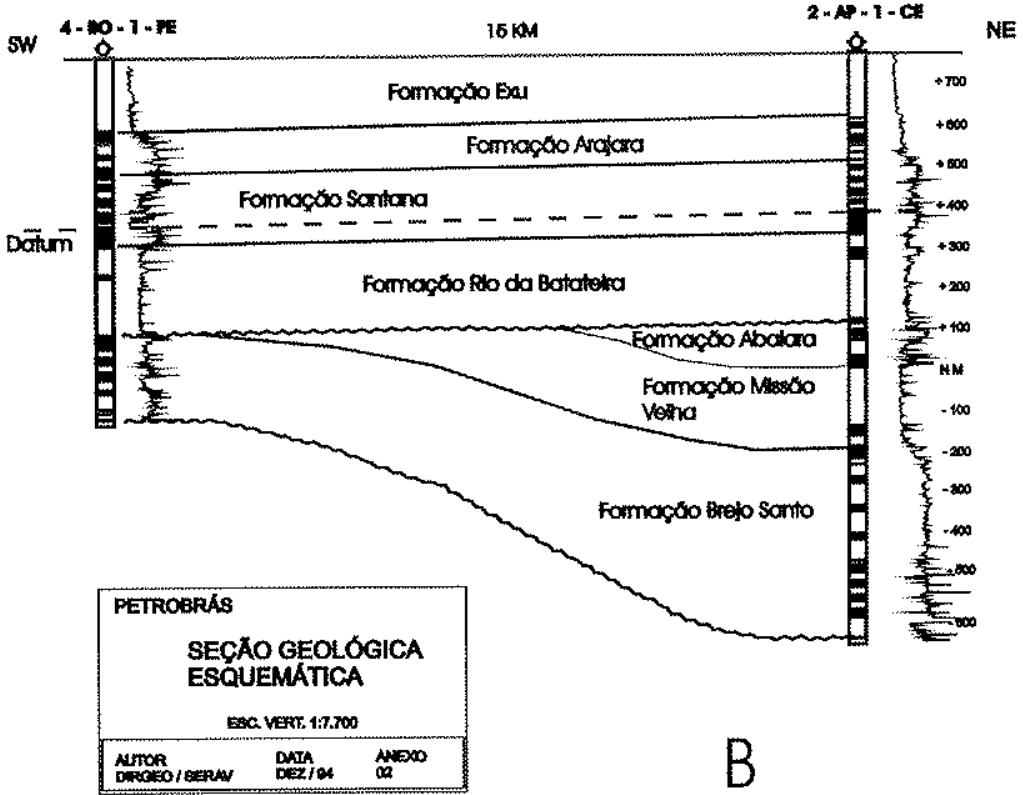

Figura 12 - A, Perfil litoestratigráfico do poço 2-AP-1-CE (ASSINE, 1990); B, perfil de correlação entre os poços 4-BO-1-PE e 2-AP-1-CE (LIMA \& VIEIRA-FILHO, 1997). 


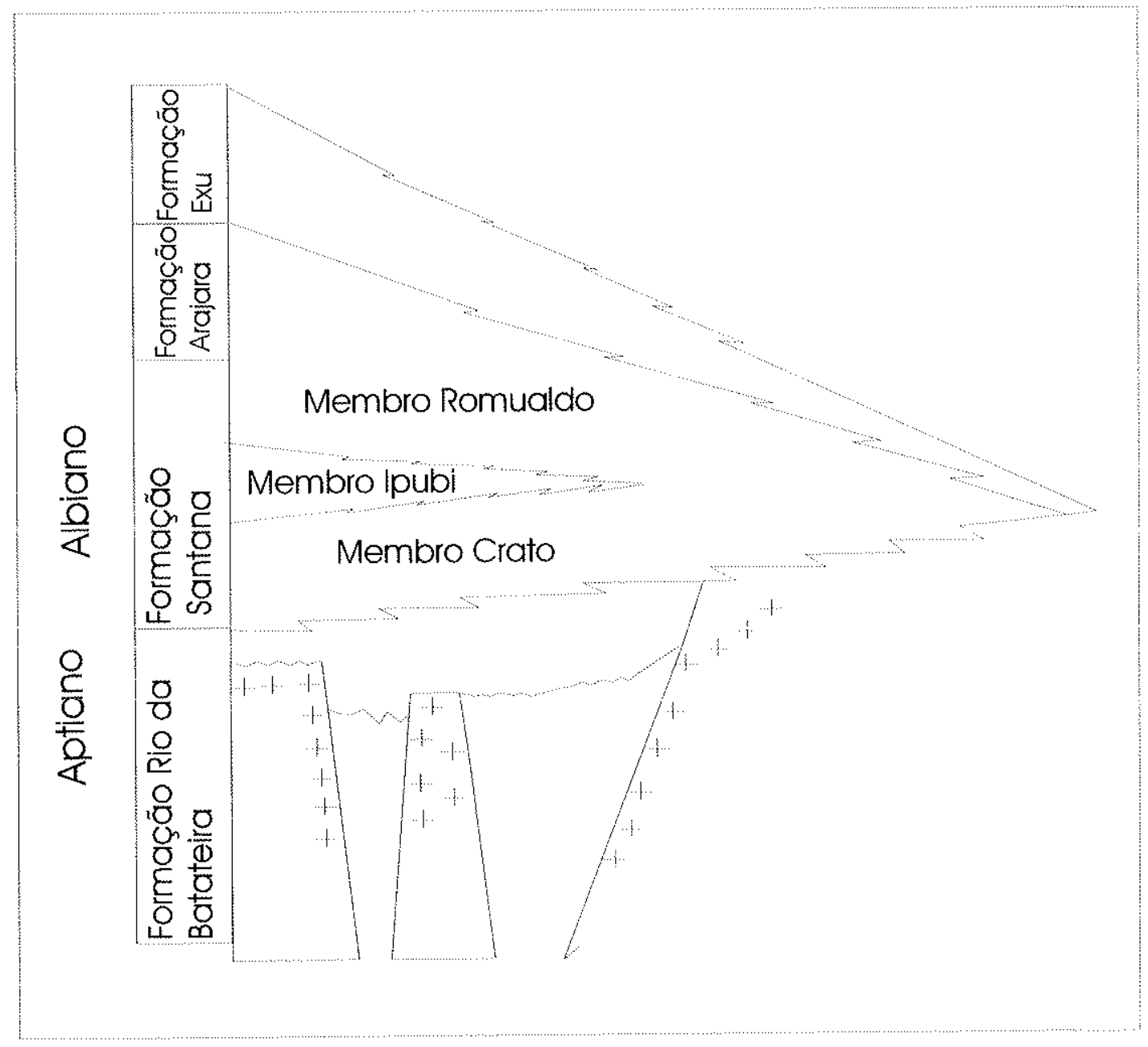

Figura 13 - Esquema ilustrativo do ciclo transgressivo-regressivo da Seqüência Pósrifte ( $2^{\mathrm{a}}$ ordem), da Bacia Sedimentar do Araripe (PONTE, 1994). 


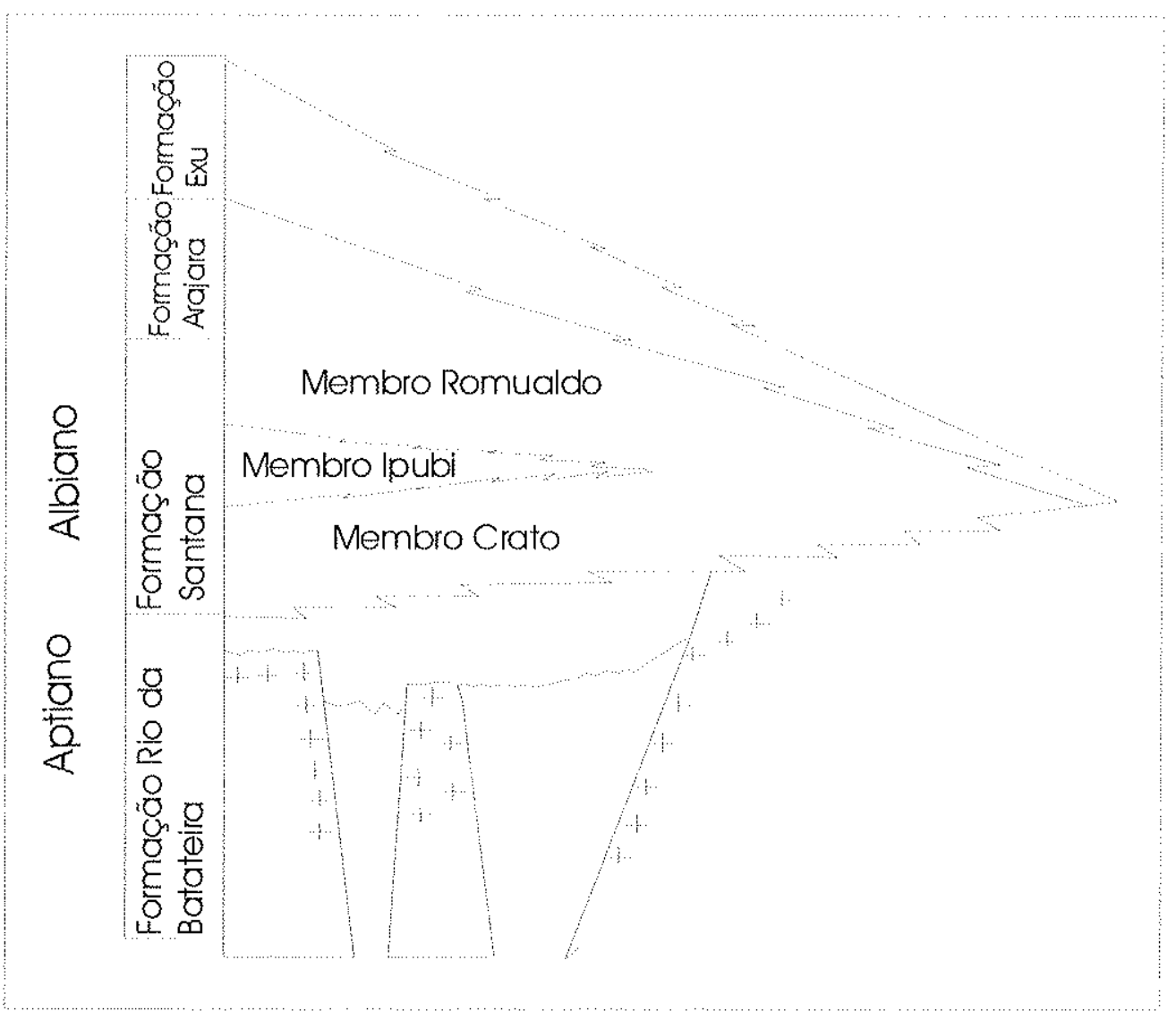

Figura 13 Esquema ilustrativo do ciclo transgressivo-regressivo, da seqüência pós-rifte (2 ${ }^{\circ}$ ordem) da Bacia do Araripe (PONTE, 1994).

\subsection{Atividades de Campo}

Os trabalhos de campo são os primeiros realizados, visando levantamento e reconhecimento dos depósitos carbonáticos fossiliferos, com coleta das concentrações de macroinvertebrados bentônicos no Membro Romualdo, Albiano, Formação Santana, na Bacia Sedimentar do Araripe.

A partir do mapa geológico de Dantas \& Lopes (1996), e uso da coluna litoestratigrafica de Ponte \& Appi (1990), foram planejadas e realizadas as etapas de campo. No total de 50 dias efetivos de campo, os trabalhos ocorreram na regiäo limítrofe dos estados do Ceará, Pernambuco e Piaui (Figura 2, p. 3). Em grande parte, os maiores esforços foram referentes à localização dos depósitos fossiliferos citados na literatura e para o registro de novas ocorrências (Tabela 01, p. 34 ). 
As visitas ocorreram nas encostas da Chapada do Araripe, locais onde afloram os depósitos, em geral, de difícil acesso (Prancha 2, Foto A,) ou em frentes de lavras de gipsita, com desmonte mecânico diário (Prancha 1, Fotos D,). Em alguns casos, procedeu-se a abertura de trincheiras no intuito de confirmar ocorrências (Prancha 2, Foto $B$,)

$\mathrm{Na}$ porção cearense da bacia, foram realizadas pesquisas com visita aos municípios de Santana do Cariri, Nova Olinda, Crato, Barbalha, Missão Velha, Abaiara, Porteiras e Jardim; no Estado de Pernambuco, aos municípios de Exu, Trindade, Ipubi e Araripina e no Estado do Piaui, aos municípios de Fronteiras, Marcolândia e Simões (Figura 2, p. 3).

Para deslocamento e identificação da toponímia, foram utilizadas as cartas topográficas: Fronteiras (SB-24-Y-C-III), Campos Sales (SB-24-Y-D-I), Santana do Cariri, (SB-24-Y-D-II) Crato (SB-24-Y-D-III), Milagres (SB-24-Z-C-I), Simões (SB-24-YC-VI), Ouricuri (SB-24-Y-D-IV), Bodocó (SB-24-Y-D-V) e Jardim (SB-24-Y-D-VI), na escala 1:100.000, publicadas pela Superintendência para o Desenvolvimento do Nordeste (SUDENE) / Serviço Geográfico do Exército (SGE), em 1982.

TABELA 1. OCORRÊNCIAS E CITAÇÕES DE MACROINVERTEBRAdOS FÓSSEIS NO MEMBRO ROMUALDO (FORMACÃO SANTANA), BACIA DO ARARIPE, NE DO BRASIL.

\begin{tabular}{|c|c|c|}
\hline Local & Citação & Táxon \\
\hline $\begin{array}{l}\text { Mina Pedra Branca (Nova } \\
\text { Olinda, CE) }\end{array}$ & 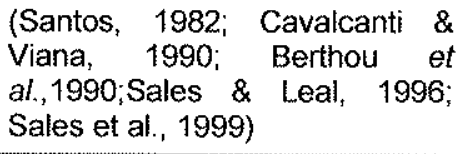 & $\begin{array}{l}\text { Gastrópodes Turritellidae (Cassiopinae } \\
\text { sp.), bivalves (mitilóides e indistintos) e } \\
\text { equinóides }\end{array}$ \\
\hline $\begin{array}{l}\text { Mina Pedra Preta da Conceição } \\
\text { (Santana do Cariri, CE) }\end{array}$ & (Cavalcanti \& Viana, 1990) & Bivalves \\
\hline (Santana do Cariri, CE) & (Beurlen, 1963) & $\begin{array}{l}\text { Gastrópodes Turritellidae e bivalves } \\
\text { Mytilidae (Braquidontes) e Pteridae }\end{array}$ \\
\hline $\begin{array}{l}\text { Sítio São Gonçalo (Santana do } \\
\text { Cariri, CE) }\end{array}$ & $\begin{array}{l}\text { (Sales \& Leal, 1996; Sales et al., } \\
\text { 1999) }\end{array}$ & $\begin{array}{l}\text { Gastrópodes Turritelidae e bivalves } \\
\text { Mytilidae (Braquidontes) }\end{array}$ \\
\hline Sítio Romualdo (Crato, CE) & $\begin{array}{l}\text { (Beurlen,1963, 1964; Santos, } \\
\text { 1982; Simőes et al., 1995) }\end{array}$ & $\begin{array}{l}\text { Gastrópodes Turritellidae, Cerithiidae e } \\
\text { bivalves indistintos }\end{array}$ \\
\hline Rio Batateiras (Crato, CE) & (Simöes et al., 1995) & Bivalves, gastrópodes \\
\hline Jamacaru (Missão Velha, CE) & Novo & $\begin{array}{l}\text { Gastrópodes Turritellidae e bivalves } \\
\text { indistintos }\end{array}$ \\
\hline $\begin{array}{l}\text { Sítio Talhada (Missão Velha, } \\
\text { CE) }\end{array}$ & (Santos, 1982) & Bivalves Corbulidae, Arcidae e equinóides \\
\hline Encruzilhada & Novo & $\begin{array}{lcc}\text { Gastrópodes } & \begin{array}{c}\text { Turritellidae, } \\
\text { bivalves }\end{array} & \begin{array}{c}\text { Epitonidea, } \\
\text { Mytilidea }\end{array}\end{array}$ \\
\hline
\end{tabular}




\begin{tabular}{|c|c|c|}
\hline Vellha, CE) & & (Braquidontes sp.) \\
\hline $\begin{array}{l}\text { Serra da Mãozinha (Missão } \\
\text { Velha/Abaiara, CE) }\end{array}$ & (Martil, 1993) & $\begin{array}{l}\text { Gastrópodes Turritellidea (Paraglauconia } \\
\text { cf. lyrica) e bivalves Corbulidae }\end{array}$ \\
\hline Sitio Engenho (Jardim, CE) & Novo & $\begin{array}{l}\text { Gastrópodes, bivalves Mytilidae e } \\
\text { indeterminados }\end{array}$ \\
\hline Sítio dos Negros (Jardim, CE) & Novo & $\begin{array}{l}\text { Gastrópodes Turritellidae e bivalves } \\
\text { indistintos }\end{array}$ \\
\hline Sítio Lagoa (Jardim, CE) & Neste & $\begin{array}{l}\text { Gastrópodes Turritelidea e bivalves } \\
\text { indistintos }\end{array}$ \\
\hline Sitio Sobradinho (Jardim, CE) & Novo & $\begin{array}{l}\text { Bivalves Mytilidae e indeterminados, } \\
\text { gastrópodes Turritellidae }\end{array}$ \\
\hline (Porteiras, CE) & (Martill, 1993) & Gastrópodes, bivalves e equinóides \\
\hline Sítio Saco (Porteiras, CE) & Novo & $\begin{array}{l}\text { Gastrópodes Turritellidae, Naticidae, } \\
\text { bivalves Mytilidae, indeterminados e } \\
\text { equinóides }\end{array}$ \\
\hline Sítio Jatobá (Porteiras, CE) & Novo & $\begin{array}{l}\text { Gastrópodes Turritellidae, bivalves } \\
\text { Mytilidae e indeterminados }\end{array}$ \\
\hline Sítio José Gomes (Exu, PE) & (Beurlen, 1963) & $\begin{array}{l}\text { Gastrópodes Turritellidae e bivalves } \\
\text { indeterminados }\end{array}$ \\
\hline Sítio Saudade (Exu, PE) & (Beurlen, 1963) & Bivalves Anomidae (Anomia sp.) \\
\hline (Ipubi, PE) & (Beurlen, 1962, 1963) & Gastrópodes Turritellidae e Cerithiidae \\
\hline Sítio Trindade (Trindade, PE) & (Santos, 1982) & $\begin{array}{l}\text { Bivalves indeterminados e gastrópodes } \\
\text { Cerithiidae }\end{array}$ \\
\hline Casa de Pedra (Trindade, PE) & (Beurlen, 1962, 1963) & $\begin{array}{l}\text { Gastrópodes Turritellidae, Cerithiidae, } \\
\text { Epitonidae (Scala), Aporrhaidae } \\
\text { (Aporrhais) e Naticidae, bivalves } \\
\text { indeterminadose equinóides (Faujasia) }\end{array}$ \\
\hline Lagoa de Dentro (Araripina, PE) & $\begin{array}{l}\text { (Beurlen, 1963, } 1966 \text {; } \\
\text { Cavalcanti \& Viana, 1990; Sales } \\
\text { \& Leal, 1993) }\end{array}$ & $\begin{array}{lrr}\text { Gastrópodes, } & \text { bivalves } & \text { Bakevelliidae } \\
\text { (Aguileria), Crassatellidae } & \text { (Crassatella), } \\
\text { Anomiidae } & \text { (Anomia), } & \text { Mytilidae } \\
\text { (Braquidontes), Veneridae e } & \text { equinóides } \\
\text { (Faujasia) } & & \\
\end{array}$ \\
\hline Rancharia (Araripina, PE) & (Beurlen, 1963, 1966) & $\begin{array}{l}\text { Gastrópodes Turritellidae, Cerithiidae, } \\
\text { Naticidae e equinóides (Faujasia) }\end{array}$ \\
\hline Sitio Canastra (Araripina, PE) & (Oliveira et al., 1979) & Equinoides (Pygurus tinocol) \\
\hline $\begin{array}{l}\text { Estrada Araripina - Torre } \\
\text { (Araripina, PE) }\end{array}$ & Novo & $\begin{array}{l}\text { Gastrópodes Turritellidae, Cerithiidae, } \\
\text { Naticida e Epitoniidae, bivalves Mytilidae e } \\
\text { equinóides }\end{array}$ \\
\hline Faz. Caroá (Araripina, PE) & (Santos, 1982) & Bivalves Mytilidae (Braquidontes) \\
\hline (Marcolândia, Pl) & $\begin{array}{l}\text { (Mabessone e Tinoco, 1973; } \\
\text { Domingues, 1978) }\end{array}$ & Gastrópodes, bivalves e equinóides \\
\hline $\begin{array}{l}\text { Sítio Pau dos Ferros (Fronteiras, } \\
\text { PI) }\end{array}$ & (Santos, 1982) & $\begin{array}{l}\text { Gastrópodes Cerithiidae (Cerithium), } \\
\text { bivalves Plicatulidae (Plicatula) }\end{array}$ \\
\hline $\begin{array}{l}\text { Sitio Ladeira do Belenga } \\
\text { (Fronteiras, PI) }\end{array}$ & (Santos, 1982) & $\begin{array}{l}\text { Gastrópodes Cerithiidae (Cerithium), } \\
\text { bivalves Plicatulidae (Plicatula) }\end{array}$ \\
\hline Sítio Caboclos (Fronteiras, Pl) & Novo & $\begin{array}{l}\text { Gastrópodes Turritellidae (Turrilella), } \\
\text { Bivalves Mytilidae e indeterminados }\end{array}$ \\
\hline
\end{tabular}




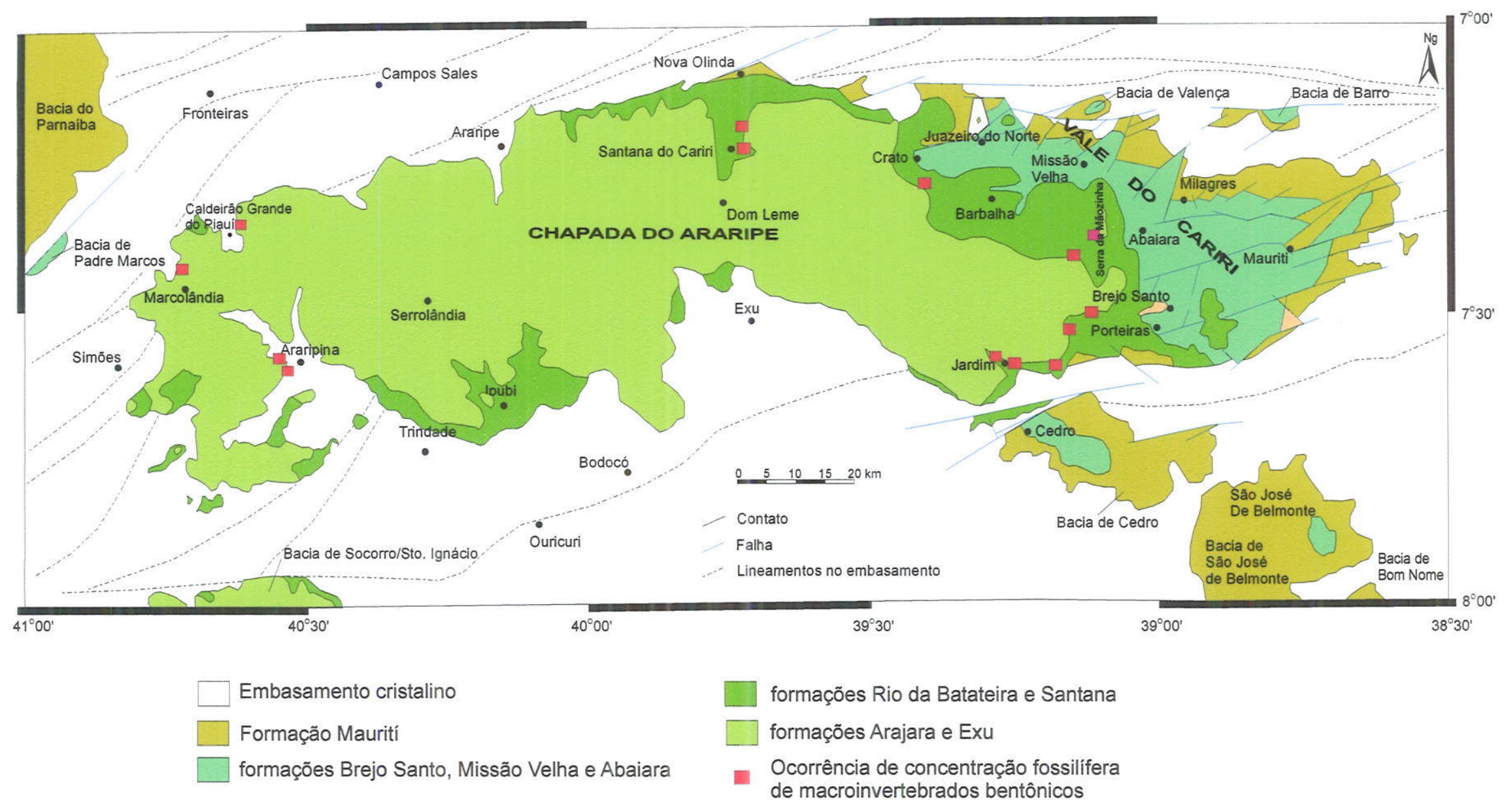

Figura 14. Mapa geológico simplificado da Bacia do Araripe com pontos de ocorrência das principais concentrações fossiliferas de macroinvertebrados do Membro Romualdo, Formação Santana. 


\subsubsection{Coleta}

Durante a fase de coleta, seguiu-se metodologia apropriada para estudos tafonômicos (GHILARDI, 1999, HOLZ \& SIMÕES, 2002; SIMÕES \& GHILARDI, 2000), onde, para cada bloco de rocha amostrado, obtiveram-se posição azimutal e controle de topo e base. Ressalta-se que, para análises tafonômicas, a coleta, amostrada na forma de blocos, em geral decimétricos, deve abranger toda a espessura dos depósitos (Prancha 2, Foto $\mathrm{C}$,).

A localização, descrição e conteúdo dos pontos visitados e coletados, encontramse descritos, no capítulo 6 , contendo os resultados.

Foram coletadas amostras em 31 localidades, somando um total aproximado de $700 \mathrm{~kg}$. Todas depositadas na litoteca do Laboratório de Paleozoologia Evolutiva (LPE), Departamento de Zoologia, Instituto de Biociências, (IB-UNESP), Campos de Rubião Júnior, Botucatu, SP.

\subsubsection{Levantamento de seções}

O levantamento de seções colunares representa esquematicamente a distribuição vertical da sucessão sedimentar, onde ocorrem as concentraçöes fossiliferas dos macroinvertebrados do Membro Romualdo.

$\mathrm{Na}$ análise estratigráfica de afloramentos, enfase é dada ao reconhecimento de ciclos, que podem apresentar-se incompletos, ou parcialmente completos, principalmente nas lavras de gipsita com grande exposição temporal (Prancha 1, Fotos $\mathrm{C}, \mathrm{e} \mathrm{D}$,). Os calcários laminados do Membro Crato e as camadas gipsiferas do Membro Ipubi são usadas como bons marcadores. 


\subsection{Trabalhos de laboratório}

Os trabalhos de laboratório constam das etapas de descrição tafonômica, descrição petrográfica e aquisição de imagens. Seguem abaixo as técnicas empregadas para cada etapa. Essas atividades foram executadas no Laboratório de Paleozoologia Evolutiva do Departamento de Zoologia (DEZOO), Instituto de Biociências de Botucatu (IBB), Universidade UNESP, e nos laboratórios do Instituto de Geociências, da Universidade de São Paulo (USP), Campus de São Paulo.

Todo o material identificado, codificado e catalogado, encontra-se na litoteca do LPE/DEZOO/IBB/UNESP.

\subsubsection{Descrição tafonômica}

Para um melhor ordenamento na descrição, adotou-se o agrupamento das feições em macroscópicas e microscópicas. Na literatura, Kidwell (1991a) esquematiza a descrição macroscópica, para a interpretação da gênese dos depósitos de bioclastos, em quatro categorias:

A) feições sedimentológicas;

B) bioestratinômicas dos bioclastos;

C) estratigráficas dos depósitos fossiliferos; e

D) paleoecológicas dos depósitos fossiliferos.

Simões \& Holz (2000) propõem a descrição em cinco grupos distintos, adicionando àqueles as feições diagenéticas dos bioclastos (Tabela 2, p. 39). Devido ao tamanho reduzido dos bioclastos e à recristalização dos depósitos, a observação das feições macroscópicas foi descrita em quatro grupos de feições. A descrição das feições diagenéticas dos bioclastos, encontra-se na descrição microscópica das seções petrográficas (item 6.2.). 
TABELA 2 - CATEGORIA DE FEIÇÕES MACROSCÓPICAS USADAS NA ANÁLISE TAFONÖMICA, PARA A INTERPRETAÇÃO DA GENEESE DOS DEPÓSITOS DE BIOCLASTOS (ADAPTADO DE SIMÕES \& HOLZ (2000).

\section{Feições sedimentológicas}

Grau de empacotamento dos bioclastos

Volume dos bioclastos (\%) no depósito

Tamanho - grau de seleção dos bioclastos

Tipo de matriz

Tamanhos relativos e equivalência hidráulica dos bioclastos e da matriz

Estruturas sedimentares inorgânicas e biogênicas associadas

\section{Feições tafonômicas (bioestratinômicas) dos bioclastos}

Orientação em planta e seção

Grau de articulação das carapaças ou esqueletos

Fragmentação

Arredondamento

Superficie abrasão, corrosão, bioerosão ou incrustação

\section{Feições estratigráficas do depósito}

\section{Espessura}

Extensão lateral

Escala relativa às fácies

Geometria do depósito

Contatos estratigráficos e associação às superficies de erosão/omissão

Estrutura interna ou microestratigrafia

Posição na seqüência deposicional

Feições paleoecológicas dos bioclastos

Número de espécies

Abundância relativa de espécies

Composição taxonômica

Modo de vida

Classes de idade

Mineralogia e microarquitetura originais

Feições diagenéticas dos bioclastos

Mineralogia e microarquitetura preservadas 


\subsubsection{Terminologias empregadas na descrição das feições macroscópicas}

$\mathrm{Na}$ análise tafonômica, efetuou-se a descrição macroscópica das amostras com aquisição de dados bioestratinômicos, estratigráficos, paleoecológicos e sedimentológicos; dos depósitos fossilíferos, com a obtenção de dados qualitativos, e dados semiquantitativos, devido à alta coesão e recristalização dos depósitos.

As feições sedimentológicas e bioestratinômicas das concentrações, abrangendo o estudo da biotrama, foram efetuadas nos bioclastos grossos ( $>2 \mathrm{~mm}$ ). Seguindo o trabalho clássico de (KIDWELL \& HOLLAND, 1991), as terminologias empregadas (denso, frouxo, disperso e suas combinações), para a biotrama, relacionam-se A) ao grau de empacotamento dos bioclastos na matriz sedimentar, com base na abundância volumétrica; B) aos diferentes graus de empacotamento, de acordo com a forma e tamanho, originando biotramas densamente empacotadas, fracamente empacotadas e dispersas; C) à seleção com agrupamentos semiquantitativos distintos (intervalos), nas classes de tamanho de $2 \mathrm{~mm}$ - 3,9mm / 4mm - 7,9mm / 8mm - 15,9mm / 16mm $31,9 \mathrm{~mm} / 32 \mathrm{~mm}-63,9 \mathrm{~mm}$ ). Uma ilustração esquemática dos graus de empacotamento e seleção para bioclastos encontra-se na Figura 15 (p. 41).

Outros termos presentes são: A) abrasão - processos físicos de desagregação por choque e atrito de litoclastos e bioclastos, durante transporte e retrabalhamento; $B$ ) fragmentação - quebra das partes duras, por agentes físicos (hidráulicos) e biológicos (predação) e C) corrosão - destruição de restos esqueletais através da dissolução e bioerosão são comuns em estudos tafonômicos de concentrações esqueléticas.

A orientação dos bioclastos em planta possibilita a observação da dinâmica deposicional e identificação de direções dos paleofluxos nos tipos: unimodal, bimodal e polimodal (CLIFTON \& BOGGS,1970; FÜRSICH, 1980; ALLEN, 1990) (Figura 16, p. 42). As conchas de animais desarticulados e retrabalhados em posição côncava e/ou convexa podem refletir condições de estabilidade, quando sujeitas às correntes unidirecionais (Figura 16, p. 41). Uma discussão sobre o transporte, a interferência entre as partículas bioclásticas e clásticas, e os possíveis padrões resultantes, podem ser encontradas em Kidwell et al. (1986); Kidwell \& Bosence (1991); Holz \& Simões, (2002). 

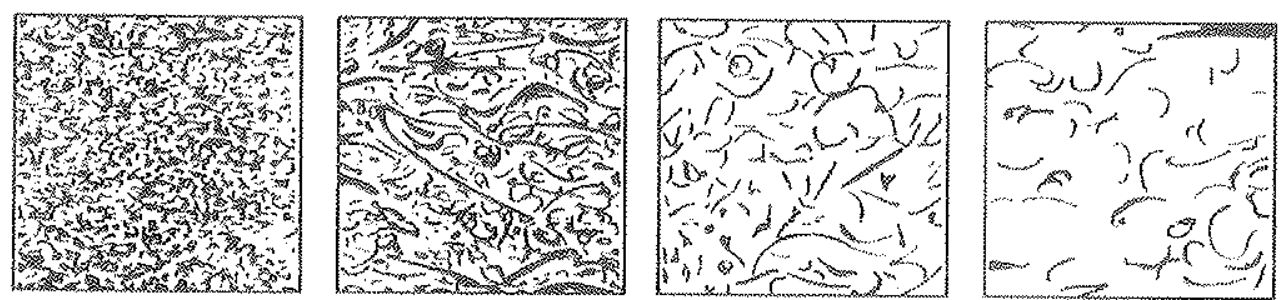

Denso

$70 \%$

Oenso

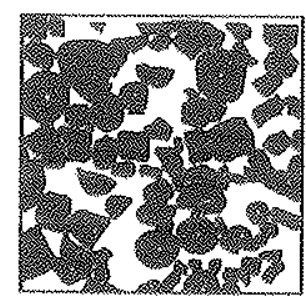

$\mid \begin{gathered}\text { Densolfrouxo } \\ 25 \% \\ \text { Frouxo }\end{gathered}$
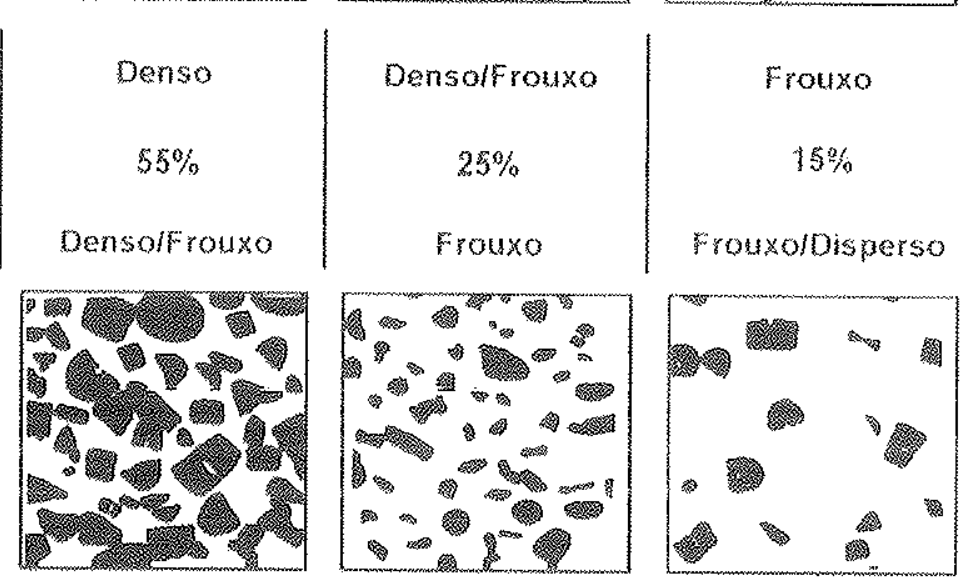

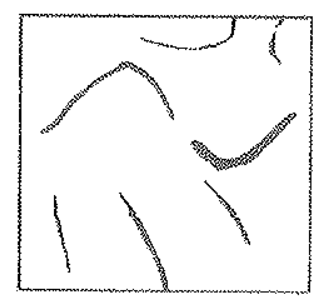

Frouxo

$5 \%$

Disperso

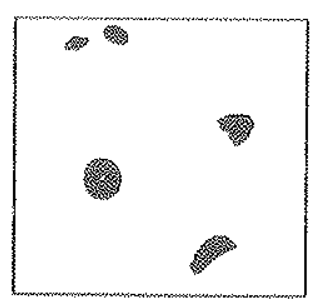

(A)

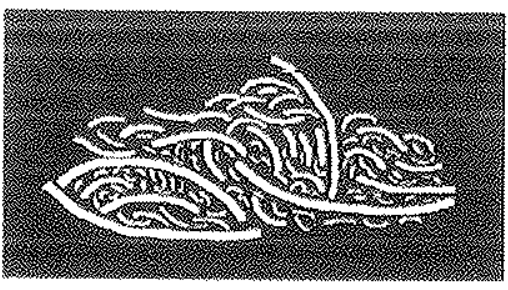

Densamente Empacotado auportacto por bicalasto

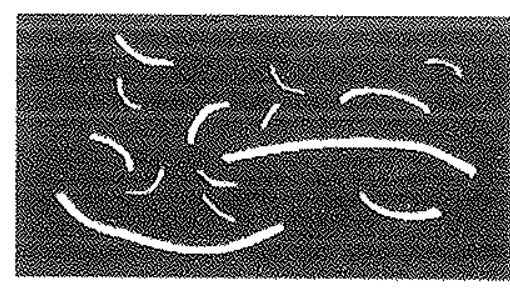

Fracsmente Lmpacoiado ouportado peta matrke

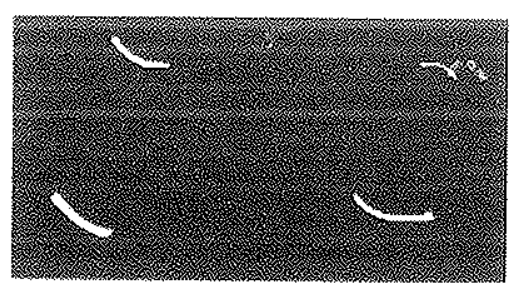

[3!sperso atuportisto palo matriz

(b)

Figura 15. A - Terminologia empregada na descrição do grau de empacotamento dos bioclastos na matriz sedimentar. B - Diferentes graus de empacotamento dos bioclastos, segundo a forma e o tamanho das partículas bioclásticas, Kidwell e Holland (1991). 


\section{CORRENTES}

Posição de estabilidade assumida por conchas sob

fluxo unidirecional forte (Allen, 1990).
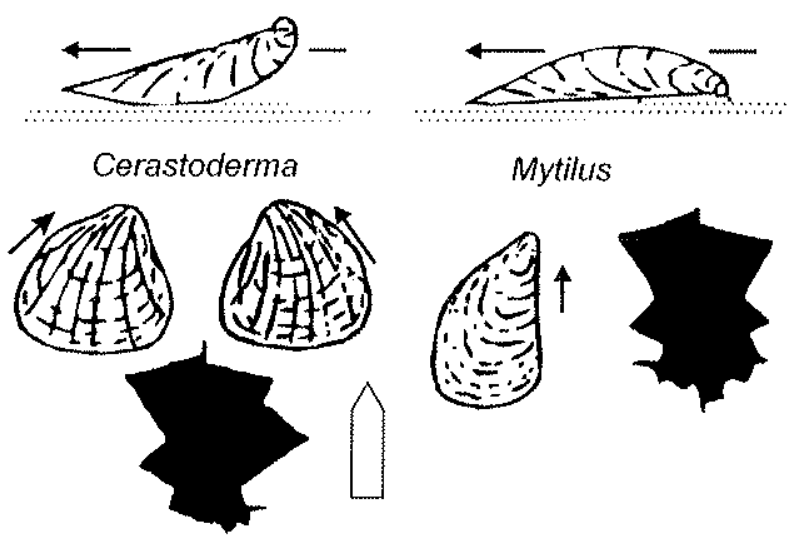

Alinhamento

de gastrópodes

Turritella

sob fluxo

unidirecional

(Seilacher, 1953).

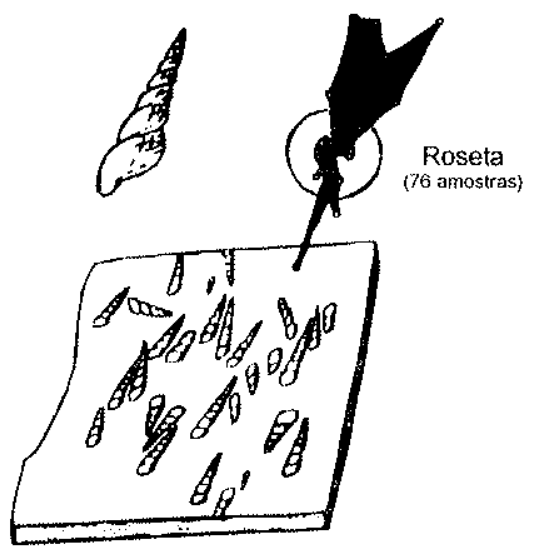

Orientação

bimodal de

bioclastos sob

fluxo oscilatório

(Allen, 1990).

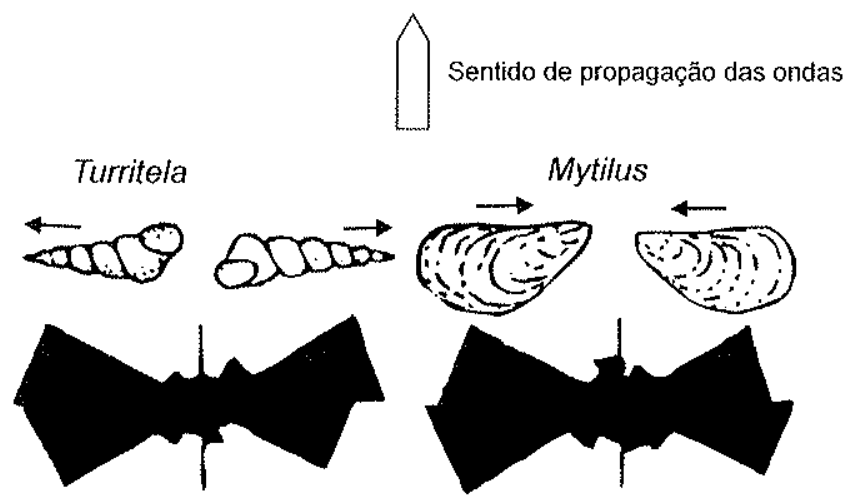

Figura 16. Orientação dos bioclastos em planta, com identificação de direções dos paleofluxos (correntes e fluxos oscilatórios), Clifton \& Boggs (1970), Fürsich (1980), Allen (1990). 
Na observação e descrição da biotrama, em corte, são empregados os termos propostos em Kidwell et la. (1986) e Kidwell \& Bosence (1991) (Figura 17, p. 44), destacando: A) concordante para bioclastos com eixo longo alinhado paralela ou subparalelamente em relação ao plano de acamamento; $B$ ) oblíquo para bioclastos que exibem posições intermediárias; C) perpendicular para bioclastos dispostos na matriz em ângulo reto, em relação ao plano de acamamento; D) imbricação para bioclastos obliquos, adensados, evidenciando uma possível direção de fluxo; E) empilhamento para conchas de bivalves, com adensamentos paralelos ao plano de acamamento, refletindo deposição sujeita a fluxos oscilatórios (influências de tempestades).

Os bioclastos, tomando-se como exemplo os moluscos bivalves, podem apresentar-se em posição perpendicular ou ligeiramente inclinada em relação ao plano de acamamento. Em alguns casos, evidenciando fossilização em posição de vida, representando no depósito, tafocenoses autóctones (STANLEY, 1970) (exemplos brasileiros, GHILARDI, 1999; HOLZ \& SIMÕES, 2002).

A observação das feições estratigráficas e geométricas dos depósitos foram estabelecidas, a partir de parâmetros bidimensionais, tridimensionais e da natureza da superfície deposicional, da bioturbação de organismos, do modo de vida dos organismos e dos processos físicos, de acordo com Kidwell et al. (1986), como exemplificado na Figura 18 (p. 45).

$\mathrm{Na}$ caracterização da variação vertical e lateral dos atributos tafonômicos (estrutura interna) dos depósitos, usa-se os conceitos de estrutura simples e complexa, empregados no sentido restritamente descritivo. A estrutura interna simples é verificada em concentrações internamente homogêneas, em relação aos seus atributos bioestratinômicos, sedimentológicos e paleoecológicos e, as concentrações com estrutura interna complexa, mostram variações laterais e verticais de suas feições bioestratinômicas, sedimentológicas e paleoecológicas.

Em geral, as concentrações com estrutura interna complexa denotam múltiplos eventos de erosão e deposição, ou são geradas por um evento único, atingindo uma ampla área, com variações geomorfológica e batimétrica (SIMÕES \& HOLZ, 2002). 


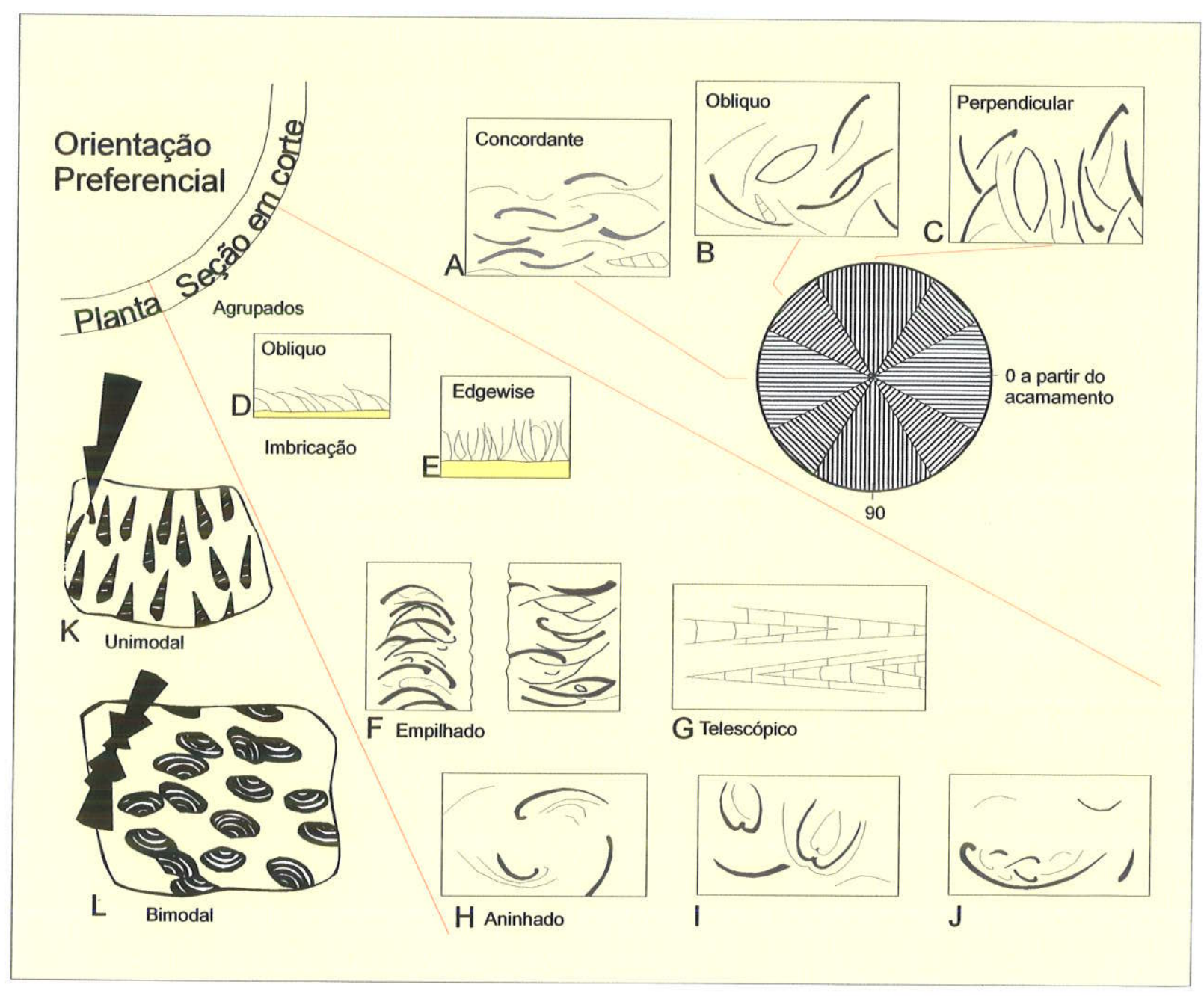

Figura 17. Descrição da biotrama, para a observação dos bioclastos em corte, e planta, com emprego dos termos segundo Kidwell et al. (1986) e Kidwell \& Bosence (1991). 
Duas dimensões

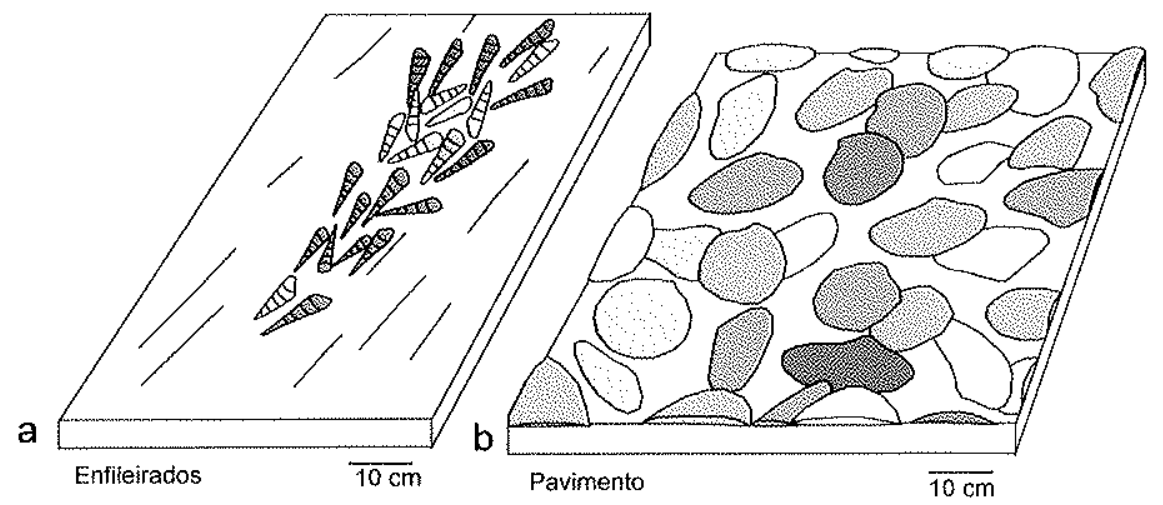

Três dimensões
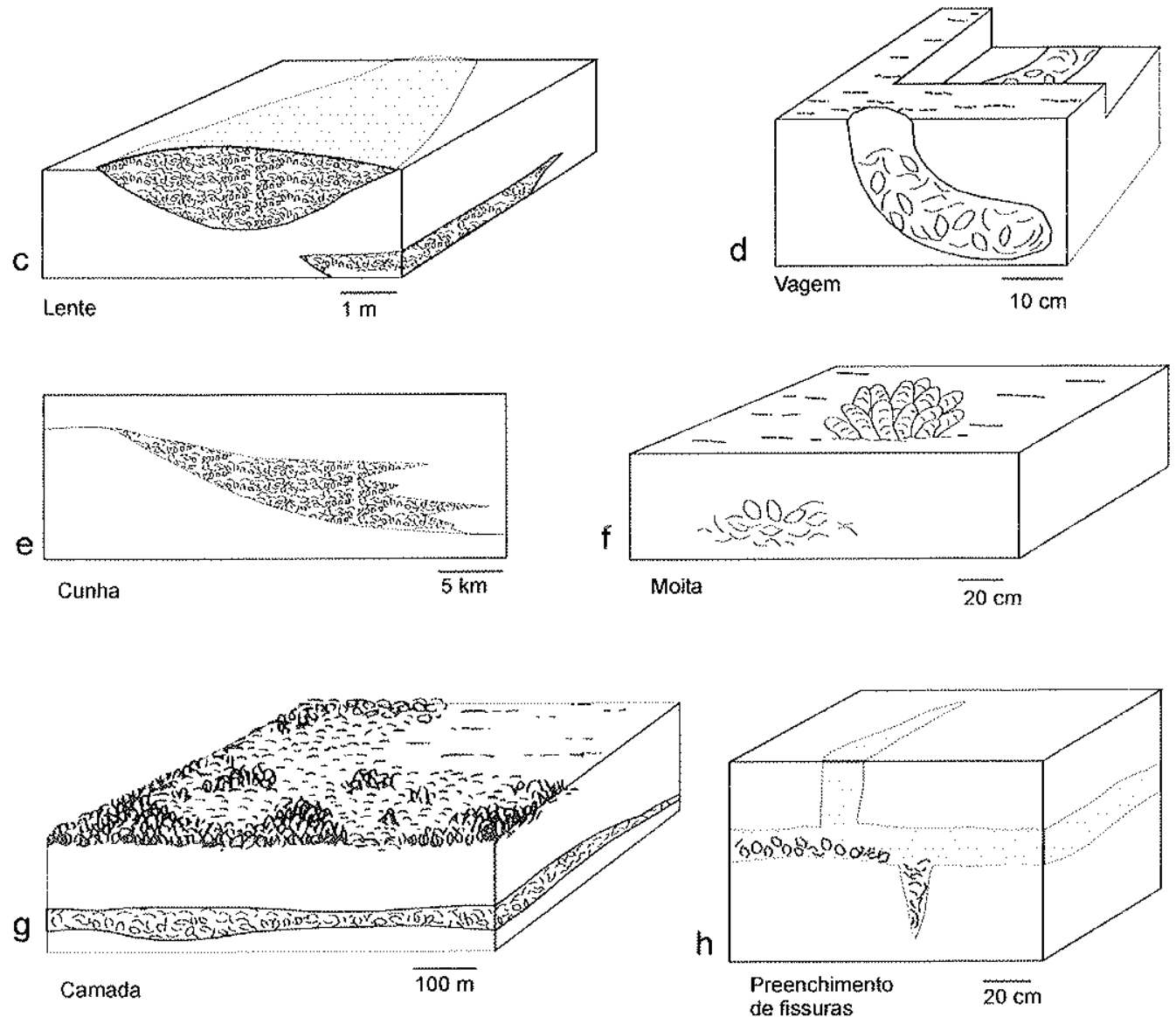

Figura 18. Geometria dos depósitos, de acumulações esqueletais. estabelecida a partir de parâmetros bidimensionais, da natureza da superficie deposicional, da bioturbação de organismos, do modo de vida dos organismos e dos processos físicos, $\mathrm{d} e \mathrm{a} \mathrm{cord}$ o com $\mathrm{kidw}$ ell et al. (1986). 
$\mathrm{Na}$ descrição das feições paleoecológicas das concentrações fossiliferas (conteúdo de sua biota) foram identificadas às composições taxonômicas monotípicas e politípicas. No caso de tafocenoses compostas por invertebrados, adota-se a classificação de Speyer \& Brett (1988), para os diferentes tipos de esqueletos, sendo esqueleto univalve, para os gastrópodes esqueleto bivalve (conchas de ostracodes e moluscos bivalves) e esqueleto multielemento, para os equinóides.

Tafonomicamente e paleoecologicamente, as concentrações fossilíferas monotípicas, com acúmulo de um único tipo de esqueleto têm grande significado e podem refletir condições de mortandade em massa, condições de alto estresse ambiental, de intensa seleção hidrodinâmica ou preservação diferencial, durante os processos diagenéticos. Já concentrações politípicas podem representar a influência de uma baixa seleção hidrodinâmica (HOLZ \& SIMÕES, 2002).

Os termos voltados para a caracterização dos tipos de fossilização são os usados em Mendes (1988), Simões \& Holz (2000). Nos depósitos fossilíferos que contêm as concentrações de macroinvertebrados bentônicos, da Formação Santana, a fossilização é tridimensional, compreendendo moldes, contramoldes e as petrificações.

Também compuseram a descrição termos como: A) indivíduos autóctones, representando fósseis preservados em posição de vida; B) individuos parautóctones, representando fósseis autóctones, transportados, mas ainda dentro do seu habitat original; e $\mathrm{C}$ ) individuos alóctones, representados por fósseis transportados para fora de seu habitat de vida (KIDWELL \& BOSENCE, 1991). 


\subsubsection{Classificações das concentrações fossilíferas}

No presente estudo é empregada a classificação de concentração genética de concentrações fossiliferas, mormente a de Fürsich \& Oschmann (1993) (Figura 19, p. 49), que está fundamentada, principalmente na biotrama e nas sssinaturas tafonômicas. Dessa forma utilizadas em conjunto, essas duas feições permitem inferências sobre os processos e os produtos que estão preservados no registro estratigráfico (SPEYER \& BRETT, 1991; BRETT \& BAIRD, 1993).

Os processos que geram as concentrações fossiliferas são distintos, sendo: A) os processos finais de deposição (responsáveis pela biotrama, pela incipiente influência na qualidade de preservação dos bioclastos e pela natureza da matriz) e B) os processos responsáveis pelos eventos anteriores à deposição final dos bioclastos [parafraseando Simões (1998), são os "...processos que atuam no ambiente de origem dos bioclastos, especialmente aqueles que operam no dia-a-dia". O segundo grupo pode ser identificado pelas assinaturas tafonômicas dos bioclastos, enquanto que os primeiros, pela naturea da biotrama.

No ambiente marinho, os principais processos que atuam na gênese das concentrações fossilíferas são as ondas de bom tempo, ondas de tempestades, fluxos de tempestades, correntes unidirecionais ou oscilatórias de longa duração e a produtividade biológica (FÜRSICH \& OSCHMANN, 1993), gerando assembléias fósseis ou concentrações fossiliferas com tipos geneticamente distintoa, ou seja A) concentrações geradas por ondas de bom tempo; B) concentrações por ondas de tempestades; C) concentrações geradas por tempestitos proximais; D) concentrações geradas por tempestitos distais; E) correntes de longa duração e E) concentrações geradas pela produção biogênica de partes duras (Figura 19, p. 49). 


\subsubsection{Conceitos empregados}

Neste item, são abordados os conceitos aplicados nos estudos tafonômicos com destaque para o uso de "retro-alimentação", "tafofácies", "assinatura tafonômica" e "mistura temporal".

\subsubsection{Retroalimentação tafonômica}

O conceito de retroalimentação tafonômica ou taphonomic feedback, introduzido por Kidwell \& Jablonsky (1983) e Kidwell (1986), reflete a influência de acumulações de restos esqueléticos nas comunidades marinhas viventes. No modelo dos autores, os animais de infauna, suspensivoros ou detritivoros que colonizam os substratos moles, contribuem com seus exoesqueletos na formação de substrato para uma variada epifauna bissada ou cimentada. Este processo de estabilidade e endurecimento do substrato acorre pelo acúmulo de carapaças, a partir da contribuição de sucessivas gerações ou introdução por transporte. Evidentemente, neste processo ocorre a eliminação da infauna. Em outras palavras, estas mudanças na estrutura e na dinâmica populacional da comunidade bentônica, tendem para uma comunidade cada vez mais dominada por taxa adaptada a fundos cascalhosos.

As mudanças faunísticas ao longo do tempo têm como causa os processos bióticos/abióticos e tais mudanças em geral, nas comunidades marinhas, são atribuídas aos processos biológicos (síntese em, HOLZ \& SIMÕES, 2002). O aumento dos substratos endurecidos, formados pelo crescente acúmulo de bioclastos, propicia o interligamento (interlock de KIDWELL \& JABLONSKI, 1983) e a crescente colonização do fundo marinho, provoca um aumento da bioerosão, com posterior redução dos bioclastos, podendo chegar a granulometria de sedimentos finos.

Desta forma, concentrações fossiliferas com gênese relacionada a tais condições são internamente complexas, representando registro de eventos episódicos (tempestades, deposição de finos), com retrabalhamento parcial e atuações posteriores por correntes ou processos associados a tempestades subseqüentes (GHILARDI, 1999). 


\section{Tipos de concentrações esqueléticas}

Águas rasas

Águas profundas
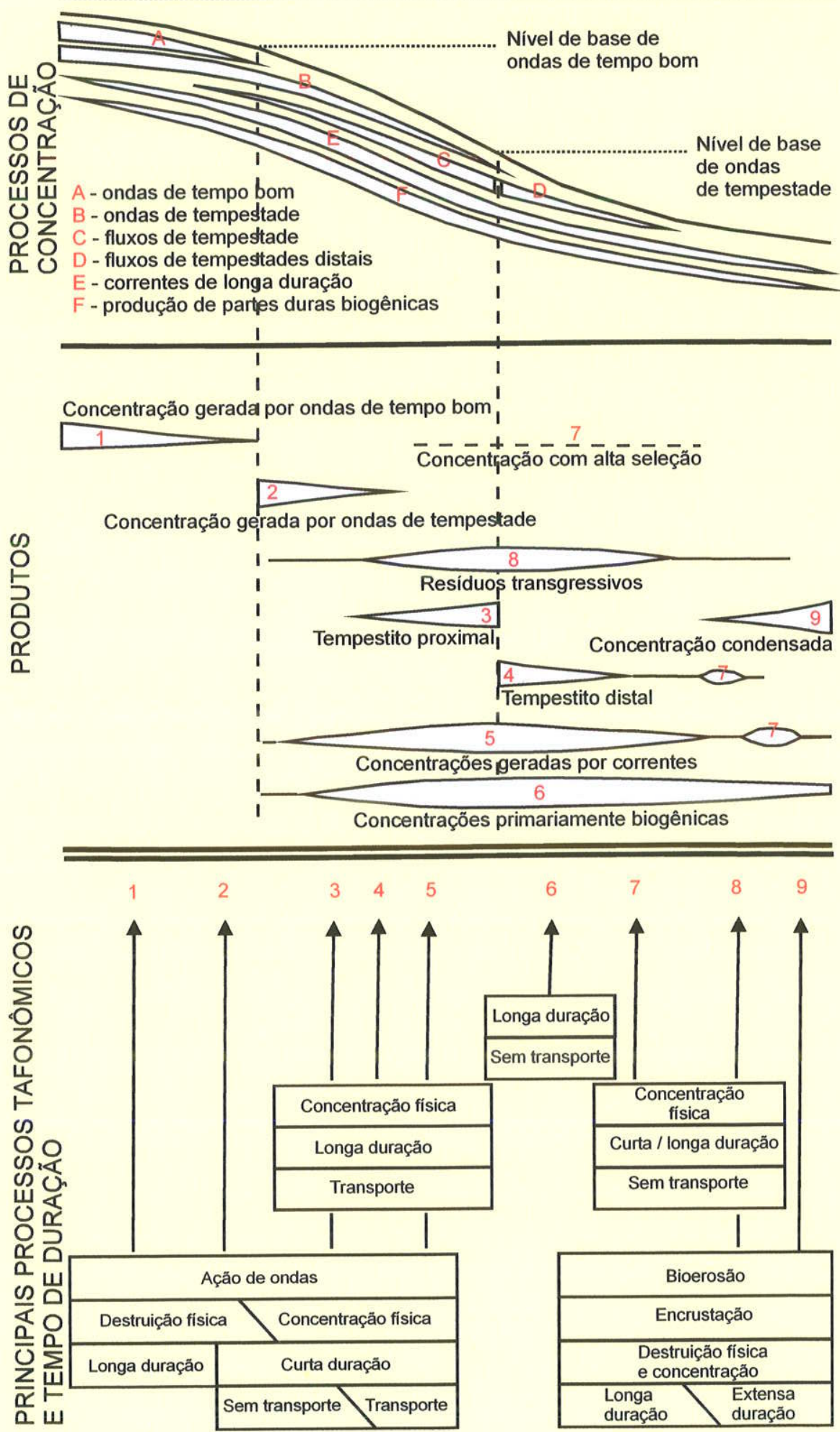

Figura 19. Processos relacionados a classificação das concentrações esqueletais em nove tipos e suas distribuições ao longo de gradiente de águas rasas-profundas (onshore-offshore) (FÜRSICH \& OSCHMANN, 1993). 
A exemplificação desses processos foi apresentada em Simões (1998), onde no litoral da Malásia, em ambientes marinhos recentes, a interação da sedimentação, produção de bioclastos e o retrabalhamento e deposição de lama, ser conhecidas (Modelo Jeram), tendo em geral, mudanças na composição faunística (SEILACHER, 1985, In SIMÕES, 1998). Logo, esporadicamente ocorrente em ambientes siliciclásticos, mas comum em ambientes carbonáticos, a granulometria do substrato influi diretamente na distribuição da comunidade e as relações sedimento-organismo são interativas, resultando em retroalimentação tafonômica.

\subsubsection{Fácies tafonômicas}

Fácies tafonômicas ou tafofácies são definidas com base em caractéres tafonômicos (SPEYER \& BRETT, 1988), particularmente bioestratinômicos, também almejando a tafonomia comparativa (sensu, BRETT \& BAIRD, 1986), onde detalhes da preservação dos fósseis refletem as condições sedimentológicas e podem levar à interpretação do ambiente deposicional. Caracteristicas diagenéticas podem ser empregadas, mas de maneira subsidiária, sendo, segundo a literatura, mais empregadas nas fácies de águas mais profundas, em função de sua limitação na avaliação das condições ambientais, do tempo decorrido e do local de soterramento (SPEYER, e BRETT 1986,1988,1991).

Em sua maioria, as concentrações fossilíferas geradas em mares epicontinentais são produtos de eventos de tempestades (BRETT \& BAIRD, 1986, 1993, 1997; SIMÕES, 1996, 1998; SPEYER, 1988; SPEYER \& BRETT, 1986, 1998, 1991) e os efeitos produzidos são previsiveis, relacionados à erosão do fundo, seleção e cobertura de finos (lama) (e.g. MILLER ET AL., 1988; SIMÕES ET AL., 1998), com influência sobre: A) a qualidade da preservação (sensu, FÜRSICH \& OSCHMANN, 1993); B) a espessura e geometria das concentrações (sensu, FÜRSICH \& OSCHMANN, 1993; BRENCHLEY \& HARPER, 1988) e C) a complexidade interna das acumulações esqueléticas (SIMÔES, 1998; SIMÕES \& KOWALEWSKI, 1998 a, b). 


\subsubsection{Assinaturas tafonômicas}

O primeiro conceito de "assinatura tafonômica" foi reconhecido por Davies et al (1989) com aplicação para os elementos esqueletais em concentrações de conchas (shell beds) que refletem em maior grau os habitats originais das espécies, em comparação aos processos responsáveis pela deposição final.

Assinatura tafonômica, segundo Fürsich \& Oschmann (1993), representa um conjunto de feições tafonômicas que expressam a qualidade de preservação dos biociastos (e.g., articulação, desarticulação, seleção, fragmentação, abrasão, incrustação, corrosão, bioerosão, etc), podendo o registro conter os parâmetros abióticos e bióticos do ambiente.

Os pontos determinantes da assinatura tafonômica são agrupados, em geral, em três categorias distintas: A) feiçōes derivadas de ação física (e.g. estruturas sedimentares, gradação, abrasão, seleção); B) feições derivadas de ação física e biológica (grau de empacotamento, orientação, fragmentação) e C) feições derivadas unicamente por ação biológica (bioturbação, incrustação, bioerosão).

\subsubsection{Mistura temporal}

A mistura temporal (time averaging) (sensu, WALKER \& BAMBACH, 1971; KOWALEWSKI, 1996, 1997) ocorreram e como descrito em Simões \& Ghilardi (1999), conceitualmente "refere-se ao resultado da mistura de restos de organismos, que não viveram juntos, encontrados em um mesmo estrato sedimentar, influenciando as conclusões paleosinecológicas. Assim sendo, restos de organismos que viveram em tempos distintos (dias, semanas, anos, séculos) e nunca interagiram, podem ser encontrados preservados juntos, em um dado estrato sedimentar, não sendo necessariamente contemporâneos".

Influem no processo de mistura temporal os fatores extrinsecos e intrinsecos. Os extrínsecos são a mistura vertical (FÜRSICH, 1971), a condensação faunística (FÜRSICH \& ABERHAN, 1990) e as falhas na obtenção de dados (FÜRSICH \& 
ABERHAN, 1990; BEHRENSMEYER \& HOOK, 1992), já os intrínsecos, envolvem o potencial de preservação, a abundância de restos esqueléticos, as características paleoecológicas e biogeográficas de organismos produtores de partes duras (KIDWELL \& BRENCHLEY, 1994, 1996; KOWALEWSKI, 1996, 1997). Sendo os fatores extrínsecos responsáveis pela definição do arcabouço temporal do processo de mistura temporal, e os fatores intrínsecos, responsáveis pelo potencial de mistura temporal, como observam Ghilardi \& Simões (1999). O processo de mistura temporal pode ser entendido a partir de duas escalas temporais: uma absoluta e outra relativa.

Kowalewski (1996) e Kowalewski; et al. (1998) demonstraram em concentrações de conchas coletadas lateralmente (imediatamente adjacentes) e com grande controle estratigráfico que restos esqueléticos, naturalmente, apresentam o fenômeno de mistura temporal e espacial (time-averaging), sendo uma regra e não uma exceção. Kowalewski; et al (1998) e Simões et al (1998a, b) complementam que esse fenômeno de mistura temporal não é eliminado por coleta cuidadosa (sensu, mistura temporal analítica; FÜRSICH \& ABERHAN, 1990); nem está associado à deposição e seus processos, mas sim à presença de restos bioclásticos antigos. (Pois,) Se hipoteticamente eliminarmos os processos tafonômicos, haverá sempre de modo inerente, uma tendência para a mistura temporal, visto que o tempo envolvido para o desenvolvimento de diferentes gerações de organismos é sempre menor do que o tempo envolvido na taxa de acumulação dos sedimentos (MARTIN, et al. 1999; GHILARDI \& SIMÕES, 1999). De fato, em acumulações residuais, geradas em ambiente marinho raso, Kowalewski et al. (1998) também sugerem que o grau de mistura temporal para acumulações, contendo conchas de bivalves (macroinvertebrados), é da ordem de $10^{2}$ a $10^{4}$ anos. A duração dos processos de mistura temporal, disponiveis para microfósseis (MARTIN ET AL., 1996) e vertebrados (BEHRENSMEYER \& HOOK, 1992), indicam um intervalo temporal da ordem de $10^{3}$ $10^{5}$ anos; comparável e similar à escala observada para as concentrações de macroinvertebrados marinhos (sinteses, SIMÕES, 1998; HOLZ \& SIMÕES, 2002). 


\subsection{Estudos petrográficos}

Os estudos petrográficos compreenderam as etapas de preparação de amostras, confecção de lâminas delgadas, descrição petrográfica, obtenção de imagens digitais com uso de equipamentos tais como microscópios petrográficos Axioplan 2-Zeiss; macro viewer Kaiser RT 1, lupa Stemi SV 11-Zeiss, em conjunto com analisador de imagens Leica Awin 550 e o software Imaging para Windows.

A petrografia das rochas carbonáticas é complexa, devido aos seus vários constituintes, sobretudo fósseis, que as compõem e dos processos diagenéticos, incluindo substituição, recristalização, cimentação, que influem de maneira considerável na sua composição e textura original (Tucker 2001).

Para melhor entendimento, segue um resumo da metodologia empregada com termos, classificações e constituintes principais dos carbonatos.

\subsubsection{Carbonatos}

Os carbonatos são mais sensíveis às mudanças diagenéticas em relação aos sedimentos siliciclásticos e as razões para a referida sensibilidade são: 1) a dissolução e precipitação de carbonato de cálcio $\left(\mathrm{CaCo}_{3}\right)$ sob várias condições de superfície; 2$)$ a instabilidade, principalmente da aragonita e da calcita nos diversos ambientes diagenéticos e 3) a influência de processos orgânicos na diagênese (Tucker, 2001).

Os esqueletos carbonáticos dos organismos presentes nas lâminas têm mineralogia específica, representada na Tabela 3 (p. 55) e, durante a diagênese, essa mineralogia pode ser alterada ou substituída (ex: aragonita é metaestável e invariavelmente é substituída por calcita; a calcita, com alto teor de magnésio, perde o magnésio, TUCKER, 2001).

As classificações usadas são as de Folk (1959) (Figura 20, p. 56) e Dunham (1962) (Figura 21, p. 56), que se baseiam no conceito de maturidade textural, onde a trama é relacionada ao nível de energia durante a deposição dos calcários, também fundamentadas nas proporções relativas de componentes aloquímicos, lama 
microcristalina e calcita espática. Folk (1959) é referenciado, pelo emprego dos termos descritivos na matriz, tipo de grão e cimento. Já Dunham (1962), pelos termos

empregados na classificação das rochas. No reconhecimento dos bioclastos fósseis e estruturas, seguiu-se Adams et al. (1997, 1998) e Majewske (1969).

\subsubsection{Calcários}

Na observação de calcários (pré-pleistocênicos), em lâmina petrográfica, convém salientar que, além dos poros, existem três constituintes básicos: A) calcita microcristalina; B) calcita espática e C) componentes aloquímicos. Uma breve descrição desses constituíntes segue abaixo, sumarizada, a partir de Bricker et. al. (1971), Adams \& Mackenzie (1998) e Tucker (2001).

A calcita microcristalina, A) ou lama carbonática microcristalina, com cristais menores que $5 \mu \mathrm{m}$ de diâmetro Microscopicamente, apresenta-se de translúcida a opaca. Em sedimentos modernos, pode ser constituída, além de calcita, por calcita magnesiana e/ou aragonita;

A calcita espática, B) arranjada na forma de cristais unidos, translúcidos, com clivagem romboedral, atua como cimento. Texturalmente, sendo microesparítica, quando reconhecidos mosaicos de microspar (cristais entre $5-15 \mu \mathrm{m}$ ); esparitos, ou spar (cristais com até $50 \mu \mathrm{m}$ ) e pseudo esparito ou pseudospar (>50 $\mu \mathrm{m}$ ) (sensu, FOLK, 1959).

Os componentes aloquímicos, C) sendo os intraclastos, fragmentos de sedimentos carbonáticos, contendo ou não bioclastos, pouco litificados $e$ penecontemporâneos à sedimentação e redepositados por correntes, vindo a apresentar qualquer tamanho; os oóides, grãos esféricos a sub-esféricos, consistindo de um ou mais lamelas concêntricas regulares em volta de um núcleo, usualmente uma partícula carbonatada ou um grão de quartzo (diâmetro de 0,2 a $0,5 \mathrm{~mm}$ ), que em geral, se formam em águas agitadas, mas podem ser acumulados em ambientes marinhos calmos (lagunas e planícies de maré) e os pelóides, grãos subesféricos, 
elipsoidais ou angulares, em geral do tamanho de $100 \mu \mathrm{m}$ a $500 \mu \mathrm{m}$ de diâmetro, compostos de carbonato microcristalino, mas sem estrutura interna.

Ressalta-se que os pelóides são poligênicos em calcários, podendo ter origem de A) excrementos fecais (pe/let), comuns em sedimentos de ambientes protegidos, B) grãos micritizados como conchas abradadas ou oóides; C) algas ou calcificação de cianobactérias em matéria algálica; D) intraclástos (fração areia) ou litoclastos e E) grãos bioclásticos micritizados (alteração de fragmentos esqueletais) de micróbios microperfuradores e recristalizados (sensu, TUCKER, 2001, p. 117)

$\mathrm{Na}$ identificação dos tipos de porosidades e estruturas asssociadas, adota-se o esquema de Choquete \& Pray (1970) (Figura 22, p. 57).

Em parte das amostras, foi aplicada metodologia de impregnação com saturação por líquidos densos, previa a etapa de confecção de lâmina delgada, que permitiu a visualização da fábrica aberta, das concentrações, a partir da visualização de poros e espaços vazios.

Soluções ácidas de "Potassim ferricyanida" e "alizarin red S", foram usadas na diferenciação dos conteúdos calcítico e dolomítico, de acordo com a metodologia de Dickson (1965).

TABELA 03. MINERALOGIA DOS ESQUELETOS CARBONÁTICOS DESCRITOS NAS LÅMINAS, DOMINANTE $X$, MENOS COMUM - (X), (TUCKER, 2001).

\begin{tabular}{|c|c|c|c|c|}
\hline \multicolumn{5}{|c|}{ Mineralogia } \\
\hline Organismo & Aragonita & $\begin{array}{l}\text { Calcita pouco } \\
\text { magnesiana }\end{array}$ & $\begin{array}{l}\text { Calcita muito } \\
\text { magnesiana }\end{array}$ & Aragonita + calcita \\
\hline \multicolumn{5}{|l|}{ Moluscos } \\
\hline Bivalves & $x$ & $x$ & & $x$ \\
\hline Gastrópodes & $x$ & & & $x$ \\
\hline Equinodermos & & & $x$ & \\
\hline Ostracodes & & $x$ & $x$ & \\
\hline \multicolumn{5}{|l|}{ Foraminiferos } \\
\hline Benticos & $(x)$ & & $x$ & \\
\hline Pelágicos & & $x$ & & \\
\hline
\end{tabular}




\begin{tabular}{|c|c|c|c|}
\hline & & TIPOS DE CA & CARIOS \\
\hline & & CIMENTADOS POR ESPARITO & COM MATRIX MICRITICA \\
\hline & $\begin{array}{l}\text { GRAOS ESQUELETAIS } \\
\text { (BIOCLASTOS) }\end{array}$ & BIOESPARITO & BIOMICRITO \\
\hline$\frac{8}{8}$ & OOIDES & OOSPARITO & OOMICRITO \\
\hline $\bar{g}$ & PELOIDES & PELSPARITO & PELMICRITO \\
\hline & INTRACLASTOS & INTRAESPARITO & INTRAMICRITO \\
\hline & $\begin{array}{l}\text { CALCARIOS FORMADOS } \\
\text { IN SITU }\end{array}$ & BIOLITITO & $\begin{array}{l}\text { CALCARIO FENESTRAL } \\
\text { DISMICRITO }\end{array}$ \\
\hline
\end{tabular}

Figura 20. Quadro com a classificação dos calcários (Folk, 1959),

\begin{tabular}{|c|c|c|c|c|c|}
\hline \multicolumn{5}{|c|}{ TEXTURA DEPOSICIONAL RECONHECIVEL } & \multirow{5}{*}{$\begin{array}{c}\text { TEXTURA } \\
\text { DEPOSICIONAL } \\
\text { NAO } \\
\text { RECONHECIVEL }\end{array}$} \\
\hline \multicolumn{4}{|c|}{$\begin{array}{l}\text { COMPONENTES ORIGINAIS NĀO INTERLIGADOS } \\
\text { DURANTE ADEPOSIÇĀO }\end{array}$} & \multirow{4}{*}{$\begin{array}{c}\text { COMPONENTES } \\
\text { ORIGINAIS } \\
\text { INTERCALADOS } \\
\text { DURANTEA } \\
\text { DEPOSIÇAOO }\end{array}$} & \\
\hline \multicolumn{3}{|c|}{$\begin{array}{c}\text { CONTÉM LAMA } \\
\text { (PARTICULAS TAMANHO ARGILAE SILTE) }\end{array}$} & \multirow{3}{*}{$\begin{array}{c}\text { SEM LAMA } \\
\text { E } \\
\text { SUSTENTADO } \\
\text { POR GRÃOS }\end{array}$} & & \\
\hline \multicolumn{2}{|c|}{ SUSTENTADO POR LAMA } & \multirow{2}{*}{$\begin{array}{c}\text { SUSTENTADO } \\
\text { POR } \\
\text { GRAOS }\end{array}$} & & & \\
\hline $\begin{array}{l}\text { MENOS DE } \\
10 \% \text { DE } \\
\text { GRAOS }\end{array}$ & $\begin{array}{l}\text { MAIS DE } \\
10 \% \text { DE } \\
\text { GRAOS }\end{array}$ & & & & \\
\hline MUDSTONE & WACKESTIONE & PACKSTONE & GRAINSTONE & BOUNDSTONE & CARBONATO CRISTALINO \\
\hline
\end{tabular}

Figura 21-Quadro com a classificação de rochas carbonáticas (Dunham, 1962). 


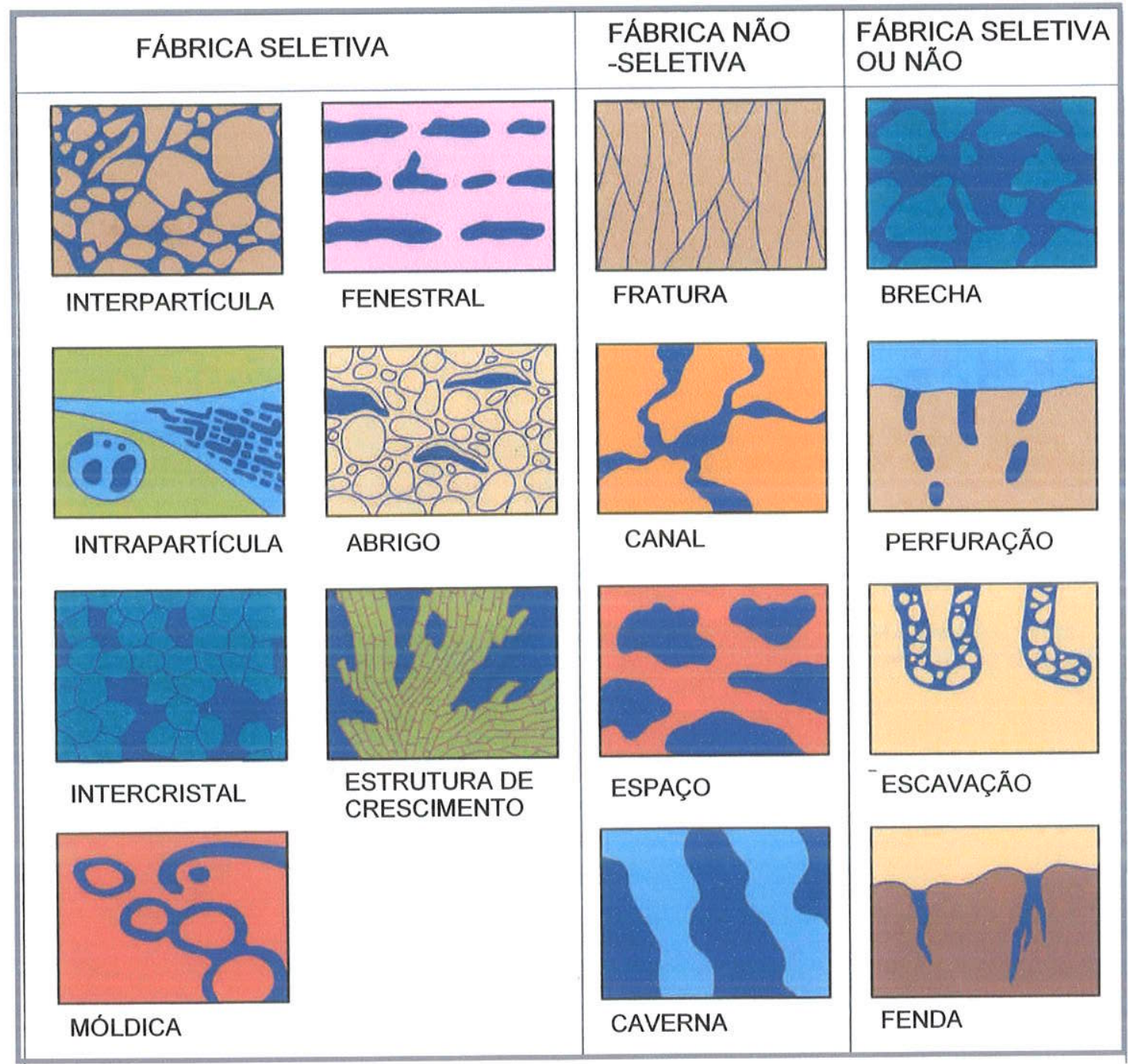

Figura 22. Classificação da porosidade (na cor azul) em sedimentos carbonáticos (CHOQUETE \& PRAY, 1970). 


\subsection{Trabalhos de Gabinete}

\subsubsection{Correlação de perfis}

Na pesquisa, há uma tentativa da aplicação da Estratigrafia de Sequências à parte albiana da seqüência sedimentar da Bacia do Araripe, especificamente ao intervalo representado pela porção superior da Formação Santana (Membro Romualdo), com nítida influência marinha, manifestada, principalmente, pelo seu conteúdo fossilífero.

A seção sedimentar da Formação Santana compõe um trato de sistema essencialmente transgressivo, incluida em um grande ciclo transgressivo-regressivo da Seqüência Pós-Rifte de Ponte (1992). Na bacia do Araripe, a pilha sedimentar da Formação Santana está registrada nos poços estratigráficos: 2-AP-1-CE e poço estratigráfico 4-BO-1-PE (distanto $15 \mathrm{~km}$ ao Sul do primeiro) (Figura 12, p. 31), localizados na porção centro-oeste da bacia (Figuras 3 e 5, p. 10 e 13), na sub-bacia de Feira Nova (Figura 4, p. 12). Outros poços abarcam, quase que totalmente, os litótipos da Formação Santana, 1PS-12-CE e 1PS-11-CE, localizados na porção sudeste da bacia (Figuras 3 e 5, p. 10 e 13), ambos executados pelo Projeto Santana (OLIVEIRA ET AL., 1979).

Pretende-se utilizar, na correlação estratigráfica, os dados de subsuperfície dos poços 1PS-12-CE e 1PS-11-CE e das seções levantadas. Nos perfis se buscará o intervalo sedimentar da Formação Santana, com possibilidades de A) reconhecimento de ciclos de aprofundamento e raseamento, com caracterização de variações texturais, com possibilidades de identificação de superfícies e/ou limites B) intervalos que apresentem ocorrências de fósseis de macroinvertebrados bentônicos. 


\section{Resultados}

\subsection{Concentrações fossilíferas}

$\mathrm{Na}$ descrição dos caracteres tafonômicos das concentrações fossiliferas de macroinvertebrados bentônicos, usam-se as terminologias próprias, o agrupamento de feições (Tabela 2, p. 39) e a escala de trabalho em camada (Figura 11, p. 30). Apresentam-se os dados tafonômicos e seções colunares com o posicionamento das concentrações fossilíferas de macroinvertebrados bentônicos.

Geometricamente, os depósitos fossiliferos são descontínuos e constituem-se de wackestones a packstones (Prancha 3, Fotos A; Prancha 5, Fotos B e C). em geral recristalizados, coesos $e$, por vezes, friáveis (Prancha 4, Foto B). Os bioclastos ocorrem na forma de conchas calcíticas e moldes recristalizados. As concentrações são predominantemente politipicas, com conchas univalves (gastrópodes), bivalves (bivalves e ostracodes) e multielemento (equinóides) (Prancha 2, Foto D, Prancha 4, Foto $\mathrm{C}$; Prancha 8 , Foto B). Em seção, apresentam distribuição caótica de bioclastos (conchas e fragmentos), gradação, grau de empacotamento dos bioclastos na matriz variável de denso a frouxo (SENSU, KIDWELL \& HOLLAND, 1991), com proporção volumétrica de bioclastos visualizada de $15 \%$ a $70 \%$ (Figura 15, p. 40), (Prancha 7 , Foto $F$, Prancha 8 , Foto $B$ ) e exibem desde espessuras centimétricas até decimétricas. Algumas concentrações esqueléticas são complexas, contendo unidades microestratigráficas internas com alto grau de adensamento, configurando coquinas amalgamadas (Romualdo, Prancha 3, Foto D). Os contatos basais dos depósitos apresentam-se, em geral, bruscos, ondulados e erosivos. A seleção dos bioclastos é predominantemente baixa,com varias classes de tamanho. Feições como aninhamento e empilhamento de conchas são observáveis. Quando observados em planta, os bioclastos apresentam distribuição polimodal, quanto à orientação de suas conchas (Prancha, 3, Foto A; Prancha 6, Foto F; Prancha 7, Foto H; Prancha 10, Foto A). A diversidade de espécies é, em geral, baixa.

Superfícies de abrasão, corrosão, bioerosão ou incrustação, não são observáveis. 
Suas ocorrências estão presentes em toda a bacia e a localização aproximada dos pontos constam na Figura 14 (p. 36).

Na figura 23, seguem as legendas usadas nas seções colunares.

\subsubsection{Concentrações em Romualdo}

Na seção Romualdo, Crato, CE, localizada a $7,3 \mathrm{~km}$ a sudeste da cidade de Crato, próximo à Rodovia CE-125 (Crato-Arajara), ocorrem quatro concentrações que exibem grau de empacotamento denso a frouxo dos bioclastos na matriz sedimentar. As concentrações, compõem-se de conchas e fragmentos de gastrópodes turritelideos e bivalves indistintos (Prancha) (Figura 24, p. 62). As concentrações das cotas 632 e 630 metros são internamente complexas e coquinóides, com contatos basais bruscos, ondulados e erosivos, assim como nos limites de suas unidades microestratigráficas internas (Prancha 3, Fotos C, D e E).

As concentrações ocorrem em arenitos e folhelhos. Os dados tafonômicos das concentrações (cotas $632 \mathrm{~m}, 630 \mathrm{~m}$ e $627 \mathrm{~m}$ ) constam no Anexo I.

\subsubsection{Concentrações em Jamacaru}

Próximo da localidade de Jamacaru, aflora concentração com fósseis recristalizados, alterado e friável, com $5 \mathrm{~m}$ de espessura (Prancha 4, Foto A,. Figura 25 , p. 62). Nesse, ocorrem concentrações fossiliferas de conchas e fragmentos de moluscos (gastrópodes turritelídeos e bivalves indistintos), exibindo grau de empacotamento de denso a frouxo de bioclastos na matriz sedimentar. Lateralmente, o depósito tem extensão de até 12 metros (Prancha 4, Foto A). Nos níveis recristalizados, foram amostrados blocos (Prancha 4, Foto B, C e D).

Os dados tafonômicos das concentrações constam no Anexo 1. 


\section{LEGENDAS}

Litotipos,

minerais e

cimentos

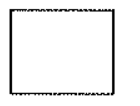

Arenito

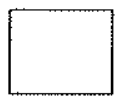

Siltito (lamito)

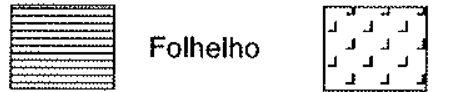

Gipsita

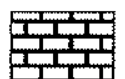

Calcário

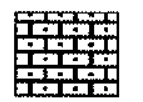

Calcarenito

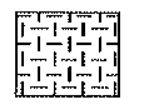

Marga

$\Leftrightarrow \therefore$ coquina

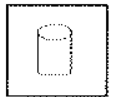

$\left.\begin{array}{c|c}\text { Betume } & E\end{array}\right]$ Enxofre
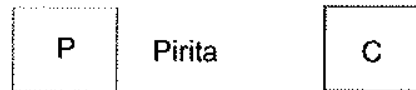

$\mathrm{Ca} \mathrm{Co}_{3}$

Cimento carbonático

\section{Fósseis}

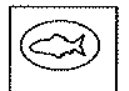

Concreção

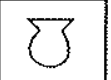

Bivalves

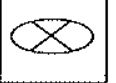

Septária com com ictiólito

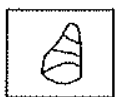

Gastrópodes

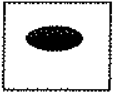

Coprólitos

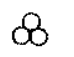

Microfóssil

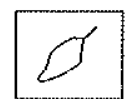

Vegetais e/ou

fragmentos

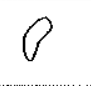

Escama de peixe

10

Restos de

vertebrados

\section{Estruturas}

\begin{tabular}{|c|c|c|c|c|c|}
\hline$\underline{\underline{m}}$ & $\begin{array}{l}\text { Estratificaçäo } \\
\text { plano-paralela }\end{array}$ & 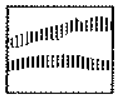 & $\begin{array}{l}\text { Calcita fibrosa } \\
\text { (cone em cone) }\end{array}$ & & $\begin{array}{l}\text { Estratificação } \\
\text { cruzada tabular } \\
\text { de pequeno porte }\end{array}$ \\
\hline$\approx$ & Marcas onduladas & & $\begin{array}{l}\text { Gretas de } \\
\text { Contração }\end{array}$ & & $\begin{array}{l}\text { Estratificaçäo } \\
\text { cruzada tabular } \\
\text { medio porte }\end{array}$ \\
\hline 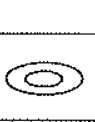 & Concreção & & $\begin{array}{l}\text { Marcas de } \\
\text { sulcos }\end{array}$ & & $\begin{array}{l}\text { Estratificação } \\
\text { cruzada tabular de } \\
\text { médio porte }\end{array}$ \\
\hline & Nódulo & $\infty$ & $\begin{array}{l}\text { Estratificaçäo } \\
\text { hummocky }\end{array}$ & & $\begin{array}{l}\text { Ciclos de aprofundamento } \\
\text { para o topo }\end{array}$ \\
\hline CA & $\begin{array}{l}\text { Clastos de argila } \\
\text { (Rip up clasts) }\end{array}$ & $\mathbb{1}$ & $\begin{array}{l}\text { Estratificação } \\
\text { acanalada }\end{array}$ & & $\begin{array}{l}\text { Ciclos de raseamento } \\
\text { para o topo }\end{array}$ \\
\hline CL & $\begin{array}{l}\text { Clastos líticos } \\
\text { (Rip up clasts) }\end{array}$ & & $\begin{array}{l}\text { Estratificaçäo } \\
\text { cruzada tabular } \\
\text { pequeno porte }\end{array}$ & bाm & $\begin{array}{l}\text { Superficie de } \\
\text { Máxima Inundação }\end{array}$ \\
\hline
\end{tabular}

Figura 23. Explicação das legendas para litótipos e minerais, fósseis, estruturas e feições estratigráficas que constam nos perfis esquemáticos das seções levantadas. 


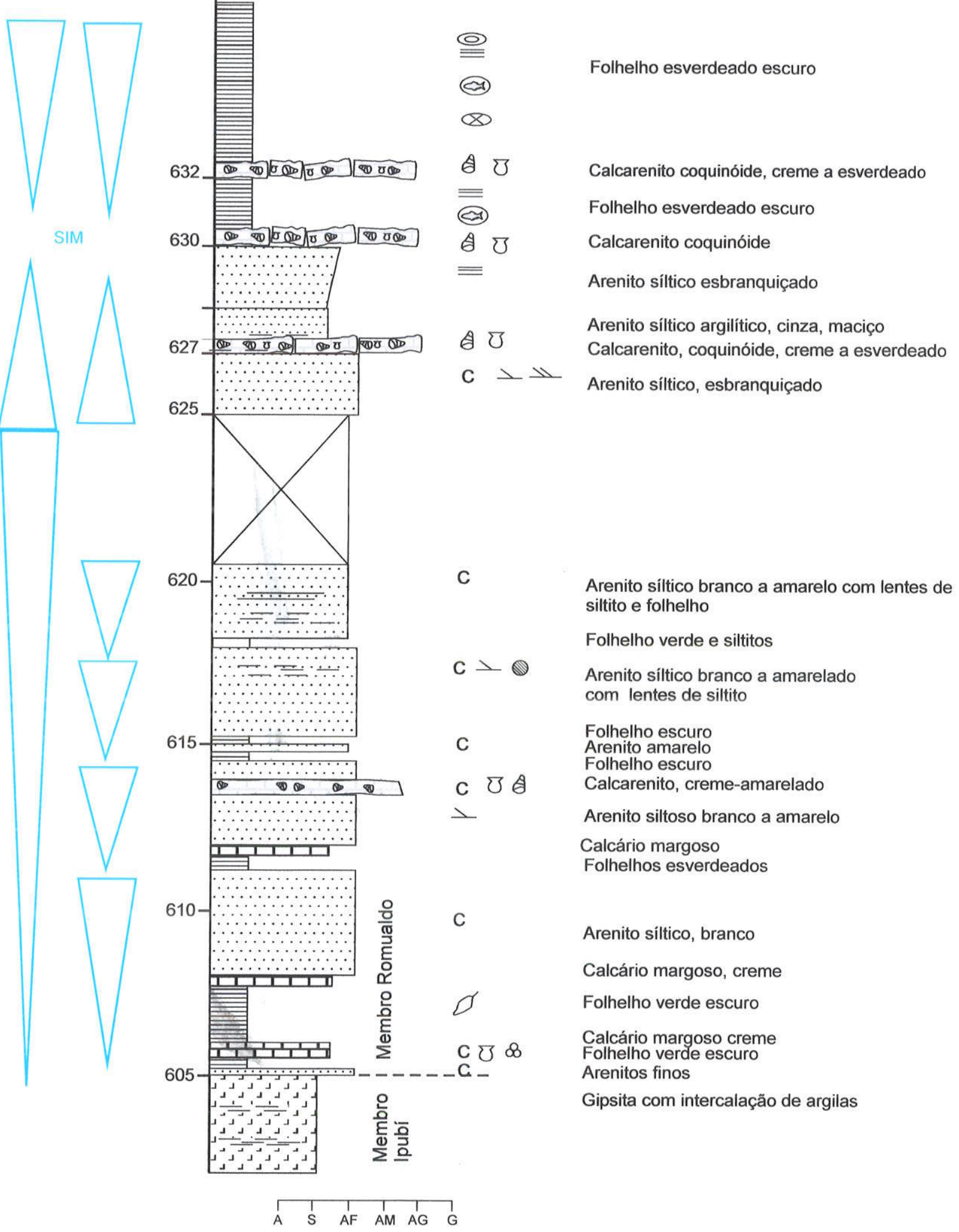

Figura 24. Perfil estratigráfico esquemático da seção Romualdo, Crato, CE, localizada a 7,3 km a sudeste da cidade de Crato, próximo a Rodovia CE-125 (Crato-Arajara), Coordenadas geográficas S $07^{\circ} 17^{\prime} 603^{\prime \prime}$ e W $39^{\circ} 23^{\prime} 536^{\prime \prime}$ do topo do perfil, ocorrência de concentrações fossilíferas de macroinvertebrados bentônicos.. 


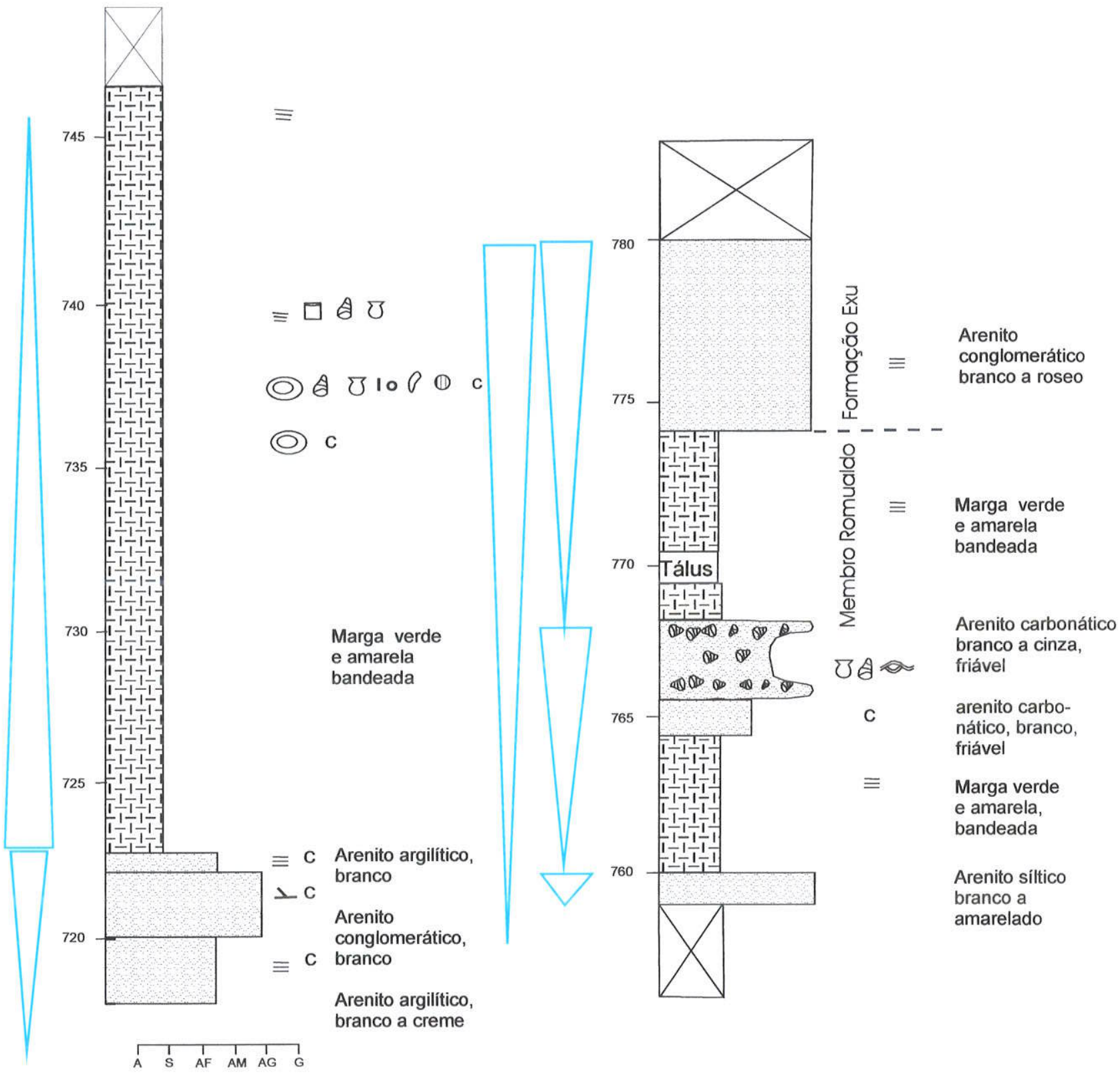

Figura 25. Perfil estratigráfico esquemático parcial do Membro Romualdo, levantado em Jamacaru, Missão Velha, CE, localizado em drenagem primária, a 300 metros da Rodovia Estadual CE 113, Km 18 (Missão Velha - Jamacarú), coordenadas geográficas S $07^{\circ} 23^{\prime} 856^{\prime \prime}$ e W39 $08^{\prime} 592^{\prime \prime}$. No topo acumulações esqueléticas. 


\subsubsection{Concentrações em Serra da Mãozinha}

No distrito de Serra da Mãozinha, no Sítio Encruzilhada, nos perfis levantados (localização nas figuras 26 e 27, p. 66 e 67), ocorrem dois tipos de concentrações fossilíferas, sendo:

A) concentrações com grau de empacotamento denso a frouxo dos bioclastos na matriz sedimentar, com espessura em torno de $12 \mathrm{~cm}$, e apresentando recristalização. Os fósseis correspondem à gastrópodes Paraglauconia cf. lyrica (Prancha 5, Foto A), intercalando espesso pacote de folhelhos.

B) três níveis de concentrações apresentando grau de empacotamento de bioclastos na matriz de denso a frouxo, contendo fósseis de moluscos (bivalves indistintos e braquidontes e gastrópodes turritelídeos, epitonídeos, cerritideos e naticideos), intercalando margas e arenitos argilosos-siltosos (Figura 26, p. 66), (Prancha 5, Fotos B e C). Estruturas sedimentares como laminação plano-paralela, laminação sigmoidal, marca ondulada, são observadas (Prancha 5, Fotos B e C). Os dados tafonômicos das concentrações (tipos A e B) constam no Anexo II.

\subsubsection{Concentrações em Sitio Saco}

Na região de Porteiras, Sítio Saco, próximo à estrada não pavimentada, PorteirasSaco, afloram concentrações fossilíferas de macroinvertebrados bentônicos (Figura 28, p. 68). Os bioclastos das concentrações apresentam grau de empacotamento denso a frouxo e compõem-se por fósseis de gastrópodes turritelideos e bivalves corbulidae [= Cyrenidae) e indistintos (Prancha 6, Fotos A, B, C, D e E). As ocorrências são descontínuas, por cerca de 30 metros de extensão e apresentam espessura de até 0,6 m. A visualização é prejudicada pela densa vegetação. Os depósitos são parcialmente alterados e friáveis. Apresentam gradação lateral e vertical do grau de adensamento de bioclastos, constituindo concentrações coquinóides. A geometria possivelmente representa uma cunha (Figura 18, p. 45).

Efetuou-se coleta em dois pontos distintos (ponto 1 e ponto 2, Figura 28, p. 68). No ponto 1, ocorre o empilhamento de duas concentrações complexas, apresentando amalgamento (Prancha 6, Fotos A e B), intercaladas por argilito verde (Figura 28, p. 
68). No ponto 2, a concentração fossilífera também é complexa, com várias unidades micro-estratigráficas. Nesta concentração, tem-se elevado grau de conchas de bivalves fechados articulados (Prancha 6, Foto D).

Os dados tafonômicos das concentrações em Sítio Saco constam no Anexo III.

\subsubsection{Concentração em Jatobá}

No topo da seção sedimentar, no Sítio Jatobá, levantada ao longo do leito do riacho dos Bois, na região de Porteiras, $C E$, ocorre banco, na forma de blocos recristalizados, pouco espessos e exibindo contatos ondulados. A ocorrência é descontínua, por uma área de aproximadamente $500 \mathrm{~m}^{2}$, sugerindo uma geometria de lente. O depósito intercala espesso pacote de folhelhos cinza-escuros (Figura 29, p. $69)$.

Nos blocos, observa-se concentração, com bioclastos na matriz apresentando grau de empacotamento denso a frouxo. Os fósseis compõem-se de conchas de gastrópodes turritelídeos e bivalves de conchas mitilóides e indistintos (Prancha 2, Foto D; Prancha 6, Foto F).

Os dados tafonômicos da concentração constam no Anexo IV. 


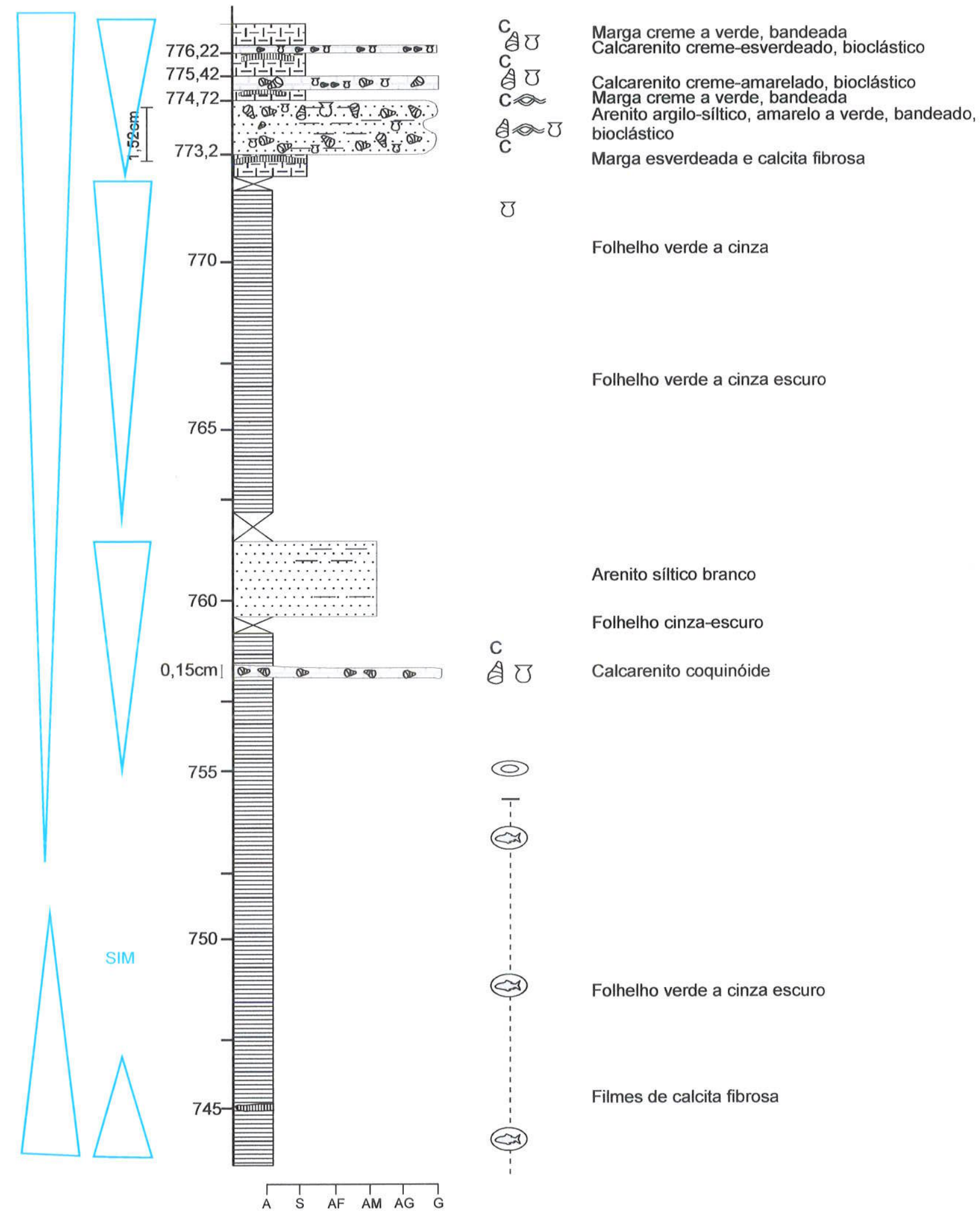

Figura 26. Perfil estratigráfico esquemático da seção 1, Membro Romualdo, Formação Santana, Serra da Mãozinha, Missão Velha, CE. Coordenadas UTM no topo do perfil (0489121 / 9186484), onde ocorrem acumulações fossilíferas, próximo a estrada não pavimentada Sitio Encruzilhada-Abaiára. 


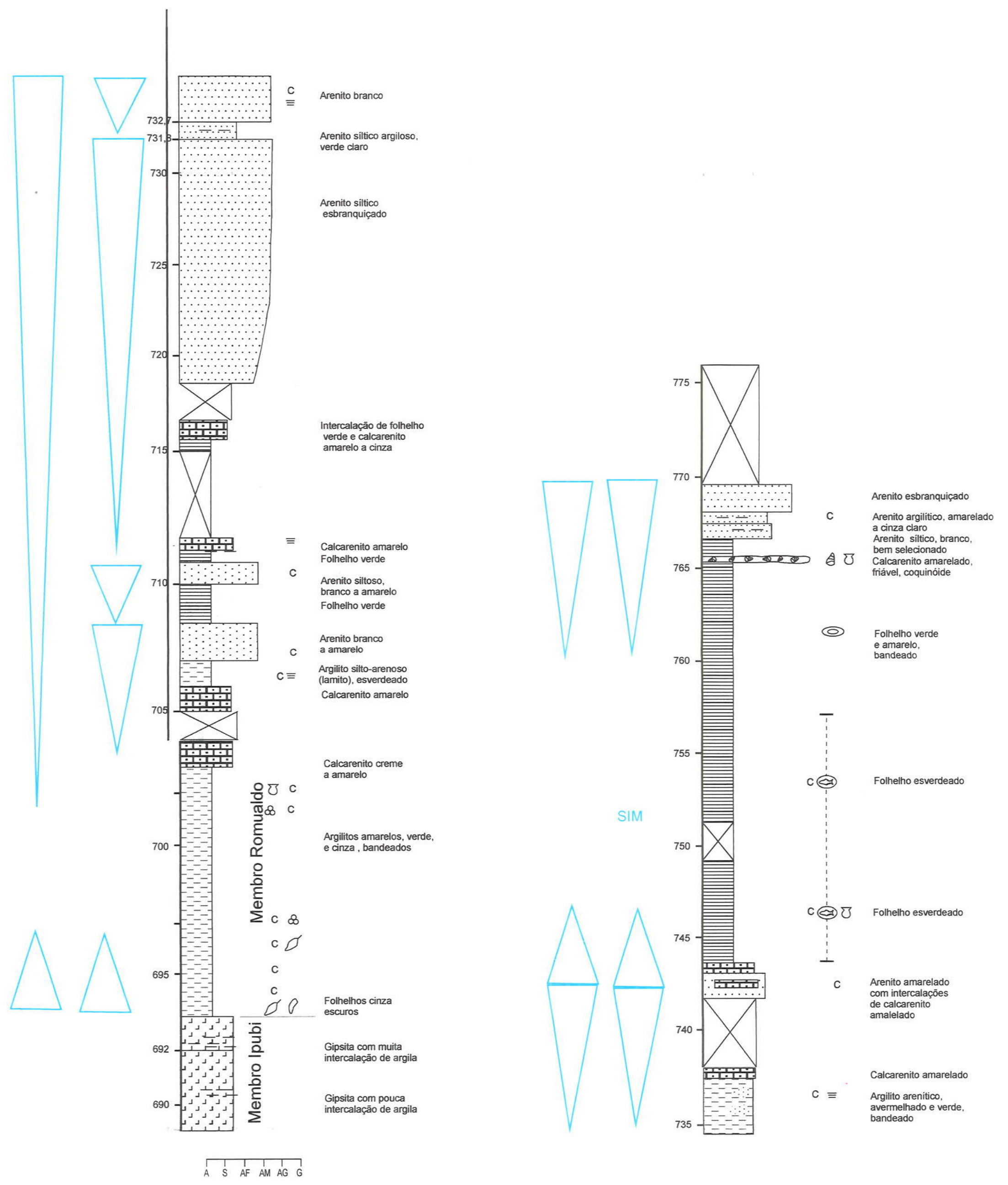

Figura 27. Perfil estratigráfico esquemático da seção 2, Formação Santana, Serra da Mãozinha, Missão Velha, CE. Coordenadas UTM (0489443 / 9186270), no topo do perfil, onde ocorre concentração fossilífera, próximo a estrada não pavimentada Sitio Encruzilhada-Abaiára. 


\begin{tabular}{|c|c|c|c|c|}
\hline $33 \mathrm{~m}$ & $15 \mathrm{~m}$ & $0 \mathrm{~m}$ & $150 \mathrm{~m}$ & $200 \mathrm{~m}$ \\
\hline NW & & & & \\
\hline $\begin{array}{l}\text { Ponto } 03 \\
\text { POCEA }\end{array}$ & $\begin{array}{l}\text { Ponto } 02 \\
\text { POCEA }\end{array}$ & $\begin{array}{l}\text { Ponto } 01 \\
\text { POCEA }\end{array}$ & $\begin{array}{l}\text { Ponto } 04 \\
\text { POCEA }\end{array}$ & POCEA \\
\hline
\end{tabular}

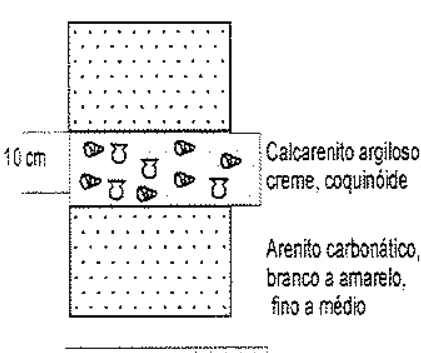

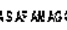

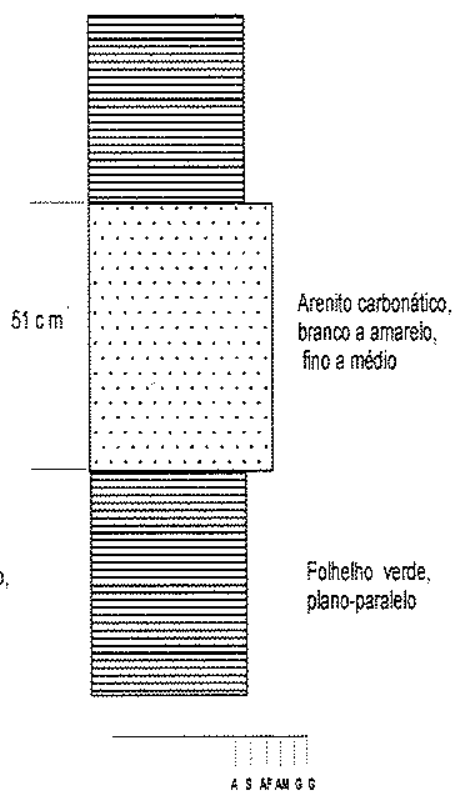

Figura 28. Representação litológica esquemática das concentrações do sítio Saco (ponto $1 \mathrm{e} .2$ ), Porteiras, $\mathrm{CE} e$ ocorrências correlatas, $8 \mathrm{~km}$ ao norte da sede do município, próximo à estrada não pavimentada, com coordenadas geográficas: S $07^{\circ} 29^{\prime} 904^{\prime \prime}$ e W $39^{\circ} 09^{\prime} 616^{\prime \prime}$ e cota de $759,5 \mathrm{~m}$. 


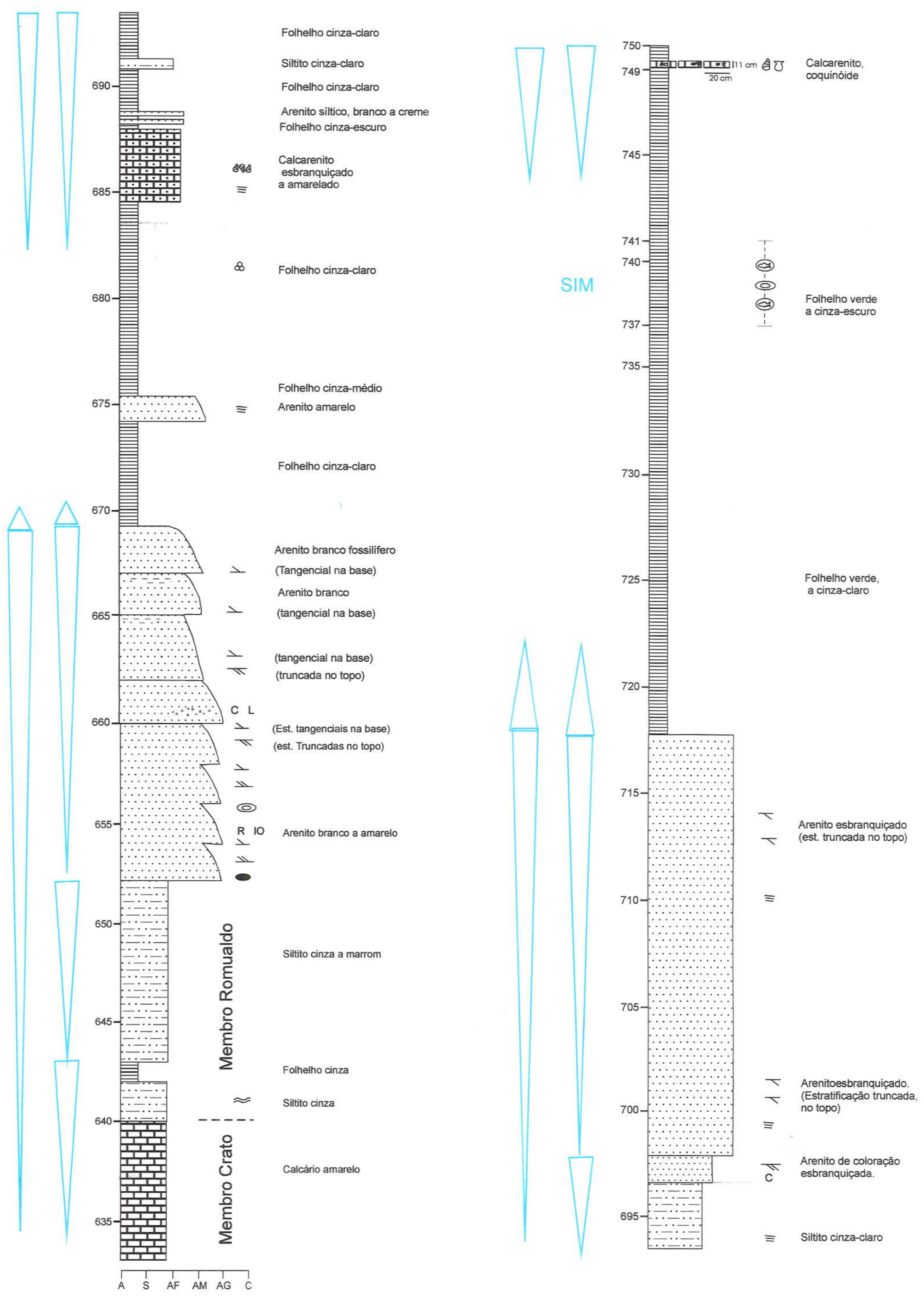

Figura 29. Perfil estratigráfico esquemático da Formação Santana em Porteiras, CE, 4 km a NW da cidade homônima, curso de drenagem (Riacho dos Bois). Coordenadas geográficas: S 070 31' 49, 1" e W 390 09' 48,8" da concentração fossilífera de macroinvertebrados, no topo da seção. 


\subsubsection{Concentração em Sítio dos Negros}

$\mathrm{Na}$ localidade de Sítio dos Negros, $3 \mathrm{~km}$ a norte da sede do Município de Jardim, em barranco na estrada pavimentada Jardim-Boca da Mata, coordenadas UTM $0489121 / 9186484$ e cota $755 \mathrm{~m}$, ocorre concentração fossilifera com conchas e fragmentos de macroinvertebrados bentônicos (gastrópodes turritelídeos e bivalves de conchas indistintas e mitilóides) e eventualmente fósseis de dentes de peixes picnodontes, isolados e/ou associados a fragmentos de mandíbula. Os bioclastos mostram grau de empacotamento de denso a frouxo na matriz sedimentar e porções densamente empacotadas suportadas por bioclastos. Somado a isso, as várias unidades microestratigráficas (Prancha 7, Foto B), denotam uma concentração complexa. A exposição se extende lateralmente por 10 metros e tem até $85 \mathrm{~cm}$ de espessura, com geometria aparentemente lenticular. Os blocos do depósito, ligeiramente basculados, têm direçäo de acamamento $195^{\circ} \mathrm{Az}$, mergulho $9^{\circ}$, para SW.

O depósito contém packstone, com fósseis recristalizados, é alterado e friável, com contatos bruscos e erosivos (Prancha 7, Fotos A). Este depósito intercala lâminas de arenitos finos argilosos carbonáticos, brancos a cinza, plano paralelos ( $\mathrm{mm}$ a $\mathrm{cm})$, por sua vez, encaixados em margas esverdeadas.

Dados tafonômicos da concentração em Sítio dos Negros, constam no Anexo IV.

\subsubsection{Concentrações em Engenho}

$\mathrm{Na}$ localidade de Sítio Engenho, $1 \mathrm{~km}$ a Leste da sede do Município de Jardim, CE, com coordenadas geográficas; $S 7^{\circ} 34^{\prime}$ 912" e W 39 16' 165" e cota de 703 metros em área de ocorrência de margas esverdeadas, contendo concreções fossiliferas com ictiólitos, encontram-se wackestones a packstones em parte recristalizados, contendo concentraçōes fossiliferas de macroinvertebrados bentônicos. O depósitos apresentam blocos com espessuras centimétricas de até $17 \mathrm{~cm}$ e contatos ondulados. A extensão lateral e sua geometria são dificeis de serem estabelecidas. As concentrações apresentam grau de empacotamento, denso a frouxo, dos bioclastos na matriz sedimentar e alguns blocos exibem conchas de bivalves em posição de vida (in situ). Dessa forma, dois tipos de concentrações são reconhecidos: 
A) concentração internamente complexa, coquinóide, densamente a frouxamente empacotada (Prancha 7, Fotos $\mathrm{C}$ e D). com unidades microestratigráficas apresentando contatos bruscos erosivos. Porções ou horizontes internos (unidades microestratigráficas) apresentam-se densamente empacotados, sendo suportados por bioclastos (predominando fragmentos, seguidos por conchas de bivalves mitilóides, indistintos e conchas de gastrópodes turritelídeos, naticídeos e neritídae. Horizonte (unidade microestratigráfica) de matriz lamosa, apresenta conchas inteiras de bivalves de infauna rasa, articuladas, fechadas, em posição de vida (Prancha 7, Foto D) e;

B) concentrações complexas com bioclastos, apresentando grau de empacotamento denso, com conchas e fragmentos de bivalves indistintos e mitilóides, articuladas e desarticuladas e, gastrópodes turritelídeos e naticídeos. Observam-se gradação descontínua interna, contatos bruscos e erosivos (Prancha 7, Fotos $\mathrm{E}$ e F) e estruturas como empilhamento e aninhamento.

Dados tafonômicos das concentraçōes constam no Anexo V.

\subsubsection{Concentração em Sobradinho}

No Sitio Sobradinho, no topo da seção Santana, ocorre concentração apresentando grau de empacotamento dos bioclastos, denso a frouxo na matriz sedimentar, composto por conchas fósseis de moluscos (gastrópodes turritelídeos e bivalves de conchas mitilóides e indistintos) (Prancha 7, Foto G).

Os blocos que contém a concentração são em parte, recristalizados. A ocorrência é descontínua, por uma área de aproximadamente $400 \mathrm{~m}^{2}$. Os blocos exibem contatos ondulados e gradação descontínua interna. $\mathrm{O}$ depósito intercala espesso pacote de folhelhos cinza escuros (Figura 30, p.72).

Dados tafonômicos da concentração constam nos Anexo IV. 

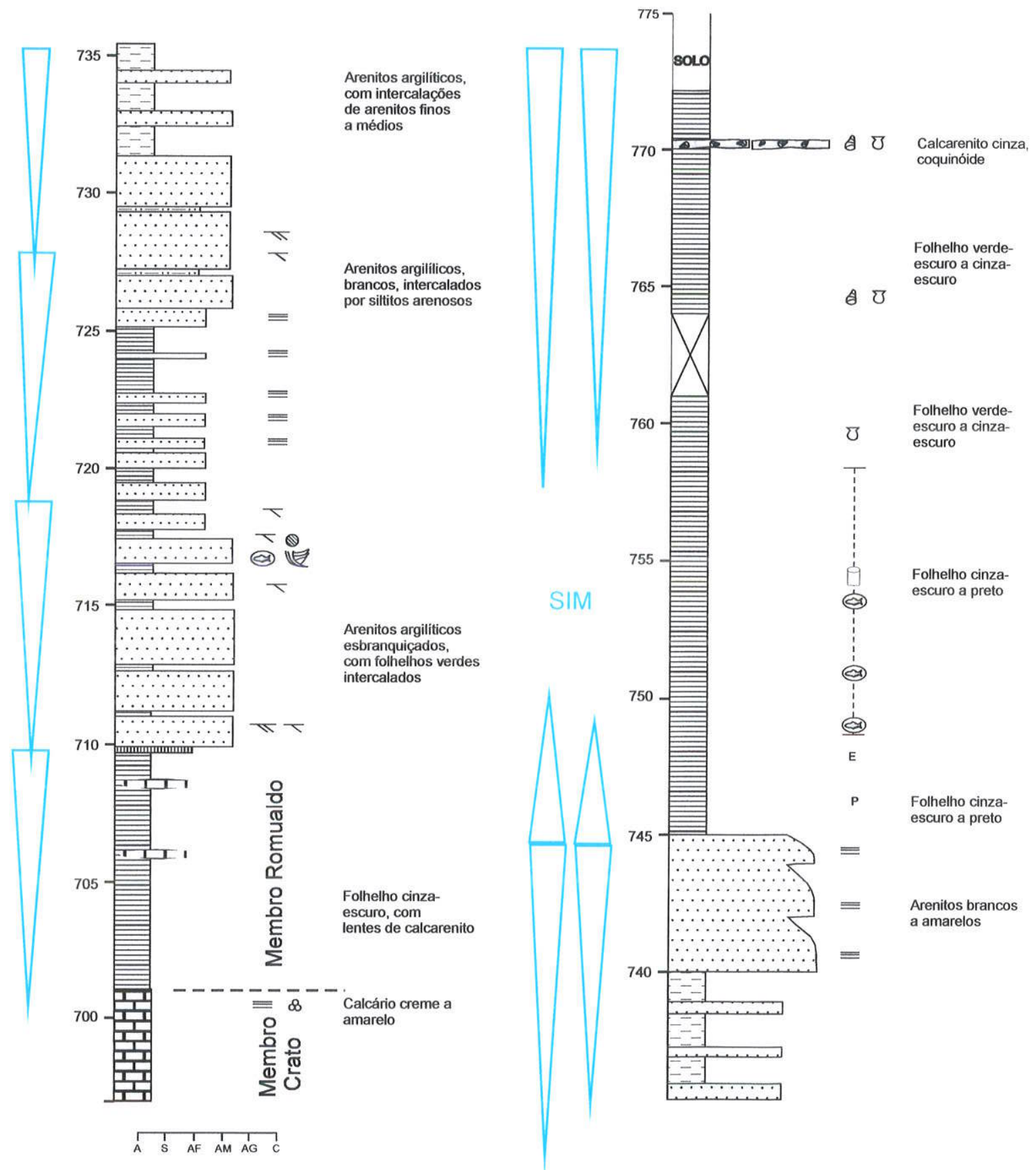

Figura 30. Perfil estratigráfico esquemático, Formação Santana, Sítio Sobradinho, Jardim, $\mathrm{CE}$, distando $19 \mathrm{~km}$ no rumo $\mathrm{E}$, da sede do município. No topo da seção, cota $770 \mathrm{~m}$ e coordenadas geográficas S $07^{\circ} 34^{\prime} 16^{\prime \prime}$ e W $39^{\circ} 09^{\prime} 50,3^{\prime}$ concentração fossilífera de macroinvertebrados bentônicos. 


\subsubsection{Concentrações em Canastra}

Nas proximidades da cidade de Araripina, Sítio Canastra, coordenadas S $03^{\circ} 31^{\prime}$ 955" / W 91' 61' 867" e cota 647 metros, ocorrem concentrações distintas de macroinvertebrados bentônicos (moluscos e equinóides). A partir da abertura de trincheiras, foram encontrados blocos decimétricos a métricos (Prancha 2, Foto $B$ ), que de acordo com o tamanho, disposição e espessura, possivelmente correspondem a depósitos com geometria de lentes, recristalizados (Prancha 8, Foto A e B). Dois são os tipos de concentrações:

A) concentração com empacotamento frouxo de bioclastos na matriz sedimentar, contendo carapaças fósseis de equinóides e fragmentos (Prancha 8, Fotos $B, C, D, E$ e F; Prancha 9, Fotos A, B e C) com poucas conchas fósseis de bivalves e gastrópodes associados. Nesse depósito, há ocorrências lâminares de esteiras algálicas e/ou estromatolíticas (Prancha 9, Foto B). Na superfície dos blocos, observam-se carapaças de equinóides inteiras (Prancha 9, Foto A) e carapaças parcialmente fraturadas (Prancha 8, Foto B), carapaças com quebra e colapso da região centro adapical, com fraturamentos concêntricos dos tipos: interradial; perradial e adapical, segundo os planos de sutura (partes de interambúlacros, ambúlacros e pétalas), (Prancha 8, Foto F), e carapaças apenas com esboços ou contornos das carapaças preservadas inteiras, mas desgastadas por processos erosivos (Prancha 08, Fotos C e E) Em seção, as carapaças inteiras e as parcialmente fragmentadas, apresentam, em geral, ápice voltado para cima, com preservação da região adapical (Prancha 9, Fotos B e C). As carapaças inteiras predominam paralelas ao plano de acamamento do depósito e em menor número, oblíquas e invertidas (Anexo VI), apresentando quebra por compactação (Prancha 9, Foto $C$ ). Os poucos espinhos de equinóides presentes, estão dissociados das carapaças e distribuídos de maneira aleatória no depósito e

B) concentração densa de bioclastos na matriz sedimentar (Prancha 8, Foto A). formada por conchas de bivalves indistintos e gastrópodes (Turritella, Cerithium e indeterminados) com alta fragmentação.

Os dados tafonômicos das concentrações constam no Anexo VI. 


\subsubsection{Concentração em Torre}

Em Araripina, na estrada Araripina-Torre, coordenadas S $07^{\circ} 35^{\prime} 49,8^{\prime \prime} \mathrm{W} 040^{\circ} 31^{\prime}$ 19 " e cota de 649 metros, são encontrados blocos contendo concentração com grau de empacotamento denso a frouxo dos bioclastos fósseis na matriz sedimentar. Com a abertura de trincheiras, confimou-se a ocorrência e efetuou-se coleta de blocos decimétricos a métricos. Trata-se de wakestone a packstone, creme a amarelo, recristalizado ou friável e alterado, exibindo contatos ondulados. O depósito corresponde geometricamente a uma lente. Os moluscos fósseis são gastrópodes turritelideos (Prancha 9, Foto D) cerritídios e epitonídeos, bivalves de conchas mitilóides e indistintos (Prancha 9, Foto E) e eventualmente carapaças de equinóides.

Dados tafonômicos da concentração encontram-se no Anexo VI.

\subsubsection{Concentração em Caboclos}

Na região de Caldeirão Grande do Piauí, no Sítio Caboclos, próximo à estrada não pavimentada Marcolândia - Fronteiras, ocorrem blocos contendo concentração de macroinvertebrados fósseis (moluscos) (Prancha 10, Fotos A e B). A concentração apresenta grau de empacotamento denso a frouxo de bioclastos na matriz sedimentar. Os blocos ocorrem em uma área com cerca de $2000 \mathrm{~m}^{2}$, porém a continuidade do depósito não é observada, sendo de difícil estabelecimento a sua geometria. São recristalizados (Prancha 10, Fotos C e D) e apresentam aparente contato ondulado.

A concentração fossilífera é amalgamada e aparentemente bioturbada. Os bioclastos presentes correspondem a conchas de gastrópodes turritelídeos e bivalves de conchas mitilóides e indistintos e seus fragmentos.

Duas seções foram levantadas, a primeira (Figura 31), e uma segunda seção, distando cerca de $100 \mathrm{~m}$ da anterior, com cerca de 30 metros de exposição. Na segunda não se observa a continuidade lateral da concentração de macroinvertebrados bentônicos. Neste perfil, esteiras algálicas ocorrem em calcarenitos com coordenadas Geográficas S 07 18' 009" / W 40³6' 463".

Dados tafonômicos da concentração constam no Anexo Vl. 


\subsubsection{Concentração em Marcolândia}

Próximo à Rodovia $\mathrm{BR}$ - 318, sentido Marcolândia-Picos, na encosta da serra do Araripe, $10 \mathrm{~km}$ após a cidade de Marcolândia, nas coordenadas UTM 0310120 / 9181428 e cota 683 metros, observam-se blocos centimétricos (15cm de comprimento e $10 \mathrm{~cm}$ de espessura) de wackstones a packstones de coloração creme a amarelada, apresentando contatos ondulados. Nestes é encontrada concentração fossilífera, apresentando grau de empacotamento de bioclastos denso a frouxo, caoticamente distribuídos na matriz sedimentar. A concentração é composta por conchas e fragmentos de bivalves (conchas mitilóides e indistintos), conchas de ostracodes desarticulados (predominando) e articulados e gastrópodes (turritelídeos e epitonídeos) (Prancha 10, Foto F). Estruturas como empilhamento e aninhamento, são observáveis.

Os dados tafonômicos da concentração constam no Anexo VI.

\subsubsection{Concentração em Santana do Cariri}

Na estrada Santana do Cariri - Nova Olinda, coordenadas geográficas $07^{\circ} 09^{\prime}$ $887^{\prime \prime} \mathrm{S} / 39^{\circ} 43^{\prime} 713^{\prime \prime} \mathrm{W}$, a $3 \mathrm{~km}$ da cidade de Santana do Cariri, afloram concentração de macroinvertebrados bentônicos, intercalando folhelhos verdes. Os depósitos ocorrem lateralmente por aproximadamente 15 metros de extensão e têm espessura de até 26 $\mathrm{cm}$. A geometria do depósito tem aspecto de camada, contatos bruscos, ondulados $e$ erosivos (Prancha 11, Fotos A, B, C e D)

A concentração apresenta grau de empacotamento de bioclastos de denso a frouxo na matriz sedimentar. Estrutura de gradação dos bioclastos é observada. As conchas fósseis constituem-se de pequenos gastrópodes (?Paraglauconia cf. lyrica) e fragmentos indistintos.

Os dados tafonômicos encontram-se no Anexo VII. 


\subsubsection{Concentração em São Gonçalo}

No Sítio Säo Gonçalo, Municipio de Santana do Cariri-CE, estratigraficamente próximo ao contato com a Formação Arajara, coordenadas geográficas S $07 / 10^{\prime} 24^{\prime \prime}$ / W $39^{\circ} 43^{\prime} 24^{\prime \prime}$, tem-se afloramento contendo três niveis com concentrações fossiliferas de macroinvertebrados bentônicos, com contatos bruscos, intercalando folhelhos verdes de até $8 \mathrm{~cm}$ de espessura.

As concentrações apresentam grau de empacotamento dos bioclastos na matriz sedimentar, de denso a frouxo. No afloramento, na base, ocorrem concentração constituída por gastrópodes turritelídeos, associados à moldes e fragmentos de bivalves (? Brachidontes sp) e ostrácodes de até $5 \mathrm{~mm}$ de diâmetro (Prancha 11, ); na porção intermediária e superior, os depósitos carbonàticos têm, como caracteristica notável, a predominância de moldes externos de conchas desarticuladas de bivalves mitilóides.

Os dados tafonômicos encontram-se no Anexo VII. 


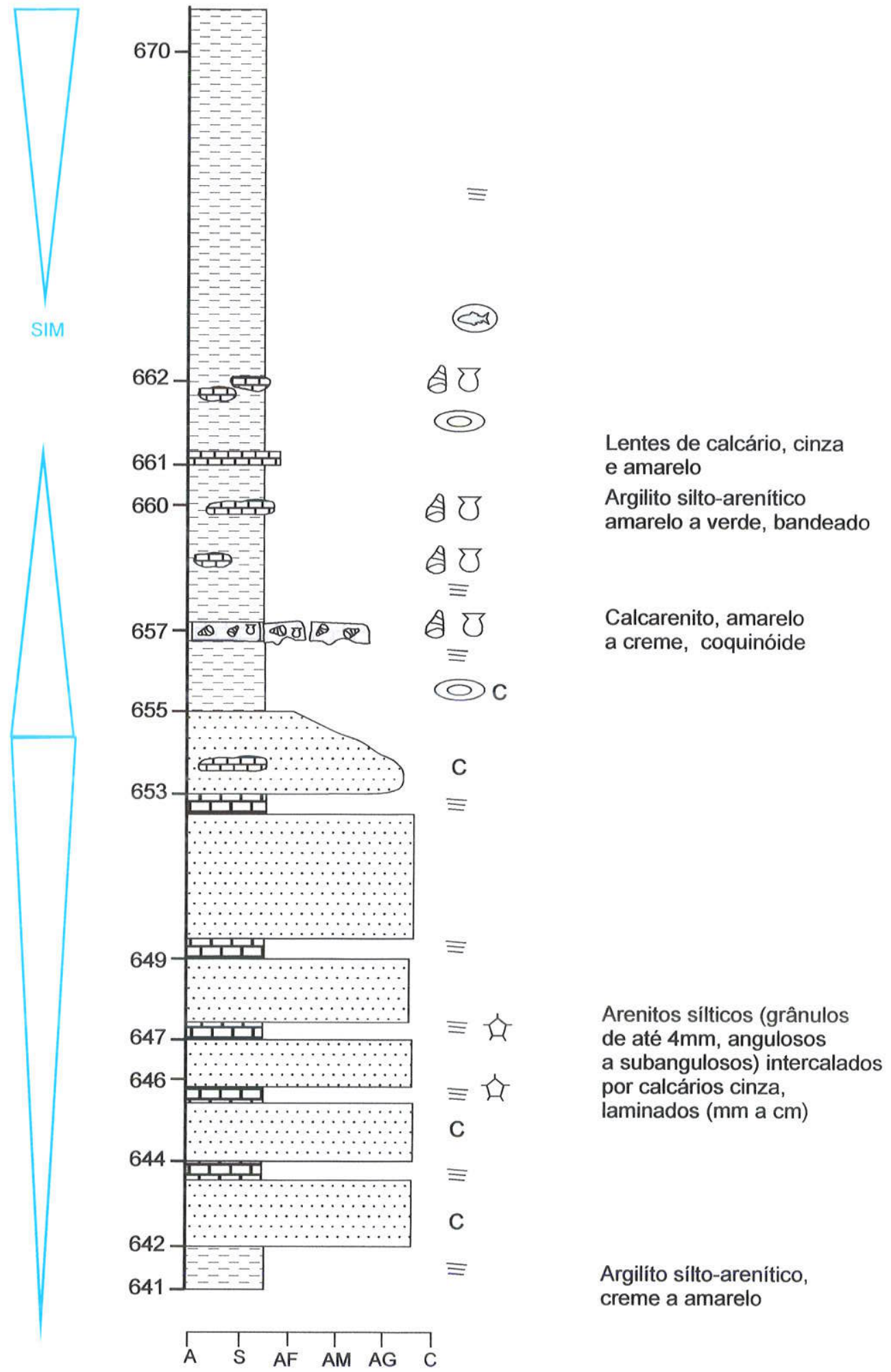

Figura 31 . Seção estratigráfica esquemática, Membro Romualdo, Formação Santana, do Sítio Caboclos, Caldeirão Grande do Piauí, Fronteiras, PI. A seção dista 8 km para NW, de Caldeirão Grande do Piauí, com início em S $07^{\circ} 17^{\prime} 58^{\prime \prime} \mathrm{W} 040^{\circ} 36^{\prime} 27,1^{\prime \prime}$. 


\subsection{Dados petrográficos}

A mineralogia das rochas carbonatadas referente aos depósitos fossiliferos, contendo as assembléias esqueléticas de macroinvertebrados bentônicos, mostrou o franco predomínio de calcita com percentagens superiores a $60 \%$, na forma de bioclastos e cimentos. Das 53 amostras/seções descritas, 13 seções foram tingidas por soluções ácidas, para identificação dos tipos de calcita (predominância de calcita não ferrosa, com pouca calcita ferrosa e raras contribuiçōes dolomíticas) e 03 amostras foram impregnadas previamente à confecção das seções petrografica. A abordagem metodológica, tendo como base critérios descritivos, permitiu a classificação dos litótipos em wackestones a packstones bioclásticos. Segue abaixo, resumidamente, as características petrográficas. Dados podem ser observados na Tabela 4 (p. 80).

Os grãos constituintes minerais não carbonáticos apresentam de modo geral uma baixa percentagem, sendo quartzo metamórfico e primário (na média com $5 \%$ a $15 \%$ ), feldspatos (microclina e plagioclásio com $2 \%$ a $5 \%$ ), micas (muscovitas e biotitas com $1 \%$ a $3 \%$ ), minerais pesados $(1 \%$ a $2 \%$ ) e opacos (1\%) (Pranchas $12,13,14$ e 15). Quartzo em poucos casos ultrapassa $20 \%$ (Jamacaru, Saco e Negros). De maneira incipiente ocorre quartzo autigênico, com processo de silicificação nas bordas de bioclastos, sendo pronunciado nas lâminas dos depósitos de Canastra e Torre (Prancha 14, Foto F). Eventualmente, ocorrem litoclastos milimétricos (Romualdo, Canastra e Torre).

Os constituintes bioclásticos apresentam, via de regra, envelope micrítico (Prancha 12, Foto A; Prancha 13, Foto B) e são representados por conchas e fragmentos de bivalves (Prancha 12, Fotos C, D e E; Prancha 13, Foto B; Prancha 14, Foto B; Prancha 15, Foto D), gastrópodes (Prancha 12, Foto B; Prancha 13, Fotos A e D; Prancha 14, Foto $F$ ) ostracodes (Prancha 12, Foto B; Prancha 13, Fotos $E$ e $F$ ), foraminíferos miliolideos (Prancha 14, Foto D), equinóides (Prancha 13, Foto A;Prancha 14, Foto C; Prancha 15, Foto A), pelóides micritizados (Prancha 14, Fotos A e B; Prancha 15, Foto C) e possíveis artrópodes (Prancha 13, Foto C; Prancha 14, Foto E).

Quanto à forma, os bioclastos apresentam fragmentos angulosos a subarredondados, com o predomínio dos primeiros. 
Características comuns são estrutura reliquiar de concha de composição aragonítica (Prancha 12, Fotos A e B) com calcita neomórfica, estrutura geopetal, shelter (Prancha 12, Foto D) e cavidade intraesqueletal (Prancha 15, Foto B).

Na matriz, predominam os cimentos micríticos e microesparíticos (Prancha 12, Foto C e D; Prancha 13, Fotos D e F; Prancha 15, Fotos C e D), preenchendo espaços intergranulares e espaços porosos-móldicos. Presentes também esparito e pseudoesparito (Prancha 12, Fotos B e E; Prancha 13, Fotos A, B e C) com ocasional zonação composicional (drusas de cristais espáticos) (Prancha 12, Fotos B, e F; Prancha 13, Foto C; Prancha 14, Foto A). A ocorrência de blocos com cristais euhedrais de calcita, preenchendo espaços entre os bioclastos, representam diagênese submarina (Prancha 12, Foto F). Franjas ou crostas de cristais calcíticos fibroradias também ocorrem, por vezes, isopacas, que englobam conchas de bivalves (Prancha 14, Foto A), conchas de ostracodes articuladas fechadas (Prancha 12, Foto B) ou os preenchem (Prancha 13, Foto F).

No processo de compactação, o adensamento (Prancha 15, Foto D) originou quebras (Prancha 13, Fotos B e C) e a interpenetração de bioclastos (Prancha 12, Foto E).

A porosidade apresenta os tipos interpartícula, intraparticula, abrigo (Prancha 15 , Foto $B$ ), veios e pequenas fraturas, de acordo com o esquema de Choquete \& Pray (1970) (Figura 22, Página 57).

Nas lâminas, a seqüência diagenética mostra ocorrência de micritização, cimentação precoce e dissolução de bioclastos; recristalização parcial e neomorfismo agradacional, mascarando cimentos reliquiáres, compactação com influências na porosidade. 
TABELA 4 - CONSTITUINTES E CARACTERISTICAS DAS SEÇ̃̃ES PETROGRÁFICAS DAS ROCHAS CARBONÁTICAS QUE CONTÉM ASSEMBLÉIAS FÓSSEIS ESQUELÉTICAS DE MACROINVERTEBRADOS BENTÓNICOS DO MEMBRO ROMUALdo, FORMAÇĂO SANTANA. MINERALOGIA: $\mathrm{CACO}_{3}$ - CARBONATO, QT QUARTZO, FE - FELDSPATOS, MI - MICAS, MP - PESADOS, OP - OPACOS; BIOCLASTOS: GA GASTRÓPODES, BI - BIVALVES, EQ - EQUINÓIDES, FO - FORAMINIFEROS, OS - OSTRACODES, AR ARTRÓPODES, PE- PELLOIDES; FORMA DOS BIOCLASTOS; AN - ANGULOSOS, SA - SUBARREDONDADOS; CIMENTOS: MI - MICRITICO, ME - MICROESPARITICO, ES - ESPARITICO, PE - PSEUDOESPARITICO; COMPACTAÇĂO: QU - QUEBRA, IN - INTERPENETRAÇÃO; POROSIDADE: MO - MÓLDICA, TE INTERPARTÍCULA, TR - INTRAPARTICULA, AB - ABRIGO, VE - VEIOS, FR - FRATURAS.

\begin{tabular}{|c|c|c|c|c|c|c|c|c|c|c|c|c|c|c|c|c|c|c|c|c|c|c|c|c|c|c|c|c|}
\hline \multirow{3}{*}{ Amostra } & \multirow{3}{*}{\begin{tabular}{|l}
$\mathrm{N}^{0}$ \\
se- \\
çõe \\
s
\end{tabular}} & \multicolumn{19}{|c|}{ constituintes } & \multicolumn{8}{|c|}{ caracteristicas } \\
\hline & & \multicolumn{6}{|c|}{ minerais } & \multicolumn{7}{|c|}{ biociastos } & \multicolumn{2}{|c|}{\begin{tabular}{|l|}
$\begin{array}{l}\text { forma } \\
\text { bioclasto } \\
\mathrm{s}\end{array}$ \\
\end{tabular}} & \multicolumn{4}{|c|}{ cimento } & \multicolumn{2}{|c|}{$\begin{array}{c}\text { compa } \\
\text { c- } \\
\text { taçâo }\end{array}$} & \multicolumn{6}{|c|}{ porosidade } \\
\hline & & $\begin{array}{c}c \\
a \\
c o \\
3\end{array}$ & $\begin{array}{c}q \\
t \\
\end{array}$ & $\begin{array}{l}f \\
e\end{array}$ & $\begin{array}{c}m \\
i\end{array}$ & $\begin{array}{l}m \\
p\end{array}$ & $\begin{array}{l}o \\
\mathrm{p}\end{array}$ & $\begin{array}{l}\mathrm{g} \\
\mathrm{a}\end{array}$ & $\begin{array}{l}b \\
i\end{array}$ & $\begin{array}{l}\mathrm{e} \\
\mathrm{q}\end{array}$ & $\begin{array}{l}1 \\
0\end{array}$ & $\begin{array}{l}0 \\
\mathrm{~s}\end{array}$ & $\begin{array}{l}a \\
r\end{array}$ & $\begin{array}{l}p \\
\mathrm{e}\end{array}$ & an & sa & $\begin{array}{c}\mathrm{m} \\
\mathrm{i}\end{array}$ & $\mathrm{m}$ & \begin{tabular}{|l|}
$e$ \\
s
\end{tabular} & $\begin{array}{l}p \\
e\end{array}$ & qu & in & $\begin{array}{c}m \\
0\end{array}$ & $\mathrm{t}$ & $\begin{array}{l}t \\
r\end{array}$ & $\begin{array}{l}a \\
b\end{array}$ & $\begin{array}{l}v \\
e\end{array}$ & fr \\
\hline $\begin{array}{c}\text { Romualdo } \\
\text { Cota } 632 \\
m\end{array}$ & 03 & $x$ & $x$ & $x$ & $x$ & $x$ & & $x$ & $x$ & & & $\mathrm{x}$ & & $x$ & $x$ & $x$ & $x$ & $x$ & $x$ & $x$ & $x$ & & $x$ & $x$ & $x \mid$ & $x$ & $x$ & $x$ \\
\hline $\begin{array}{c}\text { Romualdo } \\
\text { If } \\
\text { Cota } 627 \\
m\end{array}$ & 01 & $x$ & $x$ & & $x$ & $x$ & & $x$ & $x$ & & & $x$ & & $x$ & $x$ & $x$ & & $x$ & $x$ & $x$ & & & $x$ & $x$ & $x$ & & & \\
\hline Jamacarú & 02 & $x$ & $x$ & $x$ & $x$ & $x$ & & $x$ & $x$ & & & & & $x$ & $x$ & & & $x$ & $x$ & & $\mathrm{X}$ & & & $x$ & $x$ & & & \\
\hline $\begin{array}{c}\text { Serra } \\
\text { Mäozinha } \\
\text { I } \\
\text { Cota } 773 \\
\text { m } \\
\end{array}$ & 04 & $\mathrm{x}$ & $x$ & $x$ & $x$ & $x$ & & $x$ & $x$ & & & & & $x$ & $x$ & & & $\mathrm{x}$ & $x$ & & & $x$ & $x$ & $x$ & $x$ & $x$ & $x$ & \\
\hline $\begin{array}{c}\text { Serra } \\
\text { Mãozinha } \\
\text { ॥l } \\
\text { Cota } 758 \\
m \\
m\end{array}$ & 02 & $x$ & $x$ & $x$ & $x$ & & & $x$ & $x$ & $x$ & & $x$ & & & $x$ & & & $x$ & $x$ & $x$ & & & $x$ & & $x$ & & & \\
\hline Saco & 11 & $x$ & $x$ & $x$ & $x$ & $x$ & $x$ & $x$ & $x$ & $x$ & $x$ & $x$ & & $x$ & $x$ & $\mathrm{x}$ & $x$ & $x$ & $x$ & $x$ & $x$ & $x$ & $x$ & $x$ & $x$ & $x$ & & $x$ \\
\hline Jatobá & 03 & $x$ & $x$ & $x$ & $x$ & $x$ & $x$ & $x$ & $x$ & & & & & $x$ & $x$ & $x$ & & $x$ & $x$ & $x$ & $x$ & $x$ & $x$ & $x$ & $\mathrm{x}$ & & & $x$ \\
\hline $\begin{array}{c}\text { Sobradinh } \\
0\end{array}$ & 03 & $x$ & $x$ & & & & & $x$ & $x$ & $x$ & & $\mathrm{x}$ & & $x$ & & & & $x$ & $x$ & $x$ & & & $x$ & & $x$ & & & $x$ \\
\hline Engenho & 05 & $x$ & $x$ & $x \mid$ & $x$ & $x$ & & $x$ & $\mathrm{x}$ & $x$ & & & & & $x$ & $x$ & $x$ & $x$ & & $x$ & $x$ & $x$ & $x$ & $x$ & $x$ & & $x$ & $x$ \\
\hline Negros & 04 & $x$ & $x$ & $x$ & $x$ & $x$ & $x$ & $x$ & $x$ & $x$ & & $x$ & & & $x$ & $x$ & & $x$ & $x$ & $x$ & $x$ & $x$ & $x$ & $x$ & $x$ & & & \\
\hline Canastra I & 03 & $x$ & $x$ & $x$ & & $x$ & & $x$ & $x$ & $x$ & $x$ & $x$ & $x$ & & $x$ & $x$ & & $x$ & $x$ & $x$ & $x$ & & $x$ & $x$ & $x$ & & $\times$ & $x$ \\
\hline $\begin{array}{c}\text { Canastra } \\
\vdots\end{array}$ & 02 & $x$ & $x$ & $x$ & & $x$ & & $x$ & $x$ & $x$ & $\mathrm{x}$ & $\mathrm{x}$ & $x$ & & $x$ & & & $x$ & $x$ & $x$ & $x$ & & $x$ & $x$ & $x$ & & $x$ & $x$ \\
\hline Torre & 01 & $x$ & $x$ & $x$ & $x$ & $x$ & $x$ & $x$ & $x$ & $x$ & & & $x$ & & $x$ & $x$ & & $x$ & $x$ & $x$ & $x$ & & $x$ & $x$ & & & $x$ & $x$ \\
\hline Caboclos & 03 & $x$ & $x$ & $x$ & $x$ & & $x$ & $x$ & $x$ & $x$ & & $x$ & $x$ & & $x$ & $x$ & $\mathrm{x}$ & $x$ & $x$ & $x$ & $x$ & $x$ & $x$ & $x$ & $x$ & $\begin{array}{lll}x & \\
\end{array}$ & $x$ & $x$ \\
\hline $\begin{array}{c}\text { Marcolând } \\
\text { ia }\end{array}$ & 01 & $x$ & $x$ & & $x$ & $x$ & & $x$ & $x$ & $x$ & & $x$ & $x$ & & & & & $x$ & $x$ & & $x$ & $x$ & $x$ & $x$ & & & $x$ & $x$ \\
\hline $\begin{array}{c}\text { São } \\
\text { Gonçalo }\end{array}$ & 02 & $x$ & $x$ & & & & & $x$ & $x$ & $x$ & & $x$ & & & $x$ & $x$ & $x$ & $x$ & $x$ & & $x$ & $x$ & $x$ & $x$ & $x$ & $x$ & & \\
\hline $\begin{array}{c}\text { Santana } \\
\text { Cariri }\end{array}$ & 03 & $x$ & $x$ & & & & & $\mathrm{x}$ & $x$ & & $x$ & $x$ & & & $x$ & & $x$ & $x$ & $x$ & & & & $x$ & $x$ & $x$ & & & \\
\hline
\end{tabular}




\subsection{Dados palinológicos}

Análise de palinomorfos fósseis foi realizada em algumas amostras de assembléias fossilíferas de macroinvertebrados (Serra da Mãozinha e Saco). Nos depósitos do Sítio Saco, na porção leste da bacia, a associação é rica em palinomorfos continentais, com destaque para Classopolis (Tabela 5, p. 81). Nas amostras da Serra da Mãozinha, na porção nordeste, ocorre uma associação com destaque para dinoflagelados do gênero Subtilisphaera, que supera os demais microfósseis (polens e esporos) (Tabela 6, p. 81).

TABELA 5. ASSEMBLÉIA DE PALINOMORFOS DE SITIO SACO

\begin{tabular}{|l|c|c|}
\hline Táxon palinológico & Amostra ponto 2 & Amostra ponto 3 \\
\hline Araucariacites $(\mathrm{P})$ & & 1 \\
\hline Arcellites $(\mathrm{E})$ & & 2 \\
\hline Cicatricosisporites $(\mathrm{E})$ & & 4 \\
\hline Cicatricosisporites microstriatus $(\mathrm{E})$ & & 2 \\
\hline Classopollis $(\mathrm{P})$ & 1 & 55 \\
\hline Inaperturopollenites $(\mathrm{E})$ & & 8 \\
\hline Klukisporites $(\mathrm{E})$ & & 1 \\
\hline Pilosisporites $(\mathrm{E})$ & & 2 \\
\hline Schizosporis ? $(\mathrm{X})$ & & 1 \\
\hline Trilete liso $(\mathrm{E})$ & & 5 \\
\hline Trilete ornamentado $(\mathrm{E})$ & & 1 \\
\hline P-pólens, $E$-esporos, $\mathrm{D}$-- dinoflagelados- & & \\
\hline
\end{tabular}

TABELA 6. ASSEMBLÉIA DE PALINOMORFOS DE SERRA DA MÃOZINHA

\begin{tabular}{|c|c|c|c|c|}
\hline Táxon palinológico & $\begin{array}{c}\text { Amostra } \\
\text { Cota } 775 \mathrm{~m} \text { base }\end{array}$ & $\begin{array}{c}\text { Amostra } \\
\text { Cota } 775 \mathrm{~m} \text { meio }\end{array}$ & $\begin{array}{l}\text { Amostra } \\
\text { Cota } 775 \mathrm{~m} \text { topo }\end{array}$ & $\begin{array}{c}\text { Amostra } \\
\text { Cota } 776 \mathrm{~m}\end{array}$ \\
\hline Araucariacites $(\mathrm{P})$ & & & & 1 \\
\hline Callialasporites $(\mathrm{P})$ & 1 & & & \\
\hline Cicatricosisporites (E) & 5 & & 1 & \\
\hline Cicatricosisporites microstriatus (E) & 1 & & & \\
\hline Cicatricosisporites venustus (E) & 1 & & & 1 \\
\hline Classopollis (P) & & 13 & 7 & \\
\hline Cutícula de estômatos & 5 & 1 & 10 & 15 \\
\hline Densoisporites (E) & 1 & & & 1 \\
\hline Gnetaceaepollinites (P) & 2 & & 2 & \\
\hline Inaperturopollenites (E) & 3 & 6 & 1 & \\
\hline Klukisporites (E) & & 1 & & \\
\hline Pilosisporites (E) & 10 & & & \\
\hline Plicatella (E) & 1 & & & \\
\hline Substifisphaera (D) & 17 & 60 & 40 & 70 \\
\hline Trilete liso (E) & 1 & & & \\
\hline Trilete ornamentado (E) & 3 & & & \\
\hline
\end{tabular}




\section{Discussão}

A investigação dessa pesquisa tem como foco principal o estudo tafonômico dos depósitos carbonáticos que contêm as concentrações fossiliferas de macroinvertebrados bentônicos, que ocorrem no Membro Romualdo, Albiano, da Formação Santana, Bacia do Araripe, NE do Brasil. Desta forma, a seguir serão abordados os resultados tafonômicos, petrográficos, sedimentológicos, estratigráficos e paleoecológicos obtidos durante esse projeto, em associação com as informações geológicas e paleontológicas disponiveis, para a seção Santana, da Bacia do Araripe.

Os resultados proporcionam a interpretação da gênese das assembléias fósseis, o reconhecimento de suas asssinaturas e classsificação, que em conjunto com o arcabouço estratigráfico, possibilitam a visualização da distribuição vertical dos padrões de preservação.

\subsection{Tafonomia}

A análise tafonômica dos elementos esqueléticos permitiu a interpretação dos parâmetros abióticos e bióticos do antigo ambiente (Tabela 2, p. 39). Isto é corroborado pelas feições observadas (sedimentológicas, bioestratinômicas, estratigráficas, paleoecológicas e diagenéticas) dos bioclastos e dos depósitos (cap. 6 e anexos) estudados.

A presença de agentes bióticos é notada com icnofósseis e moldes fósseis de conchas de bivalves escavadores rasos, articuladas fechadas, em posição de vida, em um horizonte (unidade micro-estratigráfica) com acumulação de conchas autóctones, Anexo $\mathrm{V}$, em uma concentração internamente complexa, na porção sudeste da bacia.

Nas concentrações fossiliferas, em sua quase totalidade, não foram observadas os sinais de corrosão e incrustação. A inobservância destes caracteres pode sugerir que os bioclastos não permaneceram, por um tempo prolongado, na zona tafonômicamente ativa (TAZ), após sua morte. Observa-se que algumas conchas de 
gastrópodes naticídeos foram ainda encontradas, em concentrações, com padrão de coloração preservado (SALES ET AL., 2002).

A fragmentação dos bioclastos é comum estudadas, apresentando várias classes de tamanho e muitas vezes angulosidade. Estes fragmentos angulosos presentes em todas as classes de tamanho e formas, sem abrasão ao longo de suas margens (Prancha 3, Fotos E e F; Prancha 8, Foto D), sugerem processos de quebra de conchas por predação de elementos durofagos. A grande quantidade de organismos durofagos (peixes teleósteos, répteis e crustáceos) do Membro Romualdo, principalmente picnodontes, foram encontrados em associação a concentrações, na região de Jardim, CE, porção sudeste da bacia (SIMÕES \& SALES, 2003). Nos depósitos analisados, os fragmentos arredondados poderiam ter sido angulosos, gerados inicialmente por predação. Embora esses fragmentos possam ter origem por predação, aqui, apenas se faz referência aos fragmentos angulosos, apesar de não se observar, nas conchas e fragmentos do Araripe, incrustação ou marcas de predação, do tipo perfuração. A recristaliação das conchas pode ser um fator diagenético importante, que dificulta e oblitera a visualiação de tais feições.

Trabalhos dessa natureza, relacionando fragmentação com angulosidade a predação de organismos durofagos, foram realizados em concentraçōes de conchas no Japão e comprovaram a influência de predadores na origem dos fragmentos maiores e angulosos de concentrações fósseis de conchas depositadas por tempestades (OJ) ET AL., 2003). Estes autores comprovaram ainda que, abrasão e fragmentação por agentes hidrodinâmicos, testadas artificialmente em laboratório por tamboreamento (conchas de bivalves e gastrópodes de zonas de intermaré a submaré), não geraram fragmentos com margens angulosas.

Assumindo que sobre as conchas operaram processos sedimentologicamente similares, a fragmentação pode ter sido seletiva, mostrando uma predileção dos elementos durofafos, visto que há ocorrências de conchas inteiras, principalmente de gastrópodes turritelideos e naticídeos e pequenos bivalves corbula $\mathrm{sp}$. e braquidontes (Prancha 2, Foto D; Prancha 3, Foto A; Prancha 6, Foto D e F; Prancha 7, Foto G). 
Nas concentrações, têm-se ocorrências de conchas de moluscos (esqueletos também inteiros, univalves e bivalves) e carapaças de equinóides (esqueletos multielemento). (Prancha 6, Foto D; Prancha 8, Foto B; Prancha 9, Foto A). Esse estilo de preservação, demonstra que as algumas conchas não eram fragmentadas, mesmo em águas agitadas por eventos tempestíticos.

As concentrações densamente empacotadas e complexas, constituem coquinas. No caso das concentrações coquinóides do Membro Romualdo, a pouca diversidade de espécies parece resultar de aspectos bióticos e abióticos, em virtude do paleoambiente restrito lagunar, cuja, a diversidade de espécie é em geral, menor do que nos ambientes francamente marinhos. A presença e, por vezes, a predominância de conchas fósseis de gastrópodes Turritellidae (Craginia araripensis Beurlen, Turitella n.sp., Gymnentone romualdoi Beurlen) e de pequenas conchas de bivalves não facilmente determináveis (? Corbula) (MABESSONE \& TINOCO, 1973), que superam em muito, as ocorrências dos demais taxas (Tabela 1, 34), sugere em termos ecológicos, que aqueles organismos predominavam na área da bacia.

As coquinas formadas por conchas de moluscos bivalves e gastrópodes, tafonomicamente podem ser classificadas como "Estilo Moderno" (sensu, KIDWELL, 1990), isso é: formam um corpo tridimensional, de geometria, em geral lenticular, amalgamadas, com bioclastos densamente empacotados, representando tempestitos proximais (Sítio Romualdo, Prancha 3, Foto D). Seu registro ocorre em função da disponibilidade de bioclastos representados por conchas, aragoníticas e calcíticas, em condições de águas rasas, afetadas por tempestades, que marcaram o final da sedimentação da porção superior da Formação Santana.

Essas coquinas amalgamadas correspondem a concentrações que envolvem um tempo "Time averaging", da ordem de centenas a milhares de anos "thousand year multiple-event concentration" (sensu, FLESSA ET AL., 1993; FLESSA \& KOWALEWSKY, 1994; MELDAHL ET AL., 1997; KOWALEWISKY AT AL., 1998), onde os intervalos de tempo, razoavelmente distantes, são um fator de maior influência temporal, que os mecanismos ecológicos. 


\subsection{Petrografia e palinologia}

Os carbonatos foram classificados em wackestones a packestones bioclásticos, comumente cimentados por calcita microesparítica, seguida pelos tipos esparítica e pseudoesparítica (Prancha 15, Fotos A, B, C e D), não ferrosa, seguida por ferro-calcita e raras contribuições dolomíticas.

O conteúdo fóssil revelou em associação aos moluscos (bivalves e gastrópodes) fragmentos de equinóides, foraminiferos miliolideos, ostracodes e possiveis artrópodes. Os depósitos carbonáticos fossiliferos mostram um caráter detrital, principalmente em função do conteúdo das acumulações esqueléticas, recristalização, incluindo os restos orgânicos e dissolução de praticamente todos os pequenos fósseis, ficando presentes os maiores.

O material bioclástico se encontra substituído por calcita esparítica a pseudoesparitica (drusas de calcita) e suas cavidades preenchidas por material micrítico e esparítico. Conchas fósseis neoformadas apresentam ainda relíquias de sua estrutura original (Prancha 12, Foto $C$, Prancha 15, Foto B). A substituição por calcita espática e a dissolução das conchas (Prancha 11, Foto E), sugerem fases de oxidação e redução durante a diagênese. As formas dos fragmentos variando de angulosos a subarredondados, vistas nas lâminas, mostram a maior ou menor influência dos fatores físicos (ex. transporte) e da micritização precoce, que influênciou na conservação das formas das conchas e fragmentos a partir da época de deposição, com relação à dissolução e quebra por compactação.

A geração de cimentos isópacos (Prancha 15, Foto B), indicou precipitação nas zonas freáticas, relacionadas à cimentação de zonas de submarés a intermaré-baixa. A cimentação de menisco vista somente em algumas seções, foi relacionada à precipitação de zona vadosa, de intermaré-alta a supramaré e situações meteóricas de subsuperfície rasa (sensu, TUCKER 2001).

Comparando as lâminas petrográficas dos depósitos com conchas fósseis (wackestones a packstones), com conchas fósseis ocorrentes nas concreções carbonáticas fossiliferas, contendo ictiólitos (wackestones a packstones, VIANA, 1999), as histórias diagenéticas são semelhantes, com precipitação de calcita microcristalina, 
seguida de crescimento e incipiente dolomitização. As ocorrências estratigraficamente próximas (Figuras 24, 26, 27, 29 e 30) e seus cimentos isópacos, demonstram a influência marinha na diagênese dos fósseis. Wilby (1993) também identificou, nas concreções com os peixes, um primeiro nível externo de calcita não ferrosa, fibrosa, isopaca $(<1 \mathrm{~mm})$, ocorrendo em todos os tecidos moles fossilizados. Nos ictiólitos, pequenos bivalves, microgastrópodes e gastrópodes turritelídeos, já ocorrem dispersos e junto àqueles (VIANA, 1999, p. 92), vistos nas seções de Romualdo, Serra da Mãozinha (Prancha 5, Foto D), Sobradinho, Jatobá e Caboclos.

A saturação por líquidos densos, nas amostras, permitiu a comparação das porosidades pré e pós-confecção das seções delgadas, com os tipos móldica, intrapartícula, interpartícula, veios e pequenas fraturas, segundo o esquema de Choquete \& Pray (1970) (Figura 22, p. 57).

Por sua vêz, as análises palinológicas das amostras de Serra da Mãozinha mostraram uma associação com a ocorrência de alta quantidade de dinoflagelados do gênero Subtilisphaera (Tabela 6, p. 81), sugerindo a ocorrência de blooms (florações fitoplanctônicas), ocorridos em ambiente costeiro mixoalino, possivelmente em mar restrito. Esta influência marinha na Formação Santana também foi notada com a presença de dinoflagelados, verificada por Arai \& Coimbra (1990), em amostras do poço 2-A-P1-CE, por Viana (1999), na Mina Pedra Branca, em Santana do Cariri e ratificado por Coimbra et al. (2002).

O gênero de dinoflagelados Substilisphaera, ocorrente no Cretáceo nas bacias da costa e interiores do Nordeste do Brasil (São Luis, Ceará, Potiguar, Araripe), representam a Ecozona Subtilisphaera, com uma grande diferenciação geográfica e, também no noroeste da África (bacias do Senegal e Marocan), sugerindo que seja característica do Atlântico Tropical Norte (ARAI ET AL., 1994).

Na região de Porteiras, a associação polínica mostra-se mais característica de ambiente continental $e$, dentre os elementos polínicos, destacada quantidade de Classopollis (Tabela 5, p. 81). Os vegetais de onde provêm esses pólens, de acordo com a literatura, habitavam ambientes de baixios litorâneos, com proximidade de linha de costa de clima árido, corroborando com as idéias de Arai \& Coimbra (2001). 


\subsection{Ciclos sedimentares}

Um padrão de sedimentação cíclica é documentado e aparentemente, reconhecido por Assine (1990), quando, após o periodo erosivo Neocomiano SuperiorAptiano Inferior (Figura 12, p. 31), ocorreu o extravasamento dos limites da bacia com a deposição dos sedimentos da seqüência pós-rifte (PONTE, 1994), com incipiente tectonismo com predomínio de subsidência termal (ASSINE, 1990) (Figura, 32, p. 89).

Nas seções sedimentares do Membro Romualdo, da Formação Santana, Isto é notado a partir das seções colunares levantadas e nos perfis de poços (Figura 33, p. 90). Os ciclos podem ser interpretados como ciclos de aprofundamento e raseamento. As fases de aprofundamento são representadas por espessuras significativas crescentes na direção leste da bacia, com proporções menores para a porção oeste (Pernambuco e Piaui) (Figuras 24, 25, 26, 27, 29, 30 e 31, p. 62, 63, 66, 67, 69, 72 e 76).

Quando feitas às comparações e correlações das seções colunares obtidas durante esse projeto, visualiza-se, ciclos de $3^{a}$ ordem, com distribuição vertical das concentrações fossiliferas, contendo os macroinvertebrados bentônicos (figura 33, p. 90). Para a sucessão Santana, de acordo com a literatura especializada, o intervalo, no qual são encontradas as concreções fossiliferas, contendo principalmente os ictiólitos (peixes fósseis), no Membro Romualdo, composto por espessa camada de folhelho, corresponde à superficie de inundação, correspondendo a porção superior de Trato de Sistema transgressivo (Viana 1999). Nesse intervalo também se encontram posicionadas, as concentrações de macroinvertebrados fossiliferos (Figura 33, p. 90).

A seção condensada onde se insere esse nível de ictiólitos é variável quanto ao seu desenvolvimento, representada por pacote de sedimentos espessos na porção leste da bacia (seções de Jatobá, 737-741m. Figura 29, p. 68) e Sobradinho (749$758 \mathrm{~m}$, Figura 30, p. 72). As menores espessuras e expressão sedimentares dos ciclos podem ser explicadas pelo grau de mudança relativa do nível de base e também dependem da profundidade do substrato ao final das fases de aprofundamento e raseamento. Fato ressaltado pela seqüência sedimentar do Membro Romualdo, na porção oeste da bacia, que apresenta pouca espessura, como observado por Dantas \& 
Lopes (1996), Martill (1993) e Willb (1993), em virtude da proximidade e ondulações do embasamento cristalino (Plataforma de Araripina, Figuras 3 e 4, p. 10 e 12). Na subbacia de Cariri (Figura 4, p. 12), pela proximidade com os altos do embasamento cristalino (Alto de Dom Leme) (Figura 3 e 4, p. 10 e 12). Esse fator também influenciou na espessura dos ciclos sedimentares, como o perfil da Mina Pedra Branca, na região de Nova Olinda (Figura 34, p. 91), com a predominância e espessamento de ciclos de raseamento.

No Albiano, na Bacia do Araripe, os eventos transgressivos foram os responsáveis diretos pela entrada da fauna de peixes marinhos em grande quantidade (Viana 1999), que correspondem ao registro de ictiólitos fossilizados, encontrados nas concreções carbonáticas. Somado a essa, as informações paleoecológicas da sucessão sedimentar da Formação Santana, como: salinidade, profundidade das águas, oxigenação das águas do fundo, podem dar melhores indícios dos eventos transgressivos, na sucessão.

Aparentemente o aumento de peixes predadores durófagos, aplicou uma pressão e predação considerável no nivel de base da comunidade, incluindo gastrópodes e bivalves, ou seja, macroinvertebrados bentônicos, podendo ser um fenômeno associado ao grande evento da revolução marinha Mesozóica (VERMEIJ, 1977). O tempo preciso desse incremento é difícil de estipular. Porém, a ação de ondas, em conjunto com a ação de predadores durófagos no Araripe, foram os principais responsáveis pela produção de fragmentos de conchas angulares.

A presença de elementos estenohalinos (equinóides), pode ser indicador de maior influencia de condições marinhas, típicas de fase final transgressiva ou começo de depósitos de mar alto, quando ocorrem as melhores possibilidades de reconhecimento na seqüência estratigráfica, de superfícies que atuem como bons marcadores. $O$ aparecimento dos organismos marinhos (vertebrados e invertebrados) são indicativos de incursão marinha, associada com evento de máxima inundação. 


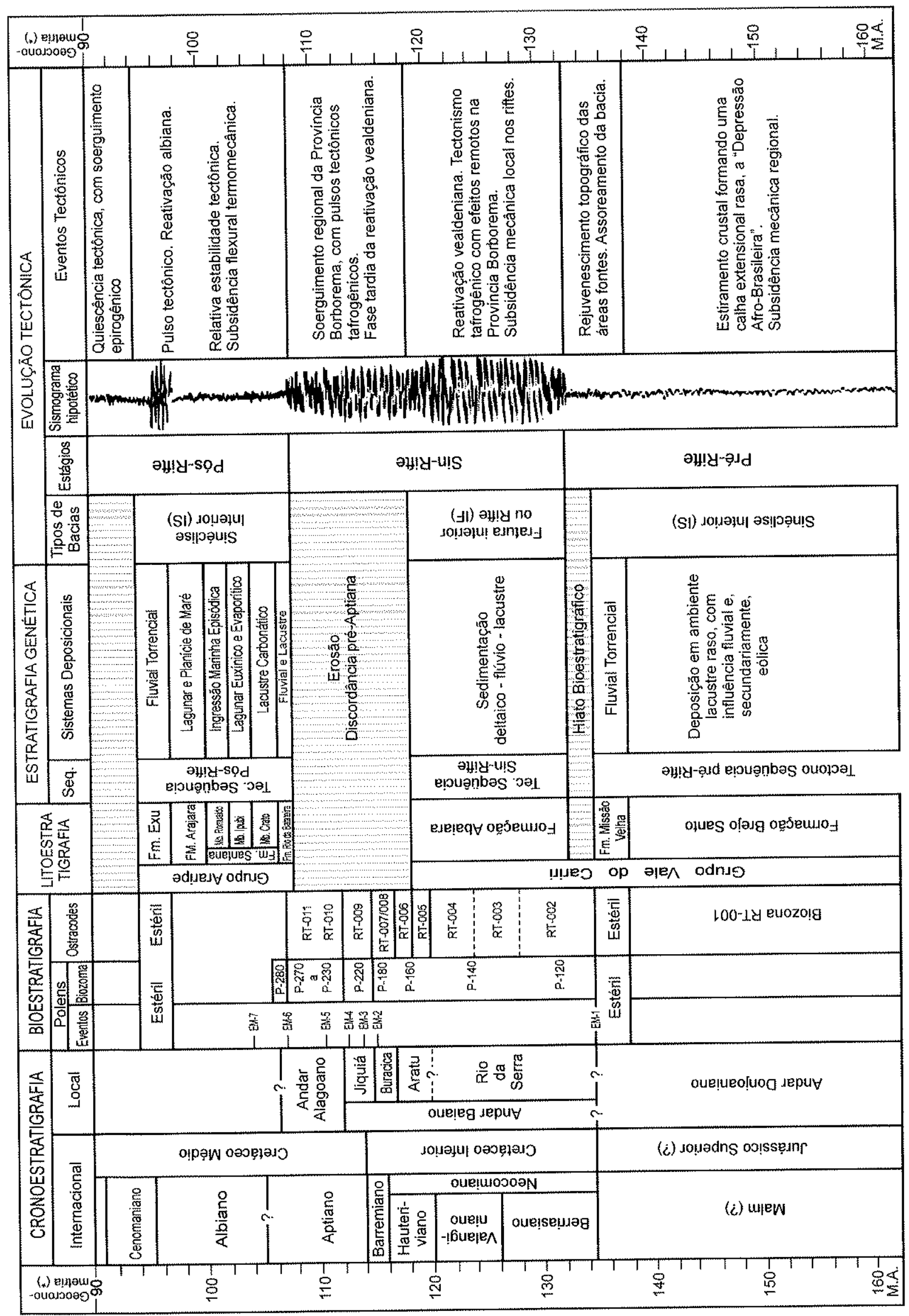

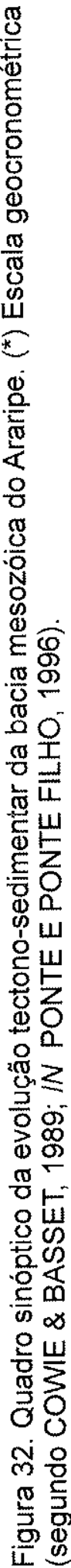




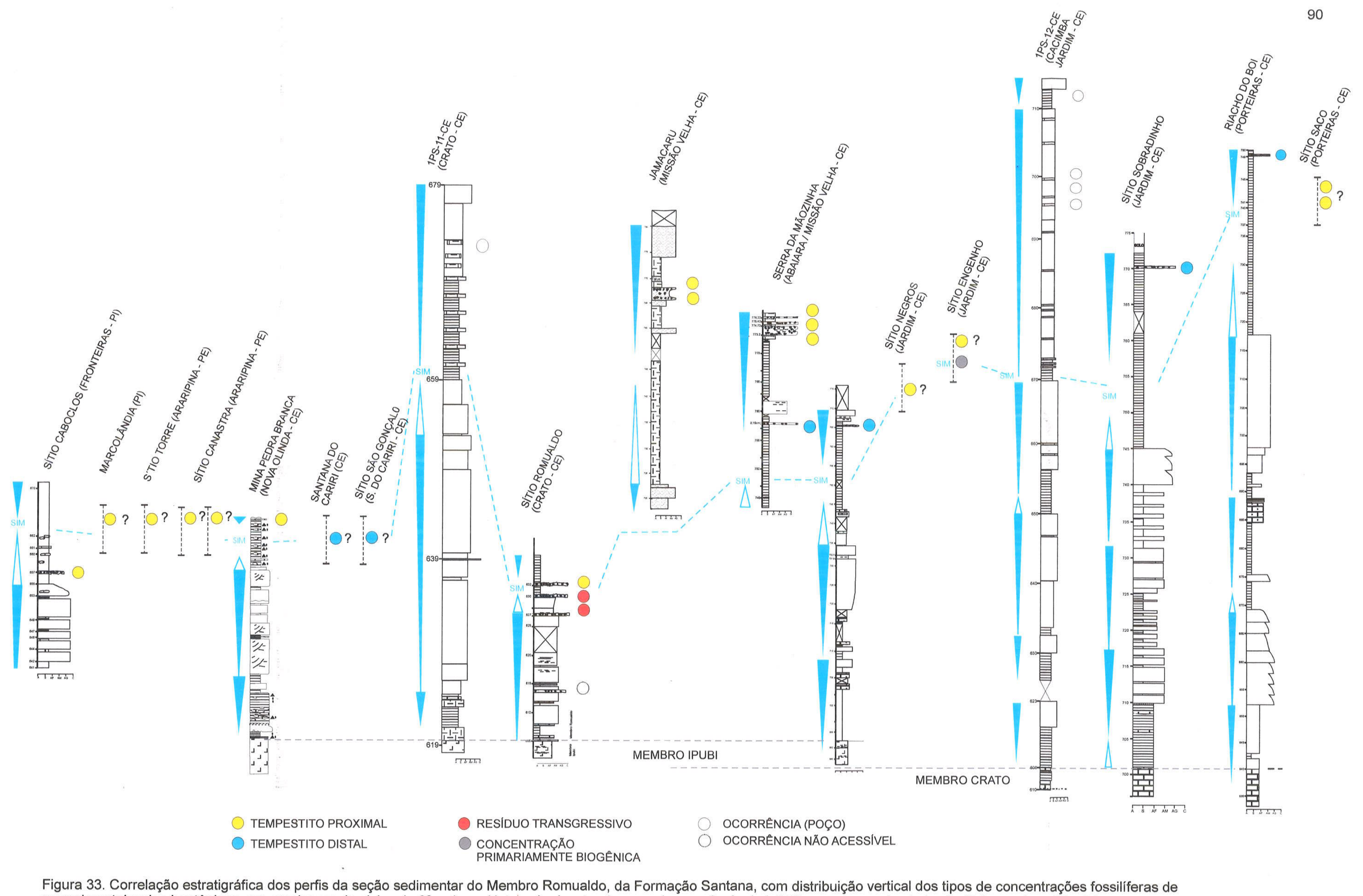

Figura 33. Correlação estratigráfica dos perfis da seção sedimentar do Membro Romualdo, da Formação Santana, com distribuição vertical dos tipos de concentrações fossiliferas de macroinvertebrados bentônicos, em arcabouço de ciclos de $3^{\mathrm{a}}$ ordem. Notar o horizonte síncrono de ocorrência de ictiólitos, ao longo da da bacia (linha azul pontilhada). 


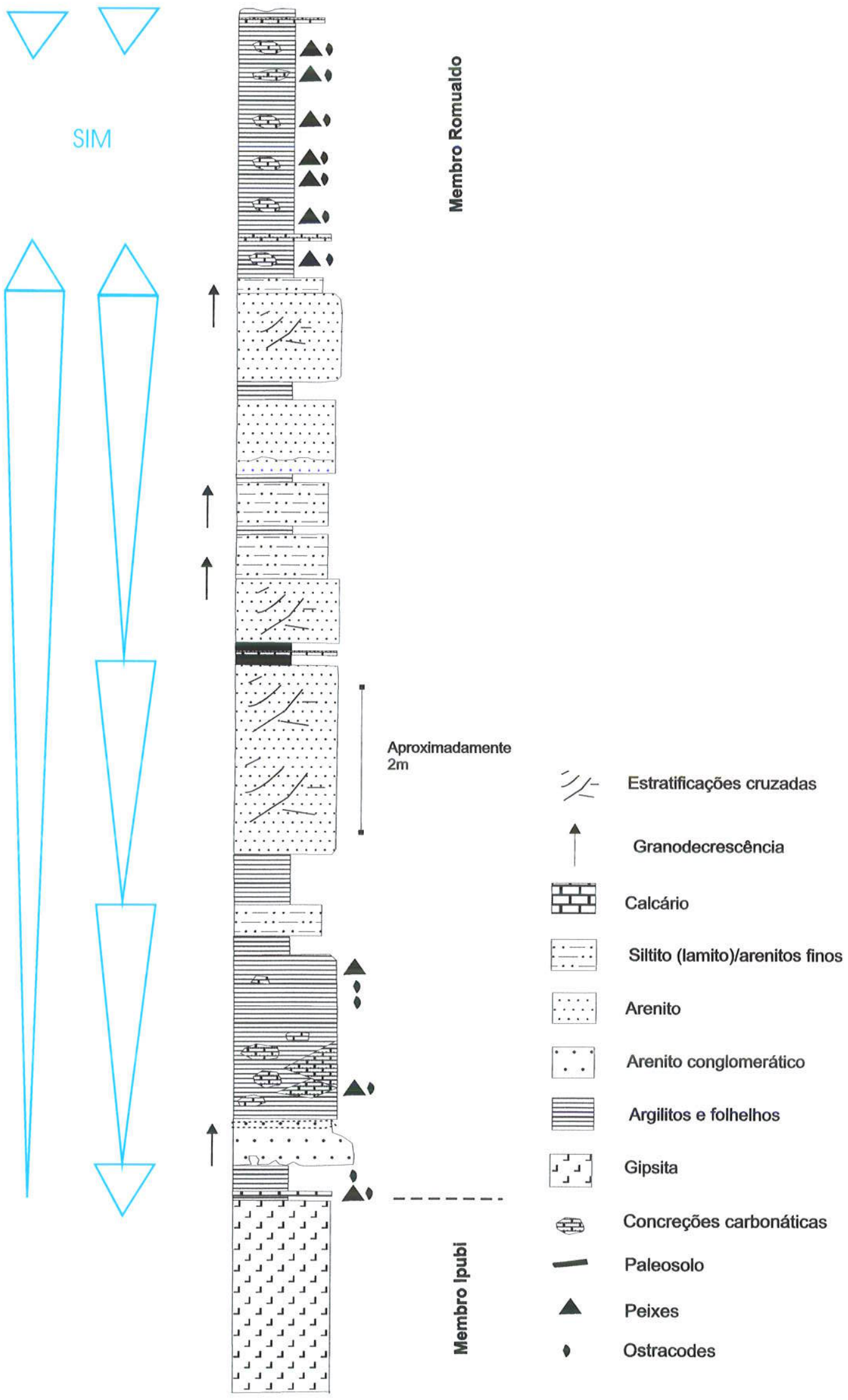

Figura 34. Seção simplificada do perfil litológico da Mina Pedra Branca, Nova Olinda, CE (MARTILL, 1993). Notar no topo, nível pouco espesso de calcarenito, onde ocorrem as concentrações de macrofósseis bentônicos. 


\subsection{Determinação dos tipos de concentrações}

Nas margens rasas de uma laguna, sujeita à tempestades, onde o nível do mar subia e invadia a zona costeira, provocando a erosão pela ação das ondas e posterior deposição pelas correntes geradas (fluxos tempestíticos), carbonatos com acumulações esqueléticas de moluscos, formando concentrações, foram depositados em zonas de intermaré a supramaré, apresentando, predominantemente, uma mistura temporal representativa de assembléias parautóctones.

Os principais atributos tafonômicos observados foram as feições bioestratinômicas; as feições sedimentológicas; as feições estratigráficas dos depósitos, as feições paleoecológicas e as feições diagenéticas dos bioclastos (Tabela 2, p. 39).

Feições como abrasão, incrustação e ataque de perfuradores não foram encontradas no material estudado. Esse fato, pode resultar, ao menos em parte, do tipo de preservação e recristalização apresentada por muitos bioclastos.

Diferentes tipos de concentrações fossilíferas foram identificadas, em relação a sua gênese, pelas características tafonômicas. A distribuição das concentrações reflete a variação topográfica da área, influênciada pelos parâmetros ambientais do meio, que refletem, de modo geral, a intensidade dos fluxos de tempestades e padrões de sedimentação.

A análise tafonômica mostrou uma origem complexa para as concentrações coquinóides. Segundo Fürsich \& Oschmann (1993), isto ocorre em virtude das concentrações serem raramente particulares a um tipo de ambiente. Entretanto, os processos que as marcam (esses) são mais comuns em alguns ambientes do que em outros, demostrando a natureza complexa e a origem de algumas concentrações (Figura 19, p. 49). A heterogeneidade dos bioclastos pode ser entendida como um indicador de mistura temporal "Time Averaging". Assim, na análise tafonômica das concentrações fossilíferas de macroinvertebrados bentônicos, uma classificação genética é mais apropriada do que uma classificação puramente descritiva.

Fundamentado nos estudos de Fürsich \& Oschmann (1993), as feições das concentrações fossiliferas exibem uma distribuição característica (de maneira semiquantitativa e em parte generalizada), ao longo de um gradiente de águas rasas e 
profundas (Figura 19, p. 49). Logicamente, o grau de sedimentação e o tempo envolvido têm grande influência sobre tais assinaturas tafonômicas.

Dessa forma, as concentrações foram classsificadas como tendo gênese relacionada a tempestitos proximais, tempestitos distais, assembléia autóctone (primariamente biogênica) e resíduos transgressivos. Os depósitos foram identificados ao longo dos ciclos de sedimentação, posicionados na porção superior de Tratos de Sistemas Transgressivos e/ou tratos de sistemas de mar alto.

Conforme demonstrado nas seções (Figuras 24, 25, 26, 27, 28, 29, 30, 31, páginas $62,63,66,67,68,69,72,76$ ), alguns dos fatores são restritos a ambientes bem definidos, por exemplo, concentração primariamente biogênica, com assembléia de organismos autóctones, é formada abaixo do nível de base de ondas de tempestade e posicionada, no intervalo de seções condensadas, possivelmente próximas a superfícies de inundação. As concentrações primariamente biogênicas dependem da produtividade orgânica, que deve ser alta, porém em virtude da ocorrência de outros processos concentradores, como tempestades e correntes (FÜRSICH \& OSCHMANN, 1993), essas concentrações são comuns em ambientes transicionais (lagunas) e porções medianas de plataformas, mas não restritos a estes. Súbitos soterramentos de populações por sedimentação induzida por tempestades podem, por exemplo, preservar concentrações primariamente biogênicas, mesmo em ambiente relativamente energéticos (FÜRSICH \& OSCHMANN, 1993).

Os tempestitos podem ocorrer ao longo de um amplo gradiente porém os produtos resultantes, em geral, ocupam uma maior amplitude marcada ao longo do gradiente batimétrico (Figura 19, p. 49), em virtude de processos diferentes atuarem em um mesmo ambiente, podendo anular um ao outro. Por exemplo, depósitos gerados por tempestitos proximais e distais têm ocorrências presumidas em entre o nível de base de ondas de bom tempo e o nível de base das ondas de tempestades. Fürsich \& Oschmann (1993) ressaltam que não é muito clara a diferenciação entre tempestitos proximais e tempestitos distais, visto que ambos são frutos de correntes e fluxos de tempestades.

Já as concentrações que representam resíduos transgressivos são caracterizadas por representarem um tempo considerável e uma multiplicidade de retrabalhamentos 
por vários processos, vindo a apresentar uma considerável mistura temporal. Estas concentrações podem eventualmente, gradar para concentrações condensadas, se a bacia se torna faminta e, portanto, o tempo em que os elementos esqueléticos são expostos aos processos tafonômicos, tem maior importância, aumentando então o grau de mistura temporal.

\subsubsection{Concentrações geradas por tempestitos proximais}

As concentrações geradas por tempestitos proximais apresentam assinatura tafonômica e biotrama indicativa de bioclastos transportados. Os tempestitos proximais são politípicos, formados por conchas de bivalves, gastrópodes e, eventualmente, equinóides e seus fragmentos. Em seção, os bioclastos mostram distribuição caótica na matriz sedimentar, baixa seleção com bioclastos, apresentando grau de empacotamento de denso a frouxo, com proporção volumétrica entre $15 \%$ e $70 \%$. As espessuras podem ser decimétricas até centimétricas. Em planta, observa-se que a distribuição das orientações de direções de bioclastos é polimodal (Romualdo, Prancha 3 , Foto $A)$.

As concentrações podem ser também amalgamadas e internamente complexas, com influência de eventos episódicos energéticos, relacionados às tempestades, como observado no Sítio Romualdo (cota 332, Figura 24, p. 62, Prancha 3, Fotos D), onde exibem espessuras centimétricas e contatos internos bruscos (Prancha 3, Foto E). As variações de espessura das unidades microestratigráficas (Prancha 3, Fotos C, F e E) ocorrem principalmente em função da variação das condições hidrodinâmicas (sensu, KIDWELL ET AL., 1986).

Outro exemplo de concentração relacionada à tempestitos proximais, formada por conchas de moluscos fósseis, ocorre em Canastra (SALES ET AL., 2003b), (Prancha 8, Foto A).

Os tempestitos proximais podem apresentar, em sua assinatura, um percentual de conchas de bivalves articulados fechados, bem preservadas, podendo esse percentual, por vezes, ser elevado (Sítio Saco, ponto 2,; Prancha 6, Foto A). A presença em uma 
mesma assembléia fóssil de conchas alóctones e parautóctones de bivalves e conchas articuladas fechadas deriva da exumação dos organismos do substrato no seu habitat de vida e incorporação às concentrações.

Nos tempestitos proximais, feições vistas em seção são o aninhamento $e \quad 0$ empilhamento e, por vezes, o embricamento de conchas desarticuladas de bivalves. Em geral, o empacotamento dos bioclastos passa a frouxo no topo, exibindo gradação da biotrama como reflexo de diminuição de energia do processo de deposição (Jamacaru, Anexo I).

A presença de litoclastos do embasamento cristalino, nas concentrações de Canastra,Torre e nos bancos de moluscos (Casiopinae e lamelibrânquios) com eventuais equinóides da Mina Pedra Branca, em Nova Olinda (sensu, BERTHOU ET $A L ., 1990$ ), refletem áreas de deposição energéticas e a proximidade com as rochas do embasamento cristalino, sugerindo deposição associada à zonas de maré a supramaré.

No depósito de Sitio dos Negros (Prancha 7, Foto B), em direção ao topo, somam-se aos bivalves desarticulados (infauna e epifauna) e gastrópodes, um pequeno percentual de conchas de bivalves articuladas fechadas (unidade microestratigráfica 4, anexo IV) e, dentes de peixes Osteichthyes (Cladocyciidae e Macromesodontidae), principalmente picnodontiformes (SALES ET AL., 2002), que são organismos durófagos marinhos, predadores de bentos. Desta forma, as diferentes unidades microestratigráficas e seu empilhamento denotam a ciclicidade de eventos e complexidade da acumulação. Como resultado, mistura temporal pode ser esperada com uma maior atuação no modelamento da composição em virtude da diversidade das espécies da assembléia.

Os contatos basais dos tempestitos proximais são bruscos e erosivos (Serra da Mãozinha, Prancha 5, Fotos B, C), em geral lateralmente descontínuos e geometricamente podem representar lentes e cunhas (Saco, Figura 28, p 68, Prancha 6, Fotos A, B, C, D, A).

Os tempestitos proximais, são mais ocorrentes na porção superior da Formação Santana, no topo do Membro Romualdo, possivelmente relacionados ao final de Tratos de Sistemas Transgressivos ou início de Tratos de Sistemas de Mar Alto, sendo o 
caráter clástico, mais pronunciado, onde a influência gradiente batimétrico é menor (Figura 33, P. 90).

\subsubsection{Concentrações com carapaças de equinóides (tempestitos proximais)}

Na porção sudoeste da bacia, depósitos com bancos de calcarenitos, contendo carapaças de equinóides irregulares (Pygurus tinocoi Beurlen, 1966 e Faujasia araripenses Beurlen, 1966 [=Pygidiolampas araripenses Brito, 1981]), associados a moluscos, foram descritos na região sudoeste do município de Araripina (Rancharia, Sítio Capim, Lagoa de Dentro e cidade de Araripina, Beurlen, 1962, 1963, 1966, veja Tabela 1, p. 34). A ocorrência destes depósitos em ampla área sugere um evento energético (tempestade), transportando as carapaças do ambiente marinho próximo e depositando-as, na área da plataforma de Araripina, que representava um local raso à época da deposição da Formação Santana (Figuras 3 e 4, p. 10 e 12).

Os equinóides representam um caso especial entre os invertebrados pela maneira cuja sua construção esqueletal é concebida, sendo muito susceptiveis a desarticulação das placas, que uma vez iniciada, é rápida, passando por estágios sucessivos de desintegração (KIDWELL \& BAUMILER, 1990; DONOVAN, 1991). Os equinóides irregulares são organismos escavadores rasos, que se alimentam do material orgânico do substrato e em geral, habitam zonas com deposição sedimentar ativa, garantindo thes maiores chances de preservação de carapaças (KIER, 1977; SMITH, 1984).

$\mathrm{Na}$ localidade de Canastra, ocorre uma concentração com bioclastos exibindo empacotamente frouxo, formado por carapaças e fragmentos de equinóides fósseis e subordinamente moluscos. Tafonômicamente (Anexo VI), a partir dos dados coletados, mostra a presença de depósito gerado por tempestito proximal, representado por elementos alóctones a parautóctones. Bioestratinomicamente exibem baixa seleção, alta fragmentação, onde predominam fragmentos milimétricos a centimétricos $(n=400)$ de vários tamanhos (Prancha 8), com um baixo percentual de carapaças inteiras $(n=59)$, (Prancha 8, Foto B; Prancha 9, Foto A) e poucos espinhos disseminados na matriz sedimentar $(n=24)$, (Prancha 14, Foto C). 
As poucas carapaças inteiras quando transportadas, já se encontravam em processo de desarticulação pós-morten, com breve exposição na interface águasedimento, como sugerido por Sales et al. (2003). As carapaças registram quatro estágios de desarticulação, quando confrontadas com o modelo de escala semiquantitativa de desarticulação para carapaças de equinóides, proposto por Kidwell \& Baumiller (1990), (Figura 35, p. 97), amplamente usado na literatura especializada.

\begin{tabular}{|l|c|}
\hline \multicolumn{2}{|c|}{ Escaia semi-quantitativa para a desintegração de equinóides } \\
\hline \multicolumn{1}{|c|}{ Kidwell \& Baumiller } & $\begin{array}{c}\text { Carapaças de equinóides } \\
\text { do Araripe }\end{array}$ \\
\hline 1.Mais de $50 \%$ de espinhos & \\
2. Menos de $50 \%$ espinhos nas testas & \\
3.Membranas orat e aboral perdidas & \\
4. Laterna disarticulada e fora da testa \\
Carapaças vazias \\
5. Carapaças fraturadas ou danificadas
\end{tabular}

Figura 35. Escala semiquantitativa de desarticulação de carapaças de equinóides, proposta por Kidwell \& Baumiller (1990) e estágios de desarticulação das carapaças na Bacia do Araripe.

Em geral, a grande quantidade de fragmentos, com partição ao longo dos planos de sutura, podem estar relacionados ao rápido decaimento das carapaças, após a morte, que pode ser de dias a semanas, sob ação de escavadores, bioturbação e alguma agitação (KIDWELL \& BAUMILER, 1990; DONAVAN, 1991) e posterior soterramento. Como agentes causadores dessa intensa quebra de carapaças, duas interpretações são factiveis: A) o ataque de predadores (DONAVAN, 1991) e B) a alta energia envolvida no transporte, por ação de tempestades (SMITH, 1984; SCHÄFER, 1972), sendo estas, os agentes responsáveis pelo soterramento final. O sucessivo 
retrabalhamento, também provocaria a desarticulação completa das carapaças (DONAVAN, 1991).

Algumas feições não têm origem bioestratinômica e são atribuídas ao preenchimento parcial das carapaças pelo sedimento inconsolidado (pré-diagênese), resultando em quebra por compactação, com fraturamentos mecânicos (diagênese) (Prancha 9, Foto $\mathrm{C}$ ). Outra feição não bioestratinômica são os contornos preservados "anéis de contorno", das carapaças pelos processos intempéricos (Prancha 8, Fotos C e E).

As concentrações contendo os equinóides apresentam ainda estruturas biogênicas (pequenas esteiras algálicas milimétricas), (Prancha 9, Foto B e C). Estas intercalações indicam uma possivel sazonalidade; reflexo de curtos periodos de deposição de lamas carbonáticas, com momentos de exposição e colonização por microorganismos que, através do metabolismo, induzem a precipitação do carbonato de cálcio, produzindo uma nova lâmina. Bioturbação, convolução e enrugamento também são feições observadas. Estas esteiras microbianas produzem durante seu crescimento uma gama de estruturas laminadas (microbialitos), sendo os estromatólitos planares ou lâminas microbianas os mais simples (são), que se desenvolvem tipicamente em planicies de marés protegidas (TUCKER, 2001, p. 124, 125).

$\mathrm{Na}$ Formação Santana, Cavaicanti \& Viana (1990), Martill (1994) e Srivastava (1996) reconheceram presença de estromatólitos. Srivastava (1996) reportou boas exposições na porção oeste da bacia "... in municipality of Simões, the limestones just below the marine transgressive gasteropod - rich strata contain rich and diverse forms of stromatolites, viz. stratiform, domal and colunar with active and passive ramifications...". Estas ocorrências do Membro Romualdo corroboram com a ocorrência dos tempestitos proximais em Canastra, contendo carapaças de equinóides e associados à presença de microbialitos, sugerindo gênese em ambiente de águas rasas, possivelmente, com deposição em zonas de intermaré a supramaré.

Segundo Tucker (2001), um padrão de crescimento diurno tem sido demonstrado para as lâminas em alguns ambientes de submaré, mas em outros casos, como em planicies de marés e em lagos efêmeros, o crescimento do material é, provavelmente, 
sazonal ou relacionado a periódicos alagamentos ou fluxos e sedimentação errática, sendo controlada principalmente por fluxos de tempestades.

\subsubsection{Concentrações geradas por tempestitos distais}

As concentrações geradas por tempestitos distais diferem dos tempestitos proximais, em geral, por apresentarem um discreto aumento na seleção de bioclastos, menor espessura dos depósitos e por posicionarem-se nas seções sedimentares, intercalando espessos pacotes de folhelhos/argilitos/margas. Também, a exemplo dos tempestitos proximais, apresentam fragmentação, porém um pouco menor em percentagem.

Os depósitos contendo as concentrações exibem em geral, em relação aos tempestitos proximais, contatos bruscos e ondulados bem marcados, bioclastos menores e menor grau de articulação, a exemplo das concentrações de Santana do Cariri (Prancha 15, Fotos A, B, C e D), São Gonçalo (Prancha 15, Foto E) e Marcolândia (Prancha 10, Foto E).

O amalgamento das unidades microestratigráficas das concentrações fossilíferas, refletem nos depósitos, os sucessivos ciclos, originados por repetidos eventos de deposição e retrabalhamento associados às tempestades.

Estratigraficamente podem situar-se em porções finais de Tratos de Sistemas Transgressivos ou ínicio de Tratos de Sistemas de Mar Alto (Figuras. 26, 27, 29, 30), p. $66,67,69,72)$, acima da superfície condensada que contém a superfície de máxima inundação, marcada pelo horizonte com concreções fósseis (ictiólitos), correlacionável em toda a bacia (Figura 33, p. 90). Estes depósitos estão também representados nos perfis de Serra da Mãozinha (Prancha 5, Foto A), Jatobá (Prancha 2, Foto D; Prancha 6, Foto F), e Sobradinho (Prancha 7, Foto G). 


\subsubsection{Concentração com assembléia autóctone (primariamente biogênica)}

Concentrações fósseis do tipo primariamente biogênicas são raras nos depósitos albianos, no Cretáceo da Bacia do Araripe, o exemplo analisado ocorre em uma concentração complexa na porção sudeste, no município de Jardim, no sítio Engenho.

A concentração é coquinóide, com unidades microestratigráficas, pouco espessas (2 a $4 \mathrm{~cm}$, Anexo V), atestando a presença de conchas fósseis de bivalves de infauna rasa, em posição de vida (in situ). Nestes estratos, os bioclastos fósseis ocorrem dispersos na matriz (lama - wakestone), preservando-os em posição de vida, a partir de um soterramento rápido por fluxos de tempestades "obrution deposits" (Prancha 7 , Foto D). As demais unidades microestratigráficas são densamente empacotadas, com acúmulo de restos de bioclastos de pequeno tamanho e boa seleção, possivelmente favorecidos por uma baixa taxa de sedimentação, e boa disponibilidade de conchas, formando níveis coquinóides (Anexo V).

A concentração, no geral, incluindo todas as unidades microestartigráficas, teve um tempo de residência considerável na interfácie água/sedimento (Prancha 7, Foto C), com baixa taxa de sedimentação, resultando em uma assembléia de moluscos com ampla mistura temporal. Isto é corroborado pela presença de icnofósseis, pela abundância de fragmentos das outras unidades microestratigráficas em relação à baixa densidade de moluscos viventes (estrato que apresenta bivalves fósseis em posição de vida). Porém a baixa diversidade da fauna dificulta as inferências sobre o paleoambiente.

O modo de ocorrência das conchas in situ sugere gênese final para a unidade microestratigráfica do depósito, relacionada a um evento catastrófico e episódico, com um denso aporte de sedimentos finos, só possível em batimetrias, abaixo do nível de base das ondas de tempestade. Logo, conclui-se que este estrato foi gerado em gradiente abaixo do nível de base de ondas de tempestades.

A concentração com bivalves em posição de vida pode ser associada a períodos relacionados a pouca influência de tectonismo, com controle eustático e baixa taxa de sedimentação. Na evolução tectono-sedimentar da Bacia mesozóica do Araripe, a fase pós-rift, representada por sinéclise interior, exibe este comportamento de relativa 
estabilidade tectônica (Figura 32, p. 89). Portanto, o tempo em que os elementos esqueléticos são expostos aos processos tafonômicos se torna mais importante, aumentando então o grau de mistura temporal.

Nessa coquina elementos de infauna e epifauna bissada (conchas mitilóides desarticuladas e articuladas) são encontrados na mesma assembléia de elementos esqueléticos, mostrando transporte. Isto é contribuído pelo fato destes organismos terem hábito de vida exposto e não enterrado. Em um primeiro momento, foi esperado encontrar presença do processo de retroalimentação tafonômica, a julgar pela mudança de substrato (mole e duro) ao longo da composição e evolução dos processos de formação da concentração coquinóide. No entanto, feições que comprovassem este processo não foram observadas.

Pelas características dos repetidos eventos de erosão de fundo e retrabalhamento e redeposição de finos, a concentração coquinóide, contendo uma assembléia de conchas em posição de vida, primariamente biogênica, corresponde a tempestito distal.

Lateralmente à coquina com bivalves em posição de vida, acima citada, foram coletados blocos de depósitos coquinóides, típicos de tempestitos. Estes apresentam uma associação de gastrópodes turritelídeos, bivalves da infauna rasa, parautóctones, e da epifauna bissada (articuladas e desarticuladas), alóctones e parautóctones (Prancha 7, Fotos F e G), evidenciando o transporte lateral das conchas, de diferentes habitats, com exumação e redeposição, mas ainda, provavelmente, dentro do mesmo ambiente de vida destas espécies. Pela posição de proximidade com a coquina, contendo concentração primariamente biogênica e com as concreções, contendo ictiólitos, esta concentração, provavelmente foi gerada em gradiente batimétrico acima do nivel de base de ondas de tempestades e abaixo do nível de base de ondas de bom tempo, com fluxos de tempestades suficientemente energéticos, para transportar esta fauna (morta e vivente) e depositá-la em um outro substrato. 


\subsubsection{Concentrações com resíduos transgressivos}

Depósitos com residuos transgressivos são em geral concentrações internamente complexas. Na bacia do Araripe ocorrem na forma de coquinas (sensu, KIDWELL \& HOLLAND, 1991), na seção do Sítio Romualdo (cotas 630 e 627, Figura 24, p. 62), na porção superior da Formação Santana, Membro Romualdo.

Essas concentrações exibem unidades microestratigráficas amalgamadas com conchas tafonômicamente em estágios bioestratinômicos distintos, sendo visível a superfície de erosão basal e ondulada.

A orientação dos bioclastos em planta é polimodal, mas em seção predomina a orientação concordante ao acamamento, com arranjo caótico e gradação irregular, onde os fluxos oscilatórios, conforme Allen (1990) podem representar influência de ondas ou correntes, respectivamente na gênese e retrabalhamento do material acumulado. As concentrações exibem alta fragmentação (bivalves e gastrópodes) e razoável concentração de conchas inteiras de gastrópodes turritelídeos. Posteriormente a deposição, elementos bioturbadores, modificaram, de maneira discreta, a biotrama.

Esses depósitos em geral, em virtude da longa exposição e tempo de residência no fundo, precisamente na interfácie água-sedimento, deveriam exibir bioerosão e ou incrustação. Porém, não se observa bioerosão, em virtude das influências diagenéticas e a intensa recristalização.

As concentrações com resíduos transgressivos (Figura 24, Página 62) podem ser usadas como marco da superfície de transgressão e o início de Trato de Sistemas Transgressivo (Figuras 24 e 33, p. 62 e 90). 


\subsection{Aspectos paleogeográficos, paleoambientais e paleoecológicos}

$\mathrm{Na}$ Bacia do Araripe, os perfis levantados do Membro Romualdo, contendo as concentrações fossiliferas esqueléticas de conchas e fragmentos de moluscos e carapaças de equinóides, apresentados em ciclos de $3^{\mathrm{a}}$ a $4^{\mathrm{a}}$ ordens (Figuras 24, 25, $26,27,28,29,30,31,32$, p. $62,63,67,68,69,72,77$ e 89), mostram que os depósitos fossiliferos se posicionam na porção superior da Formação Santana podem estar associados a Trato de Sistemas Transgressivo, representado principalmente por seção condensada, seguido por Trato de Sistemas de Mar Alto. Os dois ciclos evidenciam a transgressão que atuou na deposição das rochas que contêm as concentrações fossilíferas de organismos bentônicos, da Formação Santana, visualizada em ciclo de $2^{\circ}$ ordem, referente à seqüência pós-rifte da Bacia do Araripe (Figuras 12 e 13, p. 31 e 32).

\subsubsection{Paleogeografia}

A maior extensão paleogeográfica dos depósitos da Formação Santana ocorreu no periodo Albiano (PONTE, 1994), e na literatura, uma das hipóteses, considera como ocorrência de uma grande baia, onde os fósseis de dinoflagelados, foraminíferos, equinóides, tartarugas e conteúdo orgânico (BAUDIN ET AL., 1990; BERTHOU ET AL., 1990; ARAI \& COIMBRA, 1990), indicam a influência marinha, possivelmente relacionada a um ambiente marinho restrito raso com eventuais expansões e maiores influências marinhas ao longo da seção vertical. Porém a ocorrência de fósseis marinhos, na área não determina, em especiifico que, o mar albiano esteve presente em toda a bacia. No topo da Formação Santana, no Membro Romualdo, registra-se a presença de depósitos contendo as concentrações fossiliferas de macroinvertebrados bentônicos, com gênese relacionada a tempestades. Esses depósitos, possivelmente teriam sido transportados por ondas de tempestades, acentuados pela ação de marés. O mar certamente estava nas proximidades, mas seu registro pode ter sido erodido pelo tectonismo. A ausência de evaporitos de halita ao longo da bacia e de sais mais 
solúveis no Araripe, pode levar à suposição de que somente uma parte da laguna foi conservada, Ou seja, a parte em contato direto com o mar teria sido erodida.

Com base nas afinidades e nas suas ocorrências e sincronismo (Figura 6, p. 15), existem hipóteses com relação à transgressão marinha e a direção de sua chegada à região do Araripe, pelos ramos oceânicos, do Atlântico Equatorial e Sul. Assim como sintetizado em Mabessone et al. (1999), durante as elevações de nivel do mar, em tratos de sistema de mar alto, incursões marinhas teriam proveniência através da:

A) bacia do Parnaíba (BEURLEN, 1963, 1966, 1971A, 1971b; BEURLEN \& MABESSONE, et al., 1969; BRAUN, 1966, APUD LIMA, 1878; MEDEIROS, 1990; ARAI AT AL., 1994, VIANA, 1998), que encontra argumentos favoráveis na litologia e paleontologia (Formação Santana e Formação Codó), na fauna marinha (equinóides) e diversidade de moluscos na porção oeste (Formação Santana), nas litologias (Formação Exu e Formação Itapecuru) estratigraficamente acima e, principalmente ao seu depocentro (no Cretáceo), estar localizado no litoral norte. Os argumentos contrários residem na distância e inexistência de áreas correlatas entre as mesmas no mapa de isópacas da Formação Codó, que não mostra continuidade para sul (MESNER \& WOOLDRIDGE, 1962) e no embasamento da Bacia do Araripe, mais elevado a oeste, no Cretáceo;

B) Bacia Potiguar, passando pela faixa dos pequenos riftes neocomianos a SW (BEURLEN, 1962; LIMA, 1978, PETRI, 1987; VIANA, 1998), com argumentos favoráveis das fácies marinhas mais distais que ocorrem em Santana do Cariri. $O$ arcabouço tectônico da Bacia Potiguar é condizente com o avanço do mar para Sudoeste em direção ao Araripe. Os argumentos contrários são os sedimentos marinhos da Bacia Potiguar de idade turoniana e a carência de sedimentos cronocorrelatos, nas bacias interiores, acima do Lineamento Patos (Figura 36,p. 106), possivelmente erodidos;

C) Bacia de Sergipe-Alagoas (BEURLEN, 1971C; MABESSONE \& TINOCO, 1973, BRITO, 1976 APUD LIMA,1978; SANTOS, 1982; SILVA SANTOS, 1991), favorecida pelas áreas com empilhamento estratigráfico correlato como a Serra do Tonã (BUENO, 1996) e Serra Negra entre as bacias, pelos sedimentos marinhos alboaptianos (formações Muribeca e Riachuelo), pela seção completa na Bacia do Araripe 
para leste e diminuição para oeste pelas paleodrenagens com vales fluvias no sentido sul-sudeste da Formação Abaiara (ASSINE, 1990, atual Formação Rio da Batateira de PONTE \& APPI, 1990) e da Formação Marizal, desfavorecem a fauna de quelônios e equinóides distintas ao sul do Araripe, inclusive da Bacia Sergipe-Alagoas.

O gênero de dinoflagelados Substilisphaera, ocorrentes no Cretáceo nas bacias da costa e interiores do Nordeste do Brasil (São Luis, Ceará, Potiguar, Araripe), representam a Ecozona Subtilisphaera, com uma grande diferenciação geográfica, sendo registrada também no noroeste da África (bacias do Senegal e Marocan), sugerindo que seja característica do Atlântico Tropical Norte (ARAI ET AL., 1994).

Autores (KOUTSOUKOS \& DIAS-BRITO, 1987) defendem uma conexão do Atlântico norte e sul no Albiano Inferior, sendo uma possível explicação, para um sistema de canais na provável baia do Araripe (LIMA FILHO ET AL., 1996; VIANA, 1998; MARTILL, 1999).

Fósseis marinhos bentônicos macroscópicos (Cassiopinae e equinóides) e microscópicos (foraminíferos e dinoflagelados do gênero substilisphaera), com ocorrência em toda a Bacia do Araripe, ampliam as possibilidades para a direção de entrada do canal ou canais interconectores da bacia do Araripe ao Proto Atlântico.

Pelo exposto, ainda é motivo de discussão a configuração final de um mapa paleogeográfico da Bacia do Araripe, com a provável ou as prováveis direções de entrada do mar albiano, onde a questão encontra divergências com relação ao canal ou sistemas de canais, responsáveis pela coneç̧ão da laguna da Bacia do Araripe, com o proto Atlântico, ao norte e ao sul, como discutido por Viana (1998) e Lima-Filho et al. (1996).

\subsubsection{Paleoambiente}

As hipóteses paleogeográficas implicam, para o Membro Romualdo, um paleoambiente relacionado a um cenário lagunar, no qual mudanças bruscas na salinidade das águas superficiais (SILVA SANTOS \& VALENÇA, 1968; MEDEIROS, 1990) poderiam ser sazonais e acentuadas pelos pulsos de incursões marinhas (ARAI \& COIMBRA, 1990) e tempestades (DELLA FÁVERA, 1987). 


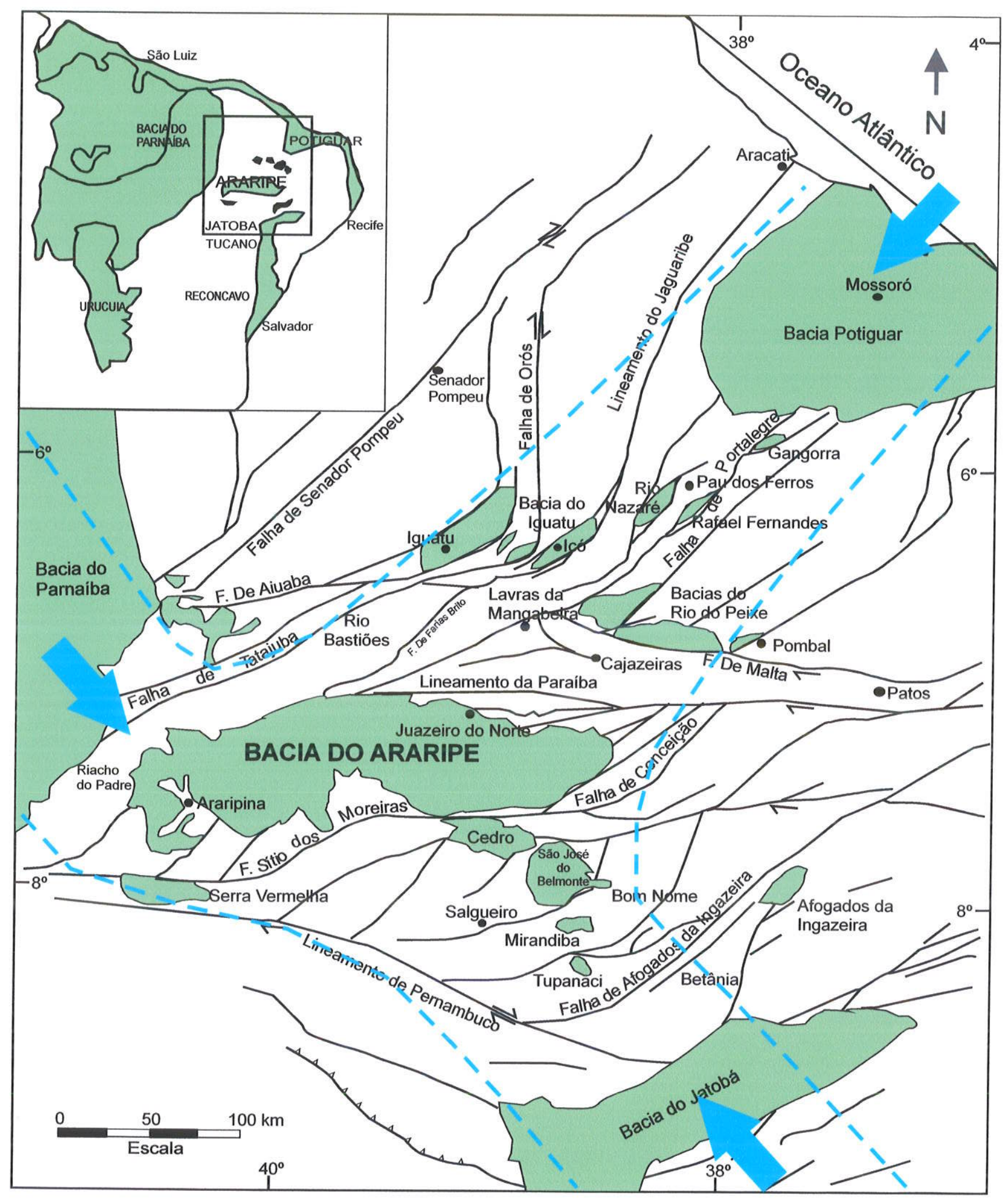

Figura 36. Mapa de localização da Bacia do Araripe no contexto tectônico regional e possíveis sentidos de direçôes de proveniência da incursão marinha Albiana, na área da Bacia do Araripe (baseado em PONTE \& PONTE-FILHO, 1996; LIMA-FILHO ET AL., 1996; VIANA ET AL., 1999 ). 
Com relação a paleobatimetria da laguna, Silva-Telles \& Viana (1990) vislumbram condições anóxicas no fundo, com eventuais perturbações episódicas de pequenos períodos de oxigenação, embora periodos de maior oxigenação tivessem ocorrido (provavelmente tempestades). Inclusive, Martins Neto (1990) descreve para a porção inferior da Formação Santana, no intervalo Aptiano/Albiano, mortandade em massa de insetos (grilos), tendo morte causada pela eliminação de gases tóxicos remobilizados do fundo por tempestades. Mas a paleobatimetria da laguna deve ter sido pouco profunda em virtude da ocorrências de estromatólitos e esteiras algalicas para todaa formaçã Santana (SRIVASTAVA, (1996).

A partir das seções colunares apresentadas, as profundidades ao longo do Membro Romualdo têm variação considerável, de leste para oeste, na bacia. $O$ raseamento é notado com os tempestitos proximais em Canastra, Torre e Mina Pedra Branca, com ocorrências de litoclastos e alcançou extremos de condições sub-aéreas, com gretas de contração na seção de Caboclos (Figura 31, p. 77).

Somada a todos esses, então, as condições de calmaria dos ciclos de aprofundamento (pelitos laminados) parecem ter sido realmente intermitentementes, interrompidas por periodos de relativa oxigenação, relacionados às tempestades, preservados, como mostram as marcas basais e superficies de erosão, como é o caso, dos depósitos tempestíticos das concentrações esqueléticas de macroinvertebrados, do Membro Romualdo, da Formação Santana.

Numa bacia dividida em subacias (Figuras 3,4 e 5, p. 10, 12 e 13), de diferentes maneiras, as amplitudes de marés, correntes rápidas e a excussão da maré, influenciariam na natureza rasa da laguna costal, possiveimente combinados com os efeitos da constrição da entrada. Uma exceção a este padrão seria a região nas proximidades da entrada da laguna.

Para essa área, apesar destas variações, o volume de sedimentos transportados para o interior da laguna seria um processo gerado primariamente pelo vento, logo, os fluxos responsáveis pelo transporte e deposição dos fósseis marinhos de equinóides. $\mathrm{Na}$ porção oeste da bacia, na região de Araripina, deveriam, possivelmente, estar posicionados nas proximidades da entrada da laguna, àquela época. 
Um exemplo atual de cenário lagunar servindo de comparação é descrito na área de Ojo de Liebre, Baja Califórnia, onde bacias restritas, a partir de lagunas adjacentes, são inundadas por altas marés (PHELEGER, 1969). Nestas porções a evaporação da água do mar concentra nutrientes que possibilitam o desenvolvimento de algas $e$ tapetes estromatolíticos, em torno da borda da laguna. Neste ambiente, há o constante reabastecimento pelas marés de sizígia e pelos alagamentos induzidos pelo vento. Esta situação paleoambiental na laguna Araripe encontraria suporte nos membros Ipubi e Romualdo, principalmente na porção oeste (Pernambuco e Piaui), assim como nas regiões norte (Nova Olinda / Santana do Cariri), nordeste (Serra da Mãozinha) e leste (Porteiras), onde há restrição dos organismos marinhos, em niveis específicos e a aparente interdigitação de organismos marinhos, salobros e de águas doces, é comum.

De acordo com as reconstruções de Petri (1987) e Baron (1987) para o Nordeste do Brasil, no periodo Albiano, a região estava localizada próximo ao equador, condicionada, predominantemente, por um clima seco (LIMA, 1978). Em latitudes tão baixas e próximas ao equador, fica difícil imaginar mudanças bruscas de temperatura. Somado a este fato, a natureza restrita de uma laguna a época Romualdo implicaria temperaturas relativamente mornas. Além disto, a abundância de carcaças de peixes desarticulados (MARTIL, 1993; WILBY, 1993; VIANA, 1999), encontradas nas concreções carbonáticas denotam que não houve grandes mudanças de temperaturas com paleotemperatura acima ou em torno de $16^{\circ} \mathrm{C}$ (ELDER, 1985 IN WILBY, 1993) e no máximo $18^{\circ} \mathrm{C}$ a $23^{\circ} \mathrm{C}$ (VIANA, 1999), caso contrário, o decaimento, que está diretamente relacionado à temperatura, não permitiria a preservação de organismos (sensu, KIDWELL \& BAUMILLER, 1990) com posteriores influências na tafonomia.

No Membro Romualdo, esse cenário seria drasticamente perturbado por tempestades, eventos episódicos de grande magnitude, responsáveis pela deposição final das concentrações fosssiliferas de macroinvertebrados bentônicos.

Esses depósitos de concentrações fossiliferas, contendo gastrópodes Paraglaucônia cf. lyrica (Maury), (identificada N. Morris) e Gymnentone, pequenos bivalves (Corbula?) (MABESSONE \& TINOCO, 1993) e subordinamente equinóides (BEURLEN, 1966), são conhecidos regionalmente a grosso modo, pelo posicionamento estratigráfico acima do horizonte concrecional dos ictiólitos. Nessa pesquisa, porém, 
visualiza-se a presença de bancos fossiliferos (Figuras 24, 25, 26, 27, 28, 29, 30, 31, p. $62,63,66,67,68,69,72$ e 77$)$, em posição estratigráfica abaixo, lateralmente correlata e acima do horizonte de ocorrência dos ictiólitos.

Isso denota que, indubitavelmente, a fauna de macroinventebrados bentônicos já estava presente na bacia antes da entrada dos peixes na laguna. Também corroborados por pequenos gastrópodes turritelídeos marinhos (VIANA, 1999), e comprovações anteriores de que a influência marinha ocorreu, em níveis estratigraficamente mais basais da bacia, com a presença de dinoflagelados, nos argilitos associados à gipsita do Membro Ipubi (LIMA, 1978).

Uma visão geral dessas ocorrências, dentro da seqüência sedimentar, em arcabouço de estratigrafia de seqüências, pode ser observada na Figura 33 (p. 90).

A presença de grãos, grânulos e de ocasionais seixos nos calcarenitos (Canastra e Torre, item 6.2), sugerem um ambiente de deposição energética, correspondendo em grande parte a tempestitos, como descrito no início da discussão.

As possiveis expansões sazonais, espasmódicas, dos limites da laguna Romualdo, demarcando seus limites paleogeográficos, devem ter tido variações a essas épocas, sendo relacionadas ao tectonismo e a intensidade e duração de cada fase de ingressão. A presença de equinóides e dinoflagelados nos depósitos indicam a proximidade de uma paleosalinidade marinha normal.

Della Faverá (1987) coloca que a fauna de peixes das concreções calcáreas, do Membro Romualdo, atingida por mortandade em massa, teria com o agente causador grandes tempestades, capazes de revolver os sedimentos orgânicos lamosos do fundo, provocando o envenenamento ambiental. Nestas situações excepcionais, as eventuais barreiras que restringiam os ambientes poderiam ser removidas, introduzindo-se profundas mudanças físico-químicas no meio (salinidade e/ou temperatura). Para o paleocenário da(s) laguna(s) Romualdo, esta hipótese é a de trabalho, onde a presença de tempestitos seria responsável pela gênese das acumulações e concentrações de macroinvertebrados bentônicos. 


\subsubsection{Paleoecologia}

As concentrações fossilíferas estudadas estão assim distribuidas ao longo da bacia: A) porção oeste, região de Araripina, equinóides (Faujásia e Pygurus), associados a moluscos Turritelidae, Epitonidae, Cerritidae, Naticidae, Mytilidea, Corbulidae [=Cyrenidae], bivalves indistintos e foraminíferos; B) porção centro-norte, região de Santana do Cariri e Nova Olinda, Cassiopinae, Turritelidae, Paraglauconia cf. Iyrica, Mytilidae, bivalves indeterminados, equinóides e foraminíferos miliolídeos; $C$ ) porção nordeste, região de Crato, Cassiopinae, Turritelidae, Cerrithidae e bivalves indeterminados; região de Missão Velha/Abaira, Paraglauconia cf. Iyrica, Turritelidae, Naticidae, Cerrithidae, Mytilidae (braquidontes); Ostreidae, Corbulidae, Arcidae, equinóides e dinoflagelados (Subtilisphaera); D) porção leste, região de Porteiras, Turritelidae, Naticidae, Corbulidae, Mytilidae e equinóides; E) porção sudeste, região de Jardim, bivalves indeterminados, Mytilidae, Turritelidae e Naticidae (Figuras 9 e 14, p. 21 e 36$)$.

Os gastrópodos marinhos são Cassiopinae, Paraglauconia (Turritela), Natica, Cerithium (BEURLEN, 1962, 1963; MABESSONE \& TINOCO, 1973). Turritellas são animais gregários, herbivoros, comuns em nossos litorais junto às algas marinhas na região intermaré, em ambientes arenosos ou argilosos. Os gastrópodes do Araripe, segundo Martill (1990), têm características de gastrópodes Albianos, correlatos ao grupo Lyrica-Sergipenses, do Albiano da Bacia Sergipe-Alagoas. O gênero Paraglauconia teve ampla distribuição nos mares albianos da Europa e, uma grande parte dos gêneros que ocorrem na Bacia do Araripe, estão presentes nas áreas da província paleobiogeográfica tetiana. Esta província de águas quentes e relativamente rasas ocupava a região equatorial durante o final do Cretáceo (SOHL, 1997).

Já os ostracodes e foraminíferos miliolídeos (ex., Mina Pedra Branca e Canastra), marcam niveis mais oxigenados, representando diminuição do confinamento da bacia, com indicação de faunas polihalinas a euhalinas, em relação aos níveis mais basais da Formação Santana, como sugerido por Berthou et al. (1990).

A assembléia de palinomorfos pontua na Formação Santana eventos de mortandade catastrófica, devido ao aumento da salinidade em periodo de transgressão 
e/ou por aumento populacional de dinoflagelados, como descrito por Arai \& Coimbra (1990). Estes são confirmados nas concentrações de Serra da Mãozinha (Tabela 6, p. 81), que marcam a Ecozona Subtilisphaera, com grande diferenciação geográfica no Cretáceo nas bacias da costa e interiores do Nordeste do Brasil, segundo Arai et al. (1994). Outros elementos polínicos encontrados, como Classopollis (Tabela 5, p. 81), são relacionados à ambientes de baixios litorâneos com proximidade de linha de praia (ARAI \& COIMBRA, 2001).

Com relação à fauna de peixes, Maisey (1991, 1993) e Martill (1990) citam que a mesma poderia ser marinha. A presença de peixes, nas concreções fossilíferas, está relacionada a ação de predadores durofagos, dos organismos bentônicos. Associados a esses, tem-se presença de fósseis de equinóides, visualizados na porção oeste da bacia, em Araripina (Prancha 10, Foto D). Os equinóides anteriormente relacionados somente para a porção sudoeste (BEURLEN, 1962, 1963 e 1966), são registrados ao longo da bacia (OLIVEIRA ET AL., 1979, SANTOS, 1982; BERTHOU, ET AL., 1990; MARTILL, 1993) nas concentrações fossiliferas de macroinvertebrados bentônicos.

A petrografia mostrou que o desenvolvimento de envelopes micriticos assegurou uma boa preservação da forma de conchas e seus contornos, durante a diagênese, implicando na presença de tapete microbiano, ao fundo, que também proveria a micritização dos bioclastos e favoreceria a abundante fauna de gastrópodes turritelídeos viventes, pastadores, como observado por Berthou et al. (1990). As esteiras algálicas encontradas na porção oeste da bacia (Caboclos e Canastra, Prancha 9, Fotos B e C), corroboram com Srivastava (1996), quando sugeriu que os sedimentos próximos à superficie experimentaram, pelo menos, em curtos períodos, proximidade com a zona fótica, pela presença de materiais estromatolíticos e esteiras algálicas ao longo da sucessão Santana.

De modo que, a partir das informações paleoecológicas, principalmente com a ocorrência de organismos fósseis estenohalinos, como equinóides, nas concentrações fossiliferas de macroinvertebrados bentônicos, coloca-se uma deposição, para a porção superior da Formação Santana, em condições lagunares, com influência marinha restrita. Onde os organismos marinhos foram transportados por marés de sizígia, por tempestades ou seriam herdados do mar no meio lagunar, favorecidos pela 
salinidade. Excessão seria o depósito com concentração fossilífera com assembléia autóctone, configurando depósitos do tipo "obrution",( item 6.1.7 e anexo V), necessariamente abaixo do nivel de base das ondas de tempestades.

Pelo exposto, os depósitos que contém as concentrações fossilíferas marcam na sucessão Santana, em seqüência deposicional, assumida como o registro de um ciclo de $2^{\circ}$ ordem (Ponte, 1994), a fase final de Trato de Sistemas Transgressivos e/ou de início de Trato de Sistema de Mar alto, dessa forma, podendo permitir o reconhecimento de superfícies chaves na Estratigrafia de Seqüências. 


\section{Conclusões}

1) A análise tafonômica dos bioclastos e dos depósitos de concentrações fossiliferas da parte superior da Formação Santana (Cretáceo), quando confrontada com um arcabouço de estratigrafia de seqüências prévio, permitiu o reconhecimento e a classificação dos depósitos com gênese relacionada a: (a) tempestitos proximais, (b) tempestitos distais, (c) concentrações autóctones (primariamente biogênicas) e (d) residuos transgressivos (sensu, FÜRSICH \& OSCHMANN, 1993);

2) Os eventos de sedimentação episódica, que ocorrem de maneira aleatória na natureza, com intervalos de recorrência da ordem de 5000 anos (sensu, Walker, 1984), foram possivelmente responsáveis pela gênese da maioria das concentrações esqueléticas. Essas correspondem a concentrações amalgamadas do tipo "thousand year multiple-event concentration";

3) Coquinas amalgamadas (tempestitos proximais) contêm conchas com diferentes assinaturas tafonômicas, sugerindo estágios de transporte e retrabalhamento distintos. Sua gênese está associada aos eventos sucessivos de tempestades, cujos bioclastos foram expostos à Zona Tafonomicamente Ativa (TAZ), por tempo considerável sugerindo apreciável mistura temporal (centenas a milhares de anos), considerando as escalas de mistura temporal disponiveis para acumulações marinhas do Recente;

4) Concentrações autóctones, amalgamadas, contendo bivalves em posição de vida, foram depositadas abaixo do nivel de base de ondas de tempestade, representando depósitos de sufocamento ou "obrution deposits";

5) Os dados de campo mostram ciclos assimétricos de $3^{\mathrm{a}}$ ordem que, na seqüência vertical de fácies, sugerem a deposição de um ciclo transgressivo de $2^{\mathrm{a}}$ ordem, com influência de elevação eustática, onde de leste para oeste, progressivamente, há deposição e a representação das unidades mais novas da seqüência sedimentar da Formação Santana (Membro Romualdo);

6) Na porção superior da Formação Santana, "litoestratigraficamente" equivalente ao chamado Membro Romualdo, as acumulações e as concentrações fossilíferas de macroinvertebrados bentônicos estão presentes em ciclos deposicionais distintos e 
sucessivos de $3^{a}$ ordem, representados por quatro niveis estratigráficos, diacrônicos. Esses niveis estão posicionados abaixo, no nível e/ou acima do horizonte que contém ictiólitos, marco estratigráfico síncrono na bacia. Isso denota a presença da fauna de bentos na bacia, antes da entrada dos peixes marinhos na provável laguna Araripe;

7) As concentrações fossilíferas são predominantemente compostas por conchas de moluscos, paleoecologicamente contendo organismos com caráter marinho: Paraglauconia cf. Iyrica, Gymnentone romualdoi, Natica, Cerithium, Braquidontes e Corbula, bem como organismos de caráter indubitavelmente marinho (Faujasia e Pygurus), foraminiferos miliolídeos e dinoflagelados Subtilisphaera;

8) Concentrações fossiliferas, que apresentaram bioclastos angulosos exibindo forma diversa e várias classes de tamanho, bem como ausência de incrustação e corrosão, podem ter sido geradas sob condições de baixa energia. A presença de peixes teleósteos em associação às conchas fragmentadas sugere que, ao menos em parte, a fragmentação pode decorrer da atividade biológica de tais organismos e não de processos hidráulicos, apenas. No entanto, estudos mais detalhados serão necessários para distinguir os diferentes agentes de fragmentação com base na morfologia dos fragmentos;

9) A presença de fósseis de elementos marinhos macroscópicos e microscópicos, não restritos somente à porção oeste da Bacia do Araripe, ampliam o limite paleogeográfico da "laguna Araripe";

10) Proveniências vindas (a) da Bacia Intracratônica do Parnaíba, na porção noroeste do atual nordeste brasileiro, registrando a presença de depósitos marinhos na área de Codó; (b) da Bacia Potiguar, na porção nordeste, com os depósitos marinhos da Bacia de Malhada Vermelha, através do "Graben" Pendência, (entre as bacias Potiguar e Araripe) e, finalmente, (c) da Bacia de Sergipe-Álagoas e porção norte da Bacia Tucano-Jatobá, sugerem polêmica ainda com relação a um possível mapa paleogeográfico preciso, apontando as direções das conexões marinhas da Bacia do Araripe, durante o Cretáceo. 


\section{Referências bibliográficas}

ABBOTT, S. T. \& CARTER, R. M. (1997). Macrofóssil associations from MidPleistocene cyclothems, Castlecliff Section, New Zealand: implications for sequence stratigraphy. Palaios, 12: 188-210.

ADAMS, A. E. \& MACKENZIE, W. S. (1998). A colour Atlas of Carbonate Sediments and Rocks Under the Microscope. Manson Publishing Ltd., $180 \mathrm{pp}$.

ADAMS, A. E.; MACKENZIE, W. S.\& GUILFORD, C. (1997). Atlas of sedimentary rocks under the microscope. (Sixth imp.) ,Longmamnas, Harlow. 1998.

AIGNER, T. (1985). Storm depositional systems. Lecture Notes in Earth Sciences, v. 3, p.1-174.

ALBUQUERQUE, P. R. F.; SALES, A. M. F. \& ANDRADE, J. A.F.G. (2000). Trace fossils in the Cariri Formation, Araripe Plateau, Ceará, NE, Brasil. In: INTERNATIONAL GEOLOGICAL CONGRESS, 31. Abstracts... Rio de Janeiro, Brazil, 2000.

ALLISON, P. A. \& BRIGGS, D. E.G. (EDS.). (1991). Taphonomy: releasing the data locked in the fossil record. Plenum Press, pp. 501-545.

ALLEN, J. R. L. (1990). Transport-hidrodynamics-shells. In: Briggs, D. E. GeCrwther, P. R. (eds.) Palaeobiology, a synthesis. London: Blackwell. P. 227-230.

ALMEIDA, F.F.M. (1967). Origem e evolução da plataforma brasileira. DGM / DNPM, Bol. 236. Rio de Janeiro.

ANDRADE, E. DE J. \& SOUZA-LIMA, W. (1999). Neithea cf. tricostata (BivalviaPectinidae) no Albiano inferior de Sergipe. In: CONGRESSO BRASILEIRO DE PALEONTOLOGIA, 10. Crato, 1999. Resumos. Crato, CE., p. 16.

APPI, C. J. HASHIMOTO, A. T. \& FREITAS, E. L. (1986). Fácies sedimentares e seqüencias deposicionais no neo-Alagoas da Chapada do Araripe. In CONG. BRAS.GEOL, 3. .Goiania, 1986 . Boletim de Resumos ...Goiania, sbg. P.47.

ARAI, M. \& COELHO, P. M. (2001). Statistical analysis of palynological assemblages from the Aptian-Albian of the Araripe Basin, northeast Braazil: a case study of paleoenvironmental significance of Cretaceous terrestrial palynomorphs. Buenos Aires, Argentina, Asociacion Paleontológica Argentina, Publicación Especial, 7: 2528.

ARAI, M.; COIMBRA, J. C.; (1990). Analise paleoecológica do registro das primeiras ingressões marinhas na Formação Santana. In: Seminário Sobre a Bacia do Araripe e Bacias Interiores do Nordeste, 1. Crato, 1990. Atas... Crato, DNPM. p. 225-239.

ARAI, M.; COIMBRA, J. C.; SILVA-TELLES JR., A. C. (1997). Síntese bioestratigráfica da Bacia do Araripe (Nordeste do Brasil). In: Seminário Sobre A Bacia Do Araripe e Bacias Interiores Do Nordeste, 2. Crato, 1997. Atas... Crato, DNPM. p. 21.

ARAI, M.; LANA, C. C.; PEDRÃO, E. (1994). Ecozona Subtilisphaera spp.: Registro eocretáceo de um importante episódio ecológico do Oceano Atlântico primitivo. Acta Geológica Leopoldensia, v. XVII, $n^{\circ}$ 39/2: 521-538.

ARMENTROUT, J. M. (1991). Paleontologic contraints on depositional modeling: examples of integration of biostratigraphy and seismic stratigraphy, PliocenePleitocene, Gulf of México. Pp. 137-170 In: Welmer P. \& Link, M. H. (eds.) Seimic 
fácies and sedimentary processes of submarine fans and turbidite systems. Springer, New York.

ASSINE, M. L. (1990). Sedimentação e Tectônica da Bacia do Araripe, Nordeste do Brasil. Rio Claro. 124 p. (Dissertação de Mestrado, IGCE/UNESP).

ATROPS, F. \& FERRY, S. (1989). Sequence stratigraphy and changes in the ammonite fauna (Upper Jurassic, S-E France). Pp. 7-9 In: Mesozoic Record of western Tethian margin. 2ème Congrés Francais de Sèdimentologie Lyon, Rèsumè.

AZEVEDO \& TRAVASSOS PETRÓLEO S. A. (1986). Perfil composto do poço 2-AP-1CE (Araripe estratigráfico). Escala1:1.000. São Paulo. Consórcio Azevedo \& Travessos Petróleo S. A. e Andrade Gutierres Energia S. A.(inédito).

BARRON, E. J. (1987). Cretaceous plate tectonics reconstructions. Amsterdam, Palaeogeography, Palaeoclimatology, Palaeoecology, N 59, p.3-29.

BAUDIN. F., BERTHOU, P. Y.; HERBIN, T.P. \& CAMPOS, D. DE A (1990). Matière organique et sedimentation argileuse dans le Crétacé du Bassin d'Araripe. Comparaison avec les dones du Cretacé d' autres bassins bréliliens. In SIMP. BACIA DO ARARIPE E BACIAS INTERIORES DO NORDESTE, 1. Crato, 1990. Atas...Crato, DNPM. p. 83-93.

BEHRENSMEYER, A. K. \& HOOK, R. W. (1992). Paleoenvironmental contexts and taphonomic modes. pp. 15-136. In: Behrensmeyer, A. K., Damuth, J. D.; Dimichele, W. A; Potts, R.; Sues, H-D.; Wing, S. L. (eds.) Terrestrial ecosystems though time. University of Chicago Press, Chicago.

BEHRENSMEYER, A. K.; KIDWELL, S. M.; GASTALDO, R. A. (2000). Taphonomy and paleobiology. In: Erwin, D. H.; Wing, S.L. (eds.) Deep time: Paleobiology's perspectives. Supplemnt to Palaeobiology (26) 4: 103-147.

BEHRENSMEYER, A. K.; KIDWELL, S. M. (1985). Taphonomy's contribuitions to paleobiology, Paleobiology, v.11, p.105-119.

BENERJE, I. \& KIDWELL, S. M. (1991). Significance of molluscan shell beds in sequence stratigraphy: an example from lower Cretaceous Mamuille Group of Canada. Sedimentology, 38: 913-934.

BERTHOU, P-Y (1994). Critical análisis of the main publications about the stratigraphical framework of the Paleozoic and Mesozoic sedimentary deposits in the Araripe Basin (Northeastern Brazil). In: SIMP. CRETÁCEO DO BRASIL, 3. Rio Claro, 1994. Boletim...Rio Claro, UNESP/IGCE. P. 123-126.

BERTHOU, P-Y; VIANA, M. S. S.; CAMPOS. D. DE A. (1990). Coupe de la formation Santana dans le secteur de "Pedra Branca" (Santana do Carirí) (Bassin d'Araripe, $\mathrm{NE}$ du Brésil). Contribuition a l'étude de la sédimentologie et des paleoenvinnements. In: Simpósio Sobre A Bacia Do Araripe E Bacias Interiores Do Nordeste, 1. Crato, 1990. Atas... Crato, DNPM. p. 173-189.

BERTHOU, P-Y; DEPECHES, F; CAMPOS. D. DE A; HERBIN. J. P. ;PIERRE, C. (1988). New data on sedimentation, paleoenvironment and stratigrafy of Chapada do Araripe. Revista Brasileira de Geociências, (resumo), 18 (3): 315.

BEST, M. M. R. \& KIDWELL, S. M. (2000a). Bivalve taphonomy in tropical mixed siliciclastic carbonate settings. I. Environmental variation in shell condition. Paleobiology, 26: 80-102. 
BEST, M. M. R. \& KIDWELL, S. M. (2000b). Bivalve taphonomy in tropical mixed siliciclastic carbonate settings. II Effect of bivalve life habits and shell types. Paleobiology, 26: 103-115.

BEURLEN, K. (1962). A Geologia da Chapada do Araripe. Anais da Academia Brasileira Ciências, 34: 365-370.

BEURLEN, K. (1963). Geologia e estratigrafia da Chapada do Araripe. In: CONGRESSO BRASILEIRO GEOLOGIA, 17, Recife, 1963. Anais... Recife, SBG/SUDENE, suplemento, $47 \mathrm{p}$.

BEURLEN, K. (1966). Novos equinóides do Cretáceo do Nordeste do Brasil. Anais da Academia Brasileira de Ciências, 389 (3/4): 455-467.

BEURLEN, K. (1964). As espécies Cassiopinae, nova sub-família dos Turritellidae, no Cretáceo do Brasil. Arquivos de Geologia, 5: 1-44.

BEURLEN, K. (1971). As condições ecológicas e faciológicas da Formação Santana na Chapada do Araripe (Nordeste do Brasil). Anais da Academia Brasileira Ciências, 43. Suplemento: 411-415.

BRENCHLEY, P. J. \& HARPER, D. A. T. (1998). Paleoecology: Ecosystems, environments, and evolution. Stanley Thornes Pub Ltd. $402 \mathrm{pp}$.

BRETT, C. E. (1995). Sequence stratigraphy, biostratigraphy and taphonomy in shallow marine environment. Palaeogeography, Palaeoclimatology, Palaeoecology, 10: 597 -
616 .

BRETT, C. E. (1998). Sequence stratigraphy, paleoecology, and evolution: biotic clues and responses to sea-level fluctuations. Palaios, 13: 241-262.

BRETT, C. E. \& BAIRD, G. C. (1986). Comparative taphonomy: a key to paleoenvironmental interpretation based on fossil preservation. Palaios, 1: 207-227.

BRETT, C. E. \& BAIRD, G. C. (1993). Taphonomic approaches to temporal resolution in Stratigraphy: examples from Paleozoic marine mudrocks. In; KIDWELL, S. M. \& BEHRENSMEYER, A. K. (eds) Taphonomis approaches to time resolution in fossil assemblages. Paleontological Society, Short courses in Paleontology, n. 6.

BRETT, C. E. \& BAIRD, G. C. (1997). Paleontological Events: stratigraphic, ecological, and evolutionary implications. Columbia University Press, new York, 604p.

BRETT, C. E. \& SEILACHER, A. (1991). Fossil Lagerstätten: a taphonomic consequence of event sedimentation. Pp. 283-297. In: Einsele, G; Ricken, W.; Seilacher, A. (eds.) Cycles and events in stratigraphy. Springer, Berlin.

BRICKER, O. P. (1971). Carbonate Cements. The Johns Hopkins University. Studies in Geology, 19. The Johns Hopkins Press, Baltimore and London.

BRITO, I. M. (1981). Os Equinóides Fósseis do Brasil. II - Holoctipóides e Cassidulóides. An. Acad. Brasil. Ciênc., 53 (3), 513-527.

BRITO, I. M. (1984). The Upper Cretaceous in Brasil. Its divisions and boundaries. An. Acad. Bras. Ciênc., 56(3): 287-293.

BRITO-NEVES, B. B. (1990). A Bacia do Araripe no contexto geotectônico regional. In: Simpósio Sobre A Bacia Do Araripe E Bacias Interiores Do Nordeste, 1, Crato,
1990. Atas... Crato, DNPM, p. 21-33.

BROMN, L.F.; FISHER, W.L. (1977). Seismic-stratigraphic interpretation of depositional systems: examples from Brasil rift and pull-apart basins. In: Payton, C.E. (Ed.). 
Seismic stratigraphy applications to hidrocarbon exploration. AAPG Memoir, 26:213248.

BUENO, G.V. (1996). Serra do Tonã: um elo estratigráfico entre as bacias de Tucano Norte (BA) e Araripe (CE), Nordeste do Brasil. In: Simpösio sobre o Cretäceo do Brasil, 4., 1996. Boletim... Rio Claro, UNESP / IGCE. p. 143-146.

CARON, J.B., \& GOSTLIN K.E.(2003). Taphofacies of the Burgess Shale Technical Program PALAEONTOLOGICAL ASSOCIATION, 47th Annual Meeting, University of Leicester, 2003.

CARVALHO, I. DE S. \& VIANA, M. S. S. (1992). Os conchostráceos da Bacia do Araripe. An. Acad. Brás. Ciênc., 65(2): 181-188.

CASSAB, R. de C. T. (1999). O gênero Tylostoma Sharpe, 1849 (Mollusca Gastropoda) a Formação Jandaíra, Cretáceo Superior do Nordeste do Brasil. In: CONGRESSO BRASILEIRO DE PALEONTOLOGIA, 10, Crato, 1999. Resumos. Crato.CE. p. 35.

CAVALCANTI, V. M. M. \& VIANA, M. S. S. (1990). Faciologia dos sedimentos não lacustres da Formação Santana (Cretáceo Inferior da Bacia do Araripe, Nordeste do Brasil). In: Seminário Sobre A Bacia Do Araripe E Bacias Interiores Do Nordeste, 1. Crato, 1990. Atas... Crato, DNPM. p. 193-207.

CHOQUETE , P. W. \& PRAY, L. C. (1970). Geologic nomenclature and classification of porosity in sedimentary carbonates: American Association of Petroleum Geologists Bulletin, v. 54, p. 207-250.

COIMBRA, J. C.; MITSURU, A.; CARREÑO, A. L. (2002). Biostratigraphy of Lower Cretaceous microfossils from the Araripe Basin, Northeastern Brazil. Geobios 35 (2002) 687-698.

CONCEIÇÃO, G. F.; ZUCON, M. H.; VIEIRA, F. S. (1999). Análise biestratigráfica de um afloramento da Formação Riachuelo, Sergipe. In: CONGRESSO BRASILEIRO DE PALEONTOLOGIA, 10, Crato, 1999. Resumos. Crato,CE, p. 37.

CÓRDOBA, V. C. (2001). Fácies e Sistemas deposicionais da rampa carbonática da Formação Jandaíra, Bacia Potiguar. (Tese de doutoramento, Universidade Júlio Mesquita Filho, UNESP, Departamento de Geociências, Rio Claro. 166pp.) (inédito).

CLIFTON, H. E. \& BOGGS, S. JR. (1970). Concave-up pelecypod (Psephidea) shells in shallow marine sand, Elk River Beds, southwestern Oregon. Journal of Sedimentary Petrology, v. 40, p. 888-897.

CPRM/DNPM (1978/1979). Perfis compostos dos poços do Projeto Santana (1-PS11CE/1-OS-12-CE). Recife. CPRM/SUREG. (Inédito).

DAVIES, D. J.; POWELL, E.N., STANTON, Jr. R. J. (1989). Taphonomic signatures as a function of environmental process. Shells and shells beds in a hurricane influenced inlet on the Texas coast. Palaeogeography, paleoclimatology, palaeoecology, 72, 317-356.

DANTAS E LOPES (1996). A Bacia sedimentar do Araripe. Recife. MME/DNPM $/ 4^{\circ} \mathrm{DR}$.

DATTILO, B. F. (1996). A quantitative paleoecological approach to hight-resoltion cyclic and event-stratigraphy: the Apper Ordovician Miamitown Shale in the Type Cicinnnatian. Lethaia, 29(1): 21-37. 
DELLA FÁVERA, J. C. (2001). Fundamentos de Estratigrafia Moderna. Eduerj, Rio de Janeiro, 278p.

DELLA FÁVERA, J. C. (1984) Eventos de sedimentação episódica nas bacias brasileiras. Uma contribuição para atestar o caráter pontuado do registro sedimentar. Anais do $33^{\circ}$ Congresso Brasileiro de Geologia, Rio de Janeiro. P. 489 501.

DELLA FÁVERA, J. C. (1987). Tempestades como agente de poluição ambiental e mortandade em massa no passado geológico: casos da Formação Santana (Bacia do Araripe) e Irati (Bacia do Paraná). Boletim de Geogiências da Petrobrás, n.1, v.2, p.239-240.

DIAS-BRITO, D. (1994). Comparação dos carbonatos pelágicos do cretáceo médio da Margem Atlântica Brasileira com os do golfo do México: Novas evidências do Tétis Sul-Atlanticano. IN: SIMP. CRET. BRAS. 3. UNESP, 1-18, Rio Claro.

DICKSON, J.A.D. (1965). A modified staining technique for carbonates in thin section. Nature 205:587

DONAVAN, S. K. (1991). The taphonomy of echinoderms: calcareous multi-element skeletons in the marine environment. In: The process of fossilization, (Ed. Donavan, S. K), Columbia Univ. Press., New York, 303 p.

DNPM/SUDENE/Serviço Geográfico do Exército. (1982). Carta Topográfica Fronteiras (SB-24-Y-C-III), Escala 1:100.000.

DNPM/SUDENE/Serviço Geográfico do Exército. (1982). Carta Topográfica Simões (SB-24-Y-C-VI). Escala 1:100.000.

DNPM/SUDENE/Serviço Geográfico do Exército. (1982). Carta Topográfica Crato (SB24-Y-D-111), Escala 1:100.000.

DNPM/SUDENE/Serviço Geográfico do Exército. (1982). Carta Topográfica. Ouricuri (SB-24-Y-D-IV), Escala 1:100.000.

DNPM/SUDENE/Serviço Geográfico do Exército. (1982). Carta Topográfica. Jardim (SB-24-Y-D-VI), Escala 1:100.000.

DNPM/SUDENE/Serviço Geográfico do Exército. (1982). Carta Topográfica. Santana do Cariri (SB-24-Y-D-II), Escala 1:100.000.

DNPM/SUDENE/Serviço Geográfico do Exército. (1982). Carta Topográfica. Bodocó (SB-24-Y-D-V), Escala 1:100.000.

DNPM/SUDENE/Serviço Geográfico do Exército. (1982). Carta Topográfica. Campos Sales (SB-24-Y-D-I), Escala 1:100.000.

DUNHAM, R. J. (1962). Classification of carbonate rocks according to depositional texture. Mem. Am. Assoc. Petroleum Geol. 1: 108-121.

EMERY, D. \& MYERS, K. J. (1998). Sequence stratigraphy. Special Publication, BP Exploration, Stockley Park Uxbridge, London, Blackwell 297p.

FERNÁNDEZ-LOPEZ, S. (1997). Ammonites, Taphonomic cycles and stratigraphic cycles in carbonate epicontinental platforms. Cuadernos de Geologia Ibérica, 23: 95136.

FERNÁNDEZ-LOPEZ, S. (2000). Ammonites Taphocycles in Carbonate Epicontinental Platforms. GeoResearch Fórum, Trans. Tech. Publications, Switzerland, v. 6, 2000, pp. 293-300. 
FERNÁNDEZ-LOPEZ, S. \& MELÉNDES, G. (1996). Phylloceratina ammonoids in the iberian Basin during the Middle Jurassic; a model of biogeographical and taphonomic dispersal related to relative sea-level changes. Palaeogeography, Palaeoclimatology, Palaeoecology, 120; 291-302.

FLESSA, K. W \& KOWALEWSKI,M. (1994). Shell survival and Time-averaging in nearshore and shelf environments: estimatives from the radiocarbon literature. Lethaia, 27: 153-165.

FLESSA, K. W.; CUTLER, A. H. \& MELDAHL, K. (1993). Time and taphonomy: quantitative estimates of time-averaging and stratigraphic disorder in a shallow marine habitat: Paleobiology, 19: 266-286.

FOLK, R. L. (1959). Practical petrographic classification of limestones. American Association of Petroleum Geologists, Bulletin, 43, 1-38.

FOLK, R. L. , (1965). Some aspects of recrystallization in ancient limestones. In: Pray, L. C. \& Murray, R. C. (eds) Dolomitization and Limestone Diagênesis: A Syposium, Society of Economic Paleontologists and Mineralogists, Special Publication, Vol. 13, 14-48.

FÜRSICH, F. T. (1971). Hartgründe and Kondensation im Dogger von Calvados: Neues Jarbuch für Geologie and Paläontologie, Abhandlungen, v. 138, p. 313-342.

FÜRSICH, F. T. (1980). Preservede some life positions of some Jurassic bivalves. Paläontt. Z. v. 54, n 3/4, p. 289-300.

FÜRSICH, F. T. \& ABERHAN, M. (1990). Significance of time-averaging for paleocommunity analysis. Lethaia, 23:143-152.

FÜRSICH, F. T. \& OSCHMANN, W. (1986). Storm shell beds of Nanogyra virgula in the upper Jurassic of France. N. Jahrb. für. Geol. Paläontol., Abhardlungen, 182: 141161.

FÜRSICH, F. T. \& OSCHMANN, W. (1993). Storm shell beds as tools in basin analysis: the Jurassic of Kachchh, western India. J. Geol. Soc. Lond, 150: 169-185.

FÜRSICH, F. T. \& PANDEY, D. K. (2003). sequence stratigraphic significance of sedimentary cycles and shell concentrations in the Apper Jurrasic-Lower Cretaceous of Kachchh, Western India. Palaeogeography, Palaeoclimatology, Palaeoecology, 19, 285-309.

GALLOWAY, W. E. - Genetic stratigraphic sequences in basin analysis I: Architetcture and genesis of flooding-surface bounded depositional units. AAPG Bull., v.73, pp. 125-142, 1989.

GASTALDO, R. A. (1988). A conspectus of phytotaphonomy. In: Dimichele, W. A. \& Wing, S. L. (eds.) Methods and Applications of plant paleoecology: notes for a short courses. Paleontological society Special Publication, 3: 14-28.

GHIGNONE, J. I.; COUTO, E. A.; ASSINE, M. L. (1986). Estratigrafia e estrutura das bacias do Araripe, Iguatu e Rio do Peixe. In: Congresso Brasileiro Geologia, 34, Goiânia, Anais... Goiânia, SBG, v. 1, p. 271-285.

GHILARDI, R. P. (1999). Paleoautoecologia dos bivalves do Grupo Passa Dois (Neopermiano), no Estado de São Paulo: bivalves fósseis como indicadores da dinâmica sedimentar. São Paulo, 160p. (Dissertação de Mestrado em Geociências. Instituto de Geociências, Universidade de São Paulo). 
GHILARDI, R. P; SIMÓES, M. G.; SALES, A. M. F. (2003). Taphonomic And Paleoecologic Signatures As A Tool In Sequence Stratigraphy: Preliminary Results From "Two" Maximum Flooding Surfaces Of The Ponta Grossa Formation (Devonian), Paraná Basin, Brazil. In: Congresso Brasileiro de Paleontologia, 18, 2003, Brasilia, DF... Boletim de Resumos. SBG/UNB: Brasília: 2003, p. 146-147.

GHILARDI, R. P.; SIMÕES, M. G.; SALES, A. M. F.; RODRIGUES, S. C.; LEME, J. M. \& HOLZ, M.. (2002). Roteiro Paleontológico da Seção Geológica da Estrada de Ferro (Jaguariaíva-Arapoti), PR, Formação Ponta Grossa, Devoniano, Bacia do Paraná, Brasil: Variações Faunísticas e Tafonômicas no Contexto da Estratigrafia de Seqüências. In: $1^{\circ}$ Simpósio de Roteiros Geológicos do PR... Guia Paraná, 2002, SBG, PR, 2002. pp. 53-66.

GÓMEZ, J. J. \& FERNANDEZ-LOPEZ, S. (1994). Condensation processces in shallow platforms. Sedimentary Geology, 92: 147-159.

GREGORY, W. A. \& HART, G. F. (1992). Towards a predictive model for the palynologic response to sea-level changes. Palaios 7: 3-33.

GUNTER, G. (1947). Catastrophism in the sea and its paleontological significance, with special reference to the Gulf of México. Am. J. Sci. 245 (11), 669-676.

HASHIMOTO, A. T.; APPI, C.; SOLDAN, A. L.; CERQUEIRA, J. R. (1987). O NeoAlagoas nas bacias do ceará, Araripe e Potiguar (Brasil): caracterização, estratigrafia e paleoambiental. Rev. Bras. Geociênc., 17(2), 118-122.

HAQ, B. U ; HARDENBOL, J. \& VAIL. P. R. (1987). Chronology of fluctuating sea levels since the Triassic. Science, 235, 1156-1165.

HOLLAND, S.M. (1995a). Depositional sequences, facies control, and their effects on the stratigraphic distribution os fossils. B.U. Haq (ed.). Sequence stratigraphy and depositional response to tectonic, and climatic forcing. Kluwer Academic Press: Dordrecht, Netherlands, p. 1-23.

HOLLAND, S. M. (1995b). Stratigraphic distribuitionn of fossils. Paleobiology. 21: 92109.

HOLLAND, S. M. (1996). Guidelines for interpreting the stratigraphic record of extinctions: distinguishing pattern from artifact. Pp. 174. In: Repetski, J. E. (ed) Sixth North American Paleontological convention, Abstracts of papers. Paleontological Society Special Publication, 8: 174.

HOLLAND, S.M. (2000). The quality of the fossil record; a sequence stratigraphic perspective. In: Erwin, D. H.; Wing, S.L.. (eds.) Deep time: Paleobiology's perspectives. Supplemnt to Palaeobiology (26) 4: 148-168.

HOLLAND, S.M. \& PATZKOWSKY, M. E. (1997). Depositional sequences and the stratigraphic distribuition of fossils: isolating the effects of condensation. pp. A 307 (1-4) In: 1998 AAPG Annual Convention Extend Abstracts, vol. 1. American Assotiation of Petroleum Geologists, Salt Lake City.

HOLZ, M. (1998). Tafonomia de Vertebrados - a arte de decifrar a origem do registro de paleotetrápodes. Ciência e Ambiente. Santa Maria, v. 25, n. 1, p. $105-117$.

HOLZ, M., BARBERENA, M. C. (1994). Taphonomy Of The South Brazilian Triassic Paleoherpetofauna:Pattern Of Death, Transport And Burial. Palaeogeography, Palaeoclimatology, Palaeoecology. Amsterdam / Holland: UFSM, v.107, p.179 - 197. 
HOLZ, M., BARBERENA, M. C. (1989). A Importância da Tafonomia No Estudo de Vertebrados Fósseis. Acta Geologica Leopoldensia. São Leopoldo: , v.13, p. 77 92.

HOLZ, M., DIAS, M. E. (1998). Taphonomy Of Palynological Records In a Sequence Stratigraphic Framework: An Example From The Early Permian From The Paraná Basin in Southern Brazil. Review of Palaeobotany and Palynology. Amsterdam/ Holland: Elsevier, v. 99, n. 1998, p. $217-233$.

HOLZ, M., SCHULTZ, C. L. (1998). Taphonomy Of The South Brazilian Middle Triassic Paleoherpetofauna: Fossilization Mode and Implications for Morphological Studies. Lethaia. Stockholm, Pergamon, v. 31, n. 4, p. 335 - 348.

HOLZ, M. \& SIMOES, M.G. (no prelo) Tafonomia e Estratigrafia de Sequencias. In: CARVALHO, I.S. (ed.) Paleontologia, $2^{\text {a }}$ Edicao. Interciência e ANP.

HOLZ, M. \& SIMÕES, M. G. 2002. (eds.) Elementos Fundamentais de Tafonomia. Editora da Universidade Federal do Rio Grande do Sul, Porto Alegre, pp. 223.

HOLZ, M. \& SOARES, M. B. (1995). Tafonomia de Vertebrados - Estado da Arte e Perspectivas Para A Paleontologia Sul-Rio-Grandense. CIENCIA E NATURA. UFSM, v.12, p.77- 81 .

HOLZ, M. \& SOUTO-RIBEIRO, A. (2000). Taphonomy of the south-brazilian Triassic vertebrates. Revista Brasileira de Geociências. Rio de Janeiro, v.30, n.3, p.487 490.

HORTON, B. P.; EDWARDS, R. J.; LLOYD, J. M. (1999). A foraminiferal-based transfer function: implications for sea-level studies. Journal of Faraminiferal Research, 29: 117-129.

KIER, P. M. (1977). The poor fossil record of regular echinoid, Smithsonian Miscellaneous Collections, 152 (2): 149 pp.

KIDWELL, S. M. (1986). Taphonomic feedback in Miocene assemblages: testing the role of dead hardparts in benthic communities. Palaios, v. 1, p. 239-255.

KIDWELL, S.M. (1991A). The stratigraphy of shell concentration. In: Allison, P.A. \& Briggs, D. E. G. (eds.) Taphonomy: releasing the data locked in the fossil record. Plenum Press, New York, p. 211-290.

KIDWELL, S.M. (1991B). Taphonomic feedback (live/dead interactions) in the genesis of bioclastic beds: Keys to reconstructing sedimentary dynamics, in: Cycles and Events in Straigraphy. Einsele,G.; Ricken, W.; Seilacher, A. (eds.) Springer-verlag, Berlin, pp. 268-282.

KIDWELL, S. M. (1991C). Condensed deposits in siliciclastic sequences: expec and observed features. pp. 682-695 In: Einsele, G.; Ricken, W.; Seilacher, A., (eds) Cycles and events in stratigraphy. Springer, Berlin.

KIDWELL, S. M. (1993). Patterns or time-averaging in the shallow marine fossil record. IN: Kidwell, S. M. \& Behrensmeyer, A. K. (eds.) Taphonomic approaches to time resolution in fossil assemblages. Paleontological Society, Short Courses in Paleontology, n. 6, p. 275-300.

KIDWELL, S. M. \& AIGNER, T. (1985). Sedimentary dynamics of complex shell beds; implications for ecological and evolucionary patterns. In: Bayer, U.; Seilacher, A. (Eds.) Sedimentary and evolutionary cycles, Springer-Verlag, Berlim, p. 382-395. 
KIDWELL, S. M. \& BAUMILLER, T.. (1990). Experimental desintegration of regular echinoids: roles of temperature, oxygen, and decay thresholds. Palaeobiology, v.16, p.247-271.

KIDWELL, S. M. \& BEHRENSMEYER, A. K. (1993). Taphonomic approaches to time resolution in fossil assemblages. Short Courses in Paleontology 6 (Special Publication of Paleontological Society, Knoxville, Kentucky).

KIDWELL, S. M. \& BOSENCE, D. W. (1991). Taphonomy and time-averaging of marine shelly faunas. In: Allison, P. A. \& Briggs, D. E. G. (eds.) Taphonomy: releasing the data locked in the fossil record. New York, Plenum Press. p. 115-209.

KIDWELL, S. M. \& BRENCHLEY, P. J. (1994). Patterns in bioclastic accumulations through the Phaneroizoic: Changes in input or in destruction? Geology, 22: 11391143.6

KIDWELL, S. M. \& BRENCHLEY, P. J. (1996). Evolution of the fossil record: thickness trends in marine skeletal accumulations and their implications. In: Jablonsky, D. H.; Erwin, D. H.; Lippis, J. H.; Brenchley, P. J. (eds.) Evolutionary Paleobiology. Chicago, University of Chicago Press, pp. 290-336.

KIDWELL, S. M. \& HOLLAND, S. M. (1991). Field description of coarse bioclastic fabrics. Palaios, 6: 426-434.

KIDWELL, S. M.; FÜRSICH, F. T. \& AIGNER, T. (1986). Conceptual framework for the analysis of fossil concentrations. Palaios, 1: 228-238.

KIDWELL, S. M. \& JABLONSKY, D. (1983). Taphonomic feedback: ecological consequences of shell accumullations. In: TEVESZ, M. J. S. \& MCCALL (eds.) Biotic interactions in Recent and fossil benthic communities. NEW YORK: Plenum Press, p. 195-248.

KIDWELL, S. M.; ROTHFUS, T. A.; BEST, M. M. .R. (2001). Sensitivity of taphonomic signatures to sample size, sieve size, damage scoring system, and target taxa. Palaios 16: 26-52.

KOUTSOUKOS, E. D. M. \& DIAS-BRITO, D. (1987). Paleobatimetria da margem continental do Brasil, durante o Albiano. Rev. Brás. Geociênc. V. 17, n. 2, p. 86-91.

KOWALEWSKI, M. (1996).Time-averaging, overcompleteness, and the geological record. J. Geol., 104: 317-326.

KOWALEWSKI, M. (1997). The reciprocal taphonomic model. Lethaia, 30: 86 88.

KOWALEWSKI, M.; GOODFRIEND, G. A. \& FLESSA, K. W. (1998). High-resolution estimates of temporal mixing within shell beds: the evils and virtues of timeaveraging. Paleobiology, 24: 287-304.

KOWALEWSKI, M.; SIMÕES, M. G. \& FLESSA, K. W. (2000a). High-resolution records preserved in time-averaged shell assemblages: holocene macrofaunas as a tool for reconstructing recent history of coastal geosystems. In: AGU Meeting.

KOWALEWSKI, M.; SIMÕES, M. G. \& FLESSA, K. W. (2000b). Time-averaged bioclastic accumulations from modern coasts: multidisciplinary insigths into ecological, environmental and climatic trends over recent millenia. In: The Geological Society Of America, 2000. Abstracts with Programs, 32 (2).

LEAL, A. DE S. (1962). Geologia da região meridional de Serra Branca, Ipubi, PE. Recife. (Relatório de Graduação, UFPE/Centro de Tecnologia. Inédito) 
LIMA, A. P. (1997). Tafonomia comparada dos trilobitas Calmoniídeos e Homalonotídeos, da Formação Ponta Grossa (Devoniano), região de Jaguariaíva, PR: implicações paleobiológicas e paleoecológicas. Botucatu. 46p. Monografia de conclusão de curso. Instituto de Biociências, Universidade Estadual Paulista.

LIMA FILHO, M. F. (1997). Análise estratigráfica e estrutural da Bacia Pernambuco. (Tese de Doutorado, IGC - Instituto De Geociencias, São Paulo,1997, 139 p.)

LIMA-FILHO, M. F.; VIANA, M. S. S. \& MABESSONE, M. J. (1996). Tectonic and stratigraphic relations bettw Afrobrazilian and Araripe Potiguar Depressions (NE Brazil). IN: CONG. BRAS. GEOL., 39 (Resumo expandido), v. 7, pp. 402-404, Salvador.

LIMA, M. R. (1971). Contribuição palinológica à estratigrafia do Cretáceo do Nordeste do Brasil: análise da perfuração GBS 1 Serra Branca, PE. Porto Alegre, 74p. (Dissertação de Mestrado, UFRS. Inédito)

LIMA, M. R. (1978). Palinologia da Formação Santana (Cretáceo do Nordeste do Brasil) (Tese de doutorado, Universidade de São Paulo, USP, 335p. Inédito)

LIMA, M. R. (1979). Considerações sobre a subdivisão estratigráfica da Formação Santana - Cretáceo do Nordeste do Brasil. Rev. Brasil. Geociências, 9: 116-121.

LOPES, C. F. (1993). Mapa morfo-estrutural da chapada do Araripe. Escala 1:250.000. In: Ponte, F. C \& Ponte Filho, F. C. (1996). Estrutura Geológica e Evolução Tectônica da Bacia do Araripe. DNPM, MME, Distritos Regionais Pernambuco e Ceará. Recife, 1996, 68p.

MABESSONE, J. M. (1985). Fanerozóico Nordestino. Recife, UFP/SBG, Núcleo Nordeste. Textos didáticos. Série D. 60p.

MABESSONE, J. M. \& TINOCO, I. M. (1973). Palaeoecology of the Aptian Santana formation (North Eastern Brazil). Palaeogeography, Palaeoclimatology, Palaeoecology, 14, 97-118.

MABESSONE, J. M.; VIANA, M. S. S. \& LIMA FILHO, M. F. (1999). Late Mesozoic history of sedimentary basins in the brazilian Borborema Province before the final separation of South America and Africa 3: Paleogeography. Boletim do $5^{\circ}$ Simpósio sobre o Cretáceo do Brasil: 621-626. UNESP - Campus de Rio Claro, SP.

MACHADO, D. M. DA C.; CASSAB, R. de C.T. (1997). Ocorrência de gastrópodes na Bacia de Padre Marcos (Cretáceo inferior), NE do Brasil. In: SEMINÁRIO SOBRE A BACIA DO ARARIPE E BACIAS INTERIORES DO NORDESTE, 2. Crato, 1997. Atas... Crato, DNPM. P. 34.

MAISEY, J. G. (ed) (1991). Santana fossils: an illustrated atlas, Tropical Fish Hobbyist Publications, New Jersey, USA, 459 pp.

MAISEY, J. G. (1993). Tectonics, the Santana Formation Lagerstäten, for Late Gondwanan biogeography, Chapter 14 (pp. 435-453). IN: Biological relationships between Africa and South America, Peter Goldbtlatt (ed), Yale University press, 1993.

MAJEWSKE, O.P. (1969). Recognition of invertebrate fossil fragments in rocks and thin sections. In: Cuvillier, J. \& Schurmann, H.M.E. (eds.) International Sedimentary Petrographical Series. E.J. Brill, Leiden. 101p. 
MANSO, C. L. DE C. (1999). Equinóides do Albiano de Sergipe: notas preliminares. In: CONGRESSO BRASILEIRO DE PALEONTOLOGIA, 10, Crato, 1999. Resumos. Crato.CE. p. 63.

MARSHALL, C. R. (1990) Confidence intervals on stratigraphic ranges. Paleobiology, 16: $1-10$.

MARTILL, D. M. (1988). Preservation on fish in the Cretaceous Santana Formation of Brazil. London, Paleontology. 31(1):1-18.

MARTILL, D. M. (1993). Fossils of the Santana and Crato Formations. Brazil. London, The Palaeontological Association. 159 p. (Field Guides to fossils 5).

MARTILL, D. M. (1990). The significance of the Santana biota. In: SIMPÓSIO DA BACIA DO ARARIPE E DAS BACIAS INTERIORES DO NORDESTE, 1. Crato, 1990. atas...Crato, DNPM. pp. 253-264.

MARTIN, R. M.; PATTERSON, R.; GOLDSTEIN, S. \& KUMAR, A. (1999). Taphonomy as a tool in paleoenvinmental reconstruction and environmental assessment. Palaeogeography, Palaeoclimatology, Palaeoecology, Special Inssue, 149, 429p.

MATOS, R. M. B. de. (1987). Sistema de rifts cretáceos do Nordeste do Brasileiro. In: simp. Nac. Estudos Tectônicos, I. Salvador, 1987. Boletim de Resumos...UFBA/IG.

MENDES, J. C. (1988). Paleontologia Básica. T.A. Queiroz Editora e Editora da Universidade de São Paulo, São Paulo, 347 p.

MEDEIROS, R. A. (1990). Estratigrafia da Chapada do Araripe: estado da arte. In: SEMINÁRIO SOBRE A BACIA DO ARARIPE E BACIAS INTERIORES DO NORDESTE, 1. Crato, 1990. Atas... Crato, DNPM. p. 43-51.

MEDEIROS, R. A. ; PONTE, F. C.; PONTE-FILHO, F. C. (1997). Análise estratigráfica da Bacia do Araripe: parte 2 -análise de fácies. In: SEMINÁRIO SOBRE A BACIA DO ARARIPE E BACIAS INTERIORES DO NORDESTE, 2. Crato, 1997. Atas... Crato, DNPM. P. 18-19.

MESNER, J. C. WOOLDRIDGE, L. C. P. (1962). Maranhão Paleozoic Basin and Cretaceous Coastal basins, North Brazil. American Association Petrolleum Geologists Bulletin, Tulsa, v. 48, n. 49, p. 1475-1512.

MIALL, A. D. (1991). Stratigraphy sequence and their chronostratigraphic correlation. Journal of Sedimentary Petrology, 61: 497-505.

MILLER, A. I.; HOLLAND, S. M.; DATTILO, B. F.; MEYER, D. L. (1997). Stratigraphic resolution and perceptions of cicle architecture: variations in meter-scale cyclicity in the type Cincinnatian Series. Journal of Geology, 105: 737-743

NEUMANN, V. H. DE M. L. (1999). Estratigrafia, sedimentologia, geoquímica y diagenesis de los sistemas lacustres aptiense-albienses de la Cuenca de Araripe (Noreste de Brasil). (Universitat de Barcelona, DEP, DGPPG, Tesis de Doctoral, 244 p.).

NORTHFLEET, A. A.; GONÇALVES, A; NETTO, A. S. T.; FRANÇA, A. M. C.; PENNA, C. A. T.; DA SILVA, C. A. M.; RIBEIRO, E. M.; DA ROSA, G. B.; LOPES, J. A.; RIBEIRO, J. C. NEVES, L. E.; DA SILVA, O B.; ARARIPE, P. T. E DE SOUSA, U. P. (1997). Análise Comparativa Da Paleogeologia Dos Litorais Atlânticos Brasileiro $E$ Africano. B. Geoci. PETROBRAS, Rio de Janeiro, 11 (1/2): 1-18, jan/dez. 19979 (Cesero, P. de (editor) \& Ponte, F. C (coordenador). 
OJl T. ; OGAYA, C.; SATO, T. (2003). Increase of Shell-crushing predation recorded in fóssil Shell fragmentation. Paleobiology, 29 (4), 2003, pp. 520-526.

OLIVEIRA, E de (1983). A chapada do araripe e sua representação pela gravimetria. Rio de Janeiro. Petrobrás /DEPEX / SEMEPO. In: PONTE, F. C \& PONTE FILHO, F. C. (1996). Estrutura Geológica e Evolução Tectônica da Bacia do Araripe. DNPM, MME, Distritos Regionais Pernambuco e Ceará. Recife, 1996, 68p.

OLIVEIRA, A. A. DE; BRITO, A. DE L. F.; SANTOS, M. E. C.; CARVALHO, M. S. S. (1979). Projeto Chapada do Araripe. Recife, DNPM/CPRM. 5 vols. (Relatório Final).

PETRI, S. (1987). Cretaceous paleogeographic maps of Brazil. Amsterdam, Palaeogeography, palaeoclimatology, palaeoecology. 59:117-168.

PHLEGER, F. B. (1969). A modern evaporite deposit in Mexico. The American Association of Petroleum Geologists Bulletin. Vol. 53, N 4, p. 824-829.

PONS, D.; BERTHOU, P-Y; CAMPOS, D. A. (1990). Qualques observations sur la palynologie de l'A Supérieur et de l'A du bassin d'Araripe (NE du Brésil). In: Seminário Sobre A Bacia Do Araripe E Bacias Interiores Do Nordeste, 1. Crato, 1990. Atas... Crato, DNPM. P. 241-252.

PONTE, F. C. (1992a). Origem e evolução das pequenas bacias cretácicas do interior do nordeste do Brasil. In: Simpósio Sobre As Bacias Cretácicas Brasileiras, 2, Rio Claro, 1992. Resumos Expandidos... Rio Claro, UNESP/IGCE. p. 55-58.

PONTE, F. C. (1992b). Sistemas deposicionais da Bacia do Araripe, nordeste do Brasil. In: Simpósio Sobre As Bacias Cretácicas Brasileiras, 2, Rio Claro, 1992. Resumos Expandidos... Rio Claro, UNESP/IGCE. p. 81-84.

PONTE, F. C. 1994. Extensão paleogeográfica da Bacia do Araripe no Mesocretáceo. In: SIMP. CRETÁCEO O BRASIL, 3, Rio Claro, 1994. Boletim... Rio Claro, UNESP, p. 131-135.

PONTE, F. C. (1996). Arcabouço estrutural da Bacia do Araripe. In: Simpösio Sobre O Cretäceo do Brasil, 4., 1996. Boletim.. Rio Claro, UNESP / IGCE. p. 169-177.

PONTE, F. C. \& APPI, C. J. (1990). Proposta de revisão da coluna litoestratigráfica da Bacia do Araripe. In: Congresso Brasileiro Geologia, 36, Natal, 1990, Anais... Natal, SBG. v. 1, p.211-226.

PONTE, F. C \& PONTE, V. L. DE A. (1996). Bibliografias sobre as bacias fanerozóicas do interior do Nordeste Oriental do Brasil: 1816-1994. CECB/SBG/DNPM, MME, Distritos Regionais Pernambuco e Ceará. Recife, 1996, 129p.

PONTE, F. C \& PONTE FILHO, F. C. (1996). Estrutura Geológica e Evolução Tectônica da Bacia do Araripe. DNPM, MME, Distritos Regionais Pernambuco e Ceará. Recife, 1996, 68p.

PONTE, F. C.; MEDEIROS, R. A.; PONTE FILHO, F. C. (1997). Analise estratigráfica da Bacia do Araripe: parte I - análise de seqüências. In: SEMINÁRIO SOBRE A BACIA DO ARARIPE E BACIAS INTERIORES DO NORDESTE, 2. Crato, 1997. Atas... Crato, DNPM. P. 17.

PONTE FILHO, F. C. (1992). Análise geohistórica do poço 2-AP-1-CE, Bacia do Araripe. In: SIMPÓSIO BACIAS CRETÁCICAS BRASILEIRAS, 2. Rio Claro, 1992. Resumos Expandidos... Rio Claro, UNESP/IGCE. P. 85-89. 
PRICE, L.I. (1973). Quelônio Amphichelidia no Cretáceo inferior do Brasil. Rev. Brás. Geociênc., São Paulo, v. 3, n. 2, p. 84-96.

RAND, H. M. \& MANSO, V. A. V. (1984). Levantamento gravimétrico e magnetométrico da Bacia do Araripe. In: Congresso Brasileiro Geologia, 33, Rio de Janeiro, 1984. Anais... SBG, v. 4, p. 2011-2016.

RIBEIRO, H. J. P. S. (org).(2001). Estratigrafia de Seqüências: fundamentos e aplicações, Editora. São Leopoldo, RS. Unisinos. 428p. II.

RODRIGUES, S. C. (2002). Tafonomia comparada dos Conulatae collins et al. 2000 , Formação Pont-Grossa, Devoniano (?Lochkoviano-frasniano), Bacia do Paraná: Implicações paleautoecológicas e paleoambientais. (Dissertação de Mestrado, Prog. Pós-Grad. Em Geol. Sedimentar, Univ; de São Paulo, São Paulo). 100p. Ined.

SALES, A. M. F. \& LEAL NETO A.(1996). Mapeamento Geológico da Porção Centro Norte da Bacia do Araripe e Embasamento Cristalino Adjacente (Área 01). 155 p. (Relatório de Graduação) - Departamento de Geologia, Universidade Federal do Ceará.

SALES, A. M. F. \& LEAL NETO A. (1993). Estudo da composição mineralógica e textural dos testemunhos de sondagem da Formação Santana (Sudoeste da Bacia do Araripe - PE). In: XII Encontro Universitário de Iniciação à pesquisa e I Encontro de Pós-Graduação. Ed. UFC, Fortaleza, resumos. G 172, p.55.

SALES, A. M. F.; GHILARDI, R. P.; LIMA FILHO, F. P. (1999). SOBRE as coquinas calcáreas do Membro Romualdo, Formação Santana (Cretáceo) Bacia do Araripe, uma contribuição estratigráfica. In: Congresso Brasileiro De Paleontologia, 10, Crato, 1999. Resumos. Crato.CE. p. 93.

SALES, A. M. F. \& SIMÕES, M. G. (2000). Tafonomia como suporte a estudos estratigráficos: exemplo das concentrações fossilíferas de invertebrados da Formação Santana (Cretáceo), Bacia do Araripe, NE do Brasil. In: Paleo-2000, SP, Botucatu, 2000, Boletim de Resumos..., 17.

SALES, A. M. F.; SIMÕES, M. G. (2003). Análise tafonômica das concentrações Fossiliferas de macroinvertebrados do Membro Romualdo (Albiano) da Formação Santana, Bacia do Araripe, NE do Brasil: significado estratigráfico, temporal e paleoambiental. In: II Workshop Científico de Pós-Graduação do IGc-USP. São Paulo, SP. ...Boletim de Resumos. São Paulo, 2003, p. 08.

SALES, A. M. F. SIMÕES, M. G.; ANELLI, L. E. (2002). Bringing Color To The Fossil Record: Color Pattern On The Cretaceous Gastropod Natica Sp., Araripe Basin, Brazil. In: Paleo 2002, Boletim de Resumos...IGc/USP - São Paulo, 2002, SBG, Núcleo São Paulo, PPG-GSA-IGc-USP, p. 19.

SALES, A. M. F.; SIMÕES, M. G ; ANDRADE, J. A. F. G. de $\left(2003^{a}\right)$. Concentração Coquinóide de Macroinvertebrados Fósseis (Moluscos) da Formação Santana (Cretáceo), Região de Araripina, SW da Bacia do Araripe. In: Congresso Brasileiro de Paleontologia, 18, 2003, Brasília, DF... Boletim de Resumos. SBG/UNB: Brasília: 2003, p. 248-249.

SALES, A. M. F.; SIMÕES, M. G; ANDRADE, J. A. F. G. de (2003b). Comparative Taphonomy Of Pygurus Tinocoi An Irregular Echinoid Of The Santana Formation (Cretaceous), Araripe Basin, Brazil. In: Congresso Brasileiro de Paleontologia, 18, 2003, Brasília, DF... Boletim de Resumos. SBG/UNB: Brasília: 2003, p. 246-247. 
SANTOS, M. E. C. M. (1960). Equinóides cretácicos do Rio Grande do Norte. Rio de Janeiro, DNPM/DGM. 26. (Boletim 189).

SANTOS, M. E. C. M. (1982). Ambiente deposicional da Formação Santana, Chapada do Araripe (PE,PI,CE). In: Congresso Brasileiro Geologia.,32. Salvador, 1982. Anais... Salvador, SBG. V. 3, p. 1412-1426.

SANTOS, M. E. C. M. \& CASSAB, R. C. T. (coord.) (1994). Range charts of the fossils of the Cretaceous Potiguar Basin. In: G. Beurlen, D. De A. Campos; M. C. Viviers (eds.) - Stratigraphic Range of Cretaceous Mega and Microfossils of Brazil. Rio de Janeiro, UFRJ. P. 273-310.

SANTOS, R. S. \& VALENÇA, J. G. (1968). A Formação Santana e sua Paleoictiofauna. Anais da Academia Brasileira de Ciências, 40 (3): 339-360.

SAVRDA, C. E.; BOTTJER, D. J.; SEILACHER, A. (1991). Redox-related benthic events. In EINSELE ET AL. (eds.) Cycles and Events in Stratigraphy, SpringerVerlag, Berlin, Heidelberg, 524-5441.

SCHÄFER, W. (1972). Ecology and Palaeoecology of marine environments. Oliver \& Boyd, Edinburgh.

SCHULTZ, C. L., HOLZ, M., GAMERMANN, N. (1990), Tafonomia de Vertebrados: A Diagenese Como Fator de Alteracao Morfologica. Ciência e Natura. Santa Maria: IG/UFRGS, v.12, p.77- 81.

SILVA A. M. M. (1983). The Araripe Basin, Northeastern Brasil: Regional geology and fácies analysis of a lower Cretaceous evaporitic depositional complex. (Ph.D. thesis, Graduate School of Arts and Sciences, Columbia University. New York).

SILVA A. M. M. (1988). Evaporitos do cretáceo da Bacia do Araripe: ambientes de deposição e história diagenética. Rio de Janeiro,. Bol. Geol. Petrobras, 2(1):53-63.

SILVA A. M. M. (1986). Lower Cretaceous Sedimentary sequence in the Araripe Basin, northeastern Brazil. A revision. Rev. Bras. Geociências, 16(3), 311-319.

SILVA SANTOS, R. (1991). Paleogeography of the Araripe Basin. In: J. G. Maisey (editor) - Santana Fossils: An Illustrated Atlas. New Jersey, TFH. P. 40-43.

SILVA TELLES JR., A C. \& VIANA, M. S. S. (1990). Paleoecologia dos ostracodes da Formação Santana (Bacia do Araripe): um estudo ontogenético de populações. In: SIMP. BACOA DO ARARIPE E BACIAS INTERIORES DO NORDESTE, 1 Crato, 1990. Atas...Crato, DNPM. P. 309-328.

SIMÕES, M. G. (1996). Pelecypod taphofacies of Corumbataí Formation (Late Permian), in Central São Paulo State, Paraná Basin, Brazil. In; $39^{\circ}$ Cong. Bras. Geologia, Salvador, Anais...p. 298-300.

SIMÕES, M. G. (1998). Tafonomia, "time-averaging" e resolução espacial de concentrações fossiliferas internamente complexas: um estudo de casos do Permiano, Bacia do Paraná-Brasil e suas implicações paleoecológicas. Botucatu. (Tese de Livre-Docência, Instituto de Biociências, Universidade Estadual Paulista.) 160 .

SIMÕES, M.G. \& KOWALEWSKI, M. (1998a). Shell beds as paleoecological puzzles: a case study from the Upper Permian of the Parana Basin, Brazil. Facies, 38: 175196. 
SIMÕES, M. G. \& KOWALEWSKI, M. (1998b). Genetic complexity and geobiological implications of "simple" shell beds: an example from the Upper Permian of the Paraná Basin, Brazil. J. Afr. Ear. Sci., 27 (1A): 179-180.

SIMÕES, M. G. \& HOLZ, M. (2000). Tafonomia; processos e ambientes de fossilização. Pp. 19-37 In: Carvalho, I. S. de (ed) Paleontologia, Rio de Janeiro: Interciência, 2000, 628p.

SIMÕES, M. G. \& GHILARDI, R. P. (2000). Protocolo tafonômico/paleoautológico como ferramenta nas análises paleossinecológicas: exemplos de aplicação em concentrações fossiliferas do Paleozóico da Bacia do Paraná. Pesquisas em Geociências, 27(2):3-13.

SIMÕES, M.G.; TORELLO, F. F.; ROCHA CAMPOS, A. C. (1994). Proximal storm beds or coquinas in the Corumbatai formation (Pinzonella llusa assemblege; late permian), in Rio Claro, SP, Paraná Basin, Brazil. In: 38 CONG. BRAS. GEOLOGIA, 38., Balneário de Camburiú, 1994. Boletim de Resumos Expandidos. P. 226-227.

SIMÕES, M. G.; LIMA FILHO, F. P.; CALDAS, E. B. (1995). Feições bioestratinômicas de concentrações fossilíferas da Formação Santana (Cretáceo), Bacia do Araripe, Brasil. $14^{\circ}$ Congresso Brasileiro De Paleontologia, Uberaba, SBP, Atas...p. 126.

SIMÕES, M. G.; TORELLO, F. F. \& ROCHA-CAMPOS, A. C. (1996). Gênese e classificação da coquina de Camaquã (assembléia de Pinzonella neotropica), Formação Corumbataí (Permiano Superior), Rio Claro, SP. An. Acad. Bras. Ci., 68(4):545-557.

SIMÕES, M. G., GHILARDI, R. P., SALES, A. M. F., RODRIGUES, S. C.; LEME, J. M. \& MELLO, L. H. C DE. (2000). Taphonomy and gênesis of the "Conularia Beds" from Ponta Grossa Formation (Devonian) within a Sequence Stratigraphy Framework. $1 \mathrm{~m}$ : Paleo-2000, SP, Botucatu, 2000, Boletim de Resumos...,20.

SIMÕES, M. G.; GHILARDI, R. P.; SALES, A. M. F.; RODRIGUES, S. C.; LEME, J. M. (2001). Taphonomy and sequence stratigraphy as integrated tools in paleoenvironmental analysis: some examples from the Paraná (Devonian) and Araripe (Cretaceos) basins, Brazil. In: CONGRESSO BRASILEIRO DE PALEONTOLOGIA. Boletim de Resumos... Rio Branco, AC, 2001.

SIMÕES, M. G.; GHILARDI, R. P.; SALES, A. M. F.; HOLZ, M.; RODRIGUES, S. C.; LEME, J. P.. (2002a). Taphonomic signatures marking parasequence boundaries in offshore settings: an example from Devonian, Paraná basin, Brazil. In: Gondwana, 11, Correlations and Conections, 2002, Christchurch, New Zealand, p. 77-77.

SIMÕES, M. G.; GHILARDI, R. P.; SALES, A. M. F.; HOLZ M.. (2002b). Sequence stratigraphic controls on the pattern of vertical distribution of taphonomic signatures: the Devonian of the Paraná basin, Brazil. In: Gondwana, 11, Correlations and Conections, 2002, Christchurch, New Zealand, p. 78-78.

SIMÕES, M.G.; GHILARDI, R.P.; RODRIGUES, S. C.; SALES, A. M. F.; LEME, J.M.. (2003). Taphonomy and Paleoecology of two Marine Flooding Surfaces in a Transgressive Systems Tract: a devonian example from the Paraná Basin, Brazil. In: Latinamerican Congress of Sedimentology, Brasil, 2003, Belém, Para, Abstract Book...Museu Paraense Emilio Goeldi; UFPA, 2003. 1v, pp. 219-220.

SIMÕES, M.G.; SALES, A. M. F.;GHILARDI, R.P.; HOLZ, M.; RODRIGUES, S.C.; LEME, J.P. (2002c). Assinaturas tafonômicas como marcadoras de limites de 
parasseqüências em offshore settings: um exemplo do Devoniano, Bacia do Paraná, Brasil. In: CONGRESSO BRASILEIRO DE GEOLOGIA, 41....Boletim de Resumos, João Pessoa, PB, 2002, pp. 680-681.

SMITH, A. B.(1984). Echinoid paleobiology, George Alen \& Unwin, London.

SOHL, N.F. (1987). Cretaceous gastropods: contrasts between Tethys and the temperate provinces. Journal of Paleontology, 61(6): 1085-1111

SPEYER, S. E. \& BRETT, C. E. 1986. Trilobite taphonomy and Middle Devonian taphofacies. Palaios, 1; 312-327.

SPEYER, S. E. \& BRETT, C. E. (1988). Taphofacies models for eperic sea environments: Middle Paleozoic examples. Palaeogeography, Palaeoclimatology, Palaeocology, v. 63, p.225-262.e

SPEYER, S. E. \& BRETT, C. E. (1991). Taphonomic controls: backguroud and episodic processes in fossil assemblege preservation. In; Alisson, P. A. \& Brigss, d. E. (eds). Taphonomy: realeasing the data locked in the fossil record. Topics in Geobiology, Plenun Press, New Your, p. 501-545.

SRIVASTAVA, N. K. (1996). Cretaceous continental stromatolites from the Araripe Basin, Northeast Brazil. IGCP PROJECT 381: SOUTH ATLANTIC MESOZOIC CORRELATIONS. In: 39 CONGRESSO BRASILEIRO DE GEOLOGIA. Anais...Salvador, BA. SBG-NE. p. 414-417.

STANLEY, S. M. (1970). Relation of the shell form to life habits in the Bivalvia (Mollusca). Geol. Soc. Am. Mem., 125: 1-296.

STRAUSS, D. \& SADLER, M. P. (1989). Classical confidence intervals and the Bayesian probabability estimates for the ends of local taxon ranges. Mathematical Geology 21: $411-427$.

TORELLO, F. F. (1999). Bioestratinomia de concentrações fossiliferas da assembléia de Pinzonella neotropica (Reed), da Formação Corumbatai (Permiano), Tambaú, SP. São Paulo. 121p. (Dissertação de Mestrado em Geociências. Instituto de Geociências, Universidade de São Paulo.)

TORELLO, F. F. \& SIMÕES, M. G. (1994). Características tafonômicas da assembléia de Pinzonella illusa Reed, Formação Corumbataí (Neopermiano), Bacia do Paraná, Brasil. Acta Geol. Leopol., 39/1(17):159-173.

TUCKER, M. E. (2001). Limestones. In: Sedimentary Petrology: an Introduction to the Origin of Sedimentary Rocks. (Ed. Tucker, M. E. ), pp. 110-165. Blackwell.

VAIL, P. R.,AUDEMARD, F., BOWMAN, S.A., EISNER, P. N. \& PEREZ-CRUZ, C.- The Stratigraphic signatures of tectonic, eutasy and sedimentology. In: Einsele, G. et al., orgs: Cycles and events in stratigraphy, Berlim, 955 p., Springer Verlag, 1992.

VAIL, P.R.; MITCHUM, R.M.; THOMPSON, S. (1977). Global cycle of relative changes of sea level. In: C.E. Payton, (ed.). Seismic stratigraphy; aplications to hydrocarbon exploration. Tulsa, American Association of Petroleum Geologist. 26:83-97.

VIANA, M. S. S. (1990). Estratigrafia e Paleontologia da Formação Santana, Cretáceo Inferior da Bacia do Araripe, Nordeste do Brasil. (Universidade Federal do Rio de Janeiro, UFRJ, Instituto de Geociências, Dissertação de Mestrado, 107p.).

VIANA, M. S. S. (1998). The proto-Atlantic Albian way and its influence on the South American-African life. In; ANNUAL CONFERENCE SOUTH ATLANTIC MESOZOIC 
CORRELATIONS (IGCP Project 381), 3. Comodoro Rivadavia (Argentina), 1998. .Associación Paleontológica Del Golfo San Jorge. Boletín 2( Edición Especial) Ano I. (ed. ) Musacchio, E. A., 1998, p. 32-34.

VIANA, M. S. S. (1999). Estudo Paleoambiental na parte Superior da Formação Santana (Cretáceo da Bacia do Araripe, Nordeste do Brasil): natureza dos sedimentos e tafonomia. (Tese de doutorado, Porto Alegre, Geociências, UFRS, 124 p.).

VIANA, M. S. S. \& CAVALCANTI, V. M. M. (1990). Localidades e conteúdo fossilífero da Bacia do Araripe, Nordeste do Brasil. In: Congresso Brasileiro de Geologia, 36. Natal, 1990. Anais...Natal, SBG. V.1, p.476-489.

VANDOROS, P., CORDANI, U., MATZKO, J. J. (1966). Idades absolutas das rochas ígneas da Região do Cabo, Pernambuco. In: CONGRESSO BRASILEIRO DE GEOLOGIA, 20., 1966. Vitória. Resumos das Comunicações... Rio de Janeiro: Sociedade Brasileira de Geologia, 1966. 131p. p. 64-66. (Sociedade Brasileira de Geologia. Publ. n. 1).

WALKER K. R. \& BAMBACH, R. K. (1971). The significance of fóssil assembleges from fine-grained sediments: time averaged communities. The Geological Society of América Annual Meeting, abstracts with programs, p. 783-784.

WENZ, S. (1980). A propos du genre Mawsonia, Coellchanthe giant du Cretace Inferieu d'Afrique et du Brazil. Mem. Soc. Geolog. Fr. N. S. 139: 187-190.

WILBY P. R. (1993). The mechanisms and timing of mineralization of fossils phosphatized soft tissues. (Ph.D. thesis, Departament of Earth Sciences, Open University, 2 vol.). 
Pranchas 


\section{PRANCHA 1}
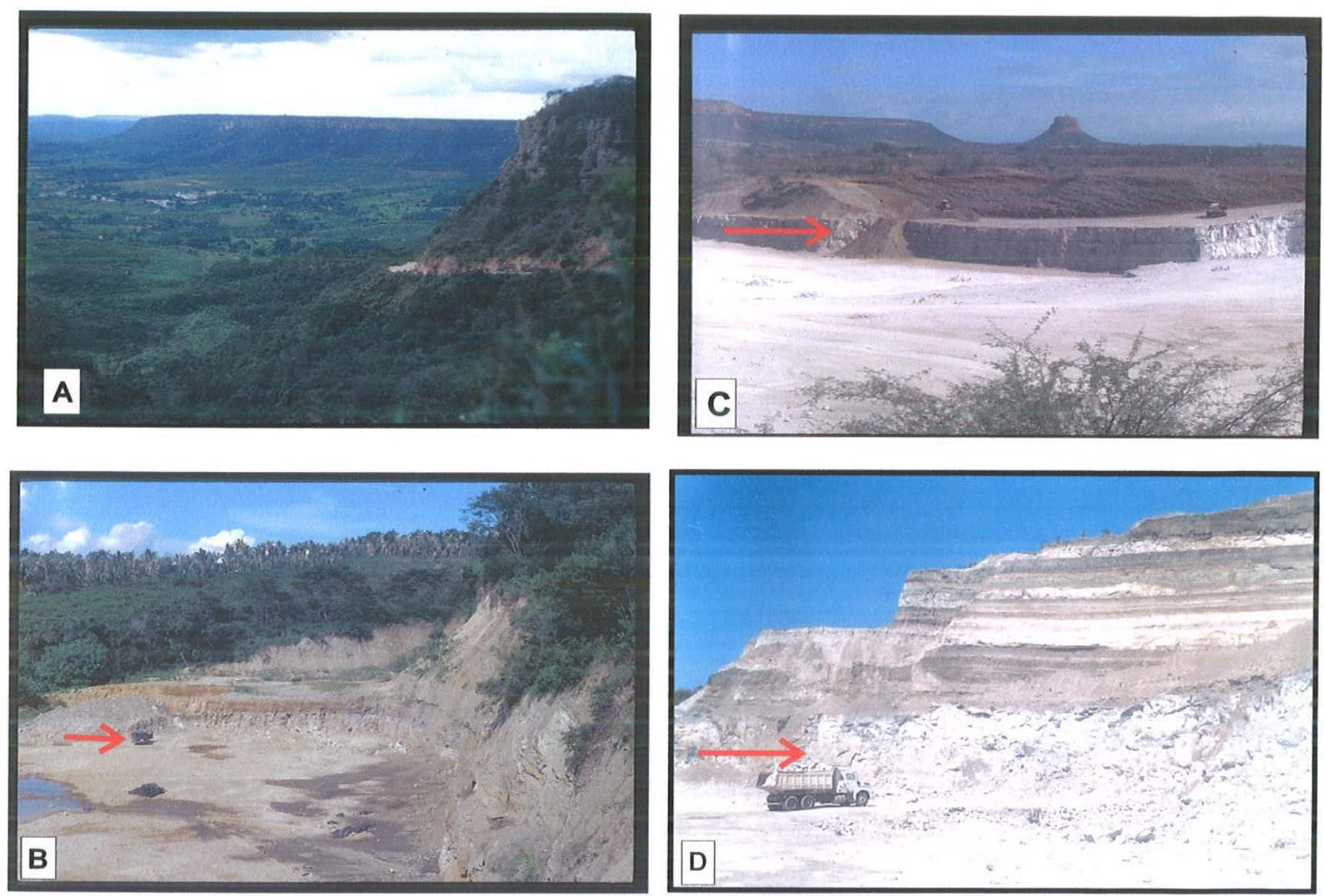

Prancha 1. Foto A - Escarpas da Chapada do Araripe, local de ocorrência dos depósitos fossilíferos da Formação Santana, Tabocas, Município de Exu, PE; B - Lavra Mina Santa Rita (IBACIP), Município de Barbalha, CE (seta aponta carro como escala); C - Mina Matarazo (antiga mina Casa de Pedra), Trindade, PE (seta em vermelho, aponta camada de gipsita do Membro Ipubi, ); D Exposição parcial dos litótipos da Formação Santana (membros Ipubi e Romualdo, na Mina Pedra Branca (seta em vermelho, aponta camada de gipsita do Membro Ipubi). 


\section{PRANCHA 2}
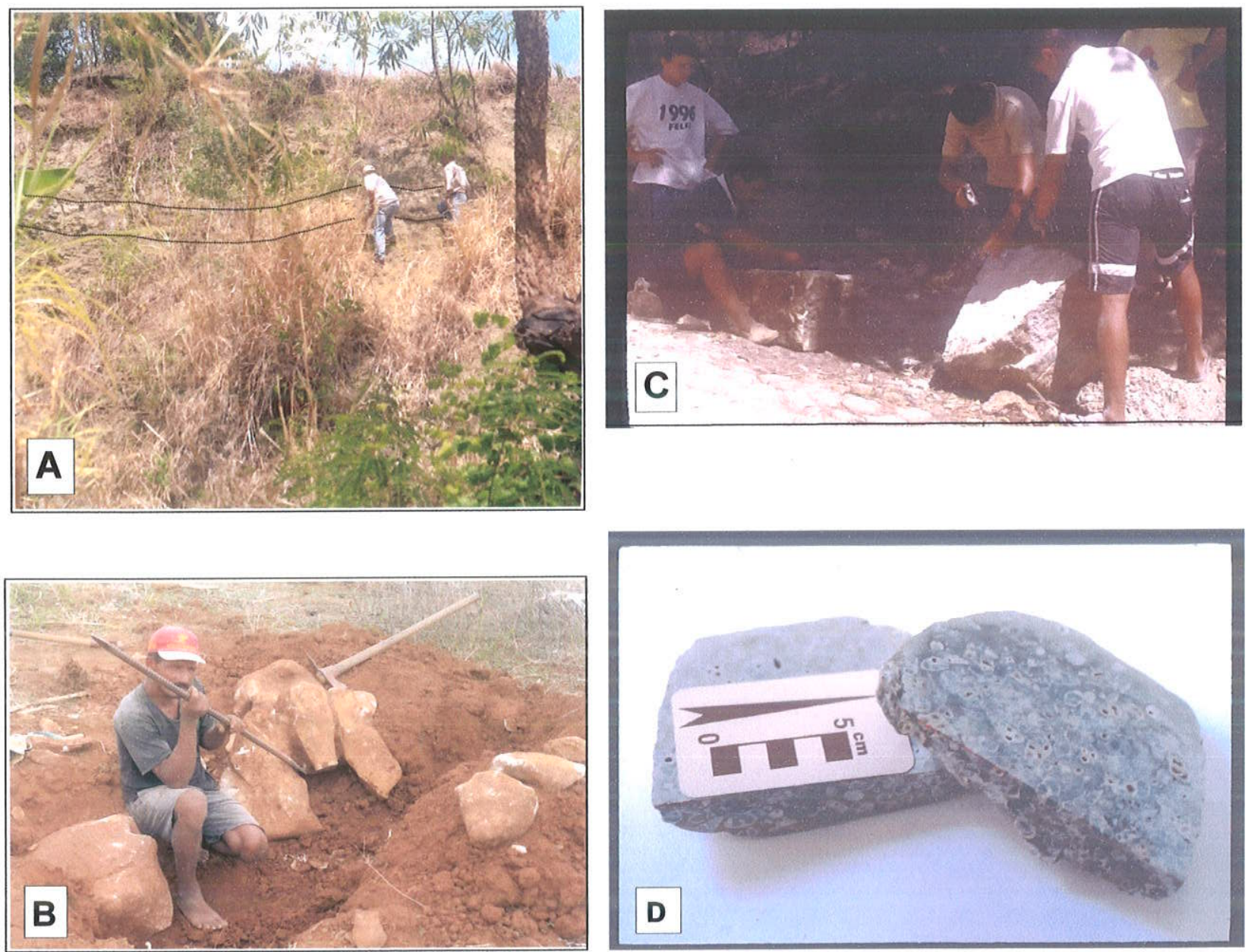

Prancha 2. Foto A - Afloramento de calcarenitos fossilíferos com macroinvertebrados bentônicos, extensão lateral de aproximadamente 10 metros, Serra da Mãozinha, Missão velha, CE; Foto B - Abertura de trincheiras, acumulação com equinóides fósseis, Canastra, Araripina, PE; Foto C - Coleta de blocos para análise tafonômica, Sítio Negros, Jardim, CE; Foto D Amostra seccionada com concentração de moluscos, amostra de Sítio Jatobá, Porteiras, CE. 
PRANCHA 3
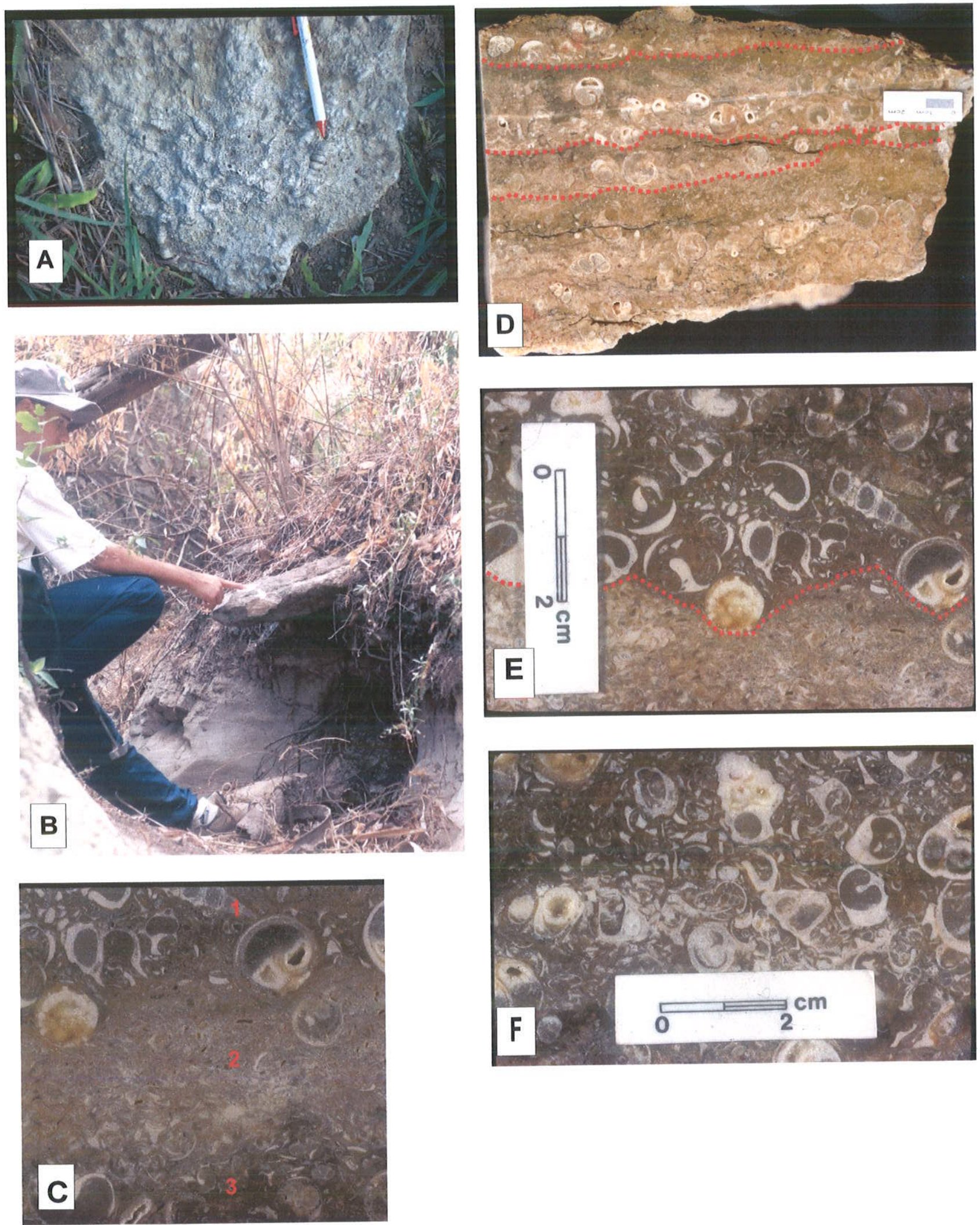

Prancha 3. Foto A - Concentração de moluscos fósseis, predominando gastrópodes turritelídeos, apresentando orientação polimodal; Foto B - Concentração fossílifera intercalando arenitos (cota 627); (Fotos C, D, E e F - concentração da cota 632, cortes em seção), Foto C - Diferentes graus de adensamento das unidades microestratigráficas; Foto D - Unidades microestratigráficas, notar bioclástos grossos na base das unidades microestratigráficas; Foto $\mathrm{E}$ - Contatos basais bruscos e erosivos das unidades microestratigráficas; Foto $\mathrm{F}$ - Intensa fragmentação e arranjo Interno caótico dos bioclastos. Concentrações de Romualdo, Crato, CE (Fotos - C, E e F, Marcello G. Simões). 
PRANCHA 4
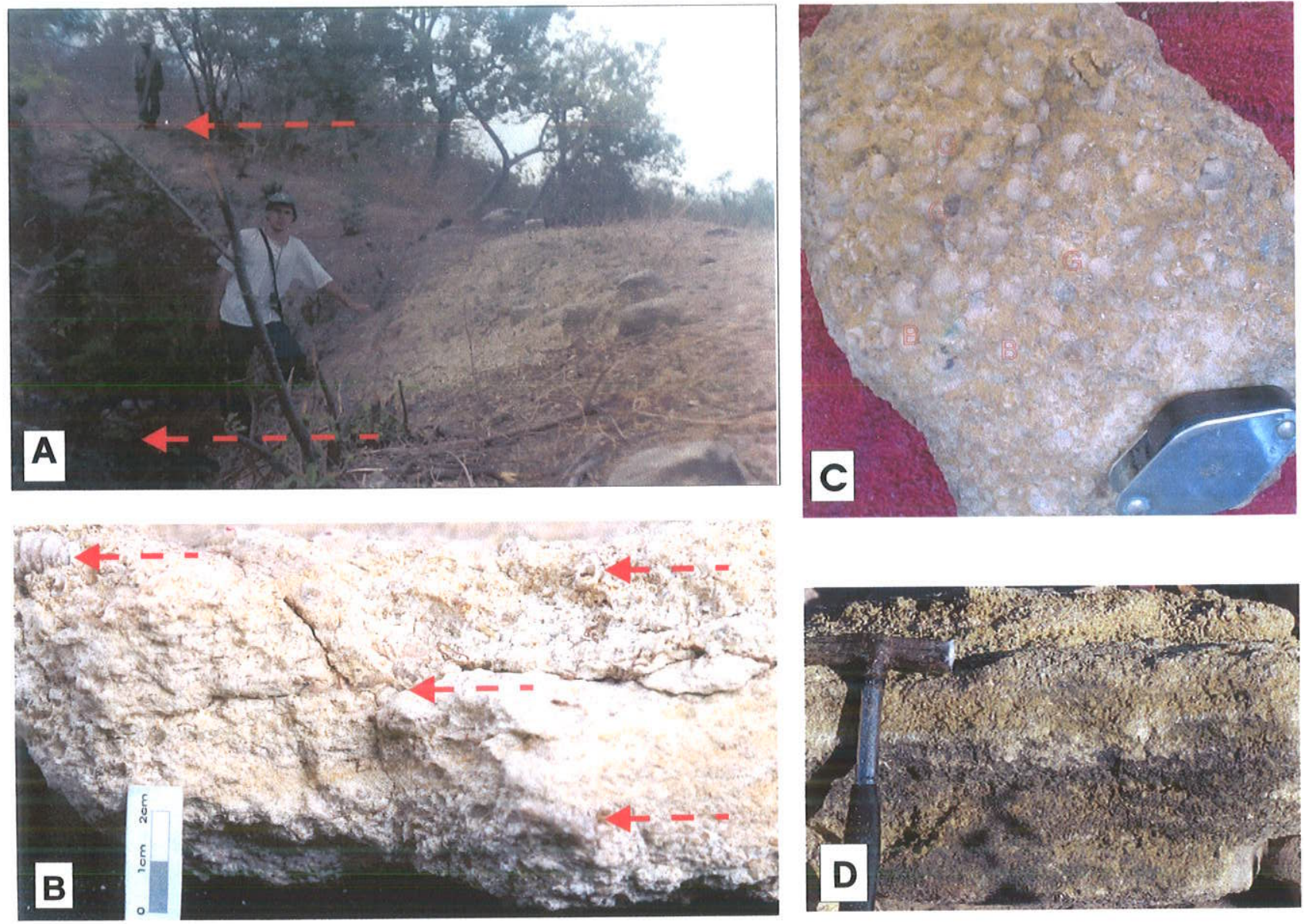

Prancha 4. Foto A - Afloramento com ocorrências de concentrações (setas em vermelhoa, apontam o início e o término das ocorrências) com níveis recristalizados e predomínio de turritelídeos e pequenos bivalves indeterminados; Foto B - Detalhe da rocha, da foto anterior (seta em vermelho aponta turritelídeo); Foto C - Depósito fossilífero, apresentando recristalização ( $\mathrm{G}$ = gastrópodes e $\mathrm{B}=$ bivalves); Foto $\mathrm{D}$ - bloco com aproximadamente $40 \mathrm{~cm}$ (Jamacaru, Missão Velha, CE). 


\section{PRANCHA 5}
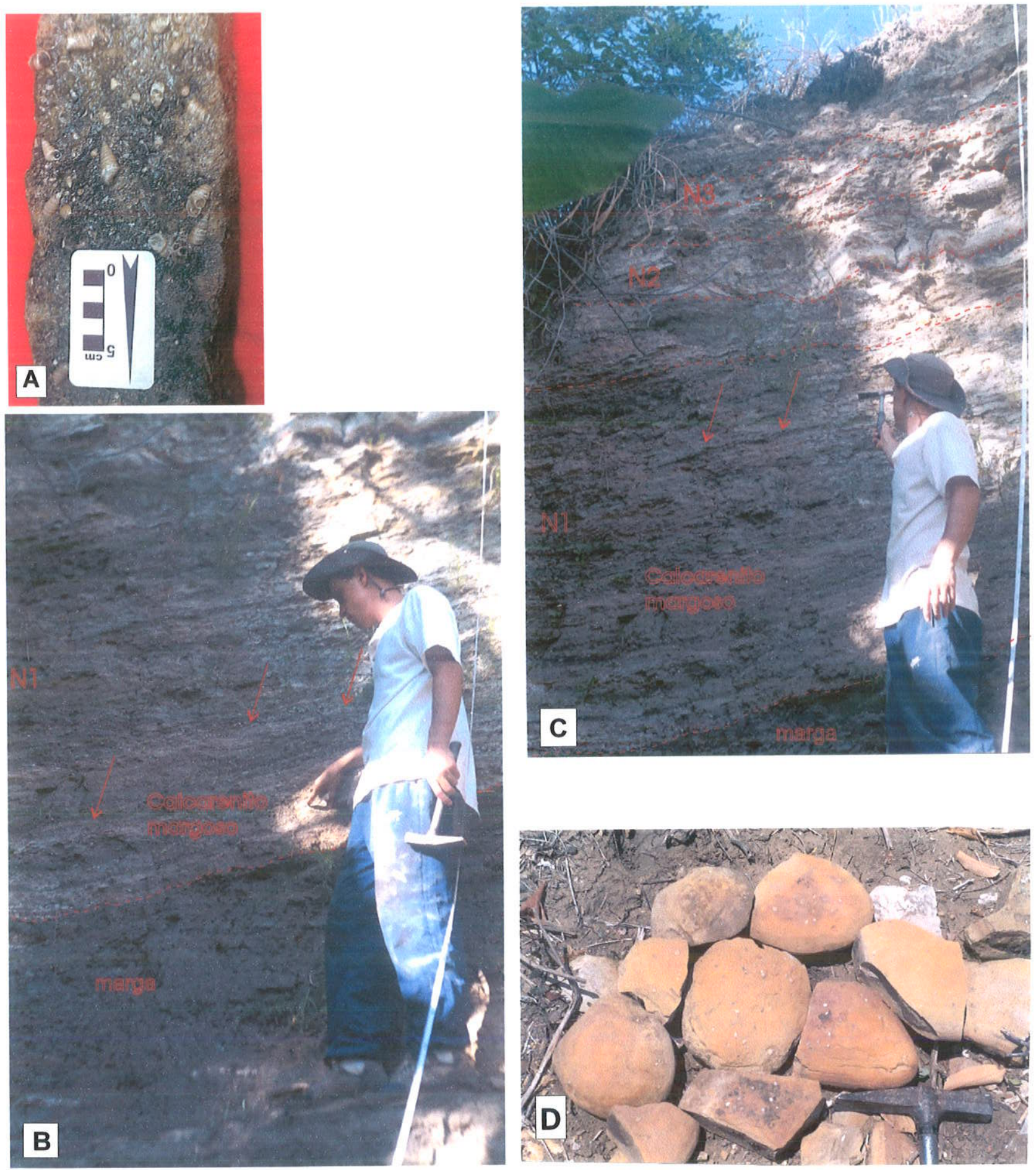

Prancha 5. Foto A - Concentração fossilifera com predomínio de gastrópodes Paraglaucônia cf. lyrica, cota $758 \mathrm{~m}$ do perfil litoestratigráfico 1; Fotos B e C - Afloramento contendo três níveis de acumulações fossilíferas intercalando margas (cotas $773 \mathrm{~m}, 775 \mathrm{~m}$ e $776,5 \mathrm{~m}$ ) no topo do perfil litoestratigráfico 1 (marcas onduladas e hummockys - setas em vermelho); Foto D- Concreções contendo ictiólitos, apresentando externamente pequenos moluscos (Sítio Encruzilhada, Serra da Mãozinha, Missão Velha, CE). 


\section{PRANCHA 6}
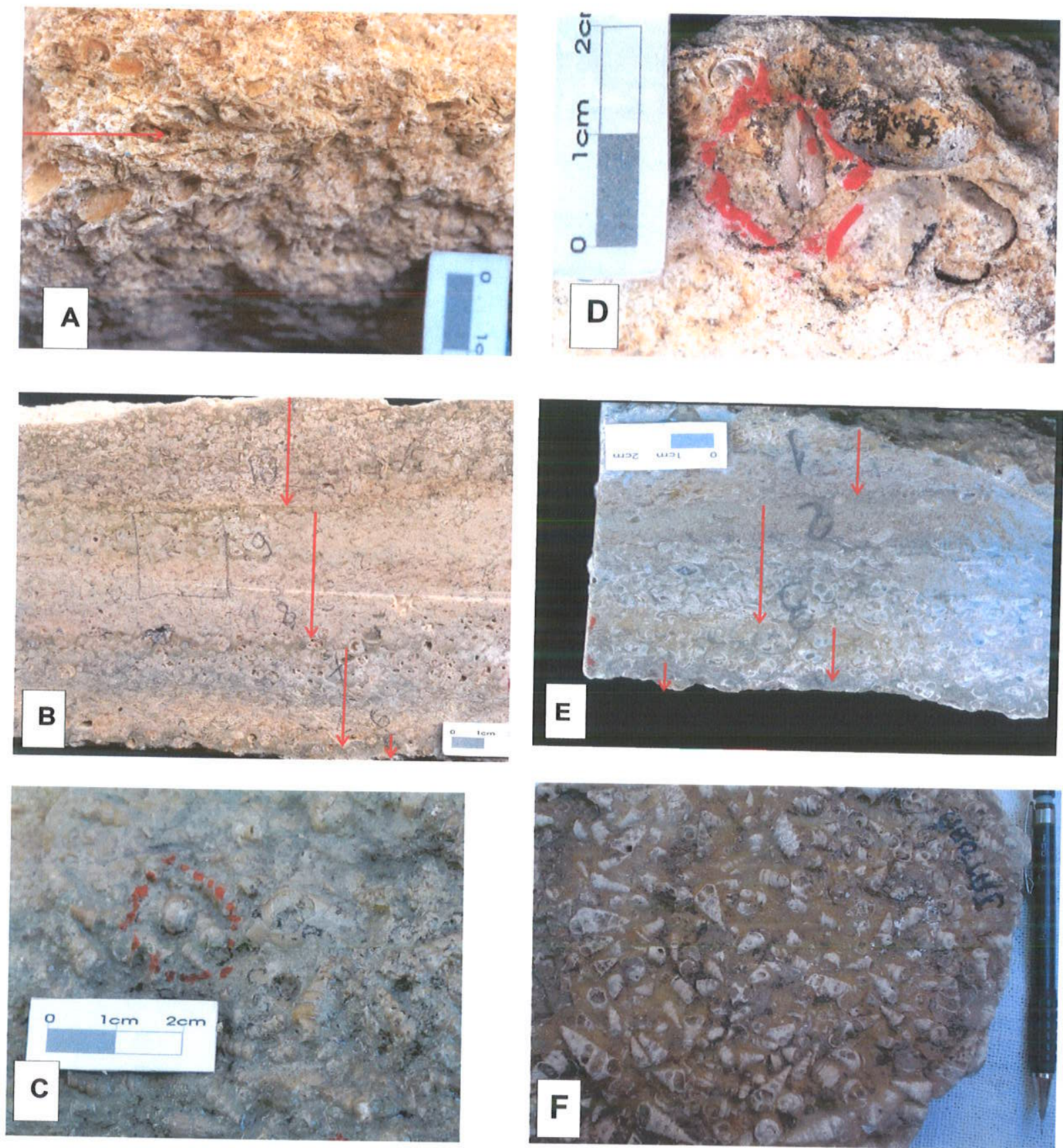

Prancha 6 . (Fotos - A, B, C, D, E - localidade de Saco, Porteiras, CE), Foto A - Estruturas de micro-estratificações (seta em vermelho) (ponto 1, concentração 1); Foto B - Seção de concentração amalgamada, contendo unidades microestratigráficas (ponto 1, coquina 2); Foto C - Visão, em planta, de concentração com gastrópodes naticídeos (marcação em vermelho)(ponto 1, coquina 2); Foto D - Concentração amalgamada, fossilífera, do ponto 2; notar presença bivalves articulados fechados; Foto $\mathrm{E}$ - Concentração ponto 3 ; Foto $\mathrm{F}$ Concentração recristalizada, pouco fragmentada, com predominio de conchas inteiras de gastrópodes turritelídeos, Sítio Jatobá, Riacho do Boi, Porteiras, CE. 

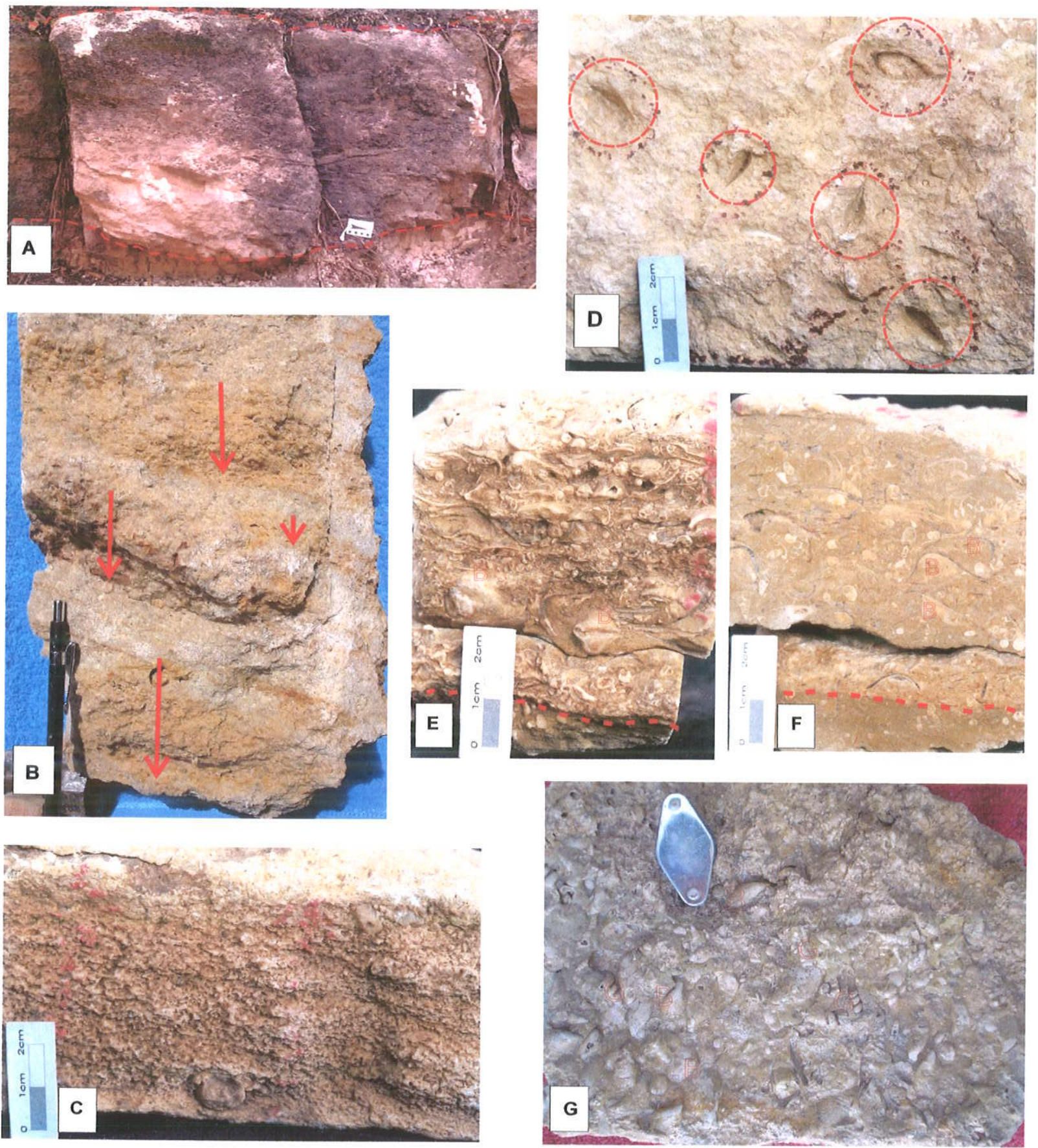

Prancha 7. (Fotos A e B - localidade de Saco dos Negros, Jardim) Foto A - Afloramento de calcarenito fossilifero, com $60 \mathrm{~cm}$ de espessura, exibindo contatos bruscos e erosivos; Foto B - Porção basal de depósito exibindo unidades microestratigráficas; (Fotos C e D, concentração com bivalves em posição de vida, Engenho, Jardim, CE); Foto C - Unidade microestrartigráfica, com bioclastos densamente empacotados, conchas apresentando dissolução e alta fragmentação; Foto D - Substrato lamoso (mole), evidências de conchas de bivalves da infauna, soterrados em posição de vida, vista em planta; Foto E e F -, Unidades microestratigráficas separadas por contato brusco e predominiode conchas mitilóides, visão em seção; Foto G - Concentração densa, vista em planta, composta por bivalves mitilóides e indistintos e gastrópodes turritelídeos (Sobradinho, Jardim-G = gatrópodes e $\mathrm{B}=$ bivalves). 


\section{PRANCHA 8}
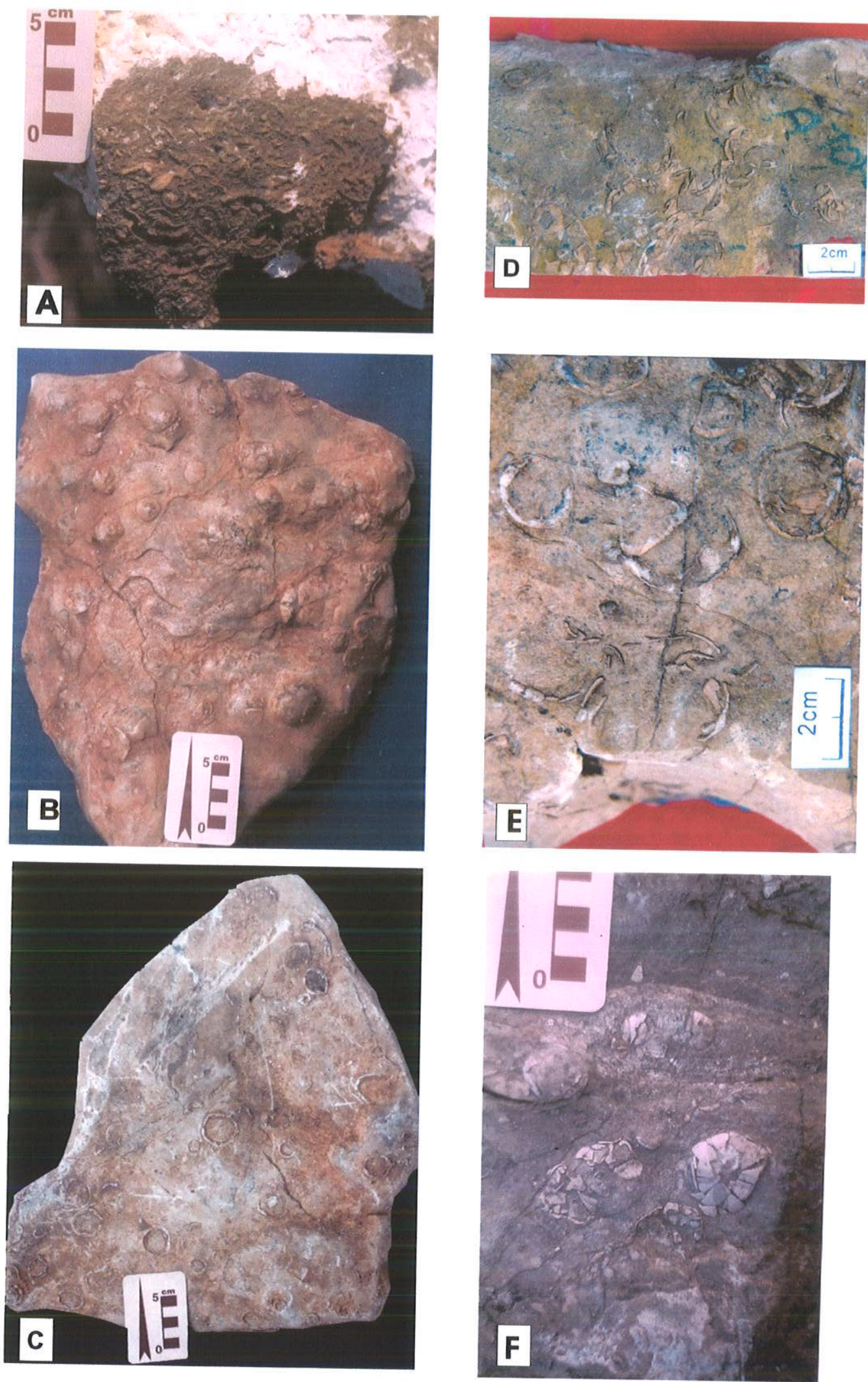

Prancha 8. (Fotos - localidade de Canastra, Araripina, PE) Foto A - Concentração densa, com conchas de moluscos, recristalizada; Foto B - Concentração de calcarenito, com carapaças inteiras de equinóides fósseis, vista em planta do topo de bloco; Foto C - Vista, em planta, da base do bloco; Foto D - Fragmentos de equinóides ( $>2 \mathrm{~mm}$ ), milimétricos a centimétricos; Foto $E$ - Carapaças fósseis de equinóides, parcialmente erodidas; Foto F - Carapaças de equinóides fragmentadas e dissociadas. 


\section{PRANCHA 9}
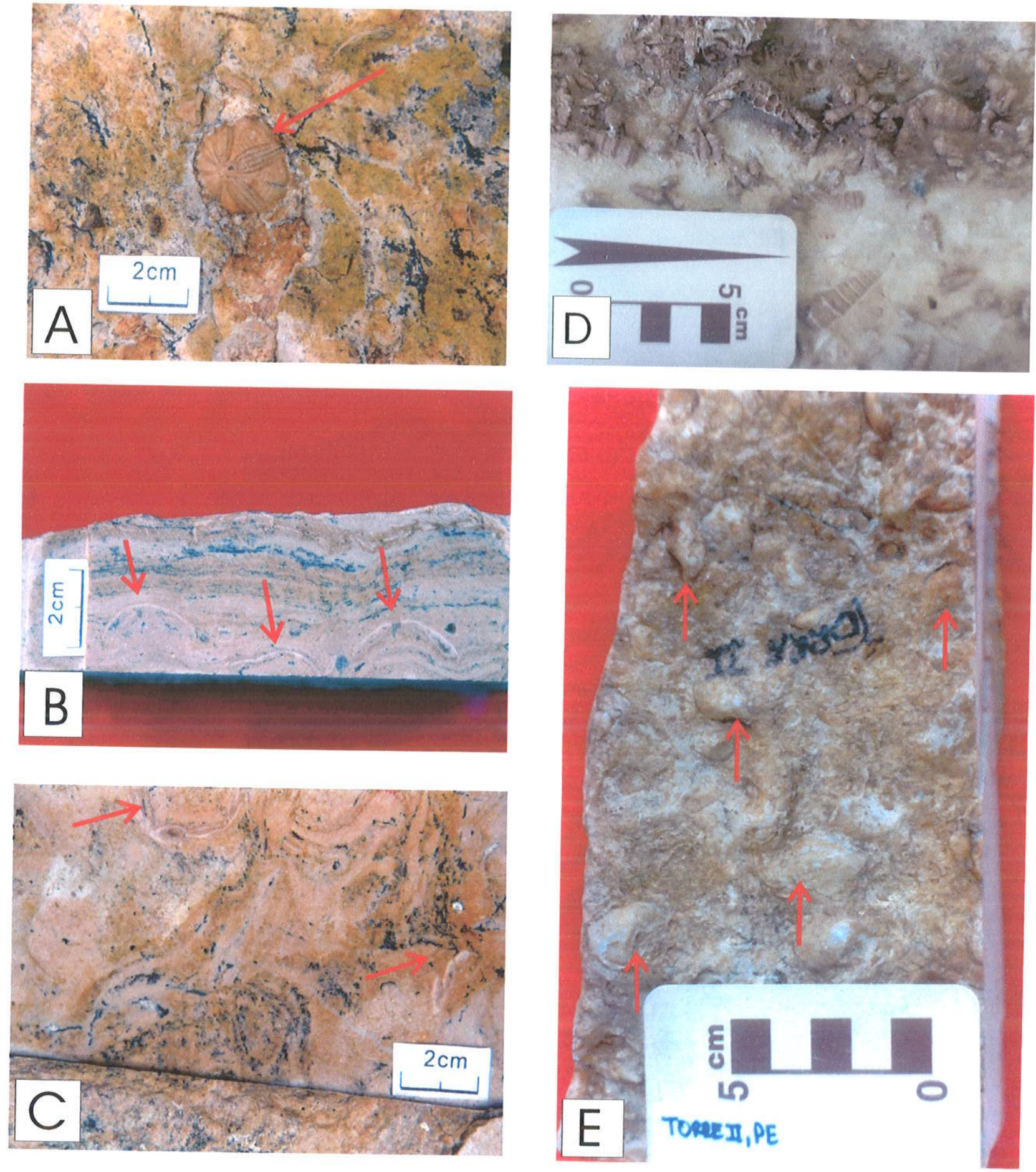

Prancha 9. (A, B e C, - localidade de Canastra, Araripina, PE) - Foto A - Carapaça de equinóide, com preservação de pétalas ambulacrais (centro da foto); Foto B - em seção, carapaças e partes de carapaças de equinóides (2 a 3cm de diâmetro), (em geral com ápice voltado para cima e preservação da região adapical (notar presença de lâminas de esteiras algálicas, na porção superior da foto); Foto C - Carapaças de equinóides e grandes fragmentos, compactados (notar algas, enrugamentos e convoluçôes), em seção; (Fotos De E - localidade de Torre, Araripina, PE); Foto D - Amostra com predomínio das conchas de gastrópodes; Foto E - Amostra com predomínio das conchas de bivalves mitilóides (setas emvermelho). 

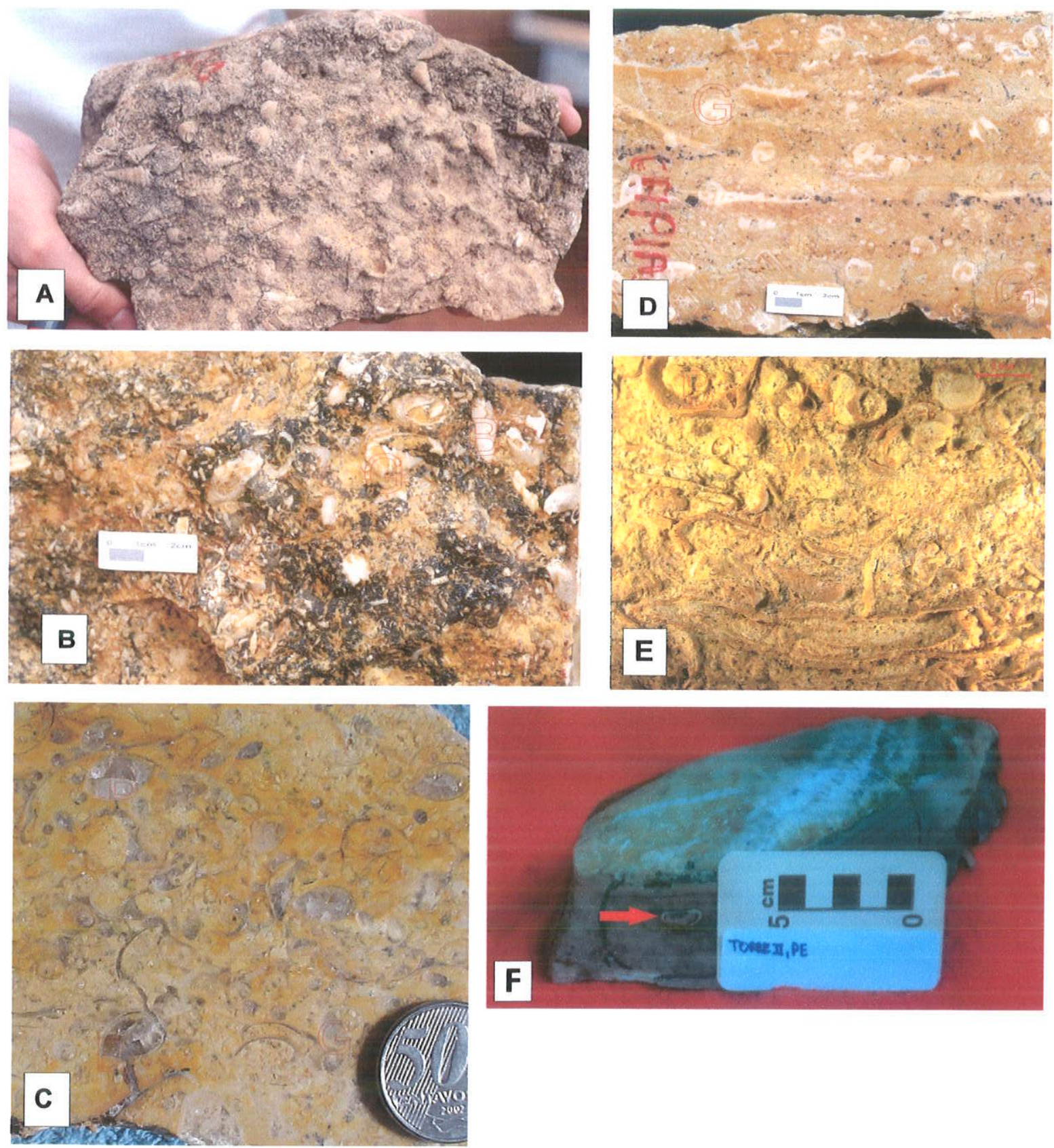

Prancha 10. (Fotos A, B, C, D - Concentração densa contendo moluscos, localidade de Caboclos) ; Foto A e B - Blocos de calcarenitos com concentração fossilífera com predômínio de gastrópodes (visão em planta); Foto B - Bloco exibindo predômínio de conchas de bivalves (indistintos e mitilóides), em seção, Foto $\mathrm{C}$ - Conchas de bivalves indistintos, articulados fechados, vistos em corte; Foto D-Aintensa recristalização dificulta a visualização de estruturas internas da concentração (visão em seção); Foto $E$ - Vista em seção, da concentração de Marcolândia (PE), mostrando arranjo caótico dos bioclastos e adensamento $(\mathrm{G}=$ gastrópodes e $\mathrm{B}=$ bivalves $)$, FOTO F- Amostra com fóssil de peixe (porção superior) e carapaça de equinóidena lateral (seta vermelha), localidade de Torre , Araripina, PE. 
PRANCHA 11
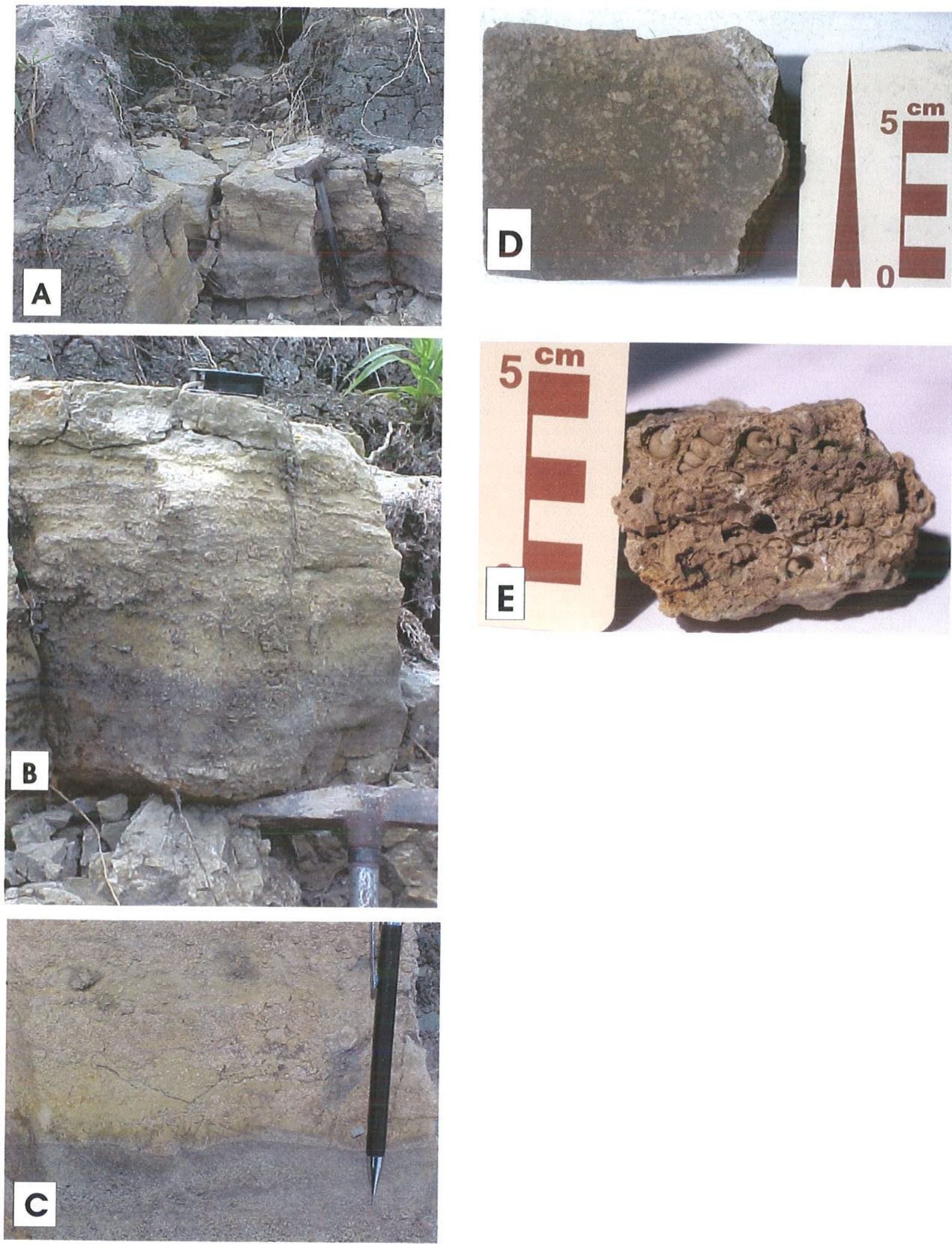

Prancha 11. (Fotos A, B, C e D) - Ocorrência com conchas frouxamente empacotadas, monotípica, composta predominantemente de gastrópodes turritelídeos. O depósito, intercala folhelhos verdes, os contatos são bruscos, ondulados e erosivos (próximo a cidade de Santana do Cariri - CE); (Foto E) - Acumulação fossilífera de moldes de gastrópodes turritelídeos, associados à moldes e fragmentos de bivalves (? Brachidontes sp), Sitio São Gonçalo, Santana do Cariri, CE. 

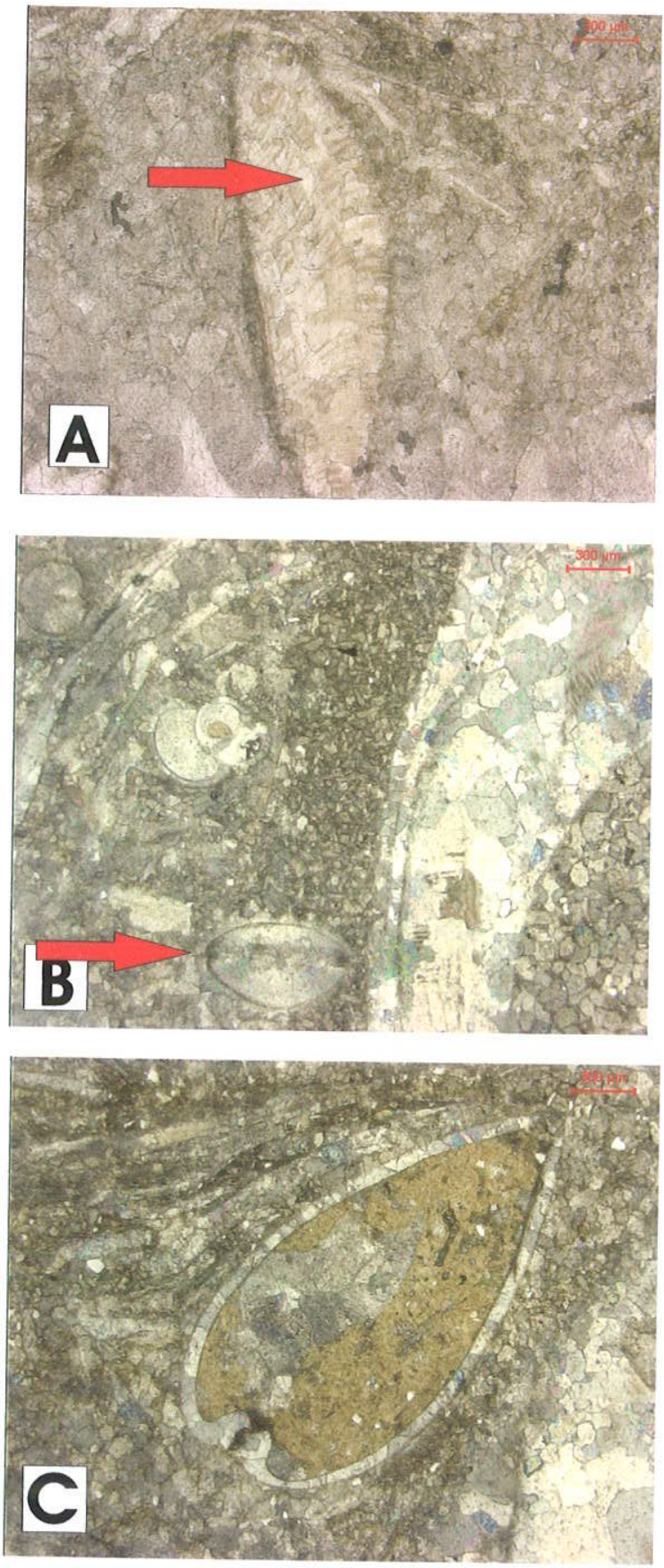
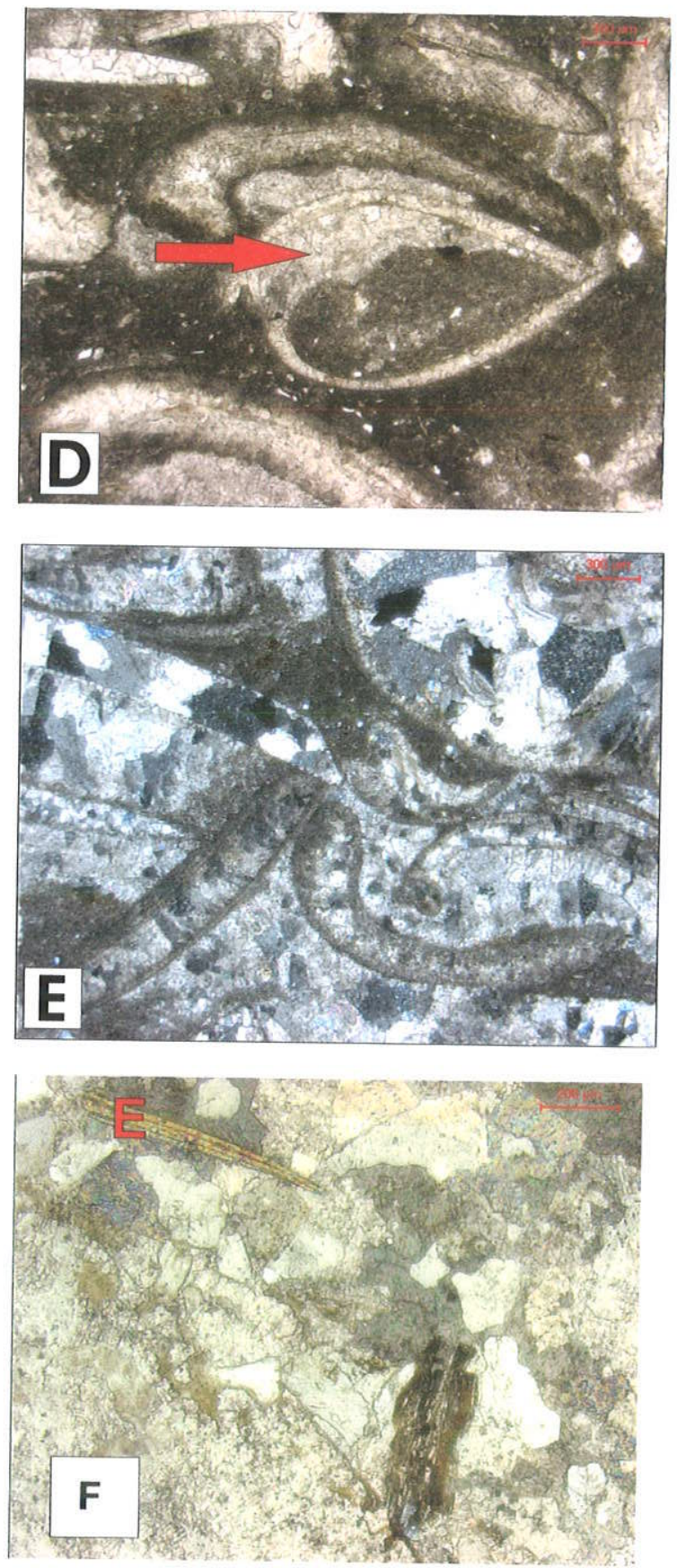

Prancha 12. ( Fotos A, B, C - Romualdo, Fotos D e E - Sítio Saco, ponto 1- concentração 2 ). Foto $A$ - Bioclastos com envelope micrítico e resquícios de composição aragonítica original (estruturas na forma de lamelas cruzadas) (seta em vermelho); Foto B - Concha articulada fechada, com cimentação precoce (cristais fibroradiados externos) (seta em vermelho), notar na porção direita da foto, concha de gastrópode, originalmente aragonítico, apresentando resquícios de lamelas cruzadas; Foto C - Concha de bivalve articulado fechado, apresentando calcita neomórfica e, internamente cimento micrítico e microesparítico, notar na porção superior da foto, adensamento de conchas desarticuladas de bivalves, matriz com cimentos microesparito e esparíto; Foto D - Aninhamento/empilhamento de valvas de bivalves, no centro estrutura do tipo abrigo (seta em vermelho), notar a micritização dos bioclastos e a disponibilidade de lama carbonática; Foto E - Bioclastos com calcita do tipo esparito e pseudoesparito, notar interpenetração de bioclastos no centro da foto ; Foto $\mathrm{F}$ Seção de Sítio dos Negros, notar fragmento de equinóides (letra E), notar entre os bioclastos, presenças de blocos com cristais euhedrais de calcita, preenchendo espaços (diagênese submarina ou subterrânea em ambiente litorâneo). 

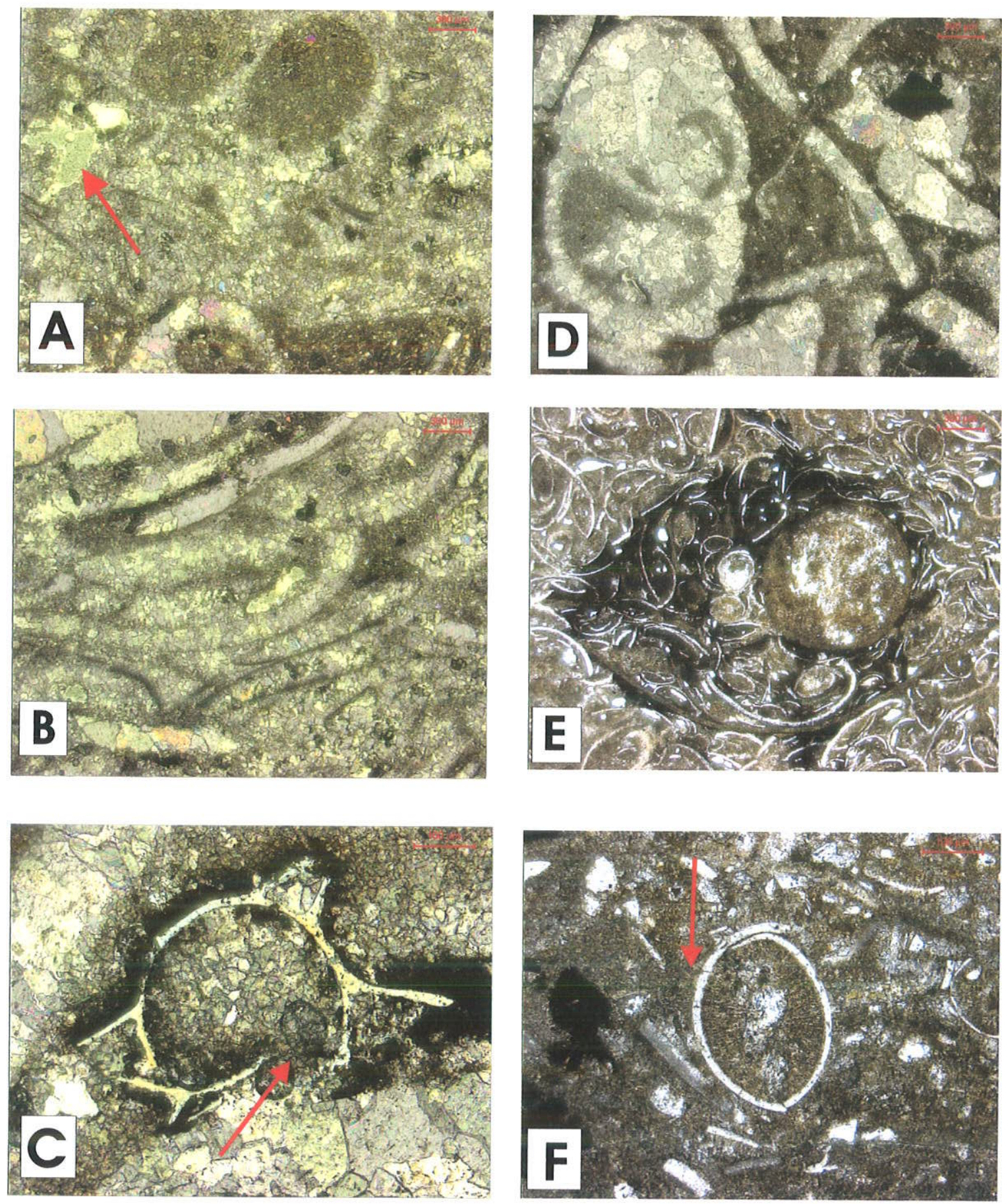

Prancha 13. (Fotos A e B - Sítio Engenho, Jardim, CE) Foto A - Intensa recristalização da matriz, notar fragmento de equinóide (seta em vermelho) e presença de siliciclástos; Foto B compactação, porosidade interpartícula e envelopes micríticos de bioclastos; (Fotos C e D Concentração de Caboclos, PI), Foto C - Fragmentos de artrópodes (?) (Seta em vermelho) e evidências de quebra por compactação; Foto D - Matriz micrítica, intensa recristalização de bioclastos; (Fotos E e F - acumulação fossilífera de Marcolândia, PI) Foto E - Empilhamento de conchas de bivalves e ostracodes (predomínio dessas); Foto F - Ostracodes articulados fechados, com preenchimento interno calcítico fibroradial, notar fibras radiais de calcita também externas à concha (seta em vermelho). 
PRANCHA 14
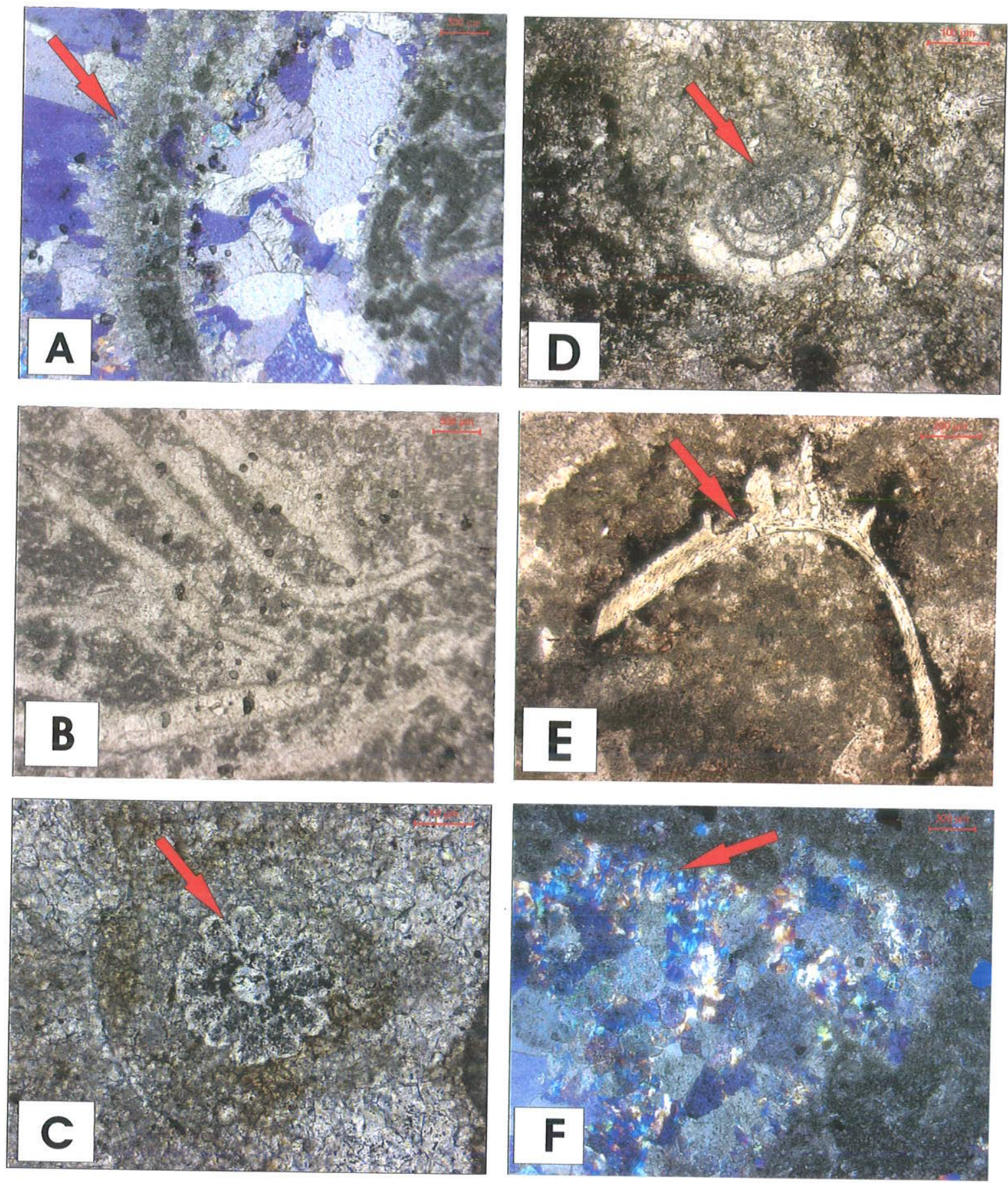

Prancha 14. (Fotos A e B - concentração de moluscos de Canastra, Araripina) Foto A Franja de calcitas fibrosas (cimento precoce)(seta em vermelho), pelóides micríticos e intraclastos; Foto B-Envelopes micríticos e cimento esparítico, no contato dos bioclastos, notar no centro da foto, a quebra de bioclastos por compactação; (Fotos C, D e E depósitos fossilíferos com carapaças de equinóides, Canastra, Araripina), Foto C espinho de equinóide (em seção) (seta em vermelho); Foto D - foraminíferos miliolídeos (seta em vermelho); Foto E - Fragmento de artrópode (?), notar aspecto perfurado da concha (seta indicando); Foto F - Matriz micrítica e gastrópode parcialmente recristalizado por sílica (seta em vermelho), apresentando ainda as porções carbonáticas (depósito fossilífero do Sítio Torre, Araripina). 
PRANCHA 15
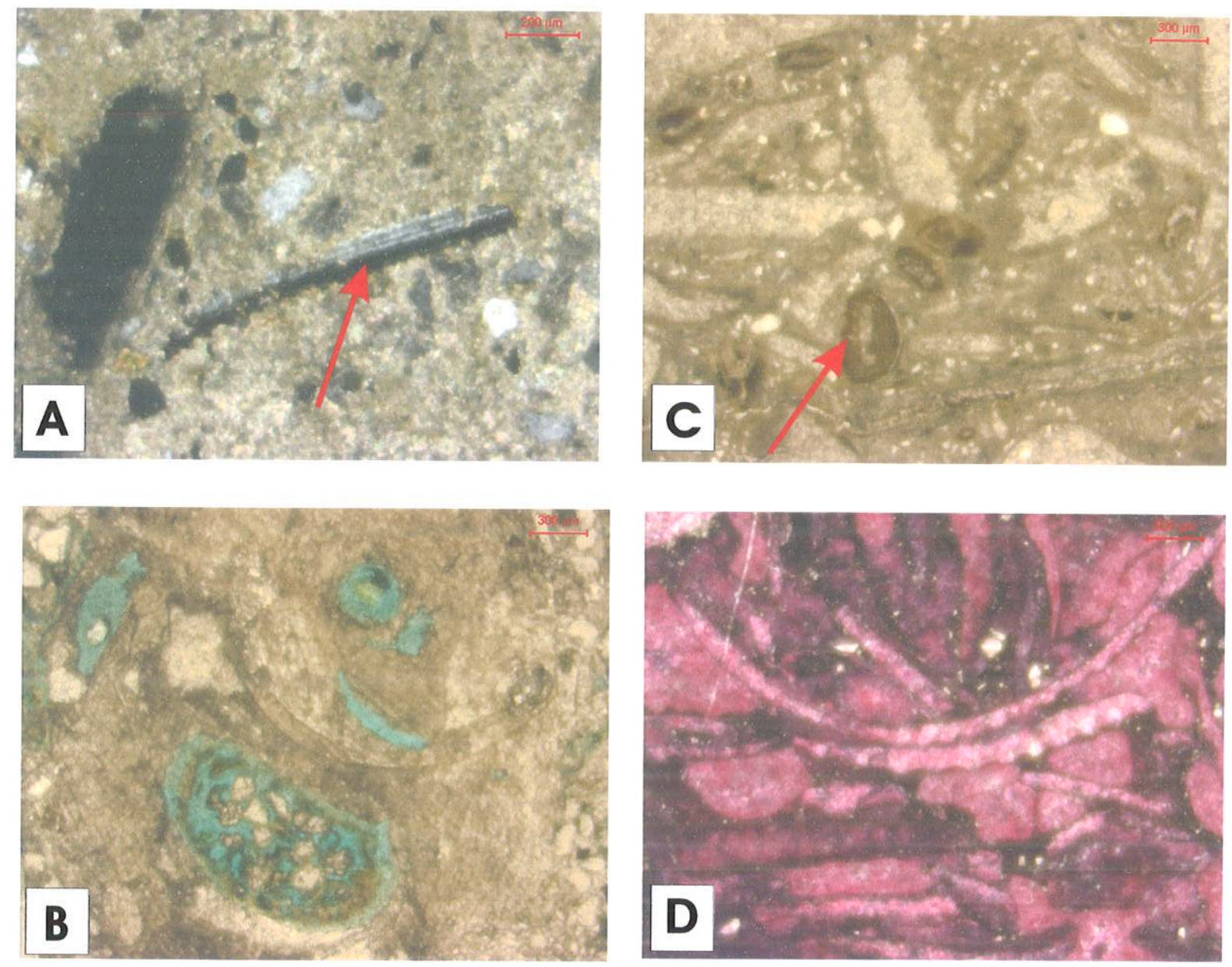

Prancha 15. Foto A - Amostra de Sítio Sobradinho, matriz carbonática e presença de siliciclásticos, notar presença de fragmento de espinho de equinóide (seta em vermelho); Foto B - Amostra impregnada por líquidos densos (prévia a confecção da seção petrográfica), depósito de Jamacaru, notar o adensamento dos bioclastos e a porosidade interpartícula, intrapartícula e móldica (na cor azul); Foto C - Lâmina da concentração de Sítio Jatobá, Porteiras - presença de pelóides (oóides - bioclastos micritizados); Foto D - Amostra tingida por soluções ácidas, Sítio São Gonçalo, Santana do Cariri, notar o adensamento dos bioclastos e a predominância de calcita ferrosa. 
ANEXOS 


\section{ANEXO !}

Dados tafonômicos das concentrações de Romualdo, Crato, CE.

\begin{tabular}{|c|c|c|c|c|c|c|c|c|c|c|c|c|c|c|}
\hline Romuaido & $\begin{array}{l}\text { Unid. } \\
\text { micro } \\
\text { estrat. }\end{array}$ & $\begin{array}{l}\text { Esp. } \\
(\mathrm{cm})\end{array}$ & Estruturas & $\begin{array}{l}\text { Biocl. } \\
\%\end{array}$ & $\begin{array}{l}\text { Frag. } \\
\%\end{array}$ & $\begin{array}{l}\text { Biv. } \\
\%\end{array}$ & \multicolumn{2}{|c|}{$\begin{array}{l}\text { Bìv. Articulaçāo } \\
\%\end{array}$} & $\begin{array}{l}\text { Gast. } \\
\%\end{array}$ & $\begin{array}{l}\text { Classes } \\
\text { tamanho } \\
\text { biocl. }\end{array}$ & \multicolumn{3}{|c|}{$\begin{array}{l}\text { Distribuição biocl. } \\
\text { em seção \% }\end{array}$} & $\begin{array}{l}\text { Orientaçäo } \\
\text { Bioci. em } \\
\text { planta }\end{array}$ \\
\hline \multirow{12}{*}{$\begin{array}{l}\operatorname{cota} \\
632 \mathrm{~m}\end{array}$} & \multirow{3}{*}{$\begin{array}{l}1 \\
\text { topo }\end{array}$} & \multirow[t]{3}{*}{2,4} & \multirow{3}{*}{$\begin{array}{l}\text { gradaçäo, } \\
\text { contato } \\
\text { brusco, } \\
\text { ondulado e } \\
\text { erosivo }\end{array}$} & \multirow[t]{3}{*}{50} & \multirow[t]{3}{*}{70} & \multirow[t]{3}{*}{15} & \multirow[t]{2}{*}{ fechada } & \multirow[t]{2}{*}{ aberta } & \multirow[t]{3}{*}{85} & \multirow[t]{3}{*}{5} & \multicolumn{3}{|c|}{ caótica } & \multirow[t]{3}{*}{ polimodal } \\
\hline & & & & & & & & & & & con. & obl. & per. & \\
\hline & & & & & & & 1 & & & & 70 & 15 & 15 & \\
\hline & \multirow[t]{3}{*}{2} & \multirow[t]{3}{*}{2,9} & \multirow{3}{*}{$\begin{array}{l}\text { gradação, } \\
\text { contato } \\
\text { brusco, } \\
\text { e erosivo }\end{array}$} & \multirow[t]{3}{*}{60} & \multirow[t]{3}{*}{75} & \multirow[t]{3}{*}{15} & \multirow[t]{2}{*}{ fechada } & \multirow[t]{2}{*}{ aberta } & \multirow[t]{3}{*}{85} & \multirow[t]{3}{*}{4} & \multicolumn{3}{|c|}{ caótica } & polimodal \\
\hline & & & & & & & & & & & con. & obl. & per. & \\
\hline & & & & & & & 4 & 1 & & & 65 & 20 & 15 & \\
\hline & 3 & 2,1 & gradaçāo, & 40 & 70 & 15 & fechada & aberta & 85 & 4 & & caótica & & polimodal \\
\hline & & & contato & & & & 2 & 2 & & & con. & obl. & per. & \\
\hline & & & e erosivo & & & & & & & & 70 & 15 & 15 & \\
\hline & & 5 & gradação, & 50 & 750 & 15 & fechada & aberta & 85 & 6 & & caótica & & polimodal \\
\hline & pase & & $\begin{array}{l}\text { contato } \\
\text { brusco. }\end{array}$ & & & & 2 & 1 & & & con. & obl. & per. & \\
\hline & & & e erosivo & & & & & & & & 70 & 15 & 15 & \\
\hline cota & 1 & 2,3 & gradaçāo, & 50 & 70 & 15 & fechada & aberta & 85 & 5 & & aótica & & polimodal \\
\hline $630 \mathrm{~m}$ & topo & & contato & & & & 1 & & & & con. & obl. & per. & \\
\hline & & & $\begin{array}{l}\text { ondulado e } \\
\text { erosivo }\end{array}$ & & & & & & & & 70 & 15 & 15 & \\
\hline & 2 & 2,7 & gradação, & 60 & 75 & 15 & fechada & aberta & 85 & 4 & & aótica & & polimoda! \\
\hline & & & $\begin{array}{l}\text { contato } \\
\text { brusco. }\end{array}$ & & & & 4 & & & & con. & obl. & per. & \\
\hline & & & e erosivo & & & & & & & & 65 & 20 & 15 & \\
\hline & 3 & 2 & gradação, & 40 & 60 & 15 & fechada & aberta & 85 & 4 & & aótica & & polimodal \\
\hline & & & contato & & & & 2 & 2 & & & con. & obl. & per. & \\
\hline & & & e erosivo & & & & & & & & 70 & 15 & 15 & \\
\hline & 4 & 4,5 & gradaçäo, & 50 & 75 & 60 & fechada & aberta & 40 & 6 & & aótica & & polimodal \\
\hline & Dase & & $\begin{array}{l}\text { contato } \\
\text { brusco }\end{array}$ & & & & 3 & & & & con. & obl. & per. & \\
\hline & & & e erosivo & & & & & & & & 70 & 15 & 15 & \\
\hline cota & 1 & 6 & gradaçäo & 50 & 80 & 40 & fechada & aberta & 60 & 5 & & aótica & & polimodal \\
\hline $627 \mathrm{~m}$ & topo & & $\begin{array}{l}\text { contato } \\
\text { brusco e }\end{array}$ & & & & 1 & & & & con. & obl. & per. & \\
\hline & & & ondulado & & & & & & & & 75 & 15 & 10 & \\
\hline & 2 & 5 & gradaçăo, & 50 & 80 & 40 & fechada & aberta & 60 & 5 & & ab́tica & & polimodal \\
\hline & Dase & & $\begin{array}{l}\text { contato } \\
\text { brusco, }\end{array}$ & & & & 1 & & & & con. & obl. & per. & \\
\hline & & & $\begin{array}{l}\text { ondulado e } \\
\text { erosivo }\end{array}$ & & & & & & & & 75 & 15 & 10 & \\
\hline
\end{tabular}

Dados tafonômica das concentrações de Jamacarú, Missão Velha, CE.

\begin{tabular}{|c|c|c|c|c|c|c|c|c|c|c|c|c|c|c|}
\hline Jamacarú & $\begin{array}{l}\text { Unid. } \\
\text { micro- } \\
\text { estrat. }\end{array}$ & $\begin{array}{l}\text { Esp. } \\
\text { (cm) }\end{array}$ & Estruturas & $\begin{array}{l}\text { Biocl. } \\
\%\end{array}$ & $\begin{array}{l}\text { Frag. } \\
0 \%\end{array}$ & $\begin{array}{l}\text { Biv. } \\
\%\end{array}$ & \multicolumn{2}{|c|}{$\begin{array}{l}\text { Biv. articulaçāo } \\
\%\end{array}$} & $\begin{array}{l}\text { Gast. } \\
\%\end{array}$ & $\begin{array}{l}\text { Classes } \\
\text { tamanho } \\
\text { biocl. }\end{array}$ & \multicolumn{3}{|c|}{$\begin{array}{l}\text { Distribuição biod. } \\
\text { em seçäo \% }\end{array}$} & $\begin{array}{l}\text { Orientação } \\
\text { biocl. em } \\
\text { planta }\end{array}$ \\
\hline \multirow{3}{*}{$\begin{array}{l}\text { cota } \\
768 \mathrm{~m}\end{array}$} & \multirow[t]{3}{*}{1} & \multirow[t]{3}{*}{20} & \multirow{3}{*}{$\begin{array}{l}\text { gradação, } \\
\text { laminaçāo } \\
\text { plano- } \\
\text { paralela }\end{array}$} & \multirow[t]{3}{*}{50} & \multirow[t]{3}{*}{80} & \multirow[t]{3}{*}{80} & \multirow[t]{3}{*}{ fechada } & \multirow[t]{3}{*}{ aberta } & \multirow[t]{3}{*}{20} & \multirow[t]{3}{*}{4} & \multicolumn{3}{|c|}{ caótica } & \multirow[t]{3}{*}{ polimodal } \\
\hline & & & & & & & & & & & con. & obl. & per. & \\
\hline & & & & & & & & & & & 90 & 10 & & \\
\hline \multirow{3}{*}{$\begin{array}{l}\text { cota } 766 \\
m\end{array}$} & \multirow[t]{3}{*}{1} & \multirow[t]{3}{*}{25} & \multirow{3}{*}{$\begin{array}{l}\text { gradaçäo, } \\
\text { laminaçāo } \\
\text { plano- } \\
\text { paralela, } \\
\text { marca } \\
\text { ondulada }\end{array}$} & \multirow[t]{3}{*}{55} & \multirow[t]{3}{*}{70} & \multirow[t]{3}{*}{60} & \multirow[t]{3}{*}{ fechada } & \multirow[t]{3}{*}{ aberta } & \multirow[t]{3}{*}{40} & \multirow[t]{3}{*}{4} & \multicolumn{3}{|c|}{ caótica } & \multirow{3}{*}{$\begin{array}{l}\text { polimodal } \\
\text { gast. } \\
\text { predominio } \\
\text { sw-ne }\end{array}$} \\
\hline & & & & & & & & & & & con. & obl. & per. & \\
\hline & & & & & & & & & & & 90 & 10 & & \\
\hline
\end{tabular}




\section{ANEXO II}

Dados tafonômicos da concentração da Serra da mãozinha (tipo A). Missão Velha, CE.

\begin{tabular}{|c|c|c|c|c|c|c|c|c|c|c|c|c|c|c|}
\hline $\begin{array}{l}\text { Serra da } \\
\text { Mãozinha }\end{array}$ & $\begin{array}{l}\text { Unid. } \\
\text { micro- } \\
\text { estrat. }\end{array}$ & $\begin{array}{l}\text { Esp. } \\
\text { (cm) }\end{array}$ & Estrutura & $\begin{array}{l}\text { Biocl. } \\
\%\end{array}$ & $\begin{array}{l}\text { Frag. } \\
\%\end{array}$ & $\begin{array}{l}\text { Biv. } \\
\%\end{array}$ & $\begin{array}{l}\text { Biv.artict } \\
\%\end{array}$ & ção & $\begin{array}{l}\text { Gast. } \\
\%\end{array}$ & $\begin{array}{l}\text { Classes } \\
\text { tamanho } \\
\text { biocl. }\end{array}$ & $\begin{array}{l}\text { Distr } \\
\text { em }\end{array}$ & $\begin{array}{l}\text { ição } \\
\text { aаă \% }\end{array}$ & & $\begin{array}{l}\text { Orientação } \\
\text { biocl. em } \\
\text { planta }\end{array}$ \\
\hline \multirow{3}{*}{$\begin{array}{l}\operatorname{cota} 758 \\
\text { m }\end{array}$} & \multirow[t]{3}{*}{1} & \multirow[t]{3}{*}{15} & \multirow{3}{*}{$\begin{array}{l}\text { contatos } \\
\text { bruscos e } \\
\text { ondulados }\end{array}$} & \multirow[t]{3}{*}{55} & \multirow[t]{3}{*}{60} & \multirow[t]{3}{*}{10} & fechada & aberta & \multirow[t]{3}{*}{90} & \multirow[t]{3}{*}{5} & \multicolumn{3}{|c|}{ caótica } & \multirow[t]{3}{*}{ polimodal } \\
\hline & & & & & & & & & & & con. & obl. & per. & \\
\hline & & & & & & & & & & & 85 & 10 & 5 & \\
\hline
\end{tabular}

Dados tafonômicos das concentrações da Serra da Mãozinha (tipo B), Missão Velha, CE.

\begin{tabular}{|c|c|c|c|c|c|c|c|c|c|c|c|c|c|c|}
\hline $\begin{array}{l}\text { Serra da } \\
\text { Mäozinha }\end{array}$ & $\begin{array}{l}\text { Unid. } \\
\text { micro- } \\
\text { estrat. }\end{array}$ & $\begin{array}{l}\text { Esp. } \\
(\mathrm{cm})\end{array}$ & Estruturas & $\begin{array}{l}\text { Biocl. } \\
\%\end{array}$ & $\begin{array}{l}\text { Frag. } \\
\%\end{array}$ & $\begin{array}{l}\text { Biv. } \\
\%\end{array}$ & \multicolumn{2}{|c|}{$\begin{array}{l}\text { Biv. articulação } \\
\%\end{array}$} & $\begin{array}{l}\text { Gast. } \\
\%\end{array}$ & $\begin{array}{l}\text { Classes } \\
\text { tamanho }\end{array}$ & \multicolumn{3}{|c|}{$\begin{array}{l}\text { Distribuição biocl. } \\
\text { em seção \% }\end{array}$} & $\begin{array}{l}\text { Orientação } \\
\text { biocl. em }\end{array}$ \\
\hline \multirow[b]{2}{*}{$\begin{array}{l}\text { cota } 776 \\
m\end{array}$} & \multirow[t]{2}{*}{1} & \multirow[t]{2}{*}{28} & \multirow[b]{2}{*}{$\begin{array}{l}\text { cone em } \\
\text { cone, } \\
\text { micro } \\
\text { laminação } \\
\text { sigmódal, } \\
\text { marcas } \\
\text { onduladas }\end{array}$} & \multirow[t]{2}{*}{50} & \multirow[t]{2}{*}{70} & \multirow[t]{2}{*}{60} & fechada & aberta & \multirow[t]{2}{*}{40} & \multirow[t]{2}{*}{4} & con. & obl. & per. & \multirow[t]{2}{*}{ polimodal } \\
\hline & & & & & & & 2 & 1 & & & 80 & 10 & 10 & \\
\hline \multirow{5}{*}{$\begin{array}{l}\operatorname{cota} 775 \\
\mathrm{~m}\end{array}$} & \multirow{3}{*}{$\begin{array}{l}2 \\
\text { topo }\end{array}$} & \multirow[t]{3}{*}{12} & \multirow{3}{*}{$\begin{array}{l}\text { cone em } \\
\text { cone, } \\
\text { micro } \\
\text { laminacaão } \\
\text { sigmóidal, } \\
\text { marcas } \\
\text { onduladas }\end{array}$} & \multirow[t]{3}{*}{55} & \multirow[t]{3}{*}{70} & \multirow[t]{3}{*}{60} & fechada & aberta & \multirow[t]{3}{*}{40} & \multirow[t]{3}{*}{5} & \multicolumn{3}{|c|}{ caótica } & polimodal \\
\hline & & & & & & & 1 & & & & con & obl. & per. & \\
\hline & & & & & & & & & & & 70 & 15 & 15 & \\
\hline & \multirow{2}{*}{$\begin{array}{l}15 \\
\text { base }\end{array}$} & \multirow[t]{2}{*}{16} & \multirow[b]{2}{*}{$\begin{array}{l}\text { cone em } \\
\text { cone, } \\
\text { micro } \\
\text { laminaçäo } \\
\text { sigmóidal, } \\
\text { marcas } \\
\text { onduladas } \\
\end{array}$} & \multirow[t]{2}{*}{25} & \multirow[t]{2}{*}{70} & \multirow[t]{2}{*}{60} & fechada & aberta & \multirow[t]{2}{*}{40} & \multirow[t]{2}{*}{5} & & caótice & & polimodas \\
\hline & & & & & & & 5 & & & & \begin{tabular}{|l} 
con. \\
70 \\
\end{tabular} & $\frac{\mid \text { obt. }}{20}$ & \begin{tabular}{|c} 
per. \\
10
\end{tabular} & \\
\hline & 1 & 35 & micro & 40 & 80 & 20 & fechada & aberto & 80 & 5 & & caótice & & polimodal \\
\hline & & & $\begin{array}{l}\text { laminaçao } \\
\text { sigmóidal, } \\
\text { marcas }\end{array}$ & & & & 3 & & & & con. & obl. & per. & \\
\hline & & & onduladas & & & & & & & & 70 & 20 & 10 & \\
\hline & 2 & 20 & micro & 20 & 80 & 20 & fechada & aberta & 80 & 5 & & caótice & & polimodal \\
\hline & & & $\begin{array}{l}\text { famınaçao } \\
\text { sigmóidal, } \\
\text { marcas }\end{array}$ & & & & 3 & & & & con. & obl. & per. & \\
\hline & & & onduladias & & & & & & & & 70 & 20 & 10 & \\
\hline & 3 & 40 & micro & 50 & 80 & 20 & fechada & aberta & 80 & 5 & & caótice & & polimodal \\
\hline cota 773 & & & $\begin{array}{l}\text { lammaçao } \\
\text { sigmóidal. }\end{array}$ & & & & 3 & & & & con. & obl. & per. & \\
\hline & & & $\begin{array}{l}\text { marcas } \\
\text { onduladas }\end{array}$ & & & & & & & & 70 & 20 & 10 & \\
\hline & 4 & 20 & micro & 20 & 80 & 20 & fechada & aberta & 80 & 5 & & caótice & & polimodal \\
\hline & & & $\begin{array}{l}\text { tamınaçao } \\
\text { sigmóida!, } \\
\text { marcas }\end{array}$ & & & & 3 & & & & con- & obli- & per. & \\
\hline & & & onduiadas & & & & & & & & 70 & 20 & 10 & \\
\hline & 5 & 35 & contato & 40 & 80 & 30 & fechada & aberta & 70 & 5 & & caótice & & pofimodal \\
\hline & Dase & & $\begin{array}{l}\text { erosivo e } \\
\text { ondulado, }\end{array}$ & & & & 3 & & & & con. & obl. & per. & \\
\hline & & & $\begin{array}{l}\text { cone em } \\
\text { cone, } \\
\text { micro } \\
\text { laminação } \\
\text { sigmóidal, } \\
\text { marcas } \\
\text { onduladas }\end{array}$ & & & & & & & & 80 & 15 & 5 & \\
\hline
\end{tabular}




\section{ANEXO III}

Dados tafonômicos de concentração no Sitio Saco (ponto 1, concentração 1), Porteiras, CE.

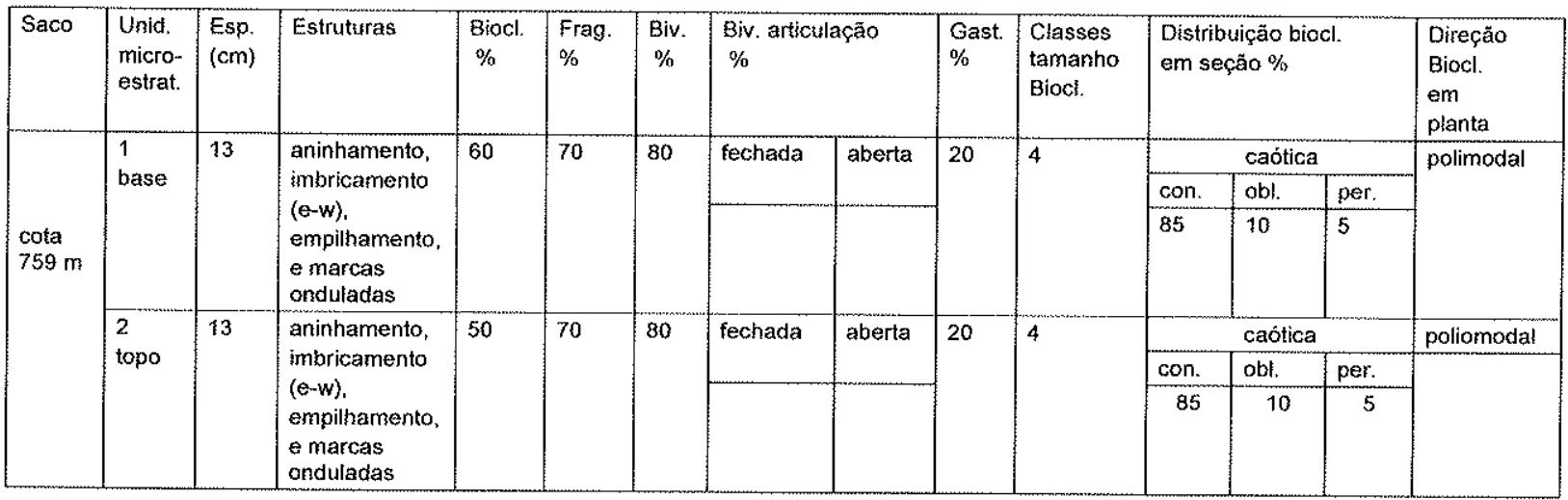

Dados tafonômicos de concentração no Sítio Saco (ponto 1, concentração 2), Porteiras, CE.

\begin{tabular}{|c|c|c|c|c|c|c|c|c|c|c|c|c|c|c|}
\hline Saco & $\begin{array}{l}\text { Unid. } \\
\text { micro- }\end{array}$ & $\begin{array}{l}\text { Esp. } \\
\text { (cm) }\end{array}$ & Estruturas & $\begin{array}{l}\text { Biocl. } \\
\%\end{array}$ & $\begin{array}{l}\text { Frag. } \\
\%\end{array}$ & $\begin{array}{l}\text { Biv. } \\
\%\end{array}$ & \multicolumn{2}{|c|}{$\begin{array}{l}\text { Biv. articulação } \\
\%\end{array}$} & $\begin{array}{l}\text { Gast. } \\
\%\end{array}$ & $\begin{array}{l}\text { Classes } \\
\text { tamanho }\end{array}$ & \multicolumn{3}{|c|}{$\begin{array}{l}\text { Distribuição biocl. } \\
\text { em seção \% }\end{array}$} & \multirow{4}{*}{$\begin{array}{l}\text { Direção } \\
\text { biocl. } \\
\text { em } \\
\text { planta } \\
\text { polimodal } \\
\text { gast. } \\
\text { predomi- } \\
\text { no sw-ne }\end{array}$} \\
\hline \multirow{12}{*}{$\begin{array}{l}\text { cota } \\
759,4 \\
m\end{array}$} & \multirow{3}{*}{$\begin{array}{l}1 \\
\text { base }\end{array}$} & \multirow[t]{3}{*}{1} & \multirow{3}{*}{$\begin{array}{l}\text { contatos } \\
\text { bruscos } \\
\text { e erosivos }\end{array}$} & \multirow[t]{3}{*}{55} & \multirow[t]{3}{*}{70} & \multirow[t]{3}{*}{30} & \multirow{2}{*}{$\begin{array}{l}\text { fechada } \\
\text { con }\end{array}$} & \multirow[t]{2}{*}{ aberta } & \multirow[t]{3}{*}{70} & \multirow[t]{3}{*}{4} & \multicolumn{3}{|c|}{ caótica } & \\
\hline & & & & & & & & & & & con. & obl. & per. & \\
\hline & & & & & & & 1 & & & & 85 & 10 & 5 & \\
\hline & \multirow[t]{3}{*}{2} & \multirow[t]{3}{*}{2,7} & \multirow{3}{*}{$\begin{array}{l}\text { aninhamento } \\
\text { imbricamento }\end{array}$} & \multirow[t]{3}{*}{35} & \multirow[t]{3}{*}{70} & \multirow[t]{3}{*}{20} & \multirow{2}{*}{$\begin{array}{l}\text { fechada } \\
\text { con./obl./ } \\
\text { per. }\end{array}$} & \multirow{2}{*}{$\begin{array}{l}\text { aberta } \\
\text { con. }\end{array}$} & \multirow[t]{3}{*}{80} & \multirow[t]{3}{*}{2} & \multicolumn{3}{|c|}{ caótica } & \\
\hline & & & & & & & & & & & con. & obl. & per. & \\
\hline & & & & & & & 2 & $t$ & & & 85 & 10 & 5 & \\
\hline & \multirow[t]{3}{*}{3} & \multirow[t]{3}{*}{4} & \multirow{3}{*}{$\begin{array}{l}\text { aninhamento } \\
\text { empihamento } \\
\text { imbricamento }\end{array}$} & \multirow[t]{3}{*}{60} & \multirow[t]{3}{*}{70} & \multirow[t]{3}{*}{65} & \multirow{2}{*}{$\begin{array}{l}\text { fechada } \\
\text { con./obl./ } \\
\text { per. }\end{array}$} & \multirow{2}{*}{$\begin{array}{l}\text { aberta } \\
\text { con. }\end{array}$} & 35 & 2 & & caótic & & \\
\hline & & & & & & & & & & & con. & obl. & per. & \\
\hline & & & & & & & 10 & 5 & & & 85 & 10 & 5 & \\
\hline & 4 & 2,3 & contato brusco, & 60 & 70 & 70 & fechada & aberta & 30 & 2 & & caótic & & \\
\hline & topo & & aninhamento & & & & obl. & & & & con. & obl. & per. & \\
\hline & & & imbricamento & & & & 15 & & & & 85 & 10 & 5 & \\
\hline
\end{tabular}

Dados tafonômicos de concentração no Sítio Saco (ponto 2), Porteiras, CE.

\begin{tabular}{|c|c|c|c|c|c|c|c|c|c|c|c|c|c|c|}
\hline \multirow{2}{*}{ Saco } & \multirow{4}{*}{$\begin{array}{l}\text { Unid. } \\
\text { micra- } \\
\text { estrat. }\end{array}$} & \multirow{4}{*}{$\begin{array}{l}\text { Esp. } \\
(\mathrm{cm})\end{array}$} & \multirow{4}{*}{$\begin{array}{l}\text { Estruturas } \\
\text { contato brusco } \\
\text { e ondulado. } \\
\text { aninhamento }\end{array}$} & \multirow{4}{*}{$\begin{array}{l}\text { Biocl. } \\
\% \\
25\end{array}$} & \multirow{4}{*}{$\begin{array}{l}\text { Frag. } \\
\% \\
30\end{array}$} & \multirow{4}{*}{\begin{tabular}{|l|} 
Biv \\
$\%$ \\
\\
80
\end{tabular}} & \multicolumn{2}{|c|}{$\begin{array}{l}\text { Biv. articulaçāo } \\
\%\end{array}$} & \multirow{4}{*}{\begin{tabular}{|l}
$\begin{array}{l}\text { Gast. } \\
\% \\
\\
20\end{array}$ \\
\end{tabular}} & \multirow{4}{*}{\begin{tabular}{|l|}
$\begin{array}{l}\text { Classes } \\
\text { tamanho } \\
\text { biocl. }\end{array}$ \\
6 \\
\end{tabular}} & \multirow{2}{*}{\multicolumn{3}{|c|}{$\begin{array}{l}\text { Distribuiçāo biocl. } \\
\text { em seçäo \% } \\
\text { caótica }\end{array}$}} & \multirow{4}{*}{$\begin{array}{l}\text { Direção } \\
\text { Biocl. } \\
\text { em } \\
\text { planta } \\
\text { gast. } \\
\text { predomi- } \\
\text { nio nw-se }\end{array}$} \\
\hline & & & & & & & fechada & aberta & & & & & & \\
\hline \multirow{8}{*}{$\begin{array}{l}\text { cota } \\
758,9 \\
\mathrm{~m}\end{array}$} & & & & & & & $\begin{array}{l}\text { obl./par. } \\
\text { con. }\end{array}$ & & & & con. & obl. & per. & \\
\hline & & & & & & & 50 & & & & 40 & 30 & 30 & \\
\hline & \multirow[t]{3}{*}{2} & \multirow[t]{3}{*}{25} & \multirow{3}{*}{$\begin{array}{l}\text { aninhamento, } \\
\text { estrat. plano- } \\
\text { palalela }\end{array}$} & \multirow[t]{3}{*}{15} & \multirow[t]{3}{*}{30} & \multirow[t]{3}{*}{90} & fechada & aberta & \multirow[t]{3}{*}{10} & \multirow[t]{3}{*}{5} & \multicolumn{3}{|c|}{ caótica } & \multirow{3}{*}{$\begin{array}{l}\text { gast. } \\
\text { predomi- } \\
\text { nio nw-se }\end{array}$} \\
\hline & & & & & & & con. & & & & con. & obl. & perf. & \\
\hline & & & & & & & 50 & & & & 85 & 10 & 5 & \\
\hline & \multirow{3}{*}{$\begin{array}{l}3 \\
\text { topo }\end{array}$} & \multirow[t]{3}{*}{30} & \multirow{3}{*}{$\begin{array}{l}\text { contato brusco } \\
\text { e ondulado, } \\
\text { aninhamento, } \\
\text { estrat. plano- } \\
\text { palalela }\end{array}$} & \multirow[t]{3}{*}{15} & \multirow[t]{3}{*}{30} & \multirow[t]{3}{*}{90} & fechada & aberta & \multirow[t]{3}{*}{10} & \multirow[t]{3}{*}{5} & & caótic & & \multirow{3}{*}{$\begin{array}{l}\text { gast. } \\
\text { predomi- } \\
\text { nio nw-se }\end{array}$} \\
\hline & & & & & & & con. & & & & con. & obl. & per. & \\
\hline & & & & & & & 50 & & & & 85 & 10 & 5 & \\
\hline
\end{tabular}




\section{ANEXO IV}

Dados tafonômicos da concentração de Jatobá, Porteiras, CE.

\begin{tabular}{|c|c|c|c|c|c|c|c|c|c|c|c|c|c|c|}
\hline Jatobá & $\begin{array}{l}\text { Unid. } \\
\text { micro- } \\
\text { estrat. }\end{array}$ & $\begin{array}{l}\text { Esp. } \\
\text { (cm) }\end{array}$ & Estruturas & $\begin{array}{l}\text { Bioci. } \\
\%\end{array}$ & $\begin{array}{l}\text { Frag. } \\
\%\end{array}$ & $\begin{array}{l}\text { Biv. } \\
\%\end{array}$ & $\begin{array}{l}\text { Biv. artic } \\
\%\end{array}$ & ação & $\begin{array}{l}\text { Gast. } \\
\%\end{array}$ & $\begin{array}{l}\text { Classes } \\
\text { tamanho } \\
\text { biocl. }\end{array}$ & $\begin{array}{l}\text { Distr } \\
\text { em s }\end{array}$ & $\begin{array}{l}\text { utçäo } \\
\text { jāo \% }\end{array}$ & & $\begin{array}{l}\text { Orientação } \\
\text { biocl. } \\
\text { em } \\
\text { planta }\end{array}$ \\
\hline \multirow{3}{*}{$\begin{array}{l}\text { cota } \\
749 \mathrm{~m}\end{array}$} & \multirow[t]{3}{*}{1} & \multirow[t]{3}{*}{10} & \multirow{3}{*}{$\begin{array}{l}\text { base } \\
\text { erosiva, } \\
\text { topo } \\
\text { ondulado }\end{array}$} & \multirow[t]{3}{*}{55} & \multirow[t]{3}{*}{40} & \multirow[t]{3}{*}{5} & \multirow[t]{3}{*}{ fechada } & \multirow[t]{3}{*}{ aberta } & \multirow[t]{3}{*}{95} & \multirow[t]{3}{*}{4} & \multicolumn{3}{|c|}{ caótica } & \multirow[t]{3}{*}{ polimodal } \\
\hline & & & & & & & & & & & con. & obt. & per. & \\
\hline & & & & & & & & & & & 85 & 10 & 5 & \\
\hline
\end{tabular}

Dados tafonômica da concentração de Sítio dos Negros, Jardim, CE.

\begin{tabular}{|c|c|c|c|c|c|c|c|c|c|c|c|c|c|c|}
\hline Negros & $\begin{array}{l}\text { Unid. } \\
\text { micro- } \\
\text { estrat. }\end{array}$ & $\begin{array}{l}\text { Esp. } \\
\text { (cm) }\end{array}$ & Estruturas & $\begin{array}{l}\text { Biocl. } \\
\%\end{array}$ & $\begin{array}{l}\text { Frag. } \\
\%\end{array}$ & $\begin{array}{c}\text { Biv. } \\
\%\end{array}$ & \multicolumn{2}{|c|}{$\begin{array}{l}\text { Biv, articulaçăo } \\
\%\end{array}$} & $\begin{array}{l}\text { Gast } \\
\%\end{array}$ & $\begin{array}{l}\text { Classe } \\
\mathrm{s}\end{array}$ & \multicolumn{3}{|c|}{$\begin{array}{l}\text { Distribuição biocl. } \\
\text { em seção \% }\end{array}$} & $\begin{array}{l}\text { Orientação } \\
\text { Biocl. em } \\
\text { planta }\end{array}$ \\
\hline \multirow{3}{*}{$\begin{array}{l}\text { cota } \\
755 \mathrm{~m}\end{array}$} & \multirow{3}{*}{$\begin{array}{l}1 \\
\text { base } \\
\text { com } 04 \\
\text { ciclos } \\
\text { sucessi } \\
\text { vos } \\
\end{array}$} & \multirow[t]{3}{*}{48} & \multirow{3}{*}{$\begin{array}{l}\text { ciclos de } \\
\text { gradaçāo } \\
\text { contatos } \\
\text { bruscos e } \\
\text { erosivos }\end{array}$} & \multirow[t]{3}{*}{$60-15$} & \multirow[t]{3}{*}{70} & \multirow[t]{3}{*}{70} & \multirow[t]{3}{*}{ fechada } & \multirow[t]{3}{*}{ aberta } & \multirow[t]{3}{*}{30} & \multirow[t]{3}{*}{3} & \multicolumn{3}{|c|}{ caótica } & \multirow[t]{3}{*}{ polimodai } \\
\hline & & & & & & & & & & & con. & obl. & per. & \\
\hline & & & & & & & & & & & 85 & 30 & 5 & \\
\hline \multirow{3}{*}{$\begin{array}{l}\text { cota } \\
755,5 \\
m\end{array}$} & \multirow[t]{3}{*}{2} & \multirow[t]{3}{*}{24} & \multirow{3}{*}{$\begin{array}{l}\text { estratos } \\
\text { lâminados } \\
\text { paralelos, } \\
\text { contatos } \\
\text { bruscos a } \\
\text { erosivos }\end{array}$} & \multirow[t]{3}{*}{15} & \multirow[t]{3}{*}{70} & \multirow[t]{3}{*}{80} & fechada & aberta & \multirow[t]{3}{*}{20} & \multirow[t]{3}{*}{4} & \multicolumn{3}{|c|}{ caótica } & \multirow{3}{*}{$\begin{array}{l}\text { polimodal } \\
\text { predominio } \\
\text { ne-sw }\end{array}$} \\
\hline & & & & & & & & & & & con. & obl. & per. & \\
\hline & & & & & & & & & & & 90 & 8 & 2 & \\
\hline \multirow{3}{*}{$\begin{array}{l}\text { cota } \\
755,7 \\
m\end{array}$} & \multirow{3}{*}{$\begin{array}{l}3 \\
\text { topo }\end{array}$} & \multirow[t]{3}{*}{40} & \multirow{3}{*}{$\begin{array}{l}\text { estratos } \\
\text { lâminados } \\
\text { paralelos, } \\
\text { contatos } \\
\text { bruscos e } \\
\text { erosivos }\end{array}$} & \multirow[t]{3}{*}{$50-15$} & \multirow[t]{3}{*}{80} & \multirow[t]{3}{*}{80} & fechada & aberta & \multirow[t]{3}{*}{20} & \multirow[t]{3}{*}{4} & \multicolumn{3}{|c|}{ caótica } & \multirow{3}{*}{$\begin{array}{l}\text { polimodal } \\
\text { predominio } \\
\text { ne-sw }\end{array}$} \\
\hline & & & & & & & 3 & & & & con. & obl. & per. & \\
\hline & & & & & & & & & & & 90 & 8 & 2 & \\
\hline
\end{tabular}

Dados tafonômicos da concentração de Sobradinho, Jardim, CE.

\begin{tabular}{|c|c|c|c|c|c|c|c|c|c|c|c|c|c|c|}
\hline Sobradinho & $\begin{array}{l}\text { Unid. } \\
\text { micro- } \\
\text { estrat. }\end{array}$ & $\begin{array}{l}\text { Esp. } \\
\text { (cm) }\end{array}$ & Estruturas & $\begin{array}{l}\text { Biocl } \\
\%\end{array}$ & $\begin{array}{l}\text { Frag. } \\
\%\end{array}$ & $\begin{array}{l}\text { Biv. } \\
\%\end{array}$ & $\begin{array}{l}\text { Biv, articu } \\
\%\end{array}$ & ação & $\begin{array}{l}\text { Gast. } \\
\%\end{array}$ & $\begin{array}{l}\text { classes } \\
\text { tamanho } \\
\text { biocl. }\end{array}$ & $\begin{array}{l}\text { distrib } \\
\text { em se }\end{array}$ & $\begin{array}{l}\text { Hiçâo b } \\
\text { cão \% }\end{array}$ & & $\begin{array}{l}\text { Orientação } \\
\text { Biocl. em } \\
\text { planta }\end{array}$ \\
\hline \multirow{3}{*}{$\begin{array}{l}\text { Cota } 770 \\
\mathrm{~m}\end{array}$} & \multirow[t]{3}{*}{1} & \multirow[t]{3}{*}{12} & \multirow{3}{*}{$\begin{array}{l}\text { contatos } \\
\text { bruscos e } \\
\text { ondulados, } \\
\text { empilhamen- } \\
\text { to e embri- } \\
\text { camento }\end{array}$} & \multirow[t]{3}{*}{50} & \multirow[t]{3}{*}{50} & \multirow{3}{*}{$\begin{array}{l}50 \\
\text { inf. e } \\
\text { epif. }\end{array}$} & \multirow{2}{*}{$\begin{array}{l}\text { fechada } \\
\text { obl./con. }\end{array}$} & \multirow{2}{*}{$\begin{array}{l}\text { aberta } \\
\text { per. }\end{array}$} & \multirow[t]{3}{*}{50} & \multirow[t]{3}{*}{4} & \multicolumn{3}{|c|}{ caótica } & \multirow[t]{3}{*}{ polimodal } \\
\hline & & & & & & & & & & & Con. & Obl. & Per. & \\
\hline & & & & & & & 5 & & & & 85 & 10 & 5 & \\
\hline
\end{tabular}




\section{ANEXO V}

Dados tafonômicos de Concentração com bivalves em posição de vida, Engenho, Jardim, CE.

\begin{tabular}{|c|c|c|c|c|c|c|c|c|c|c|c|c|c|c|}
\hline Engenho & $\begin{array}{l}\text { Unid. } \\
\text { micro } \\
\text { estrat. }\end{array}$ & $\begin{array}{l}\text { Esp. } \\
(\mathrm{cm})\end{array}$ & Estruturas & $\begin{array}{l}\text { Biocl. } \\
\%\end{array}$ & Frag. & $\begin{array}{l}\text { Biv. } \\
\%\end{array}$ & $\begin{array}{l}\text { Biv. artica } \\
\%\end{array}$ & açăo & $\begin{array}{l}\text { Gast. } \\
\%\end{array}$ & Classes & $\begin{array}{l}\text { Distrib } \\
\text { em se }\end{array}$ & $\begin{array}{l}\text { içāo ce } \\
\text { ão \% }\end{array}$ & chas & $\begin{array}{l}\text { Orientaçāo } \\
\text { conchas em } \\
\text { planta }\end{array}$ \\
\hline \multirow{12}{*}{$\begin{array}{l}\operatorname{cota} \\
703 \mathrm{~m}\end{array}$} & \multirow{3}{*}{$\begin{array}{l}1 \\
\text { base }\end{array}$} & \multirow[t]{3}{*}{13} & \multirow{3}{*}{$\begin{array}{l}\text { icnofósseis } \\
\text { contatos } \\
\text { bruscos }\end{array}$} & \multirow[t]{3}{*}{70} & \multirow[t]{3}{*}{96} & \multirow[t]{3}{*}{1} & \multirow[t]{3}{*}{ fechada } & \multirow[t]{3}{*}{ aberta } & \multirow[t]{3}{*}{3} & \multirow[t]{3}{*}{4} & \multicolumn{3}{|c|}{ caótica } & \multirow[t]{3}{*}{ polimodal } \\
\hline & & & & & & & & & & & con. & obl. & per. & \\
\hline & & & & & & & & & & & 95 & 3 & 2 & \\
\hline & \multirow[t]{3}{*}{2} & \multirow[t]{3}{*}{$2-3$} & \multirow{3}{*}{$\begin{array}{l}\text { bivalves em } \\
\text { posiçäo } \\
\text { de vida } \\
\text { icnofósseis }\end{array}$} & \multirow[t]{3}{*}{5} & & \multirow{3}{*}{$\begin{array}{l}98 \\
\text { inf. }\end{array}$} & \multirow{2}{*}{$\begin{array}{l}\text { fechada } \\
\text { obl./ per. }\end{array}$} & \multirow[t]{3}{*}{ aberta } & \multirow[t]{3}{*}{2} & \multirow[t]{3}{*}{3} & \multicolumn{3}{|c|}{ caótica } & \\
\hline & & & & & & & & & & & côn. & obl. & per. & \\
\hline & & & & & & & 90 & & & & 30 & 30 & 40 & \\
\hline & \multirow[t]{3}{*}{3} & \multirow[t]{3}{*}{4} & \multirow{3}{*}{$\begin{array}{l}\text { contatos } \\
\text { bruscos }\end{array}$} & \multirow[t]{3}{*}{70} & \multirow[t]{3}{*}{96} & \multirow[t]{3}{*}{1} & \multirow[t]{2}{*}{ fechada } & \multirow[t]{3}{*}{ aberta } & \multirow[t]{3}{*}{3} & \multirow[t]{3}{*}{4} & \multicolumn{3}{|c|}{ cadtica } & \multirow[t]{3}{*}{ polimodal } \\
\hline & & & & & & & & & & & con- & obl. & per.r & \\
\hline & & & & & & & & & & & 95 & 3 & 2 & \\
\hline & 4 & $2-3$ & contatos & 10 & 10 & 98 & fechada & aberta & 2 & 4 & & caót & & \\
\hline & & & & & & epif. & & & & & côn. & obl. & per. & \\
\hline & & & & & & e inf. & & & & & 60 & 30 & 10 & \\
\hline
\end{tabular}

Dados tafonômicos de concentração, Engenho, Jardim, CE.

\begin{tabular}{|c|c|c|c|c|c|c|c|c|c|c|c|c|c|c|}
\hline Engenho & $\begin{array}{l}\text { Unid. } \\
\text { micro- } \\
\text { estrat. }\end{array}$ & $\begin{array}{l}\text { Esp. } \\
\text { (cm) }\end{array}$ & Estruturas & $\begin{array}{l}\text { Biocl. } \\
\%\end{array}$ & $\begin{array}{l}\text { Frag. } \\
\%\end{array}$ & $\begin{array}{l}\text { Biv. } \\
\%\end{array}$ & $\begin{array}{l}\text { Biv. articul } \\
\%\end{array}$ & açāo & $\begin{array}{l}\text { Gast. } \\
\%\end{array}$ & Classes & $\begin{array}{l}\text { Distri } \\
\text { em se }\end{array}$ & $\begin{array}{l}\text { uição } \\
\text { çāo \% }\end{array}$ & chas & $\begin{array}{l}\text { Orientaçāo } \\
\text { conchas em } \\
\text { planta }\end{array}$ \\
\hline \multirow{6}{*}{$\begin{array}{l}\text { cota } \\
703 \mathrm{~m}\end{array}$} & \multirow{3}{*}{$\begin{array}{l}1 \\
\text { topo }\end{array}$} & \multirow[t]{3}{*}{$6-11$} & \multirow{3}{*}{$\begin{array}{l}\text { contatos } \\
\text { bruscos e } \\
\text { erosivos, } \\
\text { gradação, } \\
\text { empilha- } \\
\text { mento, } \\
\text { icnofósseis }\end{array}$} & \multirow[t]{3}{*}{55} & \multirow[t]{3}{*}{50} & \multirow{3}{*}{$\begin{array}{l}80 \\
\text { inf. e } \\
\text { epif. } \\
\text { (pre- } \\
\text { domin } \\
\text { na) }\end{array}$} & \multirow{2}{*}{$\begin{array}{l}\text { fechada } \\
\text { obl/com. }\end{array}$} & \multirow{2}{*}{$\begin{array}{l}\text { aberta } \\
\text { per. }\end{array}$} & \multirow[t]{3}{*}{20} & \multirow[t]{3}{*}{5} & \multicolumn{3}{|c|}{ caótica } & \multirow[t]{3}{*}{ polimodal } \\
\hline & & & & & & & & & & & con. & $o b l$ & рег. & \\
\hline & & & & & & & 8 & 1 & & & 85 & 10 & 5 & \\
\hline & \multirow{3}{*}{$\begin{array}{l}2 \\
\text { base }\end{array}$} & \multirow[t]{3}{*}{$2-6$} & \multirow{3}{*}{$\begin{array}{l}\text { contatos } \\
\text { bruscos }\end{array}$} & \multirow[t]{3}{*}{70} & \multirow[t]{3}{*}{65} & \multirow[t]{3}{*}{5} & \multirow[t]{2}{*}{ fechada } & \multirow[t]{2}{*}{ aberta } & \multirow[t]{3}{*}{5} & \multirow[t]{3}{*}{5} & \multicolumn{3}{|c|}{ caótica } & \multirow[t]{3}{*}{ polimodial } \\
\hline & & & & & & & & & & & con. & $\mathrm{obl}$. & per. & \\
\hline & & & & & & & & 1 & & & 90 & 5 & 5 & \\
\hline
\end{tabular}




\section{ANEXO VI}

Dados tafonômicos de concentração com carapaças de equinóides em Canastra, Araripina, PE.

\begin{tabular}{|c|c|c|c|c|c|c|c|c|c|c|c|c|c|c|c|c|}
\hline \multirow[t]{4}{*}{ Canastra } & \multirow{4}{*}{$\begin{array}{l}\text { Unid. } \\
\text { micro- } \\
\text { estrat. } \\
1\end{array}$} & \multirow{4}{*}{$\begin{array}{l}\text { Esp. } \\
\text { (cm) } \\
\\
50\end{array}$} & \multirow{4}{*}{$\begin{array}{l}\text { Estruturas } \\
\text { contatos } \\
\text { ondulados, } \\
\text { esteiras } \\
\text { algálicas, } \\
\text { convoluçōes, } \\
\text { enrugamentos, } \\
\text { fraturas e } \\
\text { veios }\end{array}$} & \multirow{4}{*}{$\begin{array}{l}\begin{array}{l}\text { Biocl. } \\
\%\end{array} \\
10-15\end{array}$} & \multirow{4}{*}{\begin{tabular}{|l|}
$\begin{array}{l}\text { Frag. } \\
\%\end{array}$ \\
70 \\
\end{tabular}} & \multirow{4}{*}{$\begin{array}{l}\text { Biv. } \\
\% \\
2\end{array}$} & \multicolumn{4}{|c|}{$\begin{array}{l}\text { Carapaças equin. } \\
\text { Articulaçã \% }\end{array}$} & \multirow{4}{*}{\begin{tabular}{|l}
$\begin{array}{l}\text { Gast. } \\
\%\end{array}$ \\
2
\end{tabular}} & \multirow{4}{*}{$\begin{array}{l}\text { Classes } \\
\text { tamanho } \\
\text { biocl. } \\
5\end{array}$} & \multirow{2}{*}{\multicolumn{3}{|c|}{\begin{tabular}{l} 
Distribuiçäo \\
carapaças \\
equin. em seçäo \\
$\%$ \\
\multicolumn{1}{c}{ caótica }
\end{tabular}}} & \multirow{4}{*}{$\begin{array}{l}\text { Orientaçäc } \\
\text { biocl. em } \\
\text { planta }\end{array}$} \\
\hline & & & & & & & \multirow[t]{2}{*}{ int. } & \multirow[t]{2}{*}{ frat. } & \multirow[t]{2}{*}{ frag } & \multirow[t]{2}{*}{ espin } & & & & & & \\
\hline & & & & & & & & & & & & & con. & obl. & per. & \\
\hline & & & & & & & 5 & 10 & 84 & 1 & & & 85 & 10 & 5 & \\
\hline
\end{tabular}

Dados tafonômicos de concentração em Canastra, Araripina, PE.

\begin{tabular}{|c|c|c|c|c|c|c|c|c|c|c|c|c|c|c|}
\hline \multirow[t]{3}{*}{ Canastra } & \multirow{3}{*}{$\begin{array}{l}\text { Unid.- } \\
\text { micro- } \\
\text { estrat. }\end{array}$} & \multirow{3}{*}{$\begin{array}{l}\text { Esp. } \\
\text { (cm) } \\
40\end{array}$} & \multirow{3}{*}{$\begin{array}{l}\text { Estruturas } \\
\text { contatos } \\
\text { ondulados }\end{array}$} & \multirow{3}{*}{$\begin{array}{l}\text { Biocl. } \\
\% \\
60\end{array}$} & \multirow{3}{*}{$\begin{array}{l}\text { Frag. } \\
\% \\
50\end{array}$} & \multirow{3}{*}{$\begin{array}{l}\text { Biv. } \\
\% \\
50\end{array}$} & \multicolumn{2}{|c|}{$\begin{array}{l}\text { Biv. articulação } \\
\%\end{array}$} & \multirow{3}{*}{$\begin{array}{l}\text { Gast. } \\
\% \\
50\end{array}$} & \multirow{3}{*}{$\begin{array}{l}\text { Classes } \\
\text { tamanho } \\
\text { biocl. } \\
5\end{array}$} & \multicolumn{3}{|c|}{$\begin{array}{l}\text { Distribuição biocl. } \\
\text { em seção \% }\end{array}$} & \multirow{2}{*}{$\begin{array}{l}\text { Orientaçäo } \\
\text { biocl. em } \\
\text { planta }\end{array}$} \\
\hline & & & & & & & \multirow[t]{2}{*}{ fechada } & \multirow[t]{2}{*}{ aberta } & & & \multicolumn{3}{|c|}{ caótica } & \\
\hline & & & & & & & & & & & con. & obl. & per. & \\
\hline & & & & & & & 3 & & & & 85 & 10 & 5 & \\
\hline
\end{tabular}

Dados tafonômicos da concentração em Torre, Araripina, PE.

\begin{tabular}{|c|c|c|c|c|c|c|c|c|c|c|c|c|c|c|}
\hline \multirow[t]{4}{*}{ Torre } & \multirow{4}{*}{$\begin{array}{l}\text { Unid. } \\
\text { micro- } \\
\text { estrat. } \\
1\end{array}$} & \multirow{4}{*}{\begin{tabular}{|l|}
$\begin{array}{l}\text { Esp. } \\
\text { (cm) }\end{array}$ \\
$12-25$ \\
\end{tabular}} & \multirow{4}{*}{\begin{tabular}{|l} 
Estruturas \\
$\begin{array}{l}\text { contatos } \\
\text { ondulados, } \\
\text { gradação, }\end{array}$
\end{tabular}} & \multirow{4}{*}{$\begin{array}{l}\text { Biocl. } \\
\% \\
15-50\end{array}$} & \multirow{4}{*}{$\begin{array}{l}\text { Frag. } \\
\% \\
50\end{array}$} & \multirow{4}{*}{$\begin{array}{l}\text { Biv. } \\
\% \\
50\end{array}$} & \multicolumn{2}{|c|}{$\begin{array}{l}\text { Biv. articulaçăo } \\
\%\end{array}$} & \multirow{4}{*}{$\begin{array}{l}\text { Gast. } \\
\% \\
50\end{array}$} & \multirow{4}{*}{\begin{tabular}{|l}
$\begin{array}{l}\text { Classes } \\
\text { tamanho } \\
\text { biocl. }\end{array}$ \\
4 \\
\end{tabular}} & \multirow{2}{*}{\multicolumn{3}{|c|}{$\begin{array}{l}\text { Distribuição bioci. } \\
\text { em seção \% }\end{array}$}} & \multirow{3}{*}{$\begin{array}{l}\text { Orientaçäo } \\
\text { bioct. em } \\
\text { planta }\end{array}$} \\
\hline & & & & & & & \multirow[t]{2}{*}{ fechada } & \multirow[t]{3}{*}{ aberta } & & & & & & \\
\hline & & & & & & & & & & & con. & $o b s$. & per. & \\
\hline & & & & & & & 2 & & & & 90 & 5 & 5 & \\
\hline
\end{tabular}

Dados Tafonômicos da concentração de Caboclos, Fronteiras, PI.

\begin{tabular}{|c|c|c|c|c|c|c|c|c|c|c|c|c|c|c|}
\hline \multirow[t]{3}{*}{ Caboclos } & \multirow{2}{*}{$\begin{array}{l}\text { Unid. } \\
\text { micro- } \\
\text { estrat. } \\
1\end{array}$} & \multirow{2}{*}{$\begin{array}{l}\text { Esp. } \\
(\mathrm{cm}) \\
10\end{array}$} & \multirow{3}{*}{$\begin{array}{l}\text { Estruturas } \\
\text { contatos } \\
\text { ondulados, } \\
\text { bioturbacão }\end{array}$} & \multirow{3}{*}{$\begin{array}{l}\text { Biocl. } \\
\% \\
35-50\end{array}$} & \multirow{3}{*}{$\begin{array}{l}\text { Frag. } \\
\% \\
50\end{array}$} & \multirow{3}{*}{$\begin{array}{l}\text { Biv. } \\
\% \\
50\end{array}$} & \multicolumn{2}{|c|}{$\begin{array}{l}\text { Biv. articulação } \\
\%\end{array}$} & \multirow{3}{*}{\begin{tabular}{|l|}
$\begin{array}{l}\text { Gast. } \\
\%\end{array}$ \\
50 \\
\end{tabular}} & \multirow{3}{*}{$\begin{array}{l}\text { Classes } \\
\text { tamanto } \\
\text { biocl. } \\
4\end{array}$} & \multicolumn{3}{|c|}{$\begin{array}{l}\text { Distribusiçäo biocl. } \\
\text { em seçäo \% }\end{array}$} & \multirow{2}{*}{\begin{tabular}{|l}
$\begin{array}{l}\text { Orientação } \\
\text { biocl, em } \\
\text { planta }\end{array}$ \\
polimodal
\end{tabular}} \\
\hline & & & & & & & \multirow[t]{2}{*}{ fechada } & \multirow[t]{2}{*}{ aberta } & & & \multicolumn{3}{|c|}{ caótica } & \\
\hline & & & & & & & & & & & con. & abl. & per. & \\
\hline & & & & & & & 5 & & & & 85 & 10 & 5 & \\
\hline
\end{tabular}

Dados tafonômicos de concentração em Marcolândia, PI.

\begin{tabular}{|c|c|c|c|c|c|c|c|c|c|c|c|c|c|c|}
\hline \multirow{4}{*}{$\begin{array}{l}\text { Marco- } \\
\text { |ândia }\end{array}$} & \multirow{4}{*}{$\begin{array}{l}\text { Unid. } \\
\text { micro- } \\
\text { estrat. }\end{array}$} & \multirow{4}{*}{$\begin{array}{l}\text { Esp. } \\
(\mathrm{cm})\end{array}$} & \multirow{4}{*}{$\begin{array}{l}\text { Estruturas } \\
\text { contatos } \\
\text { ondulados, } \\
\text { gradação }\end{array}$} & \multirow{4}{*}{$\begin{array}{l}\text { Biocl. } \\
\% \\
30\end{array}$} & \multirow{4}{*}{$\begin{array}{l}\text { Frag. } \\
\% \\
70\end{array}$} & \multirow{4}{*}{$\begin{array}{l}\begin{array}{l}\text { Biv. } \\
\%\end{array} \\
85 \\
\text { predomínio } \\
\text { de } \\
\text { ostracodes } \\
\text { e bival-ves }\end{array}$} & \multicolumn{2}{|c|}{$\begin{array}{l}\text { Biv, articulação } \\
\%\end{array}$} & \multirow{4}{*}{\begin{tabular}{|l|}
$\begin{array}{l}\text { Gast. } \\
\%\end{array}$ \\
15 \\
\end{tabular}} & \multirow{4}{*}{$\begin{array}{l}\text { Classes } \\
\text { tamanho } \\
\text { bioci. }\end{array}$} & \multirow{2}{*}{\multicolumn{3}{|c|}{$\begin{array}{l}\text { Distribuiçäo biocl. } \\
\text { em seção \% } \\
\text { caótica } \\
\end{array}$}} & \multirow{3}{*}{\begin{tabular}{|l|}
$\begin{array}{l}\text { Orientaçäo } \\
\text { biocl. em } \\
\text { planta }\end{array}$ \\
polimodal \\
\end{tabular}} \\
\hline & & & & & & & \multirow[t]{2}{*}{ fechada } & \multirow[t]{2}{*}{ aberta } & & & & & & \\
\hline & & & & & & & & & & & con. & obl. & per. & \\
\hline & & & & & & & 4 & & & & 80 & 15 & 5 & \\
\hline
\end{tabular}




\section{ANEXO VII}

Dados tafonômicos de concentração em Santana do Cariri, CE.

\begin{tabular}{|c|c|c|c|c|c|c|c|c|c|c|c|c|c|c|}
\hline $\begin{array}{l}\text { Santana } \\
\text { do cariri }\end{array}$ & \multirow{4}{*}{$\begin{array}{l}\text { Unid.d } \\
\text { micro- } \\
\text { estrat. }\end{array}$} & \multirow{4}{*}{$\begin{array}{l}\text { Esp. } \\
(\mathrm{cm})\end{array}$} & \multirow{4}{*}{$\begin{array}{l}\text { Estruturas } \\
\text { contatos } \\
\text { bruscos, } \\
\text { ondulados } \\
\text { e erosivos, } \\
\text { gradaçäo } \\
\end{array}$} & \multirow{4}{*}{$\begin{array}{l}\text { Bioc? } \\
\% \\
15\end{array}$} & \multirow{4}{*}{\begin{tabular}{|l|}
$\begin{array}{l}\text { Frag. } \\
\%\end{array}$ \\
40 \\
\end{tabular}} & \multirow{4}{*}{$\begin{array}{l}\text { Biv. } \\
\% \\
2\end{array}$} & \multicolumn{2}{|c|}{$\begin{array}{l}\text { Biv. articulaçāo } \\
\%\end{array}$} & \multirow{4}{*}{\begin{tabular}{|l|}
$\begin{array}{l}\text { Gast. } \\
\%\end{array}$ \\
98 \\
\end{tabular}} & \multirow{4}{*}{$\begin{array}{l}\text { Classes } \\
\text { tamanho } \\
\text { biocl. } \\
2\end{array}$} & \multirow{2}{*}{\multicolumn{3}{|c|}{$\begin{array}{l}\text { Distribuição biocl. } \\
\text { em seçăo \% } \\
\text { caótica }\end{array}$}} & \multirow{4}{*}{\begin{tabular}{|l}
$\begin{array}{l}\text { Orientação } \\
\text { biocl. em } \\
\text { planta }\end{array}$ \\
polimodal
\end{tabular}} \\
\hline & & & & & & & \multirow[t]{3}{*}{ fechada } & \multirow[t]{3}{*}{ aberta } & & & & & & \\
\hline & & & & & & & & & & & con. & obl. & per. & \\
\hline & & & & & & & & & & & 80 & 15 & & \\
\hline & \multirow{3}{*}{2} & \multirow{3}{*}{$\begin{array}{l}13 \\
\text { topo }\end{array}$} & \multirow{3}{*}{\begin{tabular}{|l} 
contatos \\
bruscos, \\
ondulados \\
e erosivos, \\
gradaçāa
\end{tabular}} & \multirow[t]{3}{*}{30} & \multirow[t]{3}{*}{40} & \multirow[t]{3}{*}{2} & \multirow[t]{2}{*}{ fechada } & \multirow[t]{2}{*}{ aberta } & \multirow[t]{3}{*}{98} & \multirow[t]{3}{*}{2} & \multicolumn{3}{|c|}{ caótica } & \multirow[t]{3}{*}{ polimoda! } \\
\hline & & & & & & & & & & & con. & abi: & per. & \\
\hline & & & & & & & & & & & 80 & 15 & 5 & \\
\hline
\end{tabular}

Dados tafonômicos das concentrações em São Gonçalo,Santana do Cariri, CE.

\begin{tabular}{|c|c|c|c|c|c|c|c|c|c|c|c|c|c|c|}
\hline \multirow{4}{*}{$\begin{array}{l}\text { São } \\
\text { Gonçalo }\end{array}$} & \multirow{4}{*}{$\begin{array}{l}\begin{array}{l}\text { Concen- } \\
\text { traçőes. }\end{array} \\
1 \\
\text { base }\end{array}$} & \multirow{4}{*}{$\begin{array}{l}\text { Esp. } \\
(\mathrm{cm})\end{array}$} & \multirow{4}{*}{$\begin{array}{l}\text { Estruturas } \\
\text { contatos } \\
\text { bruscos e } \\
\text { erosivos, } \\
\text { gradaçäo }\end{array}$} & \multirow{4}{*}{$\begin{array}{l}\text { Biocl. } \\
\% \\
20\end{array}$} & \multirow{4}{*}{$\begin{array}{l}\text { Frag. } \\
\% \\
50\end{array}$} & \multirow{4}{*}{$\begin{array}{l}\text { Biv. } \\
\% \\
20 \\
\text { epif. }\end{array}$} & \multicolumn{2}{|c|}{$\begin{array}{l}\text { Biv, articulaçäo } \\
\%\end{array}$} & \multirow{4}{*}{$\begin{array}{l}\text { Gast. } \\
\% \\
80\end{array}$} & \multirow{4}{*}{$\begin{array}{l}\text { Classes } \\
\text { tamanho } \\
\text { biocl. } \\
4\end{array}$} & \multirow{2}{*}{\multicolumn{3}{|c|}{$\begin{array}{l}\text { Distrịbuição biocl. } \\
\text { em seção \% } \\
\text { caótica }\end{array}$}} & \multirow{4}{*}{$\begin{array}{l}\text { Orientaçāo } \\
\text { biocl. em } \\
\text { planta } \\
\text { polimodal }\end{array}$} \\
\hline & & & & & & & \multirow[t]{3}{*}{ fechada } & \multirow[t]{3}{*}{ aberta } & & & & & & \\
\hline & & & & & & & & & & & con. & obl. & per. & \\
\hline & & & & & & & & & & & 80 & 10 & 5 & \\
\hline & \multirow[t]{3}{*}{2} & \multirow[t]{3}{*}{6} & \multirow{3}{*}{$\begin{array}{l}\text { contatos } \\
\text { bruscos e } \\
\text { erosivos, } \\
\text { gradaçäo }\end{array}$} & \multirow[t]{3}{*}{30} & \multirow[t]{3}{*}{60} & \multirow{3}{*}{$\begin{array}{l}98 \\
\text { epif. }\end{array}$} & \multirow[t]{3}{*}{ fechada } & \multirow[t]{3}{*}{ aberta } & \multirow[t]{3}{*}{2} & \multirow[t]{3}{*}{3} & \multicolumn{3}{|c|}{ caótica } & polimodal \\
\hline & & & & & & & & & & & con. & obl. & per. & \\
\hline & & & & & & & & & & & 80 & 15 & & \\
\hline & \multirow{3}{*}{$\begin{array}{l}3 \\
\text { topo }\end{array}$} & \multirow[t]{3}{*}{11} & \multirow{3}{*}{$\begin{array}{l}\text { contatos } \\
\text { bruscos e } \\
\text { erosivos, } \\
\text { gradaçäo }\end{array}$} & \multirow[t]{3}{*}{35} & \multirow[t]{3}{*}{60} & \multirow{3}{*}{$\begin{array}{l}98 \\
\text { epif. }\end{array}$} & \multirow[t]{3}{*}{ fechada } & \multirow[t]{3}{*}{ aberta } & \multirow[t]{3}{*}{2} & \multirow[t]{3}{*}{3} & \multicolumn{3}{|c|}{ caótica } & polimodal \\
\hline & & & & & & & & & & & con. & obl. & per. & \\
\hline & & & & & & & & & & & 80 & 15 & & \\
\hline
\end{tabular}

